$$
\text { UNIVERSIDADE DE SÃO PAULO }
$$

FACULDADE DE FILOSOFIA, LETRAS E CIÊNCIAS HUMANAS DEPARTAMENTO DE LETRAS CLÁSSICAS E VERNÁCULAS PROGRAMA DE PÓS-GRADUAÇÃO EM LETRAS CLÁSSICAS

JASMIM SEDIE DRIGO

\title{
SÍNCOPE VOCÁLICA NA ITÁLIA ANTIGA
}

VERSÃO REVISADA

São Paulo

2016 


\author{
UNIVERSIDADE DE SÃO PAULO \\ FACULDADE DE FILOSOFIA, LETRAS E CIÊNCIAS HUMANAS \\ DEPARTAMENTO DE LETRAS CLÁSSICAS E VERNÁCULAS \\ PROGRAMA DE PÓS-GRADUAÇÃO EM LETRAS CLÁSSICAS
}

\title{
SÍNCOPE VOCÁLICA NA ITÁLIA ANTIGA
}

\author{
Jasmim Sedie Drigo
}

Orientador: Prof. Dr. José Marcos Mariani de Macedo

\begin{abstract}
Dissertação apresentada ao Programa de Pós-Graduação em Letras Clássicas do Departamento de Letras Clássicas e Vernáculas da Faculdade de Filosofia, Letras e Ciências Humanas da Universidade de São Paulo para a obtenção do título de Mestre em Letras.
\end{abstract}

VERSÃO REVISADA

São Paulo

2016 
Autorizo a reprodução e divulgação total ou parcial deste trabalho, por qualquer meio convencional ou eletrônico, para fins de estudo e pesquisa, desde que citada a fonte.

Catalogação na Publicação

Serviço de Biblioteca e Documentação

Faculdade de Filosofia, Letras e Ciências Humanas da Universidade de São Paulo

D779s Drigo, Jasmim Sedie

Síncope Vocálica na Itália Antiga / Jasmim Sedie Drigo ; orientador José Marcos Mariani de Macedo. - São Paulo, 2016. $181 \mathrm{f}$.

Dissertação (Mestrado)- Faculdade de Filosofia, Letras e Ciências Humanas da Universidade de São Paulo. Departamento de Letras Clássicas e Vernáculas. Área de concentração: Letras Clássicas.

1. Linguística Histórica. 2. Latim. 3. Sabélico. 4. Síncope. I. de Macedo, José Marcos Mariani, orient. II. Título 
Nome: DRIGO, Jasmim Sedie

Título: Síncope Vocálica na Itália Antiga

Dissertação apresentada ao Programa de Pós-Graduação em Letras Clássicas do Departamento de Letras Clássicas e Vernáculas da Faculdade de Filosofia, Letras e Ciências Humanas da Universidade de São Paulo para a obtenção do título de Mestre em Letras.

Aprovada em:

Banca Examinadora

Prof. Dr. José Marcos Mariani de Macedo Instituição: Universidade de São Paulo Julgamento: Assinatura:

Prof. Dr.

Instituição:

Julgamento: Assinatura:

Prof. Dr. Instituição:

Julgamento: Assinatura:

Prof. Dr.

(suplente) Instituição:

Julgamento: Assinatura:

Prof. Dr.

(suplente) Instituição:

Julgamento: Assinatura: 
Ao meu pai,

Elso Drigo Filho 


\section{Agradecimentos}

À Fapesp, pela bolsa de auxílio auxílio á pesquisa no país e também pela bolsa BEPE (Bolsa Estágio de Pesquisa no Exterior), que tornou possível a realização deste trabalho.

Ao meu orientador, Prof. Dr. José Marcos Mariani de Macedo, pela paciência e competência com a qual me guiou ao longo da pesquisa. Além do mais, devo importante parte da minha formação e meu crescente interesse pela linguística histórica a suas interessantes aulas.

Ao meu supervisor durante a vigência da bolsa BEPE, Prof. Dr. Michael Weiss, que tentou me ensinar de modo muito solícito tudo o que podia durante meus breves meses na Universidade de Cornell.

Também sou muito grata a ajuda que recebi de alguns pesquisadores ao longo do mestrado. Agradeço aos professores Dr. Mário Viaro e Dr. Paulo Chagas, que forneceram comentários valiosos durante a minha qualificação. Ao Prof. Dr. Rex Wallace da UMass, que incentivou e me ajudou em certa medida a escolher o tema da dissertação. Ao Prof. Kanehiro Nishimura da Universidade de Tókio, que me auxiliou em alguns pontos e me incentivou a fazer o estágio com o Prof. Dr. Weiss.

À Nádia e à Bruna, minhas almas-gêmeas e companheiras de todas as horas.

À Ágata e ao Cauã, irmãos de carne e de alma.

Aos meus amigos de faculdade, Camilla, Patrícia, Ramón e Roberta, companheiros de copo, risadas e opopoi.

Às minhas avós Beatriz e Lourdes, à minha mãe Angélica, e à Socorro, que sempre quiseram ver-me realizada.

Ao Paulo, que sorriu e sofreu comigo durante todo o processo. 


\section{RESUMO}

Latim e sabélico são línguas que possuem muitos paralelos entre si, pois pertencem ao mesmo ramo do proto-indo-europeu, o ramo itálico. Uma semelhança interessante e intrigante entre essas línguas é a síncope vocálica, porque se trata de um processo fonológico recorrente.

Até algumas décadas atrás, os estudiosos não acreditavam ser possível analisar devidamente as condições nas quais a síncope ocorre em latim, por serem muito complexas. No entanto, pesquisas mais recentes mostram que isso é possível de alguma forma, apesar de a análise ser difícil. A ocorrência da síncope vocálica em sabélico parece menos complexa que em latim. Em sabélico, os ambientes fonológicos nos quais a síncope ocorre são mais limitados, mas a dificuldade em entender o significado e a etimologia de algumas palavras sabélicas também torna a análise complicada.

O objetivo desta pesquisa foi delimitar o máximo possível os ambientes fonológicos da síncope em latim e em sabélico e entender quais correlações podem ser feitas entre os exemplos listados. Ainda que seja interessante analisar todos os casos com base nas mesmas premissas, isso é muito difícil, uma vez que os dados encontrados são muito variados. As correlações que podem ser feitas entre casos de línguas diferentes são basicamente apenas de ordem etimológica, pois a ação e resultado da síncope agem de maneiras diferentes dependendo da língua e do período.

PALAVRAS-CHAVES: Síncope vocálica, latim, sabélico, linguística histórica. 


\begin{abstract}
Latin and Sabellic are languages that have many parallels, for they belong to the same Indo-European branch, the Italic branch. An interesting and intriguing phonological similarity between these languages is vowel syncope, because is a recurring phonological process.

Until a few decades ago, scholars believed not to be possible to analyze properly the conditions under which syncope occurs in Latin, because they are very complex. However, more recent researches show that this is somehow possible, though the analysis is difficult. The occurrence of vowel syncope in Sabellic seems to be less complex than in Latin. In Sabellic, the phonological environments in which syncope occurs are more limited, but the difficulty to understand the meaning and etimology of some Sabellic words make this analysis also tough.

The aim of this research was to limit as much as possible the phonological environments of syncope in Latin and in Sabellic and to understand the correlations that can be made among the examples of the corpora. Although it would be interesting to analyze all cases based on the same premises, this is very difficult, for the data do not allow it. The correlations that can be made are basically just etymological, because the way it works and the results are different according to each language and each time they existed.
\end{abstract}

KEYWORDS: Vowel syncope, Latin, Sabellic, historical linguistics. 


\section{TABELA DE ABREVIAÇÕES}

\section{Fonologia e Gramática}
A 'analogia'
abl. 'ablativo'
acs. 'acusativo'
adv. 'advérbio'
C 'consoante'
cf. 'confira; compare'
cg. 'cognato'

conj. 'conjunção'

dat. 'dativo'

gen. 'genitivo'

gerund. 'gerundivo'

impf. 'imperfeito'

IN 'incerto'

ind. 'indicativo'

K 'oclusiva'

loc. 'locativo'

$\mathrm{N}$ 'não há síncope'

nom. 'nominativo'

part. 'particípio'

pass. 'passivo'

perf. 'perfeito'

pl. 'plural'

pref. 'prefixo'

prep. 'preposição'

pres. 'presente'

R 'soante'

SF 'síncope em sílaba final'

sg. 'singular'

SM 'síncope em sílaba medial'

SNPT 'sílaba não-imediatamente pós-tônica' 
subj. 'subjuntivo'

sup. 'supino'

V 'vogal'

\section{Línguas}

Ale. 'Alemão'

Arm. 'Armênio'

Av. 'Avesta'

Fal. 'Falisco'

Gr. 'Grego'

Etr. 'Etrusco'

Fal. 'Falisco'

IrA. 'Irlandês Antigo'

Lat. 'Latim'

LA 'Latim Antigo'

LC 'Latim Clássico'

LPC 'Latim Pré-Clássico'

Mic. 'Micênico'

Osc. 'Osco'

Pg. 'Pelígio'

PIE 'Proto-Indo-Europeu'

PIt. 'Proto-Itálico'

PM 'Piceno Meridional'

Rét. 'Rético'

Rus. 'Russo'

Sab. 'Sabélico'

Scr. 'Sânscrito'

ToB 'Tocário B'

Umb. 'Úmbrio'

Vol. 'Volsco' 


\section{Símbolos}

* ' 'reconstrução de uma forma que provavelmente existiu'

** 'forma que teria existido se o desenvolvimento histórico fosse outro além do que realmente existiu'

$>\quad$ 'se torna por mudança fonológica e/ou morfológica'

$<\quad$ 'resulta de mudança fonológica e/ou morfológica'

$\rightarrow \quad$ 'mudança semântica'

// 'transcrição fonológica'

V.CV 'o ponto marca uma divisão silábica'

[ ] 'letra(s) que provavelmente existiu(ram)' (marca filológica)

< 'grafia' 


\section{SUMÁRIO}

$\begin{array}{lr}\text { INTRODUÇÃOO } & 16\end{array}$

CAPÍTULO I: CONCEITOS FUNDAMENTAIS 18

$\begin{array}{ll}\text { 1. Línguas da Itália Antiga } & 18\end{array}$

1.1. Ramo Itálico 19

1.2. Latim-Falisco 20

1.3. Sabélico 21

1.4. Etrusco 22

2. Síncope Vocálica 23

3. Enfraquecimento Vocálico 24

4. Corpora 24

CAPÍTULO II: SÍNCOPE VOCÁLICA EM LATIM 28

1. Latim 28

2. Acentuação 29

3. Quantidade de Sílabas 30

4. Qualidade das Vogais 31

5. Contraexemplos 31

6. Presença de Soantes 32

6.1. $R \_R \quad 33$

6.2. $R \_C$

6.3. $C \_R$

7. *-rVs\#>-er\# 35

7.1. - er- em Sílabas Tônicas

8. Síncope em Sílabas Fechadas com Coda em $-S \quad 38$

81. Casos Polêmicos 38

9. Síncope no Sufixo *-tero- > -tro-

10. Síncope na Antepenúltima Sílaba em Palavras Quadrissilábicas $\quad 40$

11. Síncope em Palavras que seguem a Regra de Acentuação da Penúltima $\quad 40$

12. Síncope em Palavras Tri- ou Quadrissilábicas com uma Vogal Longa 42 na Última Sílaba 
13. Diminutivos 43

14. Outros Casos de Síncope Não-Imediatamente Pós-Tônica 44

15. Caso Polêmicos 45

15.1. adūlor 'adular' 45

15.2. calficiō 'aquecer' 46

15.3. culmus 'caule' 46

15.4. cunctus 'todo; inteiro' 47

15.5. ferre, ferrem, fert, fers do verbo ferō 'carregar' 47

15.6. halō 'emitir fragrância' 48

15.7. Herclès 'Hércules' 48

15.8. imus 'parte mais baixa' 48

15.9. $\operatorname{la} r d \bar{l}$ 'toucinho' $\quad 49$

15.10. occa 'rastelo' 49

15.11. summus 'o mais alto' 49

16. Hipóteses sobre a Síncope em Latim 49

17. Conclusões Parciais 51

CAPÍTULO III: SÍNCOPE VOCÁLICA EM SABÉLICO 53

1. Sabélico 53

2. Síncope em Silabas Finais 53

2.1. $V>0 / \_s \# 54$

2.1.1. Casos Polêmicos 58

2.1.1.1. Umb. Atiersir (Vb 8; Vb 14) 'Artirse' (gentílico ou nome de uma 59 fraternidade)

2.1.1.2. Osc. ceus (nom., sg. - Lu 1, 19) 'cidadão' 59

2.1.1.3. Umb. emps (part. pass. - Um 10) 'comprado' 59

2.1.1.4. Osc. ligis (dat./abl., pl. - Lu 1, 25) 'leis’ 60

2.1.1.5. Umb. ocar, ukar (nom., sg. - VIb 46) 'cidade' 60

2.1.1.6. Umb. pacer (nom., sg. - VIa 23; VIa 30; VIa 33; VIa 40; VIa 42; 61

VIa; VIa 50; VIa 52; VIb 7; VIb 11; VIb 13; VIb 26; VIb 32; VIb 34;

VIIa 14; VIIa 17; VIIa 31; VIIa 50) 'propício'

2.2. $o>0 / i i_{-} m \# \quad 61$

3. Síncope em Sílabas Mediais $\quad 62$

3.1. Síncope no Sufixo *-tero- > -tro- 62 
Longa na Terceira Sílaba

3.3. Síncope em Formas Trissilábicas com uma Vogal Breve na Terceira Sílaba 66

3.4. Síncope Regular em Casos Oblíquos 67

3.5. Síncope em uma Sequência de Duas Vogais Breves em Sílabas Mediais 67

3.6. Síncope em Diminutivos 68

3.7. Casos nos quais a Vogal Sincopada é Incerta 69

3.8. Casos Polêmicos 70

3.8.1. Umb. amboltu ( $3^{\mathrm{a}}$ sg., imp. - VIb 52) 'dê voltas em!' 70

3.8.2. Umb. ampe(n)tu (imp. - IIa 20; III 23), apentu (imp. - III 27) 70 'aproxima-te!'

3.8.3. Umb. amprehtu ( $3^{\mathrm{a}}$ sg., imp, - Ib 21), apretu ( $3^{\mathrm{a}}$ sg., impf. - Ib 20) 71 'leva (os animais) para uma volta!'

3.8.4. Umb. a(n)tentu, andendu (3 ${ }^{\mathrm{a}}$ sg., imp. - IIa 20; III 15; III 16; III 17; 72 III 17; III 22; IV 21; IV 27; IIb 28; VIIa 46) 'ergue até o topo!'; ententu, endendu ( $3^{\mathrm{a}}$ sg., imp. - VIb 40; VIb 40; VIb 49; Ib 12; III 15) 'insere!'

3.8.5. Osc. embratur (nom., sg. - nPg 6a; nPg 6b) 'imperador' 72

3.8.6. Umb. felsva (Va 11) (significado desconhecido) 72

3.8.7. Umb. fertu (imp. - VIb 50; VIb 50) 'faz!' 73

3.8.8. Osc. herekleís (gen., sg. - Cm 1A11; Cm 1A24; Cm B4; Cm B6) 73

'Hércules'

3.8.9. Umb. herte(r) ( $3^{\text {a }}$ sg., pres., pass. - Va 6; Va 8; Va 10; IIa 40; III 1) 74

'foi necessário'

3.8.10. Umb. ninctu (imp. - VI b 60; VIIa 49) 'ataca!' 74

3.8.11. Umb. oseto, osatu (3 ${ }^{\mathrm{a}}$ sg., ind., impf. - Um 7; VIb 24; VIb 37) 75 'construído'

3.8.12. Osc. patensíns ( $3^{\mathrm{a}}$ pl., subj., impf. - Cm 1B24; Cm 1B25) 'eles

abririam', osc. patanai (dat., sg. - Sa 1A14; Sa 1B14) (significado

desconhecido), umb. Padellar (gen., sg. - VIa 14) 'Padela' (nome de uma deusa)

3.8.13. Osc. pertumum (Lu 1, 7) (significado desconhecido) 76

3.8.14. Osc. prúftú ( $3^{\mathrm{a}}$ pl., perf., pass. - Cm 1A16) 'foram estabelecidos’; 76

prúffed ( $3^{\mathrm{a}} \mathrm{sg}$., perf. - Cm 10; Sa 25) 'aprovou'

4. Síncope em Sílabas Mediais e Finais na Mesma Palavra 77

5. Hipóteses sobre a Síncope em Sabélico 78 
CONCLUSÕES

BIBLIOGRAFIA

APÊNDICE: ETRUSCO

ANEXOS

92

ANEXO I: CORPUS DE PALAVRAS LATINAS

ANEXO II: CORPUS DE PALAVRAS SABÉLICAS 


\section{INTRODUÇÃO}

Durante a leitura de alguns textos latinos me deparei com palavras que possuíam variantes sem uma vogal medial e outras com a vogal medial, como caldus x calidus. A variação não teria me chamado tanta atenção se eu não tivesse reparado que o mesmo fenômeno ocorre no etrusco, uma língua não-indo-europeia. Posteriormente, li artigos e livros que descreviam o mesmo processo em línguas sabélicas. Coincidência?

Quando um mesmo fenômeno fonológico pode ser observado em várias línguas da mesma região, é difícil acreditar em coincidência sem antes analisar os dados de forma detalhada. Como havia poucos trabalhos que estudam a síncope vocálica levando em consideração todas as principais línguas da Itália Antiga (como Nishimura: 2008), percebi que uma análise descritiva sistemática ainda era algo que precisava ser feito.

Algumas questões surgiram à minha mente: será que a síncope funciona do mesmo modo nessas línguas? Por que a síncope é frequente apenas na Península Itálica? Por que o etrusco, uma língua não-indo-europeia, também apresenta síncope vocálica de forma frequente? Qual correlação pode ser feita ao reunir os principais casos de síncope nas principais línguas da Itália Antiga?

No início, a hipótese principal era de que a síncope vocálica era um fenômeno areal, algo que tivesse ocorrido primeiro em uma dessas línguas e depois se dispersado para as demais, especialmente pelo fato de o etrusco também apresentar exemplos. Infelizmente, a questão se mostrou mais complexa do que imaginada a priori, e os dados etruscos não puderam ser analisados no mesmo nível dos casos latinos e sabélicos (ver mais no Apêndice: Etrusco).

O estudo da síncope vocálica se mostrou frutífero, pois foi possível reunir dados que até então estavam muito dispersos na bibliografia moderna e também foi possível discutir casos polêmicos, o que auxiliou uma melhor compreensão do fenômeno nessas línguas.

Por fim, a dissertação foi dividida em quatro capítulos, um apêndice e dois corpora:

O Capítulo I: Conceitos Fundamentais é basicamente uma explicação das noções que são essenciais para o desenvolvimento do trabalho. Esse capítulo inclui subcapítulos com assuntos diversos, mas todos eles possuem caráter introdutório de temas que serão mais bem desenvolvidos ao longo da dissertação: 1) Línguas da Itália 
Antiga, breve explicação histórica dos povos e línguas que existiam no período de VI a. C. a I a. C.; 2) Síncope vocálica, apresentação de diversas definições e escolha da definição que será usada na dissertação; 3 ) Enfraquecimento vocálico, comparação entre síncope e enfraquecimento; 4) Corpora, apresentação da estrutura de cada corpus e quais critérios utilizados na sua construção.

O Capítulo II: Síncope Vocálica em Latim contém a análise da síncope na língua latina, remetendo aos casos do corpus latino. No final do capítulo, há uma seção de Conclusões Parciais, que mostra os resultados encontrados apenas a partir dos casos latinos.

O Capítulo III: Síncope Vocálica em Sabélico contém a análise da síncope nas línguas sabélicas, remetendo aos casos do corpus sabélico. No final do capítulo, há uma seção de Conclusões Parciais, que mostra os resultados encontrados apenas a partir dos casos sabélicos.

A seção Conclusões retoma os passos mais importantes da pesquisa e apresenta os resultados finais.

No Apêndice: Etrusco, encontra-se uma breve lista de casos etruscos de síncope e se explica por que os exemplos etruscos não puderam ser colocados no mesmo patamar dos casos latinos e sabélicos.

Os corpora são duas listas dos mais interessantes e importantes casos de síncope vocálica: o Anexo I: Corpus de Palavras Latinas e o Anexo II: Corpus de Palavras Sabélicas. 


\section{CAPÍTULO I: CONCEITOS FUNDAMENTAIS}

\section{Línguas da Itália Antiga}

A região hoje conhecida como Itália foi uma região habitada por diversos povos, de línguas e costumes diferentes na Antiguidade. Nesta dissertação, as línguas utilizadas para a análise da síncope vocálica são o latim e o sabélico (osco, úmbrio, o pelígio e piceno meridional), escolhidas porque há vestígio de síncope em todas elas.

O recorte temporal usado, feito para que a análise possa ser mais eficaz, é o período de VI a.C. a I a.C. Começa-se no século VI a. C., quando os primeiros registros dessas línguas podem ser encontrados, e termina-se no século I a.C., quando não há mais registro do sabélico devido à expansão do império romano.

Neste recorte temporal, pode-se reconstruir um mapa linguístico da região ${ }^{1}$ :

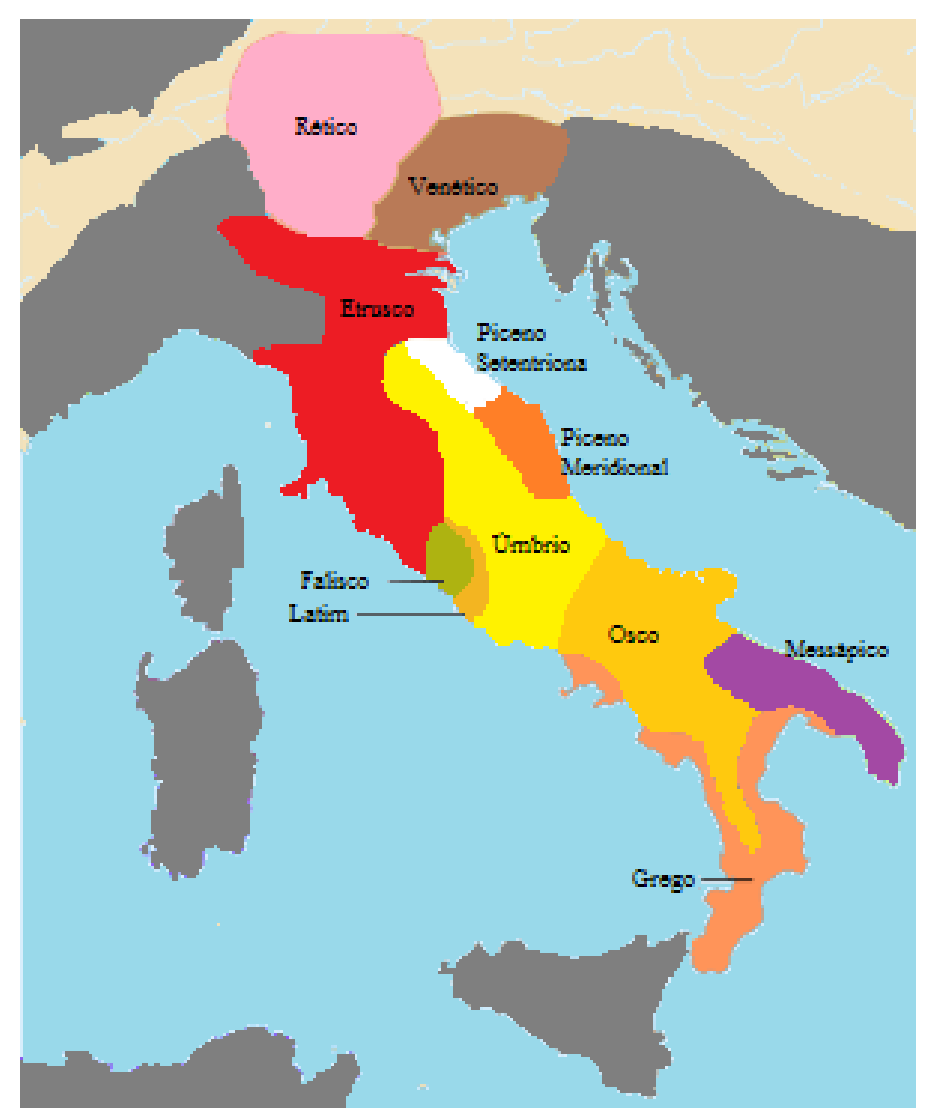

${ }^{11}$ Mapa construído por mim, com base no mapa de Rex (2007: ix). 
O mapa mostra diversas línguas: rético, venético, etrusco, osco, úmbrio, falisco, latim, piceno meridional, piceno setentrional, messápico e grego. Trata-se de línguas de diferentes ramos linguísticos: as línguas relevantes para esta pesquisa, as sabélicas e o latim-falisco se encontram no centro-sul da península itálica; o etrusco e o rético, línguas não-indo-europeias se localizam no norte; o grego era apenas falado no extremo sul da Itália; o messápico, outra língua indo-europeia de substancial importância na época, também era falado no sul. É importante mencionar algumas outras línguas além das itálicas indo-europeias para que se possa compreender a grande diversidade linguística que existia durante o período em questão.

\subsection{Ramo Itálico}

O latim e o sabélico têm fortes paralelos entre si porque ambos pertencem à família do Proto-Indo-Europeu ${ }^{2}$ e também ao mesmo ramo Itálico. Pode-se ainda dividir o ramo entre dois subgrupos: latim-falisco e sabélico.

Durante o século XX houve muita polêmica sobre a questão da unidade itálica, se o sabélico e o latim-falisco seriam línguas separadas diretamente do proto-indoeuropeu, ou se seriam dois subgrupos frutos de um proto-grupo, o proto-itálico. Beeler (1952:436-437) afirma que até o começo do século XX não existiam dúvidas sobre a unidade itálica, entretanto quando a existência de outras proto-línguas (como por exemplo, o proto-balto-eslavo) foi colocada em dúvida, a existência do proto-itálico deixou de ser defendida pela maioria dos estudiosos.

Durante esse período de incertezas, que perdurou até 1970 ou 1980, diversos autores, tais como o próprio Beeler (1952:442-443), Jones (1950:60-87) e outros, defendiam a hipótese separatista, de que essas línguas seriam ramos independentes do Proto-Indo-Europeu,. Outros autores se mostraram adeptos da hipótese do proto-itálico, inclusive durante a época de dúvidas, tais como Buck (1904; 1962: 23-30) e Wallace \& Joseph (1987:675-693).

Há muitas evidências linguísticas que apontam para um período proto-itálico, podem-se observar inovações fonológicas em comum que não se veem em outros ramos do proto-indo-europeu. Um exemplo é a difusão da fricativa surda $f$, como em PIE $* d^{h} e h_{1}-l(u) i$ - > PIt. *fêl $(u) \bar{l}$ - 'amamentação' > lat. fêlix 'afortunado' (de Vaan 2008: 209). Como Fortson (2010: 278) aponta, outro exemplo é o fato de as laringais terem se

2 Para mais sobre estudos introdutórios do proto-indo-europeu, ver Fortson (2010), Szemerényi (1999), Meier-Brüger (2003) e Mallory \& Adams (2004). 
perdido na sua forma não-silábica, enquanto se mantiveram como $a$ em outros casos, como em PIE *sth ${ }_{2}$-to- > lat. status 'parado' e em PIE * $h_{2} e n h_{1} m o->$ osc. anamúm 'respiração'. Várias outras inovações e preservações linguísticas das línguas itálicas podem ser apontadas, mas como o propósito desta dissertação é analisar a síncope vocálica, não essa discussão não será desenvolvida aqui.

A hipótese de uma unidade itálica é praticamente consensual nos dias de hoje, prova disso é que a maioria dos manuais de linguística histórica trata o ramo itálico como um ramo do proto-indo-europeu: Lehmann (1992:75-77), Beekes (1995:25-26), Bynon (1993:69), entre outros.

Ao longo desta dissertação, sempre que se falar em línguas itálicas, tem-se em mente essa definição: línguas indo-europeias que pertencem ao mesmo ramo linguístico porque possuem características estruturais em comum.

\subsection{Latim-Falisco}

Diferentemente da polêmica anterior, a questão em relação ao estatuto do falisco está longe de ser resolvida: trata-se de uma língua independente do subgrupo latimfalisco ou trata-se de um dialeto do latim? Durante muito tempo o falisco foi apenas tratado como uma língua independente que apresenta fortes semelhanças com o latim, como em Joseph \& Wallace (1991), Beekes (1995: 25), Baldi (2002: 123-5).

Estudos mais recentes, no entanto, defendem que não há diferenças substanciais em relação às duas línguas e que é mais coerente tratar o falisco como um dialeto do latim, como Giacomelli (1963). O trabalho mais recente e mais exaustivo a respeito do falisco, de Bakkum (2009A; 2009B), defende essa teoria analisando todos os aspectos linguísticos e históricos do povo falisco.

Segundo Bakkum (2009A: 100-3), o falisco é conhecido por não apresentar enfraquecimento vocálico e por não haver evidência substancial de síncope vocálica. $O$ autor argumenta que, como o latim e o sabélico apresentam diversos casos de síncope, seria estranho que o fenômeno não ocorresse em falisco e elenca alguns possíveis casos de síncope. No entanto, apenas se pode identificar um caso evidente de síncope em falisco: maximo (MF89), maxom[o] (MF98) <*magisomo. Por isso, independentemente de o falisco ser um dialeto do latim ou outra língua, ele não é muito útil para esta pesquisa e não será mais discutido aqui.

O latim, por sua vez, é a língua itálica que mais apresenta vestígios textuais e sobre a qual há muita fortuna crítica moderna. Devido à grande produção textual, 
mostrou-se necessário dividir o latim em três períodos históricos: Latim Antigo (LA), que abarca as primeiras inscrições latinas do séc. VI a. C. até 240 a. C. (início da produção literária); Latim Pré-Clássico (LPC), que compreende o período de 240 a. C. até 81 a. C. (primeiro trabalho de Cícero); e Latim Clássico, que abrange 81 a. C. até 14 d. C. (morte de Augusto) $)^{3}$.

\subsection{Sabélico}

O outro subgrupo do ramo itálico é o sabélico, também chamado de osco-úmbrio por causa das duas línguas de maior expressão do ramo, o osco e o úmbrio.

As línguas sabélicas usam mais do que um alfabeto para grafar suas línguas, há inscrições com alfabeto latino, com alfabeto grego e com alfabetos epicóricos. O latino e o grego foram emprestados das línguas latina e grega respectivamente, enquanto os epicóricos foram criados com base no alfabeto etrusco. Há um alfabeto epicórico osco, um úmbrio e um piceno meridional; apesar de possuírem a mesma base, tratam-se de alfabetos diferentes ${ }^{4}$.

Para que as diferenças entre as grafias fiquem claras, segue-se neste trabalho o método mais utilizado pela maioria dos estudiosos da área: as palavras escritas originalmente com alfabeto latino serão grafadas com o alfabeto latino e serão marcadas em itálico; as palavras escritas originalmente com alfabeto grego serão grafadas com o alfabeto grego; e as palavras originalmente escritas com alfabetos epicóricos serão transliteradas em caracteres latinos e serão marcadas em negrito.

O úmbrio é a língua não-latina que tem o mais longo vestígio escrito na região, cerca de 30 inscrições. Apesar de terem restados poucos textos úmbrios, o maior e mais famoso texto úmbrio, as Tábuas Iguvínias (texto do séc. III a. C. aproximadamente), é um longo texto composto de 7 tabletes de bronze e que descrevem um ritual religioso.

Há cerca de 400 pequenas inscrições em osco, mas a maior parte delas é composta apenas de algumas palavras ou mesmo de uma só palavra. Em termos linguísticos, pode-se dizer que o osco é a língua sabélica mais conservadora dentre as línguas itálicas. Um bom exemplo esse conservadorismo é o fato de o osco não monotongar ditongos, processo que sempre ocorre em úmbrio, e que acontece às vezes

\footnotetext{
Divisão feita com base na de Meiser (1998: 2).

4 Para mais sobre alfabetos de línguas sabélicas, ver Wallace (2007: 6-10), Marinetti (1985: 45-60), Lejeune (1970) e Lejeune (1972).
} 
em latim: tal como em osc. kvaísstur vs umb. kvestur (cf. lat. quaestor 'tipo de magistrado').

A língua pelígia (em inglês Paeligian) é considerada pelos estudiosos como uma língua do subgrupo osco, mas neste trabalho se segue a perspectiva tradicional de evidenciar quais palavras são pelígias.

Além dessas línguas sabélicas, também se usam algumas palavras do piceno meridional neste trabalho, uma língua com menos vestígios escritos do que as demais línguas sabélicas, mas na qual também se pode verificar a presença da síncope vocálica.

É possível trabalhar com essas línguas como um só grupo porque, em termos fonológicos, as línguas sabélicas são muito próximas. Wallace (2007: 11) explica que as diferenças significativas apenas aparecem no sistema vocálico. No entanto, para o objetivo desta análise, essas diferenças são pouco significativas e somente serão citadas quando influenciarem diretamente a questão da síncope vocálica.

\subsection{Etrusco}

A análise ainda contém poucos exemplos do etrusco, mas não de forma tão aprofundada quanto o que foi feito no latim e no sabélico, principalmente pela falta de compreensão da língua etrusca. Ainda que se possa constatar a síncope vocálica em diversas palavras, não há conhecimento suficiente sobre o léxico e sobre a morfofonologia para que uma análise completa seja possível.

A estrutura linguística do etrusco é bem diferente das demais línguas estudadas, pois tem algumas características peculiares, tais como processos morfológicos aglutinativos, e o fato de alguns casos serem formados a partir do pertinentivo ${ }^{5}$ e não apenas do nominativo ou do genitivo. Por ser uma língua considerada praticamente isolada, sem relação de parentesco com outras línguas bem conhecidas, a evidência textual escassa (inscrições compostas de vocabulário especializado e informações indiretas de autores gregos e romanos) é ainda mais problemática. Além disso, não há resquício de literatura, ainda que as fontes indiretas acusem a existência de literatura etrusca, e o único texto um pouco mais longo que nos chegou é o Liber Linteus Zagrebiensis (texto do séc. III a. C.), um calendário com datas de festivais religiosos.

A língua etrusca é escrita no seu próprio alfabeto, um alfabeto baseado no grego, mas modificado para suprir as necessidades fonológicas do etrusco. Algumas letras

\footnotetext{
${ }^{5}$ O caso pertinentivo tem uma função de possessão, ver Rix (2004A), autor que cunhou o termo, e Wallace (2008:46-47).
} 
foram retiradas do alfabeto, como o ômicron, e outras foram inseridas, como uma letra para o som /f/. Nesta dissertação, as palavras em alfabeto etrusco serão transliteradas em caracteres latinos e colocadas em negrito, da mesma maneira que será feito com termos sabélicos em alfabetos epicóricos.

Rix (2004A, 1998) defende que o etrusco não é uma língua isolada e que é possível identificar mais duas línguas da mesma família que o etrusco: o lêmnio (localizado no nordeste do mar Egeu) e o rético (localizado nos Alpes). No entanto, essas línguas têm ainda menos vestígios que o etrusco, ou seja, mesmo que aceitemos a premissa de Rix, isso não auxilia muito na compreensão dessas línguas não-indoeuropeias. Para mais sobre o etrusco, ver Apêndice: Etrusco.

\section{Síncope Vocálica}

A síncope vocálica é um fenômeno fonológico que pode ser observado em muitas línguas ao redor do mundo. Antes de analisar o fenômeno nas línguas da Itália Antiga, é importante definir detalhadamente o que se toma como síncope vocálica; grosso modo, trata-se da elisão de uma vogal no interior da palavra, mas essa definição é vaga demais para os propósitos deste trabalho.

Os manuais de linguística também definem síncope vocálica de modo bem simples. Lehmann (1992: 195) descreve a síncope, juntamente com a apócope, como processos de perdas vocálicas, sendo que a síncope seria a perda de vogais mediais e a apócope seria a perda de vogais finais, por exemplo: ing. ant. temede > ing. mod. tamed. Beekes (1995: 58), por sua vez, explica que sons em final de palavra ou em final de sílaba tendem a sofrer mudanças fonológicas com maior facilidade.

O próprio termo síncope não é utilizado por todos os estudiosos. Hawkins (1995:265-7), por exemplo, prefere apenas falar em perda silábica. Ele comenta sobre a posição mais fraca dentro de uma palavra; segundo o estudioso, seria a sílaba átona que segue uma sílaba tônica. Mesmo Nishimura (2008), que trata exaustivamente do assunto, não utiliza o termo síncope em sua tese, preferer usar o termo desaparecimento vocálico.

Como a questão da síncope é complexa, a definição de síncope será trabalhada melhor no contexto das línguas latina e sabélica respectivamente (ver item 16. Hipóteses sobre a Síncope em Latim no Capítulo II: Síncope Vocálica em Latim, e 5. Hipóteses sobre a Síncope em Sabélico no Capítulo II: Síncope Vocálica em Sabélico). 


\section{Enfraquecimento Vocálico}

O enfraquecimento vocálico e a síncope vocálica estão relacionados de algum modo, mas resta a dúvida de qual modo estão relacionados. Trata-se de duas etapas de um mesmo processo ou se trata de dois fenômenos fonológicos distintos que têm o mesmo estágio inicial?

Rix (1966:161-162) defende que a síncope não é um processo subsequente ao enfraquecimento vocálico, apesar de terem o mesmo estágio inicial, mas que se trata de dois processos distintos. Nishimura (2008: 6-8) também segue a premissa de Rix para analisar a síncope e o enfraquecimento.

Nesta pesquisa, concorda-se com a perspectiva de Rix e Nishimura, de modo que é possível analisar somente a síncope vocálica sem entrar em maiores detalhes sobre o enfraquecimento vocálico. Uma análise que leve em conta também o enfraquecimento vocálico nas línguas da Itália Antiga seria complexa demais para uma dissertação de mestrado.

\section{Corpora}

Para que a análise fosse feita detalhadamente e várias palavras e contextos pudessem ser comparados, foram construídos dois corpora de termos com síncope vocálica: um do latim e um do sabélico.

Os corpora não pretendem ser exaustivos, por algumas razões, mas parece seguro afirmar que os termos recolhidos são suficientes para que a análise seja profunda e detalhada. O corpus latino não é exaustivo porque a variedade de textos é muito grande em um largo período de tempo e não há um contexto preciso para se procurar mais casos. Além disso, a metodologia utilizada para colher casos de síncope consiste basicamente em procurar exemplos da bibliografia moderna, mas poucos estudiosos se propuseram a elencar casos de síncope vocálica em latim, o que torna impossível a construção de um corpus exaustivo. No sabélico, o corpus está mais perto de ser exaustivo porque há um volume bem menor de textos, mas para que a análise fosse mais objetiva, foram deixados de lado casos que são muito parecidos com outros já catalogados ou casos de grafia incerta.

Os corpora foram construídos com base em textos de pesquisadores modernos, os exemplos foram reunidos desses diversos textos e se discute a etimologia de cada um deles. Procurou-se verificar nos textos originais, especialmente em úmbrio, osco, piceno 
meridional e pelígio, a forma e o contexto das palavras analisadas. Nos casos latinos, nem sempre foi possível verificar os contextos (geralmente por serem palavras com múltiplas atestações), e foram então utilizados os dados contidos em dicionários modernos e afins.

O corpus latino é composto de 157 palavras e o sabélico de 158 palavras, encontra-se também entre essas formas casos incertos e casos de analogia. Formas marcadas como incertas (IN) são casos que não se tem certeza da síncope e da sua etimologia, de modo que não podem ser contabilizados como exemplos seguros de síncope. Palavras marcadas como analogia (A) são exemplos de casos que não possuíam uma vogal a ser sincopada na sua forma original, mas que apresentam tal forma por analogia a outras que realmente sofreram síncope.

A forma na qual estão organizados segue a seguinte ordem: 1) Termo, grafado em itálico quando em alfabeto latino, em caixa alta quando em inscrições do LA, em negrito quando em alfabeto epicórico (osco, úmbrio, piceno meridional, etrusco), em grego quando em alfabeto grego; 2) Língua (apenas no corpus sabélico); 3) Tradução, quando conhecida; 4) Ocorrência, quando possível; 5) Análise própria minha, que pode ser baseada em análises pré-existentes, pode mesclar as análise já existentes, ou pode ser uma nova proposta de análise; 6) Análises de estudiosos modernos, citando todas as análises relevantes para o estudo da síncope; 7) Ambiente Fonológico, composto por Consoantes Adjacentes, Posição da Síncope, Quantidade de Sílabas, e Sílaba Tônica (no caso do corpus latino). Segue abaixo um exemplo de verbete do corpus latino: 


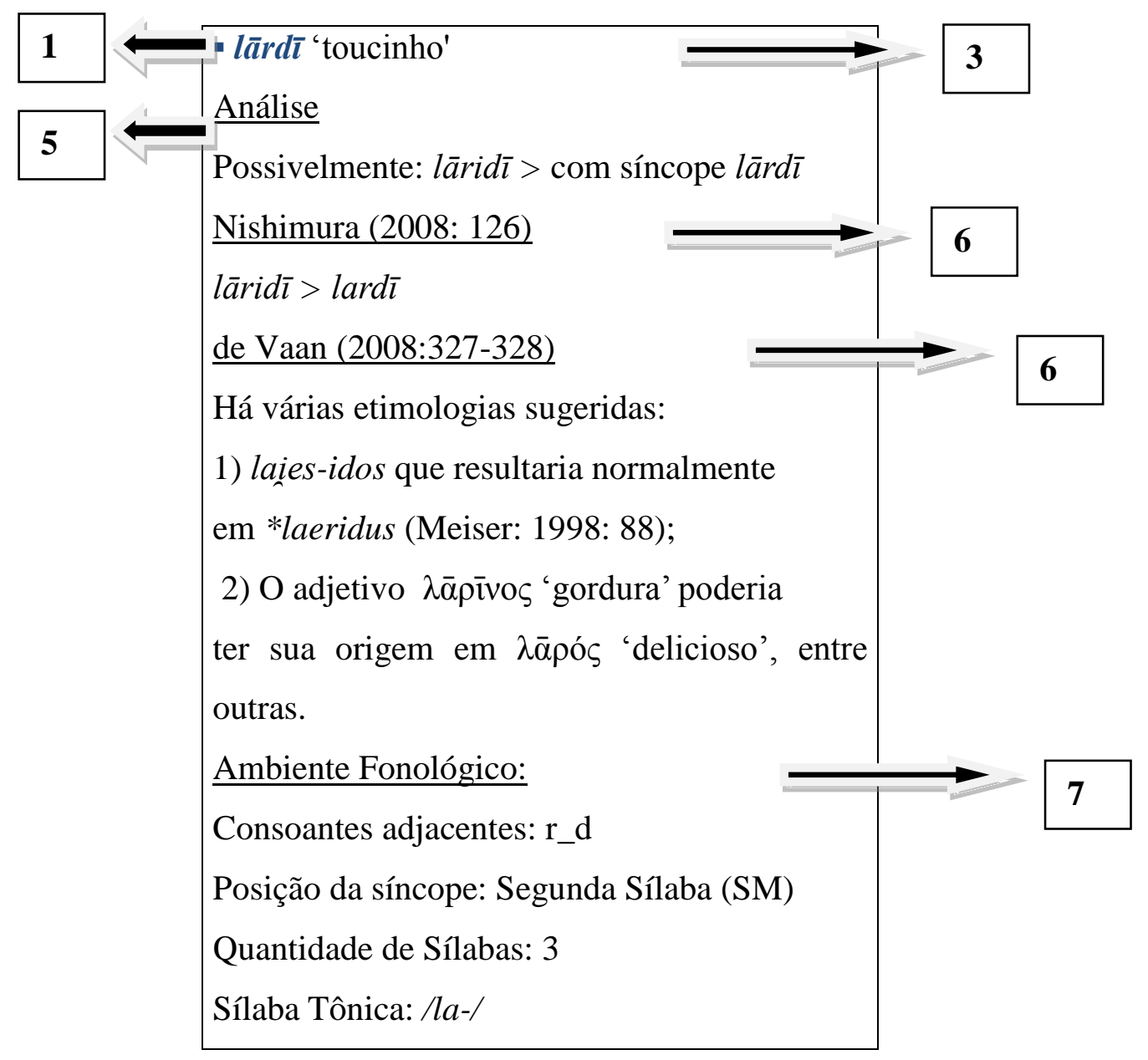

E um exemplo do corpus sabélico: 


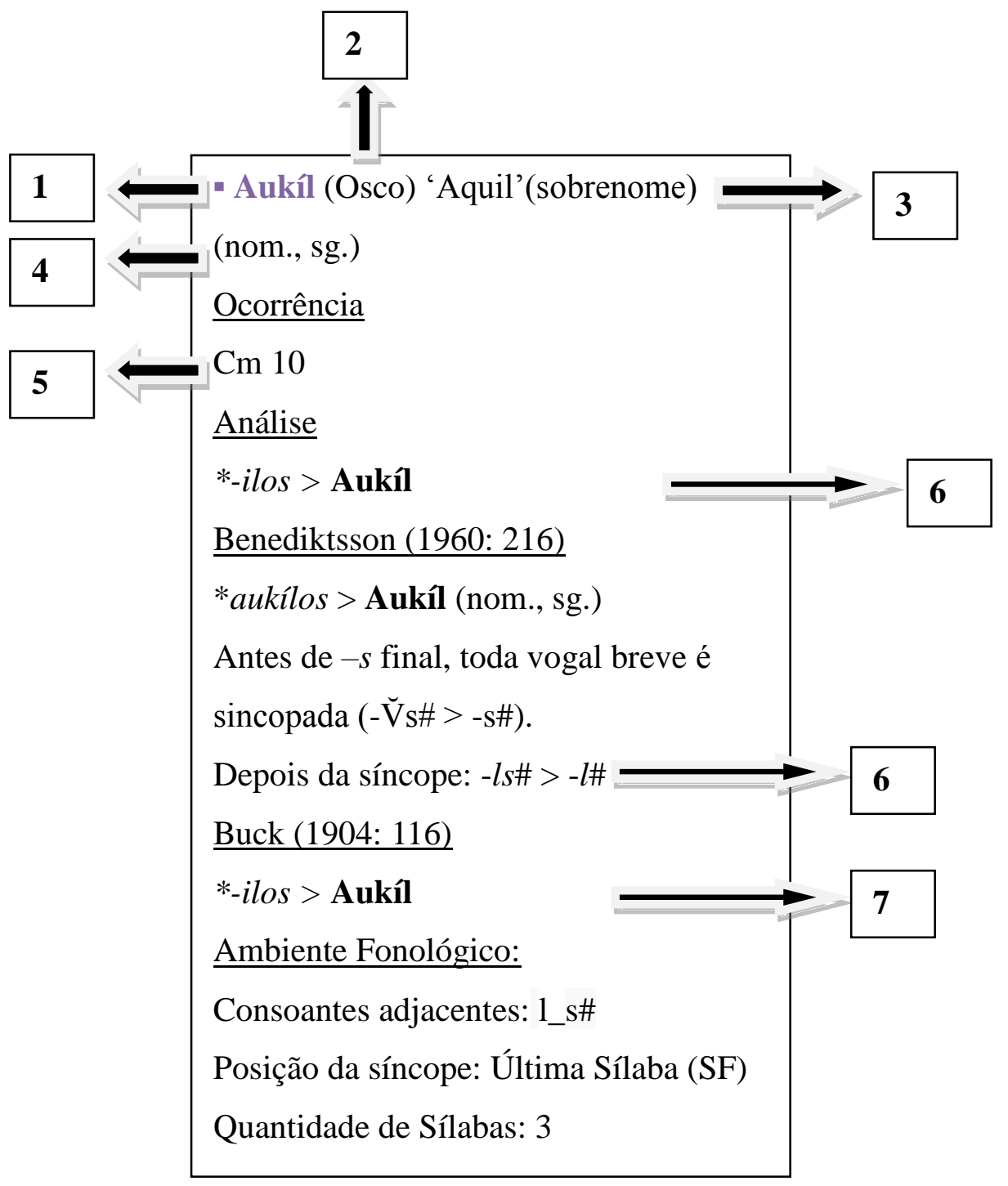




\section{CAPÍTULO II: SÍNCOPE VOCÁLICA EM LATIM}

\section{Latim}

A questão da síncope vocálica em latim é extremamente complexa e poucos foram os estudiosos que se aventuram a analisá-la de maneira detalhada. Buck (1904:57), por exemplo, afirma não ser possível precisar as condições fonológicas nas quais a síncope ocorre em latim, uma vez que os fatores envolvidos são muito complexos. Sommer (1914:133-134) também aponta a impossibilidade de descrever com detalhe as condições nas quais a síncope ocorre em latim, por serem muito complicadas.

Apesar das afirmações pessimistas de vários estudiosos da área, alguns autores defendem a possibilidade de descrever as condições do fenômeno. Dentre os primeiros a tentar uma definição (ainda que muito geral), está Exon (1907:118), que define a síncope em latim como: o desaparecimento de uma vogal breve não-acentuada entre consoantes, que resulta normalmente na perda de uma sílaba da palavra. Ainda que não de modo exaustivo, Rix (1966:158-165) também procura descrever algumas características fonológicas do processo.

Segundo Nishimura (2008: 18; 2011:1), apesar de normalmente se dizer que o desaparecimento vocálico em latim não é tão frequente quanto em sabélico, isso não é verdade, existe uma infinidade de exemplos em latim. Além disso, por meio da análise da síncope em latim e em outras línguas itálicas, o autor elenca várias condições necessárias para a existência do enfraquecimento e desaparecimento vocálico.

O estudioso analisa esse processo fonológico tendo como base a importância do acento tônico (no original, stress), assim como Exon (1907). Nishimura (2008: 6) afirma que, apesar de a questão do acento no latim clássico ainda ser controversa, as sílabas com enfraquecimento e desaparecimento vocálico são geralmente átonas (no original, unstressed).

Em outro artigo mais recente, Nishimura (2011) focaliza sua análise apenas na síncope em latim para tentar restringir as condições nas quais o fenômeno ocorre. Segundo o estudioso (2011: 5), a síncope operava de forma diferente em cada período histórico (pré-literário, pré-clássico e latim clássico), de modo que é preciso levar em consideração que diferentes fatores deveriam estar envolvidos em cada período. 


\section{Acentuação}

As condições necessárias para que a síncope vocálica aconteça são várias, mas nem sempre tais condições são suficientes para que a síncope ocorra. Um dos aspectos mais importantes, segundo Nishimura (2008, 2009), Rix (1966: 158), Leumann (1977: 97), Meiser (1998: 66), e outros, parece ser o acento tônico. Normalmente a síncope ocorre em uma sílaba pós-tônica, em uma sílaba imediatamente seguinte à sílaba tônica.

Como o acento é um fator importante, é necessário analisar as regras de acentuação em vigor em todos os períodos em questão. Nishimura (2008:116-140) analisa os casos de síncope com base na acentuação na primeira sílaba para as palavras do Latim Antigo e do Latim Pré-Clássico, e com base na acentuação da Lei da Penúltima para palavras do Latim Clássico.

No caso dos exemplos mais antigos, o estudioso (2008: 116-121) observa que a síncope ocorre em sílaba pós-tônica; se a sílaba tônica sempre for a primeira sílaba, normalmente a vogal sincopada se encontra na segunda sílaba, como em ${ }^{6}$ :

- balneum 'balneário < LPC balineum < PIt. *balaneom (Nishimura 2008: 118, 127, 134);

- dexter 'direita' < LPC *dexteros < PIt. *deksiteros (Nishimura 2008: 19, 116-117, 127, 134; Weiss 2009: 123);

- maxumus 'máximo’ < LPC *magisomo < PIt. *mag-ismmo-; cf. fal. maximo (MF89), maxom[o] (MF98) 'máximo’ (Nishimura 2008: 117; De Vaan 2008: 73-4);

Em casos excepcionais, a vogal sincopada pode-se encontrar também na terceira sílaba, como em:

- asellus 'burro' < LPC *asene-lo; diminutivo de asinus 'asno' (Nishimura 2008: 145);

- iuncus 'junco' < *iūnko < LA *ioinko- < PIt. *ioiniko- (Walde \& Hoffmann 1954: 729$30)$;

- salūber 'salubre'<*salubris (Nishimura 2008: 150).

O caso de asellus é mais complicado, pois se trata de um diminutivo construído com o sufixo *-elo-. Palavras formadas com esse diminutivo sempre apresentam síncope porque o sufixo apresenta uma vogal breve em uma sílaba átona, e a vogal também se encontra entre duas soantes. Para mais sobre síncope em diminutivos, ver item 13. Diminutivos neste mesmo capítulo.

6 Todos os exemplos citados a partir deste ponto se encontram no Anexo I: Corpus de Palavras Latinas com suas respectivas referências e análise resumida. 
A partir do Latim Clássico, a regra de acentuação mudaria para a Lei da Penúltima, que dita que o acento deve cair na antepenúltima se a penúltima sílaba for breve. Nas palavras desse período, a síncope tende a acontecer na penúltima sílaba, pois normalmente a antepenúltima é a sílaba tônica, como em:

- ārdus (Plauto) ‘árido’ < LC āridus (Nishimura 2008: 199).

O mais frequente no corpus é a ocorrência da síncope vocálica em posição imediatamente pós-tônica (104 casos, sem contar casos incertos e analogia). Quando a sílaba seguinte à sílaba tônica possui uma vogal breve, ela se torna vunerável e tende, de modo consistente, a perder a vogal. São os casos de:

- auceps 'caçador de pásssaros' < *auni-kap-s (Weiss 2009: 261; Nishimura 2008: 19, 117);

- cette (imp. - Plínio, Ênio) 'dá aqui!' < LPC *kedte < PIt. *kedate (Nishimura 2008: 118; Weiss 2009: 123).

No entanto, há casos que não seguem essa tendência e por isso necessitam ser analisados à parte. Um grande grupo de casos de síncope não-imediatamente pós-tônica é o de diminutivos, por exemplo:

- misellus 'pobrezinho' < LPC *misere-lo/ā-; diminutivo de miser 'pobre' (Nishimura 2008: 145).

Há casos de síncopes considerados não-imediatamente pós-tônicos, mas que também permitem soluções diferentes das apresentadas por outros estudiosos. Esses casos serão analisados individualmente e de modo detalhado. Esses casos são analisados no item 14. Outros Casos de Síncope Não-Imediatamente Pós-Tônica deste mesmo capítulo.

\section{Quantidade de Sílabas}

Geralmente as palavras que sofrem síncope são quadrissilábicas ou trissilábicas, 64 casos do corpus são de palavras trissilábicas ${ }^{7}$ e 45 casos são de palavras quadrissilábicas $^{8}$, tais como:

\footnotetext{
${ }^{7}$ Além das palavras trissilábicas citadas nesta seção, ainda há no corpus as palavras: agellus, anceps, antae, ārdus, auceps, auillus, caldus, cautum, citrāa, contrāa, doctus, facultās, ferrelfertis, flagellum, forceps, gaudeō,halō, Herclēs, hospes, ìmus, infrāa, integer, iugrā, lard̄̄, lībellā, libellus, macellus, miser, necdum, nōnus, nostro-, occa, ornus, palmus, pars, pergō, Pollūx, ponō, pōpulneus/nus, porgō, postrīdiē, postus, praecō, prīnceps, propter, puertia, purgō, retrō, sacellus, sacerdōs, salūbre, sēsqui-, socer, suprā, surgō, ūdos, ulna, uladē, ueclus, uernō, uestro-, uirtūs, uulnus.

${ }^{8}$ Além das palavras quadrissilábicas citadas nesta seção, ainda há no corpus as palavras:
} 
- balneum 'balneário < LPC balineum < PIt. *balaneom (Nishimura 2008: 118, 127, 134);

- cette (imp. - Plínio, Ênio) 'dá aqui!' < LPC *kedte < PIt. *kedate (Nishimura 2008: 118; 2009: 123).

No corpus, há apenas 13 casos de síncope em palavras dissilábicas ${ }^{9}$, tais como:

- sacer 'sagrado' < *sakerr < *sakers < *sakrs < LA SAKROS (Nishimura 2008: 150);

- aper 'javali' <*aper- <*apr- < PIt. *apro- (Nishimura 2008: 150).

E três de palavras pentassilábicas:

- disciplīna 'instrução' < LC discipulīna (Nishimura 2008: 119);

- nuncupāre (inf.) 'nomear' < *nōmicupāre (Leumann 1977: 97);

- officium 'trabalho' < LPC *opi-fakiom (Nishimura 2008: 116).

É possível observar que palavras com três ou quatro sílabas são mais suscetíveis a sofrer síncope vocálica. Curiosamente foram encontrados apenas dois casos de palavras pentassilábicas, o que significa que não é suficiente a palavra ser longa para estar suscetível à síncope.

\section{Qualidade das Vogais}

Segundo Nishimura (2011: 7), a síncope vocálica em latim parece acontecer com qualquer vogal, desde que seja breve. No entanto, o autor comenta que a perda do $u$ é incomum (por algum motivo desconhecido). Para que a síncope ocorra, a vogal passa por um estágio inicial no qual ela se torna *ə e apenas depois a vogal desaparece. Ou seja, a qualidade da vogal parece não influenciar tanto na ocorrência ou não da síncope, pode-se observar que outros fatores são mais importantes e produtivos.

\section{Contraexemplos}

A perspectiva diacrônica é imprescindível para que as atestações possam ser realmente identificadas como síncopes. Há dois contra-exemplos interessantes que poderiam ser identificados à primeira vista como síncope vocálica, mas que na verdade não o são: é o caso de pōculum/pōclum 'taça' e pūblicus 'público'/ populus 'povo'.

abdīcō, alter, ampulla, asellus, audère, calficio, catella, catella, catellus, cistella, concutiō, dexter, expergīscor, ferculum, figlīna, frīgdārium, hortārī, ìlignus, iunco, iuxtā, malleus, maxumus, mīsellus, misertus, nouellus, nūper, obiūrgō, offella, ōpiliō, patella, pūrgāre, quīndecim, reccidī, repperī, reppullī, rettullī, sēstertius, sinciput, tegmine, tenellus, uindecim, üsurpāre, uindēmia, uitellus.

${ }^{9}$ Além das palavras dissilábicas citadas nesta seção, ainda há no corpus as palavras: ars, caper, faber, fers/fert, iūs, mēntis, mors, niger, piger, puer, uafer. 
Podem ser atestadas, mais ou menos na mesma época, as formas pōclum e pōculum. Seria possível supor pōculum > pōclum, visto que há ocorrências de síncope vocálica em outras palavras com contextos fonológicos semelhantes, no qual a vogal $/ u /$ está entre uma oclusiva e uma soante (como discipulina > disciplīna 'instrução'). No entanto, segundo Weiss (2009: 69), essa palavra é de origem indo-europeia, o que auxilia na reconstrução do processo: *peh ${ }_{3}$-tlom $>{ }^{*}$ pōtlom $>$ pōclum > com epêntese pōculum.

Processo semelhante deve ter ocorrido com püblicus/populus, embora de maneira mais complexa, pois duas raízes existiam ao mesmo tempo: pūbl- e popul-. De acordo com De Vaan (2008:480), a palavra não tem uma etimologia conhecida, contudo é possível reconstruir a forma do Proto-Itálico, que seria *poplo-. Podem-se encontrar cognatos no úmbrio, puplum, poplom, e talvez até puplu no etrusco; e as atestações mais antigas em latim seriam POPLIOSIO e POPLICOD. Apesar de conviverem ao mesmo tempo formas como populātiō 'devastação' e populāriter 'coloquialmente', a forma original não teria a vogal medial, ou seja, não se trata de uma síncope, mas de uma epêntese que ocorreu apenas no latim.

Esses contraexemplos servem apenas para ilustrar como a diacronia e a etimologia são importantes para identificar os ambientes fonológicos nos quais a síncope vocálica ocorre em latim. Esses detalhes importantes evidenciam a complexidade do fenômeno na língua latina.

\section{Presença de Soantes}

Outro aspecto que facilita a queda de vogais mediais é a presença de soantes (nasais e líquidas) próximas a essas vogais (Rix: 1996: 157). Nishimura (2008: 133) também afirma que a queda de vogais nesses contextos resulta em encontros consonantais mais semelhantes aos que já ocorrem na língua.

O corpus desta pesquisa corrobora a visão desses autores, pois a presença de soantes é abundante, das 124 palavras que compõem o corpus (sem contar casos marcados como analogia - A - e casos marcados como incerto - IN), 73 apresentam soantes antes e/ou depois da vogal sincopada.

Embora não seja imprescindível para a ocorrência da síncope, a alta frequência de soantes indica que esse tipo de ambiente fonológico facilita a ocorrência da síncope vocálica. Outra prova de que a presença de soantes adjacentes a vogais breves é 
importante é o fato de isso acontecer em palavras com quantidades de sílabas diferentes e em palavras de diferentes períodos do latim.

\section{1. $R \_R$}

Uma vogal entre duas soantes tende a desaparecer:

- agellus 'campo' < *agerlo- < *agrlo- < PIt. *agre-lo- (Nishimura 2008: 147, 151; Leumann 1977: 97);

- expergīscor 'acordar' < *ex-pro-rgīscor; cf. av. fra-yrīsəmnō 'desperto' (Leumann 1977: 97);

- ornus 'cinzas'<*orinos <*osenos (Schrjiver 1991: 327; Leumann 1977: 96);

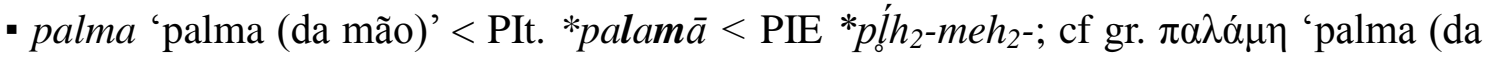
mão)', IrA. lām 'mão' (Nishimura 2008: 118; Schrjiver 1991:327);

- pōpulneus 'derivado de álamo' < pōpuli-; cf. lat. pōpulus 'árvore de álamo' (Nishimura 2008: 143-4);

- uernō (adv.) 'primavera' < LC *uēerinōd (Nishimura 2008: 126);

- ulna 'antebraço' < *olnā < *olen $\bar{a}$; cf. gr. $\grave{\omega} \lambda \varepsilon^{\prime} v \eta$ 'antebraço' (Leumann 1977: 96);

- uulnus 'ferida' < *uolnos <*uolenos (por Leumann 1977: 96).

Os casos de síncope em diminutivos também se encontram nesta categoria, pois a síncope ocorre no sufixo diminutivo *-nelo-, o qual possui duas soantes (ver reconstrução de todos os exemplos do corpus no item 13. Diminutivos). Todos os casos seguem o padrão:

- catella 'corrente leve' < LPC *katēne-lā; diminutivo de catēna 'corrente' (Nishimura 2008: 145-6).

\section{2. $R \_C$}

A presença de uma soante antes da vogal a ser sincopada é frequente, o que leva a crer que essa posição é a que mais auxilia na ocorrência da síncope:

- antae 'pilastras quadradas'<*anatā- (Leumann 1977: 97; Weiss 1993: 46);

- aper 'javali' <*aper- <*apr- < PIt. *apro- (Nishimura 2008: 150);

- ardus 'árido' < LC āridus (Plauto) < PIt. *ās-ēe- 'estar seco' (Nishimura 2008: 199; De Vaan 2008: 53); 
- calficiō 'aquecer' < LC *calefaciō (Leumann 1977: 97; Weiss 2009: 124; Nishimura 2008: 119) ${ }^{10}$;

- caper (Catulo) 'bode' < * caperr < *capers < *caprs < PIt. *kapros (Nishimura 2008: $150)$;

- faber 'artesão' < *faberr < *fabers < *fabrs < PIt. *fabros (Nishimura 2008: 150);

- ferculus 'bandeja (para alimentos)' vs praefericulus; cf. gr. $\varphi \alpha \rho \varepsilon ́ \tau \rho \alpha$ 'aljava' (Nishimura 118-9:);

- ferre, fers (do verbo ferō) 'carregar' < *feresi, *feres (Meiser 1998: 224; De Vaan 2008: 213-4) ${ }^{11}$;

- forceps 'pinça' < *formkap- < LPC *formo-kap- (Nishimura 2008: 117);

- hortārī (inf.) 'exortar' vs horitātur, horitur (Leumann 977: 96);

- iūrgōo, obiūrgō 'censurar' < LC *iūrigō < PIt. *ious-agō (Nishimura 2008: 119);

- lārd̄̄ 'toucinho' < lārid̄̄ (Nishimura 2008: 126) ${ }^{12}$;

- miser "pobre" < *miserr < *misers < PIt. *miseros (Leumann 1977: 98);

- misertus (part. passado de miseror) 'sentir compaixão' < miseritus (Leumann 977: 96);

- niger 'preto' < *nigerr < *nigers < *nigrs < PIt. *nigros (Nishimura 2008: 150);

- pergō 'continuar' < LC *perregō (Nishimura 2008: 124);

- piger 'preguiçoso' < *pigerr < *pigers < *pigrs < PIt. *pigros (Nishimura 2008: 150);

- porgō 'esticar-se' < LC *porrigō (Nishimura 2008: 124);

- prīnceps 'líder' < LA * pri(s)mo-kap-s (Nishimura 2008: 117; Leumann 1977: 96);

- puer 'menino' < *puerr < *puers < PIt. *pueros (Leumann 1977: 98);

- pūrgāre 'purificar' < *pūrigāre; cf. lat. pūrus 'puro' (Leumann 1977: 98, conjectura feita por Plauto, Aulularia, v. 753);

- purgō 'desculpar-se' < LC *purrigō (Nishimura 2008: 124);

- sacer 'sagrado' < *sakerr < *sakers < *sakrs < LA SAKROS ; cf. fal. sacra (nom., sg., f.) 'sagrado', umb. sacru (nom., sg., f.) 'sagrado', osc. sakrim (acs., sg.) 'sagrado' (Nishimura 2008: 150; De Vaan 2008: 532);

- sacerdōs 'sacerdote' < *sakrdōs < *sakro-dhōt-s; formas mais antigas: sacrilegus 'sacrilégio', sacrificāre ‘sacrificar' (Leumann 1977: 97);

- sinciput 'meia-cabeça; bobo' < *sēmi-caput < PIt. *suīno-caput (Leumann 1977: 97;

Nishimura 2008: 124; De Vaan);

\footnotetext{
${ }^{10}$ Para mais sobre calficiō, ver item 15.2.

${ }^{11}$ Para mais sobre ferre, fers, ver item $\mathbf{1 5 . 5 .}$

${ }^{12}$ Para mais sobre $l \bar{a} r d \bar{l}$, ver item 15.8.
} 
- socer 'sogro'<*socerr < *socers < PIt. *soceros; em Plauto, socerus (Leumann 1977: 98);

- surpiō 'roubar' < *sub-rapiō (Nishimura 2008: 135);

- uafer 'engenhoso' < *uaser- < *uasr- < PIt. *uasro- ou *uap-ro-; cf. lat. uarius 'variado' (De Vaan 2008: 650);

- ualdē (adv.) 'muito' < unalidē (de ualidus); cf. lat. uarius (Nishimura 2008: 9; Leumann 1977: 97);

- uindēmia 'coleta de uvas para a produção de vinho' < * unini-dēmia < PIt. *uino-dèmos (Leumann 1977: 97);

- uirtūs 'qualidade viril' < *uiro-tūs (Leumann 1977: 96, palavra nos moldes de serui$t \bar{u} s$ 'servitude');

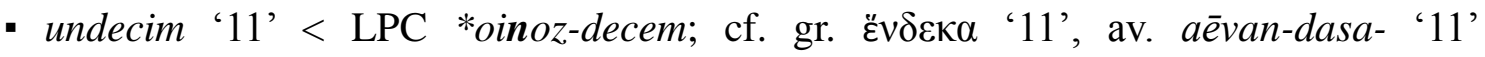
(Nishimura 2008: 19, 116; Leumann 1977: 107, 487);

- ūsurpāre 'usurpar' < * $\bar{u} s u-r a p o s$ (de $\bar{u} s u s+$ rapere); cf. lat. $\bar{u} s \bar{u}$-capiō 'usucapião' (Leumann 1977: 97; Nishimura 2008: 19).

\section{3. $C_{-} R$}

Não há tantos exemplos para esse ambiente fonológico como existe para o anterior, $R \_C$, a maior parte desses casos consiste em palavras com o sufixo *-tero(ver reconstrução de todos os exemplos do corpus no item 9. Síncope no Sufixo *-tero- > -tro-), as quais seguem o padrão:

- citrā (adv./prep.) 'desse lado' < *citr- < PIt. *citer-; cf. lat. citerior 'mais perto' (Leumann 1977: 97).

Além desse tipo de palavra, a síncope ocorre também nesse contexto em:

- disciplīna 'instrução’ < LC discipulīna(Nishimura 2008: 119);

- figlina 'oficina de vasos de argila' vs LPC figulus (Leumann 1977: 96);

- nōnus 'nono' < *nouenos (Leumann 1977: 97);

- pōnō (Plauto, Catão) 'colocar' < *posnō < PIt. *posinō (Nishimura 2008: 118, 127, 134; De Vaan 2008: 479);

- ueclus 'velho' < *uetlus < *uetulus (Leumann 1977: 97).

\section{7. *-rVs\# > -er\#}

É frequente a ocorrência de $*_{-r V s}>$-er em latim (e também em sabélico - ver Capítulo III: Síncope Vocálica em Sabélico, item 2.1., - *-ros\# > -er\#), o ideal seria 
que fosse possível explicar todos os casos por uma mesma regra, porém o acento tônico e a qualidade da vogal não permitem uma mesma explicação para todos os casos. Basicamente há duas reconstruções possíveis, uma com síncope e outra com metátese.

Nishimura (2008: 149-151) explica o desenvolvimento *-ros\# > -er\# (com síncope) com a seguinte fórmula: ${ }^{*} \mathrm{CrV}->{ }^{2} \mathrm{C}^{\curvearrowright} \mathrm{V}>*^{*} \partial r^{V}>\mathrm{Cer}$, e o exemplifica com alguns casos:

- àcer 'afiado' < *akerr < *akers < *akrs < *akris (Nishimura 2008: 149, 151);

- alacer (Ênio) 'ativo' < *alakerr < *alakers < *alakrs < *alakris (Nishimura 2008: $149,151)$

- aper 'javali' <*aper- <*apr- <*apro- (Nishimura 2008: 150);

- caper (Catulo) 'bode' < * caperr < *capers < *caprs < *kapros (Nishimura 2008: $150)$;

- faber 'artesão' < *faberr < *fabers < *fabrs < *fabros (Nishimura 2008: 150);

- hībernus 'relativo ao inverno' < *hībernos $<*$ hìbrnos $<*$ hìbrinos $<*^{h} \hat{g}^{h}$ eimr-ino(Nishimura 2008: 147);

- imber 'chuva' < *emberr < *embers < *embrs < *embris < *mb $b^{h}$ ris (Nishimura 2008: $150)$;

- integer 'intocado' < * entagerr < * entagers < *entagrs < *ntagros (Nishimura 2008: $150)$;

- miser 'pobre' $<*_{\text {miserr }}<*_{\text {misers }}<*$ miseros (Leumann 977: 98);

- niger 'preto' $<*$ nigerr $<*$ nigers $<*$ nigrs $<*$ nigros (Nishimura 2008: 150);

- piger 'preguiçoso' < * pigerr < *pigers < *pigrs < *pigros (Nishimura 2008: 150);

- puer 'menino'<*puerr <*puers < *pueros (Leumann 1977: 98);

- sacer 'sagrado' < *sakerr < *sakers < *sakrs < LA SAKROS ; cf. fal. sacra (nom., sg., f.) 'sagrado', umb. sacru (nom., sg., f.) ‘sagrado', osc. sakrim (acs., sg.) 'sagrado' (Nishimura 2008: 150; De Vaan 2008: 532);

- socer 'sogro' < *socerr < *socers < *soceros; em Plato, socerus (Leumann 1977: 98);

- uafer 'engenhoso' < *uaser- < *uasr- < PIt. *uasro- ou *uap-ro-; cf. lat. uarius 'variado' (De Vaan 2008: 650).

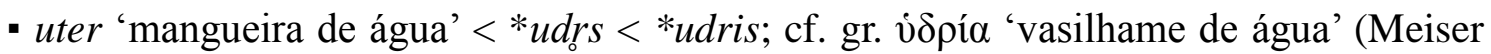
1998: 123; Untermann 2000: 785).

Quando a vogal da sílaba final no Proto-Itálico tiver sido *o, como em faber $(<$ *fabros) e niger (<*nigros), é muito provável que tenha ocorrido uma síncope na 
história da palavra, pois o $*^{*}$ não se torna $* e$ por desenvolvimento fonológico regular em latim. Portanto, para esses casos, a única explicação viável é a síncope.

Nos casos em que a vogal da sílaba final no Proto-Itálico possa ter sido $* i$, a situação é diferente, já que tanto uma síncope quanto uma metátese funcionariam bem fonologicamente.

Em latim, a sequência *-Cri- pode facilmente se tornar -er por meio de metátese:

- PIt. *akris > com metátese *akirs $>*$ akirs $>*$ akerr $>\bar{a} c e r$;

- PIt. *alakris > com metátese *alakirs $>*$ alakers $>*$ alakerr $>$ alacer;

- PIt. *keleris > com metátese *keleirs $>*$ kelers $>*$ kelerr $>$ celer;

- PIE * $\hat{g}^{h}$ eimr-ino- > *hībrinos > com metátese *hībirnos > hībernus;

- PIE *mb $b^{h}$ ris $>*$ embris $>$ com metátese *embirs $>*$ embers $>*$ emberr $>$ imber;

- PIt. *udris $>$ com metátese *utirs $>*$ uters $>*$ uterr $>$ uter $^{13}$.

\section{1. -er- em Sílabas Tônicas}

Nishimura (2008: 150) cita quatro exemplos de síncope em sílabas tônicas: cernō (< PIt. *krinō) 'distinguir', certus (< PIt. *krito) 'certo', ter (< PIt. *tris) 'três vezes', e testis (<*tersti < PIt. *triste-) 'testemunha'. Mas assim como os exemplos do item 7. *-rVs\# > -er\#, esses quatro casos permitem duas reconstruções fonologicamente possíveis: uma com síncope, e outra com metátese.

Síncope em uma sílaba tônica é um fenômeno extremamente raro e estranho, pois a síncope tende a ocorrer em sílabas átonas, como já foi mencionado acima. Uma explicação desse tipo seria somente aceitável se não houvesse uma solução alternativa, mas esses quatro casos podem ser explicados de outra maneira, com metátese. Ou seja, é mais óbvio e plausível não considerá-los como casos de síncope.

Com métatese, as reconstruções dessas palavras seriam:

- PIt. *krinō > com metátese *kirno $>*$ kerno $>$ cernō

- PIt. *krito > com metátese *kirto $>*$ kerto $>$ certus

- PIt. *tris > com metátese *tirs > *ters $>*$ terr $>$ ter

- PIt. *triste- > com metátese *tirste- > $*$ terste - > testis ${ }^{14}$

${ }^{13}$ Em latim, $d$ antes de $r$ se torna $t, * d>t$ (Meiser 1998: 123); por isso, *udris $>$ uter e não **uder.

${ }^{14}$ Nas sequências $*_{-}$rst-, $*_{-}$rsk-, a soantes se perde (Sihler 1995: 221), tal como lat. tostus 'torrado' $<*$ torstos. Por isso *terste- > testis. 


\section{Síncope em Sílabas Fechadas com Coda em $-s$}

Nishimura (2011: 17-8) discute que é possível haver síncope em sílabas fechadas se a coda for em $-S$, com silabificação $-S C(R)$-:

- mīscellus 'híbrido' < LPC *minuscellus (Nishimura 2008: 139-140; Nishimura 2011: 17).

Silabificação -SC(R)-: *mi.nu.scel.lus. A sequência de vogais breves em *minnǔscellus aponta para o fato de a síncope ter ocorrido em um período mais antigo, provavelmente no Latim Pré-Clássico;

- sēsqui- (adv./prep.) '1 e 1/2’ < LPC *sēmis-qui (Nishimura 2008: 139-140; Nishimura 2011: 17);

- sēstertius (Varrão/Cícero) '2 e 1/2’ < LPC *sēmis-tertius (Nishimura 2008: 139-140; Nishimura 2011: 17; Leumann 1977: 97).

Diferente de outros exemplos com essa sequência, o termo não apresenta uma sequência de vogais breves.

\subsection{Casos Polêmicos}

- fêstra-, fèe(n)stra 'janela' < LPC fenestra (Plauto/Catão) (Nishimura 2008: 137, 140; Nishimura 2011: 17).

Segundo Nishimura, a sequência de vogais breves nas duas sílabas iniciais de fenestra aponta para o fato de a síncope ter ocorrido provavelmente no Latim PréClássico. Meiser (2002: 66) concorda com Nishimura e explica que a vogal anterior à sequência $-s T(R)$ - tende a ser sincopada: fenestram > fênstram.

Rix (1966: 157), por sua vez, defende que a forma sincopada seria na verdade um empréstimo do etrusco, e que a palavra não teria sofrido síncope dentro do latim.

- mōnstrum 'sinal sobrenatural' < LPC *monestrum (Plauto/Catão) (Nishimura 2008: 137, 140; Nishimura 2011: 17).

A sequência de vogais breves em *mǒněstrum aponta para o fato de a síncope ter ocorrido provavelmente no Latim Pré-Clássico.

Weiss (2010: 395n131) apresenta uma solução mais interessante: lat. mōnstrum $<*$ mont-tlom ${ }^{15}$, da raiz *mont- 'mostrar', a única que funciona bem também no cognato sabélico (sobre o desenvolvimento de SP. múfqlúm, ver 5. Hipóteses sobre a Síncope

${ }^{15} \mathrm{O} r$ em mōnstrum parece ser uma analogia em relação a lūstrum 'pântano' (Vine 1993: 128). 
em Sabélico do Capítulo III: Síncope Vocálica em Sabélico). Desse modo, não se pode tomar essa palavra como um exemplo de síncope.

\section{Síncope no Sufixo *-tero- > -tro-}

O sufixo comparativo *-tero- é produtivo em latim, por isso há vários exemplos de palavras com síncope neste contexto:

- alter 'outro' < *aliter < PIt. *alitēr(os)-; cf. osc. alttrú (nCm 2a) 'outro' (Leumann 1977: 96; Weiss 2009: 285; 1960: 213).

Ernout \& Meillet (1959:22-23) argumentam que pode não ter ocorrido síncope na palavra, que a reconstrução mais provável seria *al-tero- > alter. No entanto, a geminação na forma osca alttrú sugere que houve alguma vogal, pois caso contrário haveria apenas um $t$ na palavra ${ }^{16}$. Hoje em dia, a maioria dos estudiosos também apoia a ideia da síncope.

- citrā (adv./prep.) 'desse lado' < *citr- < PIt. *citer-; cf. lat. citerior 'mais perto' (Leumann 1977: 97);

- contrā (adv./prep.) 'contra' < *contr- < PIt. *conter-; cf. osc. contrud (abl., sg., m./n. Lu 1,11; Lu 1, 17; Lu 1, 25; Lu 1, 33frag.) 'contra' (Leumann 1977: 97; Untermann 2000: 417);

- dexter 'direita' < LPC *deksteros < PIt. *deksiteros; cf. osc./umb. destr- (VIb 24; VIb

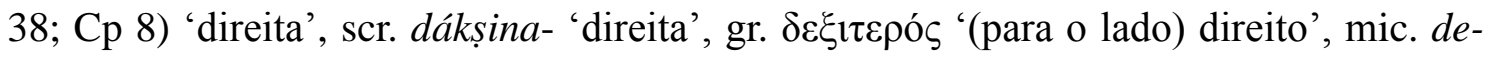
ki-si-wo /deksiwos/ '(para o lado) direito' (Nishimura 2008: 19, 116-117, 127, 134; Weiss 2009: 123; De Vaan 2008: 168; 1960: 213);

- extrā (adv./prep.) 'fora de' < PIt. *extera (Leumann 1977: 97);

- infrā (adv./prep.) ‘abaixo’ < PIt. *infera (Leumann 1977: 97);

- retrō (adv./prep.) 'atrás' < *retr- < PIt. *reter- (or Leumann 1977: 97);

- suprā (adv./prep.) 'em cima de' < LPC SUPERA; cf. umb. subra, subra (prep./adv. Va 20; VIa 15; VIb 17; VIb 41; VIIa 39; VIIb 3) 'em cima de’ (Nishimura 2008: 118; Untermann 2000: 706-7);

- ultrā (adv./prep.) 'além' < *ultr- < PIt. *ulter-; cf. lat. ulterior 'mais distante' (Leumann 1977: 97).

\footnotetext{
${ }^{16}$ Geminação de consoantes oclusivas após síncope vocálica é frequente em sabélico, isso quando a vogal sincopada não é restaurada por meio de epêntese. Para mais sobre geminação em sabélico, ver Buck (1904: 99-100).
} 
No sabélico, o sufixo *-tero também é produtivo, mais sobre isso no Capítulo III: Síncope Vocálica em Sabélico, item 3.1. Síncope no Sufixo *-tero- > -tro.

\section{Síncope na Antepenúltima Sílaba em Palavras Quadrissilábicas}

Nishimura (2011: 2) afirma que diversas palavras quadrissilábicas que apresentam síncope na antepenúltima sílaba podem ser datadas de uma época préliterária, anterior à regra de acentuação da penúltima. Essas palavras remontariam ao período do acento inicial tônico e a síncope teria ocorrido na segunda sílaba, a sílaba imediatamente pós-tônica. Se essas palavras seguissem a lei de acentuação da penúltima, a sílaba tônica seria a sílaba que foi sincopada, o que é bastante improvável. A partir dessas evidências, pode-se afirmar que o LA e o LPC possuíam acento inicial tônico.

- maxumus 'máximo' < LPC *magisomo < PIt. *mag-ismmo-; cf. fal. maximo (MF89), maxom[o] (MF98) ‘máximo’ (Nishimura 2008: 141; Nishimura 2011:2; De Vaan 2008: 73-4);

- ōpiliō 'pastor' < *áu-pol-o- < LPC *áui-pol-o- < *aui-pol-ó- < PIt. *ouni-pol-ó- < PIE *houi-polh $-o ́$ (Nishimura 2011:2; De Vaan 2008: 73-4);

- reccid̄̄ (perf. de recidō) 'cair para trás' < LPC *rekekad̄ < PIE *-kad- 'cair' (Nishimura 2011:3; Rix 2001A: 318);

- reppul̄̄ (perf. de repellō) 'repelir' < LPC *repepal̄ < PIE *-pelh $2^{-}$'aproximar-se' (Nishimura 2011:2; Rix 2001A: 470);

- repperī (perf. de reperiō) 'descobrir' < LPC *repeparī < PIE *perh $3^{-}$'fornecer' (Nishimura 2011:2; Rix 2001A: 474);

- rettulī (perf. de referō) 'carregar de volta' < LPC *retetalī < PIE *-telh $2^{-}$'levantar'; derivativo extetulisses (Ênio) 'colocaste os pés para fora' (Nishimura 2011:2-3; Rix 2001A: 622);

- sinciput 'meia-cabeça; bobo' < *sēmi-caput (Nishimura 2011:2; Leumann 1977: 97);

- undecim '11' < LPC *oino-dekem; cf. gr. èv $\delta \varepsilon \kappa \alpha ~ ' 11$ ', av. aēvan-dasa- '11' (Nishimura 2011:2; Leumann 1997: 107, 487).

\section{Síncope em Palavras que seguem a Regra de Acentuação da Penúltima}


Mester (1994) defende a tese de que o latim é baseado em troqueus bimoraicos $\left(_{\sim}=\right.$ breve/breve $^{-}{ }^{-}=$longa $)$e que isso explicaria a síncope imediatamente pós-tônica. A síncope pode ser entendida como o desaparecimento de uma vogal que não se adapta ao padrão de troqueus bimoraicos. Portanto, quando uma palavra apresenta a configuração:

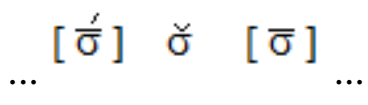

A tendência do latim é simplicar a sequência em:

\section{$[\bar{\sigma}][\bar{\sigma}]$}

E a síncope vocálica é uma maneira de reduzir a palavra (Mester 1994: 38).

Nishimura (2011: 8-10) comenta que a explicação de Mester funciona muito bem para palavras nas quais a acentuação segue a lei da penúltima, mas que ela não serve para palavras do LPC e de períodos anteriores. Ou seja, outros aspectos precisam ser levados em consideração quando se analisa a síncope em períodos diferentes do período clássico (como o acento tônico inicial, aspecto discutido no item anterior, 10. Síncope na Antepenúltima Sílaba em Palavras Quadrissilábicas deste mesmo capítulo).

Alguns exemplos ilustram devidamente como a prosódia baseada em troqueus bimoraicos pode explicar a síncope:

- aetās 'idade' < *aeuitās; cf. lat. aeuiternus 'permanente' $\mathrm{x}$ aeternus 'eterno' (Nishimura 2011: 9; Nishimura 2008: 119; Mester 1994: 38);

- frīgdārium 'despensa fria' < *frīgi- (Nishimura 2011: 9);

- pergō 'continuar' < *perregō (Nishimura 2011: 9; Mester 1994: 38);

- porgō 'esticar-se' < *porrigō (Nishimura 2011: 9; Mester 1994: 38);

- purgō (Plauto) 'desculpar-se; purificar' < *purrigō; cf. lat. pūrus 'puro' (Leumann 1977: 98; Nishimura 2011: 9; Mester 1994: 38);

- surgō 'levantar' < *subregō (Nishimura 2008: 9; Mester 1994: 38);

- (ob)īürgō 'censurar' < *iūrigō < *ious-agō (Nishimura 2011: 9; Nishimura 2008: 119, 124; Mester 1994: 38);

- ūdōs 'molhado' < ūuidōs (Nishimura 2008: 9; Mester 1994: 38);

- uernō (adv.) 'primavera' < *uērinōd (Nishimura 2008: 9). 


\section{Síncope em Palavras Tri- ou Quadrissilábicas com uma Vogal Longa na Última} Sílaba

Como esse tipo de síncope é frequente em sabélico (ver Capítulo III: Síncope Vocálica em Sabélico, item 3.2. Síncope em Palavras Tri- ou Quadrissilábicas com uma Vogal Longa na Última Sílaba), é interessante verificar se o mesmo ocorre em latim e se alguma conclusão pode ser tirada dessa comparação:

- aetās 'idade' < LC *aeuitās, aeternus 'eterno' < aeuiternus 'permanente'; cf. osc. aítateís (gen., sg. - Si 7) ‘idade’ (Nishimura 2008: 119; De Vaan 2008: 29 ${ }^{17}$ );

- ardus (Plauto) 'árido' < LC āridus (Nishimura 2008: 199);

- audēre 'ousar' < *aunid-e-e (de auidus 'ganacioso') (Nishimura 2008: 118);

- iūrgō, obiūrgō 'censurar' < LC *iūrigō < PIt. *ious-agō (Nishimura 2008: 119);

- iūstus ‘justo’ < LA iounestōd; iūs 'lei' < *iouos <*ieuos (De Vaan 2008: 316-7);

- iuxtā (adv.) 'perto de' < PIt. *iūgVstād (De Vaan 2008: 318);

- palma 'palma (da mão)' < PIt. *palamā < PIE *plíh $h_{2}-m e h_{2}$; cf. gr. $\pi \alpha \lambda \alpha ́ \mu \eta$ 'palma da mão', IrA. lām ‘mão' (Nishimura 2008: 118; Schrjiver 1991:327);

- pergō 'continuar' < LC *perregō (Nishimura 2008: 124);

- pōnō (Plauto, Catão) 'colocar' < *posnō < PIt. *posinō (Nishimura 2008: 118, 127, 134; De Vaan 2008: 479);

- porgō 'esticar-se' < LC *porrigō (Nishimura 2008: 124);

- praecō 'anunciador' < *praedkō < PIt. *praidikō (de Vaan 2008:169);

- purgō 'desculpar-se' < LC *purrigō (Nishimura 2008: 124);

- surgō 'levantar' < LC *subregō (Nishimura 2008: 124);

- surpiō 'roubar' < LC *sub-rapiō (Nishimura 2008: 135);

- ūdōs 'molhado' < LC *ūunidōs (Nishimura 2008: 125);

- ualde 'muito' < ualidē (de ualidus); cf. lat. ualidus 'forte' (Nishimura 2008: 19; Leumann 1997: 97);

- uernō (adv.) 'primavera' < LC *uerinōd (Nishimura 2008: 126);

Conforme Nishimura (2011: 2) explica, em todos esses casos a síncope vocálica parece ter ocorrido quando o acento tônico inicial estava em vigor. Desse modo, todas as vogais sincopadas se encontravam na segunda sílaba de cada palavra, ou seja, na sílaba imediatamente pós-tônica.

\footnotetext{
${ }^{17}$ De Vaan (2008:29) também apresenta duas etimologias possíveis para a palavra: *aiunotāt-s $>$ *ainotas $>$ com síncope aetās ou *ainnotāt $-s>$ *ainuitās $>$ *ainitās $>$ aetās.
} 


\section{Diminutivos}

São palavras, originalmente quadrissilábicas, com uma sequência de duas vogais breves após a sílaba inicial e tônica, que normalmente perdem a segunda vogal medial breve. 18 casos do corpus latino são desse tipo de palavra, prova de que se trata de um processo produtivo para a composição de diminutivos.

- ampulla 'garrafa' < *amporela; diminutivo de amphora 'ânfora'; cf. SLo. ampud̦da 'garrafa' (Nishimura 2008: 145; Weiss 2009: 281, 481);

- asellus 'burro' < *asene-lo; diminutivo de asinus 'asno' (Nishimura 2008: 145);

- auillus 'carneirinho' < *ag $g^{u}$ nlo < PIt. *ag ${ }^{u}$-nelo-; derivativos agniculus, agnicellulus, agnicellus 'carneirinho' (De Vaan 2008: 30; Ernout \& Meillet 1959: 15);

- catella 'corrente leve' <*katēne-lā; diminutivo de catēna 'corrente' (Nishimura 2008: 145-6);

- catellus 'filhote' < *katene-lo; diminutivo de catullus 'jovem animal'; cf. umb. katlu (acs., sg. - IIa 18; IIa 20; IIa 29) 'filhote de cachorro' (Nishimura 2008: 145; Benediktsson 1960: 238);

- cistella 'caixinha'<*kistelā; diminutivo de cistula 'caixa' (Nishimura 2008: 145);

- fiscella 'cestinha' < *fiscene-lā; diminutivo de fiscina $(<*$ fiscus) 'caixa' (Nishimura 2008: 145);

- flagellum 'chicote' < *flagrelo-; diminutivo de flagrum 'chicote' (Nishimura 2008: 147);

- lībella 'pequena moeda de prata' < *lībrelā; diminutivo de lībra 'libra' (medida de peso) (Nishimura 2008: 147);

- libellus 'livreto' < *librelo-; diminutivo de liber 'aquele que tem o status de livre' (Nishimura 2008: 147);

- macellus 'chuva fina' < *makrelo-; diminutivo de macer 'magro' (Nishimura 2008: 147);

- misellus 'pobrezinho' < *misere-lo/ā-; diminutivo de miser 'pobre' (Nishimura 2008: $145)$;

- nouellus 'jovem' < *nouele-lo/ā-; diminutivo de nouns 'jovem' (Nishimura 2008: $145)$;

- ofella 'pequeno pedaço de carne' < *offellā- < *offele-lā-; diminutivo de offula 'pedaço de carne' (Nishimura 2008: 145); 


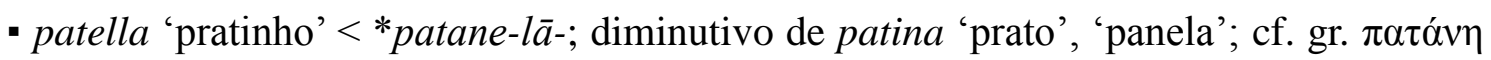
'prato raso' (Nishimura 2008: 145);

- sacellus ‘templo' < *sakrelo-; diminutivo de sacer ‘sagrado' (Nishimura 2008: 147);

- tenellus 'macio' < *tenere-lā-; diminutivo de tener 'delicado' (Nishimura 2008: 145);

- uitellus 'vitelo' < *uitele-lo-; diminutivo de uitulus 'filhote de animal'; cf. umb. vitlu, uitlu (acs., sg. - IIb 21; IIb 24; VIb 43; VIb 45, 16) 'vitelo' (Nishimura 2008: 145; Benediktsson 1960: 238).

Nishimura (2008: 146-7) apresenta também diversos casos de analogia a esse tipo de síncope, principalmente em diminutivos trissilábicos que não apresentam uma sequência de duas vogais breves, mas imitam o processo e resultam em formas semelhantes aos diminutivos quadrissilábicos: bellus (<*duene-lo) 'belo', catīllus $(<$ *katīne-lā-) 'pequena vasilha', corōlla (<*korōne-lā) 'pequena coroa', paullus (< *paure-lo-) 'pequeno', persōlla (<*persōne-lā) 'mascarazinha', pugillus (<*pugne-lo-) ‘aquilo que pode ser pego na mão', rāllus (<*rāre-lo-) 'simples', Sabellus $(<*$ sabnelo-) 'sabélico' (cg. lat. Sabinus 'sabino'), scabillum (<*scabne-lo-) 'banquinho', suillus $(<*$ suìre-lā-) 'referente a porcos', tigillum $(<*$ tigne-lo-) 'pequena viga (de madeira)'; uillum (<*uitele-lo-) 'pequena porção de vinho'; ūllus (<*oine-lo-) 'qualquer um'.

\section{Outros Casos de Síncope Não-Imediatamente Pós-Tônica}

De acordo com Nishimura (2008:143-4), vogais não-acentuadas que não são imediatamente pós-tônicas também estão sujeitas a sofrer síncope, e a presença de aproximantes (soantes) parece auxiliar o processo. Segundo o autor, essas palavras podem ser reconstruídas como:

- colurnus 'de avelã' < com metátese *corulnus $<*$ korelnos $<*$ korelinos $<*$ koselinos;

cf. lat. corilus 'aveleira';

- Falernus 'falernio' < *falerinos < *falisinos; cf. lat. Faliscus 'um tipo de salsicha; de Falerii';

- ueternus 'estado mórbido de torpor' < *ueterinos <* uetusinos.

Conforme se pode observar pelos casos de síncope dos itens anteriores, o mais comum é que a síncope vocálica ocorra em sílabas imediatamente pós-tônicas. Isso apenas não ocorre em casos especiais, como em diminutivos (por exemplo, *kistele-lā> cistella) e em palavras com quatro ou mais sílabas no período em que a acentuação da Penúltima estava em vigor (por exemplo, discipulīna $>$ disciplīna). Portanto, o ideal é 
buscar outra explicação plausível para casos de síncope em vogal não-imediatamente pós-tônica.

Ainda que partamos do pressuposto de que as formas proto-itálicas sugeridas por Nishimura estejam corretas (2008: 143-4), isso não significa necessariamente que sejam casos de síncope em sílaba não-imediatamente pós-tônica. É possível explicar a forma por meio de síncope na segunda sílaba e metátese posterior:

- *falisinos $>*$ falerinos $>$ com síncope $*$ falrinos $>$ com metátese *falirnos $>*$ falernos

$>$ Falernus;

- *uet-es-ino > *uet-er-ino > com síncope *uetrino > com metátese *uetirno > *ueterno- > ueternus;

- *koselinos > *korelinos > com síncope *korlinos > com metátese *kolrinos > *kolrunos $>$ com metátese colurnus.

O mesmo processo pode ser utilizado para analisar a palavra ìlignus, a qual é analisada normalmente com uma síncope na penúltima sílaba:

- ìlignus 'feito de azinheira ou da sua madeira' < *īliknos < *īlik-inos (De Vaan 2008:298).

É possível propor uma reconstrução semelhante à de Falernus, ueternus, e colurnus, uma reconstrução com síncope na antepenúltima sílaba e metátese posterior:

- *īlikinos > com síncope *īlkinos > com metátese *īliknos > ìlignus.

\section{Caso Polêmicos}

\section{1. adūlor 'adular'}

Muitos autores tentaram encontrar uma forma nominal que explicasse a etimologia de adūlor. Uma das hipóteses mais frequente é relacionar a palavra ao scr. vālah, vārah 'pelo da cauda', dentre os que defendem essa solução estão Ernout \& Meillet (1959: 9-10) e Walde \& Hoffmann (1954: 14). No entanto, De Vaan (2008: 25) explica que o $\bar{u}$ longo de adūlāre não pode ser explicado por meio dessa etimologia, pois o scr. vālah remontaria a uma raiz aniț, algo que não existe no latim.

A solução proposta por Meiser (1998: 186), na qual adūlor teria se originado a partir de uma forma verbal *ūlere ou *aulere, também não sustenta de acordo com De Vaan (2007: 142). Para que essa hipótese funcionasse, seria necessário uma raiz indoeuropeia com uma laringal no final, algo como * $\bar{u} l H$ - ou *aulH-, e não há evidências de que uma raiz assim tenha existido. 
Segundo De Vaan (2007: 142-4), a melhor etimologia seria correlacionar adūlāre com auidus 'ávido': *ad-auidos > com síncope *ad-audos $>$ adūdos $>$ adūlos.

\section{2. calficiō 'aquecer'}

Weiss (2009: 124) e Nishimura (2008: 19, 119) propõem a reconstrução *kale-faciō > calefaciō > com síncope calficiō. O único problema nessa proposta seria a mudança de $\bar{e}>e$, essencial para que a síncope possa ocorrer. Weiss explica tal fenômeno como abreviamento jâmbico, uma mudança de longa para breve por motivos poéticos.

Para Mester (1994: 11), o abreviamento jâmbico seria prova de como funciona o latim baseado em troqueus bimoraicos. Uma mudança

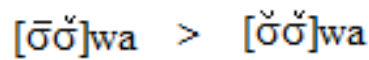

tornaria a palavra mais palatável na língua. $\mathrm{O}$ autor explica que o abreviamento não seria motivados pelo fato de que a sequência breve-longa não caberia no metro poético, mas seriam motivados pelo fato do latim ser prosodicamente baseado em troqueus bimoraicos $^{18}$.

\section{3. culmus 'caule'}

Existe uma polêmica sobre se houve síncope nessa palavra ou não. Nussbaum (1997:196-197) comenta a possibilidade da reconstrução: PIE *kolh $h_{2}-m o$ - 'caule' > PIt. *kolamos > com síncope *kolmos > culmus, mas também menciona que talvez a laringal $h_{2}$ nunca tenha sido vocalizada, pois está entre soantes depois de um grau /o/, e que talvez não tenha ocorrido síncope.

Schrijver (1991:327) também defende a hipótese de que a laringal não tenha sido vocalizada, mas utiliza o argumento de que normalmente a síncope não ocorre em palavras trissílabas com uma vogal breve em uma sílaba final. Ainda que sua conclusão possa estar certa, o argumento que Schrijver utiliza para defendê-la é falso (prova disso, é o exemplo: *kedate > cette (imp.) 'dá aqui!').

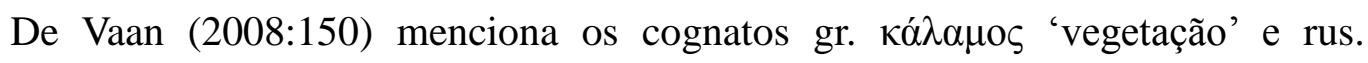
solóma 'caule', nos quais existe uma vogal na sílaba medial. No entanto, no latim a

\footnotetext{
${ }^{18}$ Para mais sobre abreviamento jâmbico, ver Adiego Lajara (1999). Para mais sobre o esquema rítmico do latim e suas limitações, ver Garnier (2012).
} 
situação é um pouco diferente, pois se trata de uma palavra de grau - $o$. De qualquer modo, parece difícil escolher uma hipótese em detrimento de outra.

\section{4. cunctus 'todo; inteiro'}

Ernout \& Meillet (1959: 157) afirmam que os latinos explicavam a etimologia de $\operatorname{cunctī}$ (pl. de cunctus) como proveniente de co-iunctī. Porém, essa etimologia não se sustenta fonologicamente. Segundo os autores, parece mais coerente que a etimologia seja con-citos (de cieō 'mover'). Leumann (1977: 217) defende a mesma hipótese de Ernout \& Meillet: con-citus (de con-cieō) > com síncope cūnctī, cūnctārī.

Apenas De Vaan (2008: 154) coloca em dúvida a existência de uma síncope nessa forma. Ele afirma que não é comum síncope em temas em -o- e, por isso, a forma parece ser uma analogia. Contudo, a explicação de De Vaan não convence, pois a vogal em cunctus não está entre soantes como no caso de culmus 'caule' e isso torna a primeira hipótese (com síncope) mais plausível. ${ }^{19}$

\section{5. ferre, ferrem, fert, fers do verbo ferō 'carregar'}

Pode-se observar síncope em todas as formas do verbo ferō $(<$ PIt. *fere/o < PIE $* b^{h}$ er-e/o) que possuem uma vogal medial ou final breve (de Vaan 2008:213-4):

fers ( $2^{\mathrm{a}}$ sg., pres., ind. $)<*$ feres;

fert ( $3^{\mathrm{a}}$ sg., pres., ind. $)<*_{\text {feret }}$;

fertis ( $2^{\mathrm{a}}$ pl., pres., ind. $)<*$ feretis;

ferre (inf.) < *feresi;

ferrem (subj., impf.) < *fererem < *feresem (exemplo dado por Meiser 1998: 224).

Visto que os casos de síncope são muitos nas formas desse verbo, provavelmente se trata de síncope regular no paradigma do verbo.

No sabélico também se pode encontrar um cognato de ferō, umb. fertu (imp. VIb 50; VIb 50). Benediktsson (1960: 165) classifica a palavra na categoria de síncope em formas tri- ou quadrissilábicas com uma vogal longa na terceira sílaba, ou seja, como um caso evidente de síncope $(*$ feretōd $>$ fertu). Contudo, não há como saber se o

19 Ainda que não seja uma etimologia aceita pela maioria dos estudiosos, vale a pena citar Sihler (1995: 145) apenas por curiosidade: o autor relaciona cunctus ao hit. pa-na-ku-uš 'todo, senado', de tema r/n; a partir dessa palavra, poder-se-ia reconstruir a forma *ponk ${ }^{w} u$-. Nessa perspectiva, a palavra úmbria puntes pode ser reinterpretada como 'todos', em vez de 'grupos de cinco'. 
verbo era temático ou atemático em sabélico, pois não se sabe o suficiente sobre o verbo. No latim, a ocorrência da síncope é bem fundamentada, mas no sabélico não há como ter certeza se houve síncope ou não.

\section{6. hālō 'emitir fragrância'}

Aparentemente, a síncope teria ocorrido nessa palavra na passagem do ProtoItálico > Latim Antigo.

Schrijver (1991:44) afirma que ocorreram dois desenvolvimentos diferentes a partir de uma mesma raiz:

PIE $* h_{2} e n h_{1}-s l->*$ anaslā- > com síncope anslā

PIE $* h_{2} n h_{1-s l->}{ }_{n} \bar{e} s l \bar{a}->$ aneslā (sob a influência de *anaslä-)

Segundo Schrijver, depois disso o segundo desenvolvimento foi contaminado pelo primeiro. E o $h$ - parece ter sido inserido posteriormente, por pura caracterização ou por analogia a hiāre 'bocejar'.

Weiss (2009: 177) apresenta uma explicação semelhante à de Schrijver. O estudioso explica que $-V n s l->\overline{V l}$ e que, portanto, *an-an-slo 'eu estou ofegante' $>$ *anenslō > an(h)ēlō (de $(h) \bar{a} l \bar{o})$, cujo cognato seria scr. ániti 'respirar'.

\subsection{Herclēs 'Hércules'}

A etimologia mais comum do nome do herói Hércules é a com síncope: *Hēracles > com síncope Herclēs (Leumann 1977: 96).

Rix (1966: 157), por outro lado, defende que a forma sincopada Herclēs tenha sido um empréstimo do etrusco. É plausível pensar em um empréstimo, pois a forma etrusca hercle é frequente nas inscrições.

Aparentemente, palavra também sofre síncope no sabélico, ver item 3.8.9. Osc. herekleís (gen., sg. - Cm 1A11; Cm 1A24; Cm B4; Cm B6) 'Hércules' do Capítulo III: Síncope Vocálica em Sabélico.

\section{8. imus 'parte mais baixa'}

Parece haver um consenso de que immus tenha passado por um processo de formação semelhante ao de summus (a partir de superus - ver item 15.11 summus 'o mais alto' neste mesmo capítulo). Ernout \& Meillet (1959: 311), Meiser (1998: 152) e Walde \& Hoffmann (1954:685) afirmam que imus teria vindo de inferus, ou seja: *inf- 
$m o>$ imus. Enquanto isso, a forma concorrente infimus refletiria um estado anterior da língua, na qual formas sincopadas e não-sincopadas ainda convivessem.

Apesar de a forma latina ser um bom caso de síncope, há um problema com a forma cognata osca imad (abl., sg., f. - Po 1), como bem apontam Ernout \& Meillet (1959: 311).O /i/ inicial não se explica em osco, a menos que se entenda como um empréstimo do latim. Untermann (2000: 341) chega inclusive a duvidar se a forma osca imad é cognata de ìmus, e se é correto pensar que ìmus foi construído no mesmo molde que summus.

\section{9. lārd̄̄ 'toucinho'}

Nishimura (2008: 126) apresenta a reconstrução lāridī > lārdī, como um exemplo comum de síncope medial. Contudo De Vaan (2008:327-328) menciona outras etimologias possíveis: *laies-idos, que resultaria normalmente em *laeridus (Meiser: 1998: 88); ou proveniente do adjetivo $\lambda \bar{\alpha} \rho \bar{i} v o \varsigma$ 'gordura', que poderia ter sua origem em $\lambda \bar{\alpha} \rho o ́ \varsigma$ 'delicioso'. Ainda assim, a hipótese de Nishimura parece mais sensata e simples.

\subsection{0. occa 'rastelo'}

De Vaan (2008:423) apresenta duas etimologias diferentes para a palavra: 1) Hipótese de Hirt (1916:230), na qual PIt. *oketa $>*$ okita $>*$ otika $>$ com síncope *otka > occa; 2) Empréstimo de algum dialeto itálico: *oketa- > *okta- > occa.

Independentemente de qual hipótese é mais plausível, as duas possuem síncope no seu desenvolvimento: *oCVCa- > okta- $($ ou $*$ otka- $)>$ occa.

\subsection{1. summus 'o mais alto'}

De Vaan (2008: 600) descreve dois desenvolvimentos possíveis a partir da etimologia PIE * $\left(h_{2}\right)$ up-m(H)o- > PIt. *sup(a)mo-. Resta a dúvida se existia /a/ na raiz itálica ou não, ou seja, se a melhor reconstrução seria 1) *supamo- > com síncope

*summo- > summus, ou 2) *sup-mo- > *summo- > summus.

Os cognatos itálicos, umb. sume (loc., sg. - IIa 15; III 1) e somo (abl., sg., m. VIa 9), também não ajudam nesse quesito, visto que há a mesma dúvida para eles.

\section{Hipóteses sobre a Síncope em Latim}


Como já foi mencionado anteriormente, a maioria dos estudiosos não analisa a síncope em latim de modo detalhado e se limita a citar exemplos. Os autores mais citados neste capítulo procuram fazer algo diferente, eles tentam identificar as características que levam a ocorrência da síncope.

Rix (1966: 156-7) estabelece algumas regras básicas para a sua ocorrência: 1) a síncope deve ocorrer em vogais breves (também ocorre em vogais que não foram originalmente breves); 2) a síncope deve ocorrer em sílabas abertas; 3) deve ocorrer em uma vogal antecedida por uma consoante.

Leumann (1977: 95) define síncope como o desaparecimento de uma vogal breve entre consoantes e aponta a presença de soantes como um fator agravante. Porém, como a síncope ocorre em praticamente todos os períodos históricos do latim, desde o Latim Antigo ao Latim Vulgar, o autor afirma ser impossível delimitar condições sólidas para a sua ocorrência.

De fato, o corpus desta pesquisa e a análise dos dados corroboram a perspectiva de Leumann: não é possível delimitar regras fonológicas específicas para a ocorrência da síncope vocálica. Apenas podem-se observar fatores que contribuem para que o fenômeno ocorra, mas mesmo que todos os fatores agravantes estejam em vigor, ainda assim é possível que não sejam suficientes e que não ocorra síncope. Dessa forma, não se pode falar em regras fonológicas, mas apenas em características facilitadoras.

Meiser (1998: 66-7), por sua vez, explica que a síncope vocálica já acontecia na língua latina desde o séc. VI ou V a. C. e também reitera a importância da presença das soantes, entre outros comentários. Weiss (2009: 122-4) procura identificar alguns ambientes fonológicos, mas apenas conclui que a síncope deve acontecer em sílabas breves, abertas e átonas.

A questão da importância de a sílaba ser aberta é explicada claramente por Sen (2012: 468), ele argumenta que vogais em sílabas abertas tendem a sofrer redução porque possuem uma duração menor que as vogais em sílabas fechadas. Desse modo, sílabas abertas são mais suscetíveis tanto ao enfraquecimento vocálico quanto à síncope.

Mester (1994) e Garnier (2012) procuram explicar a síncope vocálica com base na estrutura rítmica da língua latina. Mester (1994: 11-2) parte do pressuposto de que o latim é metricamente baseado em troqueus bimoraicos e que qualquer sequência fora dos padrões tenderia a ser simplificada para caber em troqueus bimoraicos. Assim, a síncope em sílabas imediatamente pós-tônicas poderia ser explicada como o desaparecimento de uma vogal presa (no original em inglês, trapping deletion). Garnier 
(2012: 235-6) também defende que o latim tem uma limitação rítmica na prosódia, e que a síncope funciona como uma ferramenta que auxiliaria as palavras a entrarem no esquema rítmico ideal. Segundo ele (2012: 238), a síncope seguiria um esquema bem estabelecido: 1) enfraquecimento vocálico; 2) síncope; 3) simplificação do encontro consonantal.

A explicação de Mester funciona bem para palavras do período literário do latim, mas não serve para palavras do LPC e de períodos anteriores, como Nishimura (20011: 8-10) bem afirma.

Nishimura $(2008,2011)$ é um dos poucos estudiosos que se propôs a analisar a síncope vocálica em latim de maneira sistemática. O autor executa sua análise dividindo os exemplos por períodos: Latim Pré-Literário (LPL), Latim Pré-Clássico (LPC) e Latim Clássico (LC). Esse tipo de divisão ajuda a solucionar o problema mencionado por Leumann (1977: 95), de que a síncope funciona de forma diferente em cada período histórico. No LPL e no LPC, a explicação de um sistema rítmico específico não soluciona os casos de síncope. Uma das conclusões que Nishimura (2011: 32-3) retira de sua análise é que o acento tônico inicial é a principal característica facilitadora da síncope nesses períodos mais antigos. Apesar da divisão de períodos de Nishimura possuir nomes ligeiramente diferentes dos empregados nesta pesquisa, isso não afeta os resultados, o período denominado Latim Pré-Literário equivale ao Latim Antigo (LA) que é utilizado aqui.

\section{Conclusões Parciais}

Por meio da análise de mais de uma centena de palavras latinas com síncope, foi possível observar que alguns fatores facilitam a ocorrência dessa mudança fonológica. $\mathrm{O}$ acento tônico aparece como primeiro aspecto a ser considerado, pois todos os casos do corpus (sem contar incertos e analogias) apresentam síncope em uma sílaba póstônica, imediatamente pós-tônica ou não. No entanto, o fato de existir uma vogal breve em uma sílaba átona após uma sílaba tônica não é fator suficiente para que haja síncope vocálica.

Todo o ambiente fonológico de cada palavra precisa ser levado em consideração; a presença de soantes também facilita a queda de vogais mediais, ou seja, quando há uma soante antes ou depois da vogal que sumirá (especialmente antes).

A quantidade de sílabas em uma palavra também é uma característica importante, normalmente palavras quadrissilábicas e trissilábicas são mais propensas a 
passar por essa mudança fonológica. Mas também são atestados 18 casos de síncope em palavras dissilábicas e três em palavras pentassilábicas.

A qualidade das vogais parece ser menos importante que os fatores citados acima, pois todas as vogais latinas podem sofrer síncope, embora a queda do $/ u /$ seja incomum.

Apesar de ser possível identificar alguns fatores que facilitam a ocorrência da síncope vocálica, ainda não é possível relacionar os dados encontrados cronologicamente. Na maioria dos casos, a mudança fonológica ocorre já dentro do latim, normalmente do LA e LPC para o LC, pois há exemplos que possuem atestações tanto sem quanto com síncope (como āridus x ārdus).

O esquema rítimico baseado em troqueus bimoraicos, apresentado por Mester (1994), explica bem a síncope no LC. Por outro lado, o acento tônico inicial parece ser mais importante para casos de síncope durante o LA e LPC (Nishimura 2011).

A comparação da síncope em latim com o fenômeno em sabélico também auxiliou na análise, ainda que a síncope funcione de formas diferentes em cada língua. No próximo capítulo, essas relações serão explicitadas. 


\section{CAPÍTULO III: SÍNCOPE VOCÁLICA EM SABÉLICO}

\section{Sabélico}

Pode-se observar que a síncope ocorria de forma sistemática em sabélico. Diferentes regras eram aplicadas a cada um dos dois tipos de síncope vocálica que se podem identificar: a síncope em sílabas mediais afetava basicamente qualquer vogal breve em uma sílaba aberta, enquanto a síncope em sílabas finais ocorria em ambientes fonológicos mais restritos.

Como a síncope ocorria sempre em sabélico, muitas palavras acabavam com sequências consoantais estranhas e, por causa disso, pode-se ver que vários desses casos apresentam uma vogal epentética após a síncope. É possível observar que se trata de síncope seguida de epêntese quando a qualidade da vogal de uma palavra é diferente da sua etimologia. Esse é o caso, por exemplo, da palavra *diekelo- > *dieklom > com epêntese osc. zicolom 'dia' (Benediktsson 1960: 239) ${ }^{20}$.

Os exemplos retirados do sabélico para efetuar a análise se restringem essencialmente ao osco e ao úmbrio, mas também há alguns casos do piceno meridional e do pelígio.

A notação das ocorrências das palavras sabélicas segue o livro de Rix (2002), que é a edição mais completa e confiável de textos sabélicos da atualidade. Rix marca os textos com a abreviação do nome do local da origem provável da inscrição, com o número da inscrição e/ou com a linha da inscrição. Por exemplo: $L u$ 1, 17 equivale à inscrição da Lucania número 1, linha 17; III 24 equivale ao terceiro texto das Tábuas Iguvínias (único texto que não possui abreviação de local), linha 24. Quando a inscrição for fragmentada e não há certeza absoluta da grafia da palavra, haverá a abreviação frag. após a notação de ocorrência, como em Po 12 frag.

A edição de Crawford et al. (2011), que possui imagens de praticamente todas as inscrições sabélicas, foi apenas utilizada quando a edição de Rix (2002) apontava dúvidas quanto a alguma palavra ou letra.

\section{Síncope em Sílabas Finais}

\footnotetext{
${ }^{20}$ Para mais sobre osc. zicolom ver o item 3.6. Síncope em Diminutivos deste mesmo capítulo e as notas 32 e 33 referentes ao mesmo item.
} 
Esse tipo de mudança fonológica é provavelmente pré-histórico em sabélico, tal como Benediktsson (1960: 258), Meiser (1986: 61) e outros defendem. Mesmo em piceno meridional, no qual se podem encontrar as mais antigas inscrições sabélicas, há alguns bons exemplos, como údiíns (AP 5) < PIt. *-nos (significado desconhecido), efidans (nom., sg. - AP 5) < PIt. *-nos 'Efidano' (cognome ou epíteto).

Esse tipo de síncope ocorria apenas em dois ambientes fonológicos: $V>\phi / \_s \#$; e $o>\phi /$ ii_m\#.

\subsection{V> $\quad$ /_s\#}

$$
\begin{aligned}
& \text { - *-CVs\# >-Cs\#: } \\
& \text { - } *_{-} f V s \#>*_{-} f s \#>-(s) s \#^{21}
\end{aligned}
$$

- umb. ahtis-per (dat./abl., pl. + prep. per - III 24; III 29) 'atos' < PIt. *aktifos (Benediktsson 1960: 222);

- umb. avis, aves, aueis (dat./abl., pl.) 'aves' < *auiss < *auifs < PIt. *auifos (Benediktsson 1960: 222);

- umb. berus (abl., pl. - IIa 23; IIa 35) 'estacas' < *-uss < *-ufs < PIt. *-ufos (Benediktsson 1960: 222);

- umb. fratrus (dat./abl., pl. - Vb 8; Vb13; VIIb 1) 'irmãos' < *fratruss < *fratrufs < PIt. *fratrufos (Benediktsson 1960: 222);

- umb. homonus (dat./abl., pl. - Vb 10; Vb 15) 'homens' < *homonuss < *homonufs < PIt. *homonufos (Benediktsson 1960: 222);

- umb. iouies (dat./abl., pl. - VIb 62; VIIa 23; VIIa 14; VIIa 28; VIIa 50; VM 4frag.) 'rapazes' $<*_{-} \bar{e} s s<*_{-} \bar{e} f s<$ PIt. *-êfos; cf. lat. iuuenis 'jovens' (Benediktsson 1960: 222);

- umb. karnus (dat./abl., pl. - IV 7) 'partes' < *karnuss < *karnufs < PIt. *karnufos (Benediktsson 1960: 222);

- umb. sacris (dat./abl., pl. - VIb 52; VIb 56) 'vítimas sacrificiais' <*sakriss <*sakrifs < PIt. *sakrifos (Benediktsson 1960: 222);

- osc. teremníss (dat./abl., pl. - Cm 1A14) 'limites territoriais'<*termníss $<*$ termen-i$f_{s}<$ PIt. *termen-i-fos (Benediktsson 1960: 223, 272);

\footnotetext{
${ }^{21}$ Todos os exemplos citados a partir deste ponto se encontram no Anexo II: Corpus de Palavras Sabélicas com suas respectivas referências e análise detalhada.
} 
- umb. tris (dat./abl., pl. - III 18; III 18) 'três' < *triss < *trifs < PIt. *trifos (Benediktsson 1960: 222).

$\mathrm{O}$ resultado da síncope na sequência $*_{-} C V$ s\# são duas consoantes em uma posição final, o que nem sempre é aceito pelo sabélico. Quando a primeira consoante é a fricativa $f$, o resultado é sempre uma assimilação regressiva: *-fVs\# > *-fs\# > - $(s) s \#$. Depois da assimilação, há uma degeminação da consoante dupla, na maioria dos casos: -ss\# > -s\#; somente no exemplo osc. teremníss a dupla consoante foi preservada.

- *-RVs\# > *-Rs\# > -R(s)\#

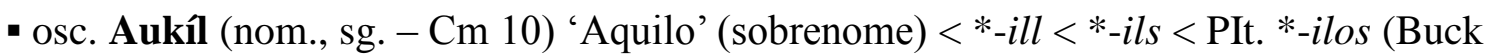
1904: 116);

- osc. censtur (nom., pl. - Lu 1,18; Lu 1,20; Lu 1,28; Lu 1, 29) 'censores' <*-tōr < *-tōrs < PIt. *-tōres (Benediktsson 1960: 219);

- pg. famel (nom., sg. - Pg 11) 'escravo' < *famell < *famels < PIt. *famelos; cf. lat. famulus 'escravo' (Benediktsson 1960: 216);

- umb. frater, frat(e)er (nom., pl. - Vb 11; II 5; Va 1; Va 14; Va 22; Vb 16) 'irmãos' < *frāterr < *frāters < PIt. *frāteres; cf. scr. bhrātara- 'irmão' (Benediktsson 1960: 218);

- umb. katel (nom., sg. - IIa 43) 'filhote de cachorro' <*katell <*katels < PIt. *katelos; cf. lat. catulus 'filhote de cachorro' (Benediktsson 1960: 216);

- osc. Mutil (nom., sg. - nPg 2; nPg 3; nPg 5; nPg 6a; nPg 6b) 'Mutilo' (cognome) <

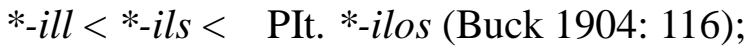

- osc. Paakul (nom., sg. - Cm 7) 'Paculo' (nome próprio) < Paakuls < PIt. *-ulos (Buck 1904: 116);

- umb. tiçel (nom., sg. - IIa 15) 'oferenda' < *dikell < *dikels < PIt. *dikelos (Benediktsson 1960: 216);

- osc. úpfals (nom., sg. - Cp 2) 'Upfalo' (nome próprio) < PIt. *upfalos (Benediktsson 1960: 216).

Quando a primeira consoante da sequência é uma soantes, $l$ ou $r$, o resultado normalmente é uma assimilação progressiva seguida de uma simplificação da dupla consoante: *-RVs\# > *-Rs\# > *-RR\# > -R\#.

O caso do osc. úpfals é curioso por ser o único que não apresenta assimilação das consoantes finais após a síncope. A sequência -ls\# pode indicar uma estágio intermediário, no qual a síncope já teria ocorrido, mas a assimilação ainda não teria 
acontecido. Infelizmente, não é possível datar a inscrição com segurança, o que dificulta a corroboração dessa hipótese.

$$
\text { - *-IVs\#>-I }
$$

- osc. fortis (nom./acs., sg. - Lu 1,12) 'mais forte' <*fortiis <*fortiios (com epêntese)

< PIt. *fort-ios; cf. lat. fortius 'mais forte' (Benediktsson 1960: 217);

- osc/pg. lúvkis (nom., sg. - Cp 36,7; Fr 6; nPg 7; Sa 24; Cm 2frag.; M 10frag.; Po 39frag.) 'Lúcio’ < PIt. *loukiiios (Meiser 1986: 60);

- osc. pústiris (nom./acs., sg. - Sa 4) 'posterior' < PIt. *posterios; cf. lat. posterius 'posterior' (Benediktsson 1960: 217);

- osc. salaus, $\sigma \alpha \lambda \alpha F_{\sigma}$ (nom., sg. - MV 7; MV 8; MV 8frag.) 'salvo' < PIt. *salauos (Benediktsson 1960: 216);

Quando a primeira consoante da sequência é um glide, $u$ ou $i$, não há assimilação entre as duas consoantes finais após a síncope, ou seja: *-I IVs\#>-I Is\#.

$$
\text { - *-KVs\# > -Ks\# }
$$

- umb. fratreks (nom., sg. - Va 23; Vb 1; VIIb 1) 'relativo a irmãos' < PIt. *frātrikos (Benediktsson 1960: 215; Meiser 1986: 59);

- osc. húrz (nom., sg. - Sa 1B23) 'bosque' < PIt. *xortos; cf. lat. hortus 'jardim' (Meiser 1986: 59);

- umb. mers, meřs (nom./acs., sg. - Ib 18; Ib 18; VIb 31; VIb 55; VIb 55) 'lei' < PIt. *medos (Benediktsson 1960: 217; Weiss 2010: 419);

- osc. puz (conj. - Cm 1A17; Po39) 'que'< PIt. *pu-tVs<PIE * $k^{u} u t i-s$; cf. lat. ut 'que' (Untermann 2000: 628);

- umb. taçez, tases, tasis (part. pass. - Ia 26; Ib 26; Ib 30; Ib; 32; Ib 44; IIa 39; IV 27; VIa 55; VIa 59; VIb 2; VIb 4; VIb 20; VIb 44; VIb 46; VIIa 7; VIIa 42; VIIa 54) 'tácito' < PIt. *taketos (Benediktsson 1960: 216);

- osc. túvtiks (nom., sg. - Cm 10; Sa 5frag.; Po 5; Po 6; Po 7; Sa 7; Sa 9; Sa 10; Sa 12; Sa 21; S 28) 'público’< PIt. *toutikos (Benediktsson 1960: 216);

- umb. uas (nom./acs., sg. - VIa 28; VIa 38; VIa 48; VIb 30) 'vício' < PIt. *uakos (Benediktsson 1960: 217);

Quando a primeira consoante da sequência é uma oclusiva, $t$ ou $k$ ou $d$, não há assimilação entre as duas consoantes finais após a síncope, ou seja: *-KVs\# > -Ks\#. A 
grafia da palavra pode variar dependendo do alfabeto utilizado, mas isso não significa que a fonologia também varie.

O umb. taçez, tases, tasis é um bom caso para exemplicar a questão da grafia, provavelmente trata-se da mesma palavra /tasets/ escrita de formas diferentes. A primeira forma está grafada em alfabeto epicórico úmbrio, no qual sequências de dupla consoantes são normalmente grafadas e a letra $<$ ç $>$ funciona como símbolo para $/ *_{s} /$. As duas últimas formas estão grafadas em alfabeto latino, no qual duplas consoantes não são sempre marcadas.

O caso do umb. uas é semelhante ao de taçez, tases, tasis; é provável que o $k$ existisse fonologicamente, mas que não foi marcado na escrita. É uma hipótese plausível pensar que o $k$ simplesmente não foi grafado e que a palavra segue o padrão dos demais casos $\left(*_{-} K V s \#>-K s \#\right)$. No entanto, como não há outras formas da palavra nem outros cognatos, não se pode ter certeza se houve ou não assimilação nas consoantes finais.

Benediktsson (1960: 219-222) leva em consideração a classe morfológica desses exemplos de síncope: nominativo plural masculino e feminino de temas terminados em consoantes: $*_{-} e s>-s$; dativo / ablativo plural de temas em $-i,-u$, - $e$ e em consoante: $*_{-} f o s>*_{-} f s>-s(s)$, entre outros.

$$
\text { - *-nVs\# > -ns\#: }
$$

- osc. aadirans (nom., sg. - Po 3) 'Adirano' (gentílico) < PIt. *-anos (Benediktsson 1960: 216);

- osc. bantins (nom., sg. - Lu 1,19) 'Bantino' (cidadão de Banto) < PIt. *bantīnos (Meiser 1986: 59);

- osc. humuns (nom., pl. - Cp 37,9) 'homens' < PIt. *homones (Benediktsson 1960: 219; Weiss 2009: 205, $468^{22}$ );

- umb. pelsans (gerundivo - IIa 43) 'a ser enterrado' < PIt. *pelsandos (Benediktsson 1960: 216; Weiss 2009: 443);

- osc. Perkens (nom., sg. - Cm 6) 'Perceno' (nome próprio) < PIt. *perkenos (Benediktsson 1960: 216);

${ }^{22}$ Segundo Weiss (em comunicação pessoal), a inscrição na qual se encontra a forma osc. humuns não apresenta letras modificadas, ou seja, não há distinção entre vogais longas e breves. O mais provável é que o $/ \% /$ medial seja uma vogal breve, assim como a forma dat./abl. pl. homonus. 
- osc. Púmpaiians (nom., sg. - Po 53frag.) 'Pompeiano' < PIt. *púmpaiianos (Benediktsson 1960: 216; apesar de a palavra estar fragmentada na inscrição, a terminação $-n s$ foi preservada e por isso o caso pode servir como exemplo).

Sempre que há -ns\# em sabélico, pode-se ter certeza de que houve uma síncope: -nVs\# > -ns\# (Buck 1904: 73); pois *-ns\# original > umb. $-f$, tal como umb. vitluf (acs., sg. - Ib 1; Ib 4) 'vitelo'<*-ns e umb. klavlaf (acs., pl. - IIa 33) 'estacas'<*-ns. O $n$ é a um dos poucos fonemas que antecede uma vogal sincopada em sílaba final que pode não sofrer assimiliação, ou seja, nunca se torna $s$. Como foi visto acima, além do $s$, as oclusivas tampouco sofrem assimilação (por exemplo, umb. fratreks e osc. húrz) e tampouco o $l$ no curioso caso do osc. úpfals.

- *-ros\# > -er\# (em dissílabo):

- umb. ager (nom., sg. - Um 10) 'campo'<*agers <*agrs < PIt. *agros, cf. PM akren ‘campo' (Benediktsson 1960: 216; Meiser 1986: 59; Untermann 2000: 77).

No caso do sabélico, há apenas uma forma que se encaixa claramente na cattegoria *-ros\# > -er\#. Optou-se por dar certa ênfase a esse caso porque é possível ver o mesmo desenvolvimento em latim, (ver o item 7. *-rVs\# > -er\# do Capítulo II: Síncope Vocálica em Latim).

Basicamente há duas reconstruções possíveis, uma com síncope e outra com metátese. No caso de ager, é provável que realmente se trate de uma síncope: *agros > agrs $>$ agers $>$ ager. Não pode ser uma metatése porque a vogal $o$ não se torna $e$ por desenvolvimento fonológico regular, e para que seja um nominativo singular, a vogal reconstruída precisa ser $*$.

Em termos de leis fonológicas, não há diferenças substanciais entre as três variantes desse tipo de síncope em sílabas finais: para que a síncope ocorra, basta que haja uma vogal breve seguida de /s/ na última sílaba. Os exemplos foram separados para que seja mais fácil visualizá-los e constatar que de fato não há diferença substancial entre eles. E a profusão de exemplos aponta para o fato de que esse tipo de síncope era produtivo.

\subsubsection{Casos Polêmicos}


Depois desses exemplos claros de síncope em sílabas finais, é necessário discutir alguns exemplos não tão claros. Trata-se de casos de etimologias incertas, de empréstimos, significado desconhecido, entre outros.

\subsubsection{Umb. Atiersir ${ }^{23}$ (Vb 8; Vb 14) 'Atierse' (gentílico ou nome de uma fraternidade)}

Benediktsson (1960: 216, 268) interpreta a forma umb. Atiersir como um nominativo singular e propõe a seguinte reconstrução: PIt. *atiiedios > Atiersir, com síncope.

É uma reconstrução atraente, porém Vetter (1953: 226-7) analisa os contextos nos quais a palavra aparece ( $\mathrm{Vb} 8 ; \mathrm{Vb} 14)$ e trata a palavra como um dativo plural. Os dois contextos são praticamente iguais:

Vb8: dirsa. herti.fratrus. atiersir. posti. acnu. farer.

Tradução de Vetter para o latim: dent oportet fratribus Atiediis quotannis farris.

Atiersir parece concordar com fratrus, não apenas pela proximidade sintática, mas também porque se trata de um gentílico ou epíteto, os quais não costumam aparecer sem um substantivo. Além disso, o verbo dirsa ( $3^{\mathrm{a}} \mathrm{sg}$., pres.) 'dar' costuma vir acompanhado de um dativo, dá-se algo a alguém; neste caso, dá-se acnu farer (acs., pl.) ‘cereais anuais' a fratrus (que somente pode ser um dativo plural) 'irmãos'.

Ou seja, é mais provável Atiersir seja um dativo plural e que não tenha havido síncope neste caso.

\subsubsection{Osc. ceus (nom., sg. - Lu 1, 19) 'cidadão'}

A palavra osc. ceus poderia ser um exemplode síncope, uma vez que apresentaria o desaparecimento da vogal /i/, conforme a proposta de reconstrução de Benediktsson (1960: 218). O autor propõe PIt. *keiuis > ceus, forma que seria cognata do lat. cìuis.

Porém, essa forma mais parece um empréstimo da palavra latina, pois no latim $* e i\rangle e\rangle \bar{l}$ e isso seria escrito no osco como $\langle e\rangle$. Se a forma tivesse realmente surgido de *keiuis, o resultado seria **ceius, já que o osco não monotonga ditongos.

\subsubsection{Umb. emps (part. pass. - Um 10) 'comprado'}

${ }^{23}$ Em úmbrio, d intervocálico aparece como $\langle r s>$ (alfabeto latino) ou $\langle\check{\mathbf{r}}>$ (alfabeto epicórico). Para mais sobre isso, ver Buck (1904: 82-3). 
Caso semelhante ao anterior acontece com umb. emps, para o qual a proposta de reconstrução de Benediktsson (1960: 216) é PIt. *emtos $>* e m t s>e m p s^{24}$.

É mais provável que se trate de um empréstimo do latim emptiō 'comprar'25. A síncope na forma osca demonstra uma tentativa aproximar o som da palavra à fonologia do osco, imitando um fenômeno que talvez já não estivesse mais em vigor na língua. Talvez o fenômeno não estivesse mais presente no osco porque a inscrição data de um período no qual a síncope não ocorria mais no úmbrio.

\subsubsection{Osc. ligis (dat./abl., pl. - Lu 1, 25) 'leis'}

O caso do osc. ligis é mais complicado que os anteriores, pois duas proposições parecem igualmente possíveis: 1) PIt. *legifos > com síncope ligis (Benediktsson 1960: 222), e 2) empréstimo do lat. legis (dat./abl., pl.) 'leis ${ }^{\text {,26 }}$. Não há evidências sificientes para que se possa escolher uma opção em detrimento da outra.

\subsubsection{Umb. ocar, ukar (nom., sg. - VIb 46) 'cidade'}

A palavra umb. ocar, ukar tem um histórico polêmico. Rix (2000:224-8) defende que a melhor tradução para o termo neste contexto é 'cidade', e desde então esse significado é aceito de forma praticamente unânime. A polêmica gira em torno da sua etimologia. Meiser (1986: 59) e de Vaan (2008: 424) defendem a etimologia tradicional de que umb. ocar possui a mesma raiz do lat. ocris 'montanha', ou seja, *okris > ocar. O significado 'cidade' teria se originado a partir do primeiro sentido: 'montanha' $\rightarrow$ 'cidade no topo da montanha' $\rightarrow$ 'cidade'.

Weiss (2012: 337-8), por outro lado, argumenta que a hipótese *okris > okrs > ocar não seria o desenvolvimento esperado, pois $*_{r}$ não se tornaria - ar em úmbrio, mas - er. Prova disso, seria o desenvolvimento *agros > ager e *-tro > ter. Visto que a etimologia tradicional não se sustenta, Weiss propõe outra explicação: o umb. ocar seria cognato do IrA. ochair 'fronteira', e o desenvolvimento em sabélico seria *okaris > ocar, ukar. Weiss (2012: 338) argumenta que o significado 'fronteira' do cognato do irlandês antigo é semanticamente mais próximo do sentido de 'cidade'.

Semanticamente as duas hipóteses são possíveis, pois no contexto (VIb 46) a melhor tradução para a palavra seria realmente 'cidade', conforme Rix (2000:224-8)

\footnotetext{
${ }^{24}$ Em ambientes com nasal seguida de $s$, há epêntese do $p$ entre as duas consoantes.

${ }^{25}$ Sugestão de Weiss em comunicação pessoal.

${ }^{26}$ Possibilidade levantada por Weiss em comunicação pessoal.
} 
defende. A explicação fonológica realmente impossibilita a solução tradicional, pois não há exemplos em qualquer língua itálica de que $*_{0} r$ se torna -ar. Desse modo, a hipótese de umb. ocar como cognato de Ir.A. ochair se torna bem atraente.

\subsubsection{Umb. pacer (nom., sg. - VIa 23; VIa 30; VIa 33; VIa 40; VIa 42; VIa; VIa} 50; VIa 52; VIb 7; VIb 11; VIb 13; VIb 26; VIb 32; VIb 34; VIIa 14; VIIa 17; VIIa

\section{1; VIIa 50) 'propício'}

É frequente a ocorrência de $*_{-} V s \#>$-er\# em sabélico (e também em latim); o ideal seria que fosse possível explicar todos os casos por uma mesma regra, porém é inevitável observar que nem todos os casos funcionam da mesma maneira. Há dois principais desenvolvimentos possíveis para essa situação, um com síncope: *pakris > *pakrs > *pakr > pacer, e outro com metátese: *pakris > pakirs > pakers > pacer. A visão tradicional, como a de Benediktsson (1960: 218) e Weiss (2010: 281), argumenta que se trata de uma síncope verdadeira, porém não é tão fácil descartar a possibilidade de uma metátese, pois fonologicamente é tão possível quanto uma síncope.

Neste caso, é mais plausível supor que houve apenas uma metátese, pois na sequência -Cri- não é estranho que -i- > -e- $(*$ akris $>$ com metátese *akirs $>*$ akirs $>$ *akerr > lat. ācer 'afiado', *alakris > com metátese *alakirs > *alakers > *alakerr > lat. alacer 'ativo'). Para mais casos no latim, ver item 7. *-rVs\# > -er\# do Capítulo II: Síncope Vocálica em Latim.

\section{2. $\quad \boldsymbol{o}>\emptyset /$ ii $m \#^{27}$}

- umb. ařkani (nom./acs., sg. - IV 28) 'canto ritual' <*-kaniiom (Meiser 1986: 60);

- umb. duti (nom./acs., sg., n. - VIb 63) 'segunda vez' < *dutiiom (Meiser 1986: 60; Untermann 2000: 193);

- umb. kazi 'nó cego' (acs., sg. - III 16; III 18) <*kates-iiom (Meiser 1986: 60; Weiss 2012: 127);

- osc. medicim (nom./acs., sg., n. - Lu 1, 30; Lu 1, 31 frag.; Lu 1, 33) 'aquele que trabalha como medix', 'praetor' < *medodik-iiiom (Meiser 1986: 60; Weiss 2009: 238);

27 Algumas palavras desta subseção apresentam duas síncopes, uma síncope em sílaba medial e outra em sílaba final, e serão analisadas como dupla síncope no item 4. Síncope em Sílabas Mediais e Finais na Mesma Palavra neste mesmo capítulo. Por enquanto, as palavras umb. kazi, osc. medicim, osc. memnin, osc. $\pi \alpha \mathbf{\alpha} \mathbf{F} \eta \mathbf{} \boldsymbol{\sigma}$, pakkuiis, pg. praicime serão analisadas apenas em relação a síncope em sílaba final. 
- osc. memnin (nom./acs., sg., n. - Cp 36) 'monumento' < *memen-iiiom (Buck 1904: 184; Meiser 1986: 60);

- osc. pakim (acs., sg. - Cp 37, 3; Cp 37, 10) 'Paco' <*pākiilom (Meiser 1986: 59);

- osc. $\pi \alpha \kappa F \eta 1 \sigma$, pakkuiis (acs., sg. - Lu 40; Si 19) 'Paco' (gentílico) < *pākouniis < *pākouiiios; cf. lat. Pacuuius 'Paco' ( Meiser 1986: 60; Benediktsson 1960: 264);

- pg. praicime (acs., sg. + prep. en - Pg 9) 'reino' < *praidikim < *praidikiiom (Meiser 1986: 60);

- osc. safinim ${ }^{28}$ (nom./acs., sg., n. - nPg 2; Sa 4) 'Safino' < *safniiom (Meiser 1986: 60; Benediktsson 1960: 229);

- umb. tehteřim (nom./acs., sg., n. - IV 20) 'teto' < *tektel-iiiom (Weiss 2010: 124; Benediktsson 1960: 229);

- umb. terti (nom./acs., sg., n. - IIa 28) 'terceiro' *trit-iiiom (Meiser 1986: 60; Untermann 2000: 749).

Benediktsson (1960: 229) explica que a síncope também pode ocorrer em sabélico antes de outras consoantes além de $/ s /$, no entanto há apenas exemplos nos quais $o>\phi / i$ i_m\#. Benediktsson (1960: 229) cita exemplos do neutro nom./acs. sg. e do masculino acs. sg em temas em -io, mas esse tipo de síncope se encontra na categoria $V$ $>\phi / \_s \#$.

Além disso, o autor (1960: 229) defende que a síncope acontece no sufixo *-iom, o que parece estranho, uma vez que o sufixo *-ios em Proto-Indo-Europeu é raro em ambientes diferentes de *med ${ }^{h}$ ios > gr. $\mu \dot{\sigma} \sigma 0 \varsigma$ ‘meio'. Meiser (1986: 63) e Nishimura (2008: 182-3) argumentam ser mais provável que o sufixo seja *-iiom, um sufixo bem mais frequente.

\section{Síncope em Sílabas Mediais}

A síncope em sílabas mediais é mais complexa do que em sílabas finais, mas também é possível estabelecer algumas regras para a sua ocorrência. Se houver uma vogal breve em uma sílaba medial aberta, há uma grande chance de que a vogal desapareça, mas é necessário analisar os contextos para se chegar a uma conclusão mais específica.

\subsection{Síncope no Sufixo *-tero- > -tro-}

\footnotetext{
${ }^{28}$ Palavra com epêntese de /i/ após síncope.
} 
O sufixo constrativo *-tero- é produtivo em sabélico, por isso há vários exemplos de palavras com síncope nesse contexto:

- osc. alttrú (nCm 2a) 'outro' < *altero- < PIt. *alitēro-; cf. lat. alter 'outro' (Benediktsson 1960: 213; duas síncopes mediais);

- osc. contrud (abl., sg., m./n. - Lu 1, 11; Lu 1, 17; Lu 1, 25; Lu 1, 33frag.) 'contra' < *kom-tero-; cf. lat. contrā 'contra' (Untermann 2000: 417);

- osc./umb. destr- (VIb 24; VIb 38; Cp 8) 'direita' < *destero- < PIt. *deksi-tero-; cf. lat. dexter 'direita' (Benediktsson 1960: 213; Untermann 2000: 170);

- osc. entraí (dat., sg. - Sa 1A8; Sa B10) 'Entere' (nome próprio ou epíteto) - < PIt.

*enterāi-; cf. lat. interior 'interior', scr. ántara- 'interior' (Benediktsson 1960: 241);

- umb. etre (acs., sg. - IIb 2; IIb 3; IIb 3; IIb 4; IIb 4; IIb 5; IIb 6; IIb 6; IIb 14), etru (abl., sg. - VIa 35; VIa 38; VIa 43) 'outro' < PIt. *e-tero-; cf. lat. cētērus 'outro', av. atāra- 'este (entre dois)' (Untermann 2000: 242-3; De Vann 2008: 112);

- umb. hutra (nom./acs., pl. + prep. $a-\mathrm{Ib} 42$ ), umb. hondra (nom./acs., pl. + prep. $a-$ VIa 15; VIIa 52), osc. huntrus (nom./acs., pl. - Cp 37, 11; Cp 37, 11frag.) 'inferiores' < PIt. *hontero; cf. lat. humus 'terra' (Benediktsson 1960: 213; Untermann 2000: 331);

- umb. mestru (gen., sg., f. - Va 24; Va 27; Vb 4) 'maior' < PIt. *maisterā (Benediktsson 1960: 213);

- umb. nertru (abl., sg. - VIb 25), umb. nertruco, nertruku (abl., sg. - VIb 37; VIb 39; Ia 32), osc. nertrak (abl., sg. - Po 39; Po 39 frag.) 'esquerda' < PIt. *nertero-; cf. gr.

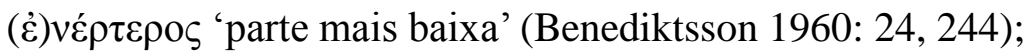

- umb. pretra (acs., pl., f. - Vb 12) 'primeiras' < PIt. *praitero- (Buck 1904: 184; Benediktsson 1960: 24, 241);

- pg. pritrome (acs., sg., n. + prep. en - Pg 9) 'anterior' < PIt. *pritero- (Benediktsson 1960: 241; Untermann 2000: 580);

- osc. pústreí, pustrei (loc., sg. - Cp 9; Cp 33; Cp 34frag.) 'posterior' < PIt. *posterei; cf. lat. posterus 'posterior' (Benediktsson 1960: 241);

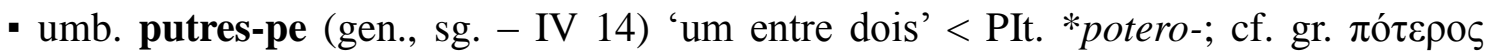
'qual? (entre dois)' (Untermann 2000: 625).

No latim, o sufixo *-tero também é produtivo, para mais sobre síncope no sufixo latino, ver Capítulo II: Síncope Vocálica em Latim, item 9. Síncope no Sufixo *-tero- > -tro-. 


\subsection{Síncope em Formas Tri- ou Quadrissilábicas com uma Vogal Longa na}

\section{Terceira Sílaba}

Bendiktsson (1960: 164-207) separa esses casos porque são produtivos.

- osc. actud (imp. - Lu 1, 15) 'age!' < PIt. *agetōd; cf. lat. agitō 'agir' (Meiser 1986: 130; Nishimura 2008: 1);

- osc. Aderl (nCm 2a) 'Adrola' (cidade osca na região da Campanha) < PIt. *adrolā (Meiser 1986: 132: $-C R V C$ - > $-C R C$ - > $-C e R C$ - e uma apócope do /a/ na forma final; Benediktsson 1960: 198);

- osc. akkatus (nom., pl. - Cm 14) 'invocado' < *adkāto- < *adokāto- < PIt. *aduokāto- (Benediktsson 1960: 189; Buck 1904: 58);

- osc. alttrú (nCm 2a) 'outro' < *altero- < PIt. *alitēro-; cf. lat. alter 'outro' (Benediktsson 1960: 213; duas síncopes mediais);

- osc. amfret ( $3^{\mathrm{a}}$ pl., pres., ind. - Cm 1B19/20) 'eles cercam' < PIt. *amferēnt; (proposta de reconstrução e tradução por Benediktsson 1960: 189);

- umb. ander-sistu (imp. com prep. ander - VIa 6) 'senta-te! (entre)'; cf. lat. sidō (<PIE *sed-) 'sentar' < PIt. *-sizdetōd; (Benediktsson 1960: 174; Buck 1904: 75);

- umb. a(n)-stintu (imp. - III 18; III 19; III 20) 'aproxima-te' < PIt. *-stingetōd ${ }^{29}$; cf. lat. īnstīgāre; PIE *steig- 'aproximar-se' (Benediktsson 1960: 178; Meiser 1986: 82);

- osc. dadid ( $3^{\mathrm{a}}$ pl., subj., perf. - Cp 37, 4) 'teria dado'< PIt. *dād-dētet (Benediktsson 1960: 189$)^{30}$;

- umb. esono (acs., sg./ nom., pl. - VIa 57; VIb 47), esunu (nom., sg., n. - Ib 8; Ib 9; Ib 38; IIa 2; IIa 2frag.; IIa 20; IIa 21; IIa 42; III 1; III 14; IV 30) 'divino' < *aizzono- < PIt. *ais-es-ōno- (Buck 1904: 74; Untermann 200: 238-40, PIt. *ais- 'Deus');

- umb. dirstu (3ª sg., imp. - VIb 17; VIb 38; VIb 38; VIb 39; VIIa 5), teřtu (3ª sg., imp. - IIa 40; IIa 40; IV 28) 'dê!'< diratod < PIt. *didatōd (Benediktsson 1960: 189).

É necessário ter em mente que em úmbrio, ${ }^{*} V d V>V r V$ (grafado como $<r s>\mathrm{em}$ alfabeto latino e $<\breve{\mathbf{r}}>$ em alfabeto epicórico). Esse exemplo prova que a mudança do /d/ intervocálico ocorreu antes da síncope em sílaba medial.

- osc. factud (imp. - Lu 1, 19) 'faze!' < PIt. *pakitōd; cf. lat. faciō 'fazer' (Benediktsson 1960: 178);

${ }^{29}$ No umb. a(n)-stintu, -ngt- é grafado como $\langle$ nt $>$, o $g$ é omitido na grafia.

${ }^{30}$ A reconstrução parece bem correta, mas é impossível saber se a forma seria /dadid/ ou /daddid/, pois essa inscrição em particular, na qual a palavra aparece, não explicita consoantes geminadas na escrita. 
- pg. fertlid (abl., sg. - Pg 9) 'fértil' < PIt. *fertelīd; cf. lat. fertilis 'fértil' (Benediktsson 1960: 1259);

- umb. fiktu /finktu/ (imp. - Ia 28) 'molda!' < PIt. *fingetōd; cf. lat. fingere 'moldar' (Benediktsson 1960: 182; Untermann 2000: 284);

- osc. fruktatiuf (nom., sg. - Cm 1A21) 'uso' < PIt. *fruge-tation (Benediktsson 1960: $185)$;

- umb. ha(h)tu (imp. - IIa 22; Ib 11) 'toma!' < PIt. *habitōd; (Meiser 1986: 126; Benediktsson 1960: 189);

- umb. kartu (3ªsg., imp. - IIa 23) 'distribui! (?)’ < *karVtōd (Benediktsson 1960: 164, mas a hipótese de tradução não é segura);

- osc. Kerrí (dat., sg. - Sa 1A3; Sa 1B7), Keri (dat., sg. - Cp 37 A1; Cp 37 A3; Cp 37

A12; Cp 37 B) 'Ceres' < PIt. *keresē; cf. lat. Ceres 'Ceres' (Benediktsson 1960: 166);

- umb. klavlaf (acs., pl. - IIa 33) 'estacas' < PIt. *klauelā-; cf. lat. clāua ' clava'; (Benediktsson 1960: 172; Buck 1904: 331);

- umb. ku-maltu (prep. kom + imp. - IIa 9/10; IIa 41; IV 28) 'tritura!' < PIt. *-maletōd; cf. lat. molō 'moer' (Benediktsson 1960: 171);

- osc. Niumsieís ${ }^{31}$ (gen., sg. - Cm 6; Cm 9frag.; Cp 21 frag.; Si 11frag.; Si 12 frag.), $v i v \mu \sigma \delta \imath \sigma^{32}$ (gen., sg. - Me 1; Me 2) 'Numério' (nome próprio ou epíteto) < *numsedieis < *PIt. *numasēdieis; cf. lat. Numerius 'Numério' (Benediktsson 1960: 215);

- osc. Núvlanam (acs., sg., f. - Cm 1B29) 'Nolano' (habitante de Nola) < PIt. *-nouelān- (Benediktsson 1960: 173);

- umb. perca(m) (acs., sg. - VIa 19; VIb 49; VIb 50; VIb 51; VIb 63; VIIa 46; VIIa 51; VIb 53), perkaf (acs., pl. - Ib 15) 'haste' < PIt. *pertikām (Benediktsson 1960: 175);

- umb. sestu (imp. - IIb 22; IIb 24) 'derruba!' < *sis-sth 2 -tōd (Benediktsson 1960: 173);

- osc. sverruneí (dat., sg. - Cm 1A2) 'pensamento’ < *PIt. *sueresōnei (Benediktsson 1960: 166; Buck 1904: 63);

- umb. teitu (imp. - IIa 26; IIb 7; IIb 25; III 9; III 25), deitu (imp. - VIb 56; VIb 63; VIb 64; VIb 65; VIIa 1; VIIa 20; VIIa 51) 'dize!' <*deittōd <*deiktōd < PIt. *deiketōd; cf. lat. dicō 'dizer' (Benediktsson 1960: 178);

${ }^{31}$ Palatalização na palavra osc. Niumsieís: /nu-/> /niu-/.

${ }^{32}$ Assimilação e simplificação da sequência $/ s d />*_{s s}>/ s /$ na palavra osc. Niumsieís, enquanto a forma osc. $v i v \mu \sigma \delta ı \eta \sigma$ mantém a sequência $/ s d /$. 
- umb. termnas (part. pass., nom., sg., m. - Um 10) 'delimitar' < *termnāa < PIt. *termenā- (Benediktsson 1960: 173);

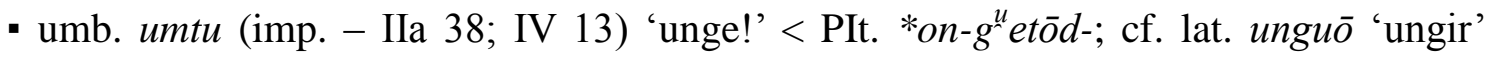
(Benediktsson 1960: 185);

- umb. veltu (imp. - IV 21) 'deseja!' < PIt. *ueletōd (Benediktsson 1960: 171);

- umb. vetu (imp. - Ib 29; Ib 37) 'divide! < *uēhtōd < *ueiftōd < *ueifetōd < PIt. *ueipetōd; cf. lat. dīuidō 'dividir', scr. vidhyati ‘dividir' (Benediktsson 1960: 176);

- umb. uernasier, uernasiaru (gen., pl., f. - III 3; Va 2; Va 15) (nome de um mês, embora seja difícil definir qual) < PIt. *ordenāsiais (Benediktsson 1960: 175; Weiss 2010: 58-9).

\subsection{Síncope em Formas Trissilábicas com uma Vogal Breve na Terceira Sílaba}

- umb. funtlere (abl., pl. - Ib 24), fondlire (abl., pl. - VIIa 3) 'Fontelo' (nome de um local) < PIt. *fontelo-; cf. lat. fōns 'fonte' (Untermann 2000: 301; Buck 1904: 184; Benediktsson 1960: 238);

- umb. menzne (abl., sg. - IIa 17) 'mês' < PIt. *mens-en-; cf. lat. mensum (gen., pl.) 'mês' (Weiss 2009: 314; Benediktsson 1960: 272);

- umb. mersto $^{33}$ (acs., sg., m. - VIa 3; VIa 4; VIa 4; VIa 16; VIa 18; VIa 18) ‘justo’ < PIt. *medes-to- (Benediktsson 1960: 59; Weiss 2010: 68);

- osc. numneís (gen., sg. - Sa 17) 'nome' < PIt. *nomen-eis; cf. lat. nōminis 'nome' (Benediktsson 1960: 272);

- umb. pelmner (gen., sg. - Vb 12; Vb 17) 'carne' < PIt. *pelpmen-eis; cf. lat. pulpa 'carne' (Benediktsson 1960: 272);

- umb. teřte ( $3^{\text {a }}$ sg., pres., pass. - IIa 40; IIa 40; IV 28frag.) 'é dado' < PIt. *didater (Benediktsson 1960: 237);

- umb. tiçlu (acs./abl., sg. - IIb 22; III 25; III 27) 'oferenda' < PIt. *dikelom (Benediktsson 1960: 238);

- osc. uincter ( $3^{\mathrm{a}}$ sg., pres., pass. - Lu 1, 21) 'ser convencido' < PIt. *uinketer (Benediktsson 1960: 237);

- umb. umne (abl., sg. - IIa 38) 'óleo para ungir < PIt. *ong ${ }^{u}$ eni (Benediktsson 1960: 272);

- osc. úpsed ( $3^{\mathrm{a}}$ sg., perf. - Cp 2) 'fez'< PIt. *opesed (Benediktsson 1960: 237);

\footnotetext{
${ }^{33} * V d V>V r V$ (grafado como $<r s>$ em alfabeto latino).
} 


\subsection{Síncope Regular em Casos Oblíquos}

Bendiktsson (1960: 256): Paradigmas nos quais ocorre síncope medial regular apenas nos casos oblíquos.

- umb. Serfer (gen., sg. - VIIa 3; VIb 57; VIb 58; VIIa 6; VIIa 9; VIIa 10; VIIa 11; VIIa 13; VIIa 15; VIIa 18; VIIa 19; VIIa 20; VIIa 21; VIIa 22; VIIa 24; VIIa 25; VIIa 27; VIIa 29; VIIa 29; VIIa 32; VIIa 33; VIIa 33; VIIa 34; VIIa 35; VIIa 36; VIIa 41) 'Ceres'

< PIt. *kereseis; cf. lat. Ceres 'Ceres' (Benediktsson 1960: 256);

- umb. termnome (dat./abl., pl. - VIIb 57; VIb 63; VIb 64) 'limites territoriais' < PIt. *termenom; cf. lat. terminus 'marco (de um limite teritorial)' (Benediktsson 1960: 256);

- umb. ufestne (dat./abl., pl. - IV 22) 'vasos' < PIt. *op-festVno- (Benediktsson 1960: 256; Buck 1904: 86);

- umb. uze (loc., sg. - IIb 27; IIb 28), onze (loc., sg. - VIb 50) 'ombro'< PIt. *omesei ; cf. lat. umerus (<*omeso-) 'ombro', véd. ámsa- 'ombro' (Benediktsson 1960: 256; Weiss 2009: 140).

\subsection{Síncope em uma Sequência de Duas Vogais Breves em Sílabas Mediais}

Bendiktsson (1960: 215): Síncope em formas quadrissilábicas com uma sequência de duas vogais breves nas sílabas mediais. As duas vogais podem sofrer síncope se forem abertas; no caso de ambas desaparecerem, é esperado que a vogal da segunda sílaba seja sincopada antes da vogal da terceira sílaba.

- osc. medíkeis (gen., sg. - Po 1) 'aquele que trabalha como medix', 'praetor' < PIt. *medo-diks (Buck 1904: 58, 135) ${ }^{34}$;

- osc. mi(n)streis (gen., sg. - Lu 1, 12; Lu 1, 18; Lu 1, 27; Lu 1, 35) 'menor' < *minstereis < PIt. *ministereis; cf. lat. minister (adv.) 'menor' (Buck 1904: 58, 135);

- umb. pupřçes (IV 26; IV 24; IV 4; III 27; III 35; IV 10frag.; IV 12; IV 11; IV 13) (epíteto) < pupřiç- < PIt. *popedik- (Benediktsson 1960: 211; Untermann 2000: 609$10)$;

- umb. stru(h)çla (acs., sg. - III 34; IIa 18; IIa 28; IV 4; IIa 41; IV 1) 'massa assada' < *strukelām < PIt. *struuekelā (Benediktsson 1960: 211);

- umb. sumtu (imp. - Ia 9; Ia 16) 'apreende! < *summetod < *submetōd < PIt. *supemetōd (ou *subemetōd) (Benediktsson 1960: 212; Untermann 2000: 220);

\footnotetext{
${ }^{34}$ Segundo Weiss (2009: 238), a formação de meddíks seria: *med- 'lei' + *dik- 'dizer'.
} 
- umb. tribřiçu, (nom., sg. - Va 9), tribrisine (abl. sg. - VIa 54) 'três em número' < PIt. *tri-pedikio (Benediktsson 1960: 213);

Apesar das pequenas diferenças na escrita das diversas formas de pupřçes, pode-se constatar que todas elas sofreram síncope: *popedik- > pupřk-, pupřç-; mesmo que haja uma forma com apenas uma síncope: *popedik- > puprrikes. A existência de ambas as formas pupřçes / pupřikes corroboram a cronologia proposta por Benediktsson (1960: 215), de que quando as duas vogais mediais desaparecem em palavras quadrissilábicas, a vogal da segunda sílaba é sincopada antes da vogal da terceira sílaba. A forma pupřikes sugere um período intermediário, no qual a segunda síncope ainda não acontece.

Meiser (1986: 130) sugere outra etimologia para o umb. tribřiçu: *tri-plek-kịiō $>$ *tri-plekio > tribřiçu. O problema dessa hipótese é que ela propõe o desaparecimento da vogal na terceira sílaba antes do desaparecimento da vogal na segunda sílaba, o que não costuma acontece em sabélico.

\subsection{Diminutivos}

No latim, o sufixo diminutivo PIt. *-elo- pode ser encontrado em diversas palavras, tais como cistella 'caixinha'< *kistele-lā- e tenellus 'macio' < *tenere-lā (ver item 13. Diminutivos no Capítulo III: Síncope Vocálica em Latim). No sabélico, esse sufixo não é tão produtivo quanto no latim, mas ainda assim existem casos de diminutivo com síncope vocálica.

- umb. katlu (acs., sg. - IIa 18; IIa 20; IIa 29) 'filhote de cachorro' < PIt. *katelo-; cf. lat. catellus 'filhote de cachorro' (Benediktsson 1960: 238);

- umb. stru(h)çla (acs., sg. - III 34; IIa 18; IIa 28; IV 4; IIa 41; IV 1) 'massa assada' < *strukelām < PIt. *struuekelā (Benediktsson 1960: 211);

- umb. veskla (acs., pl. - IIa) 'vasilhas' < PIt. *ueskelo-; cf. vol ${ }^{35}$. uesclis 'vasilhas' (Benediktsson 1960: 235; Buck 1904: 58);

- umb. vitlu, uitlu (acs., sg. - IIb 21; IIb 24; VIb 43; VIb 45, 16) 'vitelo' < PIt. *uitelo(Benediktsson 1960: 238; Buck 1904: 58; Meiser 1986: 130);

- osc. zicolom ${ }^{36}$ (acs., sg. - Lu 1, 14; Lu 1, 15frag.; Lu 1, 17), ziculud (abl., sg. - Lu 1, 16) 'dia' ${ }^{37}<*$ dieklom < PIt. *diekelo- (Benediktsson 1960: 239).

\footnotetext{
${ }^{35}$ A língua volsca é também uma língua sabélica , e possui muitas semelhanças linguísticas com o osco e o úmbrio; infelizmente há pouquíssimos vestígios dessa língua.

${ }^{36} \mathrm{Na}$ palavra osc. zicolom, ziculud, pode-se observar que houve uma epêntese após a síncope.
} 


\subsection{Casos nos quais a Vogal Sincopada é Incerta}

Em alguns casos, é possível atestar que houve uma síncope, mas não é possível identificar qual é a vogal:

- umb. fo(n)s (nom., sg. - VIa 42; VIa 50; VIa 52; VIb 7; VIb 11; VIb 13; VIb 26; VIb 32; VIb 34; VIIa 13; VIIa 17; VIIa 31; VIIa 49; VIa 23; VIa 30; VIa 33; VIa 40; VIb 26) 'gracioso' < PIt. *fauVno-; cf. lat. faueō 'ser favorável a' (De Vann 2008: 207);

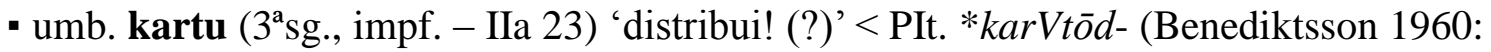
164, mas a hipótese de tradução não é segura);

- osc. maimas (gen., sg., f. - Lu 1, 3; Lu 1, 7) 'máximo'< PIt. *maisVmo- (Benediktsson 1960: 258);

- umb. parfam, parfa (acs., sg. - Ib 13; VIa 1; VIa 2; VIa 4; VIa 15; VIA 17; VIb 51) 'parra' (espécie de pássaro) < PIt. *parVsa-; cf. lat. parram 'parra' (Ernout-Meillet 1959: 485);

Buck (1904: 76) explica que, no úmbrio, *rs decorrente de síncope se torna $r f$; é o mesmo caso do umb. Cerfe, Serfe ( $<*$ keres- $\bar{e}-)$.

- osc. puz (conj. - Cm 1A17; Po 39) 'que'< PIt. *pu-tVs; cf. lat. ut 'que' (Untermann 2000: 184);

- osc. Vezkeí (dat., sg. - Sa 1A2; Sa B3) 'Vesco' (nome de um deus) < PIt. *uetVskei (1960: 272, a presença do -z- pressupõe que houve síncope);

- umb. vutu (imp. - IIa 39) 'lava!' < PIt. *louVtōd (Benediktsson 1960: 172);

$\mathrm{Na}$ maioria desses casos, não há sequer um vestígio que possa auxiliar na identificação da qualidade da vogal, o único da lista que foge dessa incerteza é osc. maimas. Buck (1904: 76) e Benediktsson (1960: 258) propõem a reconstrução PIt. *maisemo- para a palavra, na qual a vogal elidida seria um /el, porém não há vestígios suficientes para se fazer tal afirmação. Segundo Weiss (em comunicação pessoal), o

No acusativo, foi inserido um $o$ breve baseado na sílaba seguinte que possui um $o$ breve por natureza: zicolom. No ablativo, a vogal epentética é um $\bar{o}$ baseado na desinência de ablativo que possui um $\bar{o}$ por natureza: ziculud ( $\bar{o}$ grafado como $\langle u\rangle$ ).

${ }^{37}$ Osc. zicolom na Tábua Bantina 13-14 não significa apenas 'dia', mas 'o último dia possível para o pagamento'; 'data limite do pagamento'. A palavra latina dies possui a mesma característica de mudança semântica em certos contextos (Weiss: 2010: 48). Além disso, o sufixo diminutivo *-kelo- pode ser entendido em comparação à forma latina diēcula 'dia mais curto' (Untermann 2000: 868). 
único vestígio que poderia ser levado em conta é a forma pré-samnita Fo $\lambda \alpha \imath \sigma u \mu \circ \varsigma$ (significado desconhecido), a qual parece ser um superlativo tal como maimas; se isso for verdade, seria uma indicação de que a vogal sincopada na palavra osca é /u/.

O caso do umb. parfam também merece ser analisado. Benediktsson (1960: 166) e Stuart-Smith (2004: 114) propõem a reconstrução PIt. *paresām, com a vogal /e/ a ser sincopada, mas não explicam o porquê dessa escolha. Para melhor entender a situação, há alguns cognatos dessa palavra: Ernout-Meillet (1959: 484-5) relacionam a forma úmbria com gr. $\psi \alpha ́ \rho$ 'estorninho', gr. $\sigma \pi о \rho \gamma i ́ \lambda o \varsigma$ 'pardal', gót. sparwa 'pardal', e obviamente com lat. parra 'parra'. Nenhuma dessas formas responde qual seria a qualidade dessa vogal, mas como se pode observar encontros consonantais muito distintos entre os cognatos (-rf-, $-r r-,-r g-,-r w-)$, é seguro dizer que deveria existir uma vogal entre essas consoantes.

\subsection{Casos Polêmicos}

Depois desses exemplos mais claros de síncope em sílabas mediais, é preciso discutir alguns exemplos não tão claros. Esses casos tendem a ser mais difíceis que os em sílabas finais, por isso nem sempre será possível escolher uma hipótese em detrimento de outra.

\subsubsection{Umb. amboltu ( $3^{\mathrm{a}}$ sg., imp. - VIb 52) 'dá voltas ao redor de!'}

Em um artigo sobre a etimologia de amboltu, Kümmel (2012/2013) demonstra que seria mais plausível silabificar a palavra em /am.boltu/, em vez de /amb.oltu/ como os demais autores faziam usualmente. A silabificação tradicional, defendida por Benediktsson (1960: 171) e outros, afirma que a palavra seria cognata do lat. ambulāre e que teria se originado de $*_{-}$oletōd + prep. $a m b\left(<\right.$ PIE $\left.h_{2} m b^{h} i\right)$. Este seria o único exemplo do úmbrio no qual o prefixo seria marcado como amb, em vez de am (como em ampe(n)tu e amprehtu). A explicação de Kümmel retira a exceção, pois o sufixo funcionaria em amboltu da mesma forma que funciona em todas as palavras que possuem o mesmo sufixo.

O desenvolvimento proposto por Kümmel (2012/2013: 2-6) seria: *am-peltōd > *am-beltōd > *am-boltu, cujo cognato latino seria colere 'cultivar'.

\subsubsection{Umb. ampe(n)tu (imp. - IIa 20; III 23), apentu (imp. - III 27) 'aproxima-te!'}


Segundo Benediktsson (1960: 175), a etimologia dessa palavra seria *-pendetōd > ampe(n)tu, apentu, cujo cognato seria lat. pendō 'eu estou pendurado', mas essa solução já não é mais aceita pela maioria dos estudiosos.

Weiss (2010: 164) defende a ideia de que a palavra teria como origem a raiz PIE ${ }^{*}$ pelh $_{1^{-}}$'aproximar-se'. Nessa perspectiva, o desenvolvimento da raiz do verbo no presente seria *-peln(e)- > penn- e o $/ n /$ em ampentu seria apenas um infixo nasal de presente. Além disso, diferentemente da proposta de Benediktsson, na de Weiss não haveria síncope.

3.8.3. Umb. amprehtu ( $3^{\text {a }}$ sg., imp, - Ib 21), apretu ( $3^{\text {a }}$ sg., impf., - Ib 20) 'leva (os animais) para uma volta!'

Dentre as diversas etimologias propostas, algumas apresentam reconstruções com síncope e outras sem. No primeiro caso está Benediktsson (1960: 189), que defende a reconstrução PIt. *amfereitō $>$ amprehtu, e afirma que a palavra se encaixa na categoria de síncope em formas tri- ou quadrissilábicas com uma vogal longa na terceira sílaba. Junto a Benediktsson está Poultney (1959:143), o qual propõe a reconstrução PIt. *amber-ei-tōd.

Na contramão desses dois autores, há as reconstruções sem síncope. É o caso da explicação de Vetter (1953: 183), que sugere a etimologia *a(mbi)-pre-etu > apretu 'levar por ambos os lados'; e a explicação de Untermann (2000: 207-8), que seria *ampre-ei-tōd > amprehtu 'leva (os animais) para uma volta!'.

A melhor explicação sobre a composição de amprehtu, apretu é de Kümmel (2012/2013: 6): o verbo seria composto a partir da junção de duas preposições ( $a m+$ prai) mais o verbo ei 'ir'. Nessa perspectiva, as duas primeiras hipóteses se tornam improváveis, pois sequer propõem a presença da preposição prai. A etimologia proposta por Vetter (1953: 183) é a mesma de Kümmel, mas Vetter não explica todos os detalhes como Kümmel faz.

Visto que a explicação sobre a composição do verbo é bem satisfatória em Kümmel (2012/2013), obviamente sua sugestão de etimologia também se mostra satisfatória. Por isso, é mais pertinente apoiar a posição de que não há síncope na história dessa palavra. 
3.8.4. Umb. a(n)tentu, andendu ( $3^{\mathrm{a}}$ sg., imp. - IIa 20; III 15; III 16; III 17; III 17; III 22; IV 21; IV 27; IIb 28; VIIa 46) 'ergue até o topo!'; ententu, endendu (3a sg., imp. - VIb 40; VIb 40; VIb 49; Ib 12; III 15) 'insere!'

Benediktsson (1960: 175-6) propõe a reconstrução PIt. *-tendetōd > a(n)tentu, andendu (imp.) 'alonga!', cujo cognato seria lat. tendō 'alongar', e afirma que a palavra se encaixa na categoria de síncope em formas tri- ou quadrissilábicas com uma vogal longa na terceira sílaba.

Meiser (1986: 162-165) explica que, semanticamente, relacionar esse verbo ao lat. tollo 'erguer' faz mais sentido no contexto do que a hipótese tradicional (como a de Benediktsson). Desse modo, a reconstrução seria PIt. *-telnatōd > *en-tennatōd > endendu. Untermann (2000: 742) e Weiss (2010: 119n71) também apoiam a perspectiva de Meiser, de que a origem da raiz seria PIE *telh $2^{-}$'erguer'.

Ambas as etimologias, a que relaciona -tentu ao lat. tendō e a que relaciona ao lat. tollō, apresentam uma vogal sincopada. Apesar de as duas funcionarem bem fonologicamente, a segunda etimologia funciona melhor semanticamente e, por isso, a etimologia apresentada por Benediktsson já não é mais aceita pela maioria dos estudiosos.

\subsubsection{Pg. embratur (nom., sg. - nPg 6a; nPg 6b) 'imperador'}

Benediktsson (1960: 189) apresenta essa palavra como uma síncope verdadeira: *emparātōr > embratur. Untermann (2000: 222), por outro lado, afirma ser mais provável que a forma seja um empréstimo do latim (imperātor). O contexto no qual a palavra se encontra também argumenta a favor do empréstimo: ela foi gravada em uma moeda do séc. I a.C, época na qual a síncope vocálica já não estava mais em vigor na língua e a própria língua pelígia já estava em franco declínio. A síncope na forma pelígia parece uma tentativa de tornar a palavra mais palatável para os falantes, imitando um fenômeno que já não existia mais.

\subsubsection{Umb. felsva (Va 11) (significado desconhecido)}

A etimologia dessa palavra é incerta e diferentes hipóteses já foram levantadas na tentativa de resolver essa polêmica. Benediktsson (1960: 260) e Buck (1904: 94) defendem que se trata de um cognato do lat. holus 'vegetal' e que a reconstrução seria PIt. *xelesūa $>$ felsva 'vegetal'. Meiser (1988: 169) propõe a reconstrução PIE * $b^{h} e l \hat{g}^{h}$ -

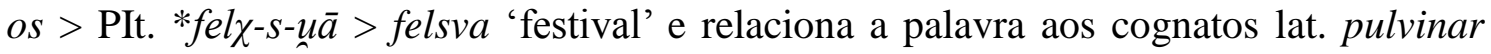


'assento com imagens de deuses' e scr. barhís 'relva sacrifical'. Vetter (1953: 223-4), por sua vez, relaciona felsva a lat. follis 'dinheiro' e propõe que sua origem seja *bhol$s i-$.

Do ponto de vista semântico, a hipótese de Meiser parece a mais plausível: alguém deve 'fornecer felsva' (ařfertur felsva), dentro do contexto religioso das Tábuas Iguvínias isso parece bem coerente.

Quanto à morfofonologia, é necessário analisar caso a caso:

*xelesūa : *x $<* g^{h}$, mas $*^{h}$ não resultaria em $f$, o que torna essa hipótese impossível.

*bhol-si-: para o latim, a morfologia funciona bem *bhol-si- > fol-si- > follis; mas nem tanto para o úmbrio, * $b h>f$, mas $o$ não se torna $e$ nessas condições, o que também torna essa hipótese impossível.

$* b^{h} e l \hat{g}^{h}-u o-$ : A forma úmbria não corresponde exatamente à forma sânscrita barhís, mas parece ser próxima o suficiente para que seja considerada um cognato ${ }^{38}$.

Portanto, a etimologia mais plausível é a apresentada por Meiser (1988: 169), que não apresenta empecilhos morfofonológicos e que funciona semanticamente. Nesse caso, não se pode falar de síncope, pois nessa solução não há vogal breve a ser sincopada.

\subsubsection{Umb. fertu (imp. - VIb 50; VIb 50) 'faz!' 39}

Benediktsson (1960: 165) classifica a palavra como sincopada e para a forma não-sincopada sugere *feretōd. Porém, é difícil estabelecer se houve síncope ou não, uma vez que não se sabe se o verbo era atemático em sabélico ou não. Como não há como sanar essa dúvida, há duas possibilidades de reconstrução: 1) *feretōd > fertu, com síncope; 2) *fertōd > fertu.

\subsubsection{Osc. herekleís (gen., sg. - Cm 1A11; Cm 1A24; Cm B4; Cm B6) 'Hércules'}

Muito provavelmente trata-se de um empréstimo, porém não se sabe se a palavra veio diretamente do grego ou por influência etrusca. Se for um empréstimo grego, então houve uma síncope: *herakleis > *herkleis > herekleís, com anaptixe. No entanto, se

\footnotetext{
${ }^{38}$ Curiosamente, a forma sânscrita bársvah 'gengiva' é um correspondente exato, mas como a relação semântica parece estranha e não há muita informação sobre essa palavra, é difícil fazer a comparação. A única informação que o dicionário Mayrhofer (1970) fornece sobre bársvah é que se trata de um empréstimo do iraniano.

${ }^{39}$ Ver comentário sobre o verbo ferō em latim no item 15.5. ferre, ferrem, fert, fers do verbo

ferō 'carregar' do Capítulo II: Síncope Vocálica em Latim.
} 
for um empréstimo etrusco, é provável que a síncope tenha ocorrido já no etrusco: hercle > herekleís, com anaptixe.

Ver a análise do cognato latino no item 16.7. Herclēs 'Hércules' do Capítulo II: Síncope Vocálica em Latim.

\subsubsection{Umb. herte(r) ( $3^{\text {a }}$ sg., pres., pass. - Va 6; Va 8; Va 10; IIa 40; III 1) 'foi necessário'}

Nussbaum (1976: 252-3) relaciona a forma umb. pisher (*pis herit) à forma herter e afirma que ambas possuem sentido médio-passivo ('ser necessário'). Outras formas construídas com -io-, como umb. heris, heriest não podem ser relacionadas às duas primeiras e possuem o sentido 'querer'. Portanto, etimologia da palavra seria: *xeriter $>$ herte(r).

\subsubsection{Umb. ninctu (imp. - VI b 60; VIIa 49) 'ataca!'}

O significado desta palavra ainda é polêmico: dentro do contexto, parece significar 'alguma coisa ruim que se faz ao inimigo', mas o significado desse verbo ainda permanece obscuro. Poultney (1959: 279) explica que o verbo está inserido em uma sequência de 10 verbos, organizados em 5 pares aliterados, os quais indicam as aflições que serão impostas aos inimigos da cidade; todos os verbos são imperativos do $2^{\circ}$ ou $3^{\circ}$ tipo:

tursitu. tremitu. hondu. holtu. ninctu. nepitu. sonitu. sauitu. preplotatu. preuilatu

A solução defendida pela maioria dos estudiosos relaciona ninctu a 'neve': para Buck (1904: 76, 95), o desenvolvimento mais provável é PIt. *ning ${ }^{u} e t o ̄ d, * n i n k^{u}$ etōd > ninctu 'neva!' e seus cognatos são ing. snow, lit. sniegas 'nevar'; para Poultney (1959: 278) e Devoto (1937: 284), ninctu significa 'neva!' e está relacionado ao lat. ninguit 'neva'. Essa solução não funciona por três motivos: 1) neste contexto, o verbo indica uma ação cometida contra os inimigos, e a noção de 'fazer nevar' como uma ameaça é mais esotérico do que o restante dos verbos (os quais indicam ataques físicos diretos); 2) o verbo deveria ser intransitivo, tal como o lat. ninguito 'nevar'; 3) Como Meiser demonstra (1986: 87), em úmbrio a sequência - $n g^{u}{ }^{u}>-m$ - (como em umtu 'unge!' imp.) e não $-n k-$.

Meiser (1986: 85-87) defende uma solução diferente: PIt. *ni-n-k-e-tōd > nénketōd > ninctu /nénktu/, cujos cognatos seriam lit. su-ninkù 'atacar alguém', gr. 
veĩkos 'disputa'. Essa etimologia é mais interessante porque funciona fonologica, sintática e semanticamente.

\subsubsection{Umb. oseto, osatu ( $3^{\text {a }}$ sg., ind., impf. - Um 7; VIb 24; VIb 37) 'construído'}

Esse verbo é atestado nas três principais línguas sabélicas, no osco, no úmbrio e no piceno meridional. Weiss (2010: 326) explica o verbo osatu (< PIt. *opesatōd) como uma forma denominal de um tema em $-s$, *opos 'trabalho', e cujo cognato seria lat. opus 'trabalho'. Meiser (1986: 130) cita a forma osca úpsannam (gerundivo - Ve 11) < *opesandam). Weiss (2010: 326) também sugere ser possível interpretar a palavra PM opesauom como uma forma não-sincopada da mesma raiz.

3.8.12. Osc. patensíns ( $3^{a}$ pl., subj., impf. - Cm 1B24; Cm 1B25) 'eles abririam', osc. patanai (dat., sg. - Sa 1A14; Sa 1B14) (significado desconhecido), umb. Padellar (gen., sg. - VIa 14) 'Padela' (nome de uma deusa)

Benediktsson (1960: 175, 208) observa síncope nas três formas. No caso do osc. patanai, o autor sugere que houve síncope seguida de epêntese e a classifica como síncope em formas tri- ou quadrissilábicas com uma vogal longa na terceira sílaba: PIt. *patenāi > *patnai > patanai . No caso do umb. Padellar, ele sugere que houve duas síncopes nas sílabas mediais e classifica a forma como síncope em formas quadrissilábicas com uma sequência de duas vogais breves nas sílabas mediais: PIt. *patenolās > *patnola- > *padla- > osc. Padella- (cg. lat. Patella). No caso do osc. patensíns, o autor sugere também que houve uma sequência de duas síncopes nas

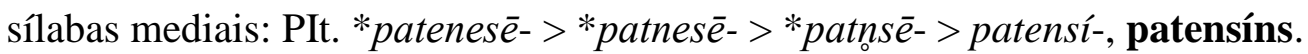

A reconstrução da primeira forma, patanai, não é confiável porque não existem exemplos nas línguas sabélicas de um $a$ epentético. A reconstrução da segunda forma, Padellar, tampouco é correta, pois o desenvolvimento *patnola- > *padla- parece impossível: normalmente $* t n>d n$ em sabélico.

A única reconstrução de Benediktsson fonologicamente possível é a de patensíns, para a qual Meiser apresenta um desenvolvimento semelhante. Para Meiser (1986: 133), PIt. *patanesēnt > * patnsēns > patensíns.

Outra possibilidade é analisar as três formas como relacionadas a uma mesma raiz: * peth $2^{-}$'abrir' ${ }^{40}$. Se esse for o caso, deve-se supor que se trata de uma antiga raiz,

\footnotetext{
${ }^{40}$ Possibilidade construída por mim com o auxílio do Prof. Weiss, apesar da grande ajuda, as
} 
na qual o grau zero pode ser silabificado como: ${ }^{*} p t . n h_{2^{-}}$. Desse modo, não haverá encontro consonantal entre *tn, o qual resulta em $d n$ em sabélico. (não há paralelos de que $* t n>* * t n)$

- patensíns (a partir de um grau zero): PIE *ptnh $h_{2}$ enti > com epêntese de um *əo entre

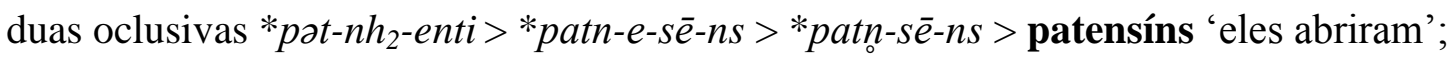

- patanai (a partir de um grau zero): PIE *pt-ne- $h_{2^{-}}>$com epêntese de um *ə entre duas oclusivas *pot-ne- $h_{2^{-}}>$patnă $>$com epêntese patanai (mesmo com essa etimologia, o significado ainda é incerto);

- Padella: PIE *ptneh $2_{2^{-}}>$com epêntese de um *o entre duas oclusivas *patneh $2^{-}$> *patnela > Padellā 'Padela' (nome de uma deusa)

Como cognato, seria possível relacionar a plavra lat. pandō 'estender'. Nessa perspectiva, não é possível ver síncope nas três formas, mas apenas em patensíns.

\subsubsection{Osc. pertumum (Lu 1, 7) (significado desconhecido)}

Neste contexto, é difícil decidir se houve um enfraquecimento ou síncope seguida de epêntese, pois o significado da palavra é desconhecido, e ainda por cima, há exemplo dos dois desenvolvimentos no mesmo ambiente fonológico. Pode-ser ver enfraquecimento no caso de pra-hubia (<* prae-habeo), no qual /a/ > /u/ antes de uma labial; pode-se ver síncope no caso de sumtu $(<*$ supemetod) e no caso de maimas $(<$ *maisemo-), no qual /e/ desaparece antes de uma labial.

Ainda que ambas as soluções sejam possíveis, parece mais plausível supor que se trata de uma síncope seguida de epêntese. Isso porque o ambiente fonológico é perfeito para sincope em sílaba medial: sílaba breve imediatamente pós-tônica entre uma oclusiva e uma labial (como em umb. sumtu 'apreender' (imp. - Ia 9; Ia 16) < *summetod $<*$ submetōd $<*$ supemetōd ou *subemetōd).

\subsubsection{Osc. prúftú ( $3^{\mathrm{a}}$ pl., perf., pass. - Cm 1A16) 'foram estabelecidos' ; prúffed ( $3^{\text {a }}$ sg., perf. - Cm 10; Sa 25) 'estabeleceu'}

Esse verbo possui atestações de diferentes formas, além de prúftú existem as formas osc. prúfat(t)ed, $\pi \rho \omega f \alpha \tau \varepsilon \delta$ ( $3^{\mathrm{a}} \mathrm{sg}$., perf.); prúfattens ( $3^{\mathrm{a}} \mathrm{pl}$., perf.) (de Vann 2008: 490). Em comparação a essas formas, as quais têm uma vogal na segunda sílaba, pode-se concluir que possivelmente houve síncope vocálica em prúftú e em prúffed. É

incongruências que existirem nessa hipótese com certeza pertencem a mim. 
exatamente isso que afirma Benediktsson (1960: 258): PIt. *propata > prúftú; PIt. *propeped > prúffed.

Apesar de as demais formas oscas apontarem para uma provável síncope, a questão da etimologia envolve mais dúvidas do que a questão da síncope. A etimologia mais aceita pela maioria dos estudiosos é a da raiz *pro- $b^{h} u-o-s$ (cf. lat. probus 'bom'), solução defendida por Meiser (1986: 185) e Buck (1904: 67). A presença do /f/ seria explicada a partir do desenvolvimento $* b^{h} u o->* b o>f o$.

Benediktsson (1960: 237) afirma que a transformação PIt. * $b\left(<\mathrm{PIE} * d^{h}\right)>f$ anteceu a ocorrência da síncope vocálica em sabélico. Portanto, a discussão sobre a etimologia anterior ao aparecimento do /f/ não acrescenta muito para o objetivo da pesquisa.

\section{Síncope em Sílabas Mediais e Finais na Mesma Palavra}

Há palavras que apresentam tanto síncope em sílaba medial quanto síncope em sílaba final. Segundo a cronologia estabelecida por Benediktsson (1960: 258) e seguida pela maioria dos estudiosos, a síncope em sílabas finais ocorreu antes que a síncope em sílabas mediais. Para mais sobre cronologia relativa, ver item seguinte deste mesmo capítulo 5. Hipóteses sobre a Síncope em Sabélico.

Os casos que contêm dois tipos de síncope são:

- osc. Fuvfdis (nom., sg. - Cm 14 C2) 'Fufídio' (gentílico) < *foufedis < *foufediios (Meiser 1986: 60; Benediktsson 1960: 264);

- osc. Kavkdis (nom., sg. - Cm 14) 'Caucideu' (gentílico) <*kaukedis <*kaukediios (Meiser 1986: 60; Benediktsson 1960: 264);

- umb. kazi (acs., sg. . - III 16; III 18) 'nó cego' < *katesim < *kates-iinom (Meiser 1986: 60; Weiss 2012: 127);

- osc. medicim (nom./acs., sg., n. - Lu 1, 30; Lu 1, 31 frag.; Lu 1, 33) 'aquele que trabalha como medix', 'praetor' < *medodikiim < *medodik-iiom; (Meiser 1986: 60; Weiss 2009: 238);

- osc. memnin (nom./acs., sg., n. - Cp 36) 'monumento' < memenim < *memen-iiom (Buck 1904: 184; Meiser 1986: 60);

- umb. mersus (dat./abl., pl. - III 6) 'justo’ < *medesus < *medesufos (Benediktsson 1960: 222$)^{41}$;

${ }^{41}$ Meiser (1986: 59, 175) propõe uma reconstrução diferente: *medesuos > mersus, 
- osc. Mitl (nom., sg. - Sa 32; tSa 21) 'Mitelo' (cognome) < *mitels < *mitelos (Benediktsson 1960: 217);

- pg. praicime (acs., sg. + prep. en - Pg 9) 'reino' < praidikim *praidik-iiom (Meiser 1986: 60; Untermann 2000: 569);

- osc. pupdiis (nom., sg. - Pg 1; Cm 34) 'Popedio' (gentílico) < *popediis < *poped(i)ios (Benediktsson 1960: 264);

- osc. teremníss (dat./abl., pl. - Cm 1A14) 'limites terrioriais'< termníss <*termen-i-fs $<*$ termen-i-fos (Benediktsson 1960: 223, 272).

Para mais sobre apenas síncope final nessas mesmas palavras, voltar no item 2.2. $\boldsymbol{o}>\boldsymbol{0} /$ ii $\boldsymbol{m} \#$ deste mesmo capítulo.

\section{Hipóteses sobre a Síncope em Sabélico}

A maioria dos estudiosos leva em consideração o acento tônico inicial quando analisam a síncope vocálica em sabélico. Benediktisson (1960) defende esse ponto de vista, especialmente em relação à síncope em sílabas mediais e imediatamente póstônicas. Para Nishimura (2008: 169), a síncope acontecer em outra sílaba que não a imediatamente pós-tônica não é um problema; é suficiente que a sílaba seja breve e átona. De fato, parece que o acento tônico inicial é uma das principais características que ocasionam a síncope, principalmente em sílabas mediais. $\mathrm{O}$ acento tônico inicial era provavelmente muito antigo, talvez até proto-itálico como Meiser (1986: 60) sugere.

Prodoscimi (1986) defende a hipótese de que houve dois períodos de acento tônico em sabélico: 1) acento antigo na penúltima sílaba da palavra, e síncope em sílabas finais seria uma consequência; 2) acento inicial, e síncope em sílabas mediais seria uma consequência. Essa é uma teria bem interessante, porém há dois problemas com ela. Primeiro, é uma explicação circular: a síncope em sílaba final é uma consequência de uma sílaba tônica porque a síncope em sílaba medial é uma consequência de uma sílaba tônica, e vice-versa. Segundo, as duas síncopes não compartilham das mesmas características, a síncope em sílaba medial ocorria em quase qualquer sílaba medial com uma vogal breve, enquanto as ocorrências da síncope em sílaba final eram bem mais restritas (não há síncope em uma sílaba final com $e$ breve, por exemplo). Ou seja, uma boa hipótese, mas que não se sustenta com os dados que temos.

relacionando a palavra úmbria *mersuuo- 'costumeiro'. 
A cronologia relativa estabelecida por Benediktsson (1960: 258) parece ser mais confiável. Segundo ele, a síncope em sílabas finais ocorreu em um período anterior ao da síncope em sílabas mediais, e ambas estavam relacionadas ao acento tônico inicial.

Nishimura (2008: 166-170), por sua vez, afirma que a síncope em sílabas mediais também datam de um período pré-histórico. Contudo, os exemplos que Nishimura fornece para corroborar sua hipótese são bem polêmicos; quase todos eles serão analisados abaixo:

- SP. aitúpas: um composto, que pode ser comparado com umb. eitipes 'eles declararam', no qual a primeira parte deve ser ai- $<* a g^{i}$ to- $<* a g^{i}$ eto- $<*$ ag-eto-

- SP. múfqlúm < *mone-stlom (cf. lat. mōnstrum) ${ }^{42}$

Buck mostra (1904: 73) que em sabélico *-ns- por síncope > -ns- e não se torna $-f$ - ; o autor apresenta apenas exemplos do osco e do úmbrio, mas não há nenhum exemplo em nenhuma língua sabélica de que $*$-ns- por síncope se tornaria $-f$-.

Como foi mencionado no item 8. Síncope em Sílabas Fechadas com Coda em -s do Capítulo II: Síncope Vocálica em Latim, uma reconstrução mais plausível é apresentada por Weiss (2010: 395n131): lat. mōnstrum < *mont-trom, da raíz *mont'mostrar'. A mesma solução funciona para SP. múfqlúm: *mont-tlom > *monstlo- > *mofqlo- > múfqlúm. Nessa perspectiva, *-ns- > -f- porque primeiro *-ttl- > -stl- e não há vogal a ser sincopada. Desse modo, não se pode tomar essa palavra como um exemplo antigo de síncope em sílaba medial.

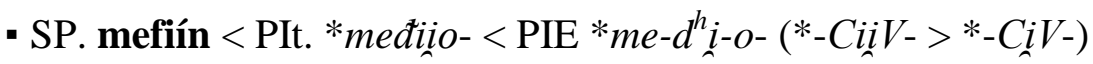

Esse não parece ser um caso de síncope, parece mais adequado afirmar que *-Cii $V$ - > *-Ci $V$ - é apenas uma redução. Ou seja, não se pode contar essa forma como um exemplo antigo de síncope em sílaba medial.

\section{- SP. uelaimes}

Essa forma é de fato um bom exemplo de síncope, mas a data da inscrição é alvo de muita polêmica, não há certeza de que se trata de um período tão antigo quanto Nishimura defende.

- Osc. núvellúm < *nounenlo- < *nounene-lo- (cf. lat. novellus 'novo') não é um bom exemplo porque se trata de um diminutivo, os quais tendem a se comportar de uma forma específica ou que são frutos de analogia. Também é comum ver esse tipo de

\footnotetext{
${ }^{42}$ Para uma reconstrução similar, ver também Marinetti (1985: 118).
} 
síncope no sufixo *-le/o em latim, como *asene-lo- > asellus 'burro' (ver item 13. Diminutivos do Capítulo II: Síncope Vocálica em Latim).

Uma vez que não há exemplos inegáveis de síncope em sílabas mediais em períodos mais antigos e há exemplos inegáveis de síncope em sílabas finais em períodos mais antigos, é razoável supor que a síncope em sílabas finais aconteceu antes que a síncope em sílabas mediais.

Além desses dois tipos de síncope, ainda existe mais um tipo de redução vocálica que é necessário discutir, é o caso de *-iioi-. Benediktsson (1960: 216, 268) explica umb. Atiersir 'Artierse' como síncope em sílaba final $(<*$ atiiedios $)$, e poderia ser um simples caso de $* \mathrm{CVs} \#>(\mathrm{C})$ s\#, mas como o le/ sobreviveu, isso sugere que a redução da sílaba final também ocorreu antes da síncope em sílaba medial. O erro de Benediktsson foi pensar que Atiersir era uma forma nominativa quando na verdade é um dativo, portanto, a melhor reconstrução seria *-iiois > Atiersir. É o mesmo caso do umb. krapuvi (dat., sg.) 'Grabóvio (epíteto de Júpiter e Marte)' < * grabouiioi, e ambos não podem ser considerados casos de síncope em sílaba final, mas sim exemplos de contração.

A partir dessas considerações, pode-se estabelecer uma cronologia relativa para o sabélico:

1) Síncope em sílaba final

2) Contração em sílaba final

3) Síncope em sílaba medial

\section{Conclusões Parciais}

É possível concluir que a síncope em sabélico funciona de forma sistemática, o que facilita a sua compreensão e análise. Um grande problema é a etimologia incerta de algumas palavras, especialmente de casos de hapax legomena. Esse capítulo foi amplamente baseado no artigo de Benediktsson (1960), um trabalho extremamente amplo e sistemático, mas se trata de um artigo antigo e algumas décadas de discussões ajudaram a entender melhor alguns casos de síncope e de suas etimologias.

Pode-se identificar dois tipos de síncope vocálica em sabélico: a síncope em sílabas finais e a síncope em sílabas mediais. A questão do acento tônico inicial parece ser importante para ambas as síncopes, embora seja mais evidente a influência do acento na síncope em sílabas mediais. Aparte do acento, os dois tipos de síncope funcionavam de modos diferentes e, por isso, é necessário analisá-los separadamente. 
A síncope em sílaba final ocorria em ambientes fonológicos mais restritos, somente no contexto $V>\phi /$ s\# e $o>\phi /$ ii_m\#. Tal síncope teria sido a primeira a ocorrer em sabélico, pois data de um período antigo; há exemplos claros em piceno meridional, como efidans (nom., sg. - AP 5) < PIt. *-nos 'Efidano' (cognome ou epíteto).

A síncope em sílaba medial ocorria em ambientes fonológicos mais diversos, quase toda sílaba átona com uma vogal não acentuada estava sujeita à síncope. As formas quadri- e trissilábicas são as que mais apresentam síncope, por vezes até perdiam duas sílabas breves mediais (como em umb. sumtu (imp. - Ia 9; Ia 16) 'apreende! < *summetod < *submetōd < PIt. *supemetōd ou *subemetōd). Como esse processo era recorrente, sequências consoantais estranhas surgiam após o desaparecimento de vogais mediais, para resolver esse problema, a epêntese também se tornou um processo fonológico recorrente.

Na próxima seção, Conclusões, os dados obtidos do latim e do sabélico serão comparados como um todo, não apenas como cognatos e em disscussões específicas como tem sido feito até agora. 


\section{CONCLUSÕES}

Depois de uma longa análise, pode-se observar que muitas dúvidas sobre a síncope vocálica nas línguas da Itália Antiga continuam sem respostas. Não é à toa que poucos autores analisaram a fundo esse processo fonológico, como Nishimura (2008) e Benediktsson (1960). No entanto, o objetivo da pesquisa não era estabelecer respostas irrevogáveis, mas apenas tentar compreender melhor a síncope, o que foi alcançado em certa medida.

Para compreender a matéria deste trabalho, fez-se uma breve explicação de quais são as línguas que foram analisadas e quais suas principais características. Após essa parte, a síncope vocálica foi analisada de forma individual em cada subgrupo linguístico do proto-itálico: primeiro no latim, e depois no sabélico.

No latim, a síncope acontece de maneira aparentemente caótica, existe síncope em todos os períodos históricos do latim, do latim antigo ao latim clássico, e até no latim vulgar (período não abarcado nesta pesquisa). Além disso, a síncope não ocorre de modo sistemático (há palavras com condições fonológicas ideiais que não apresentam síncope) e existem casos complicados de síncope em sílabas não imediatamente póstônicas.

No entanto, a questão do acento tônico e do esquema rítmico do latim contribuem para que se possa analisar esse panorama de modo mais concreto. $\mathrm{O}$ acento tônico inicial em palavras do LA e LPC parece ser fundamental para a ocorrência da síncope, basicamente se tem apenas casos de síncope em sílabas imediatamente póstônicas. Durante o LC, o acento passou a seguir a Lei da Penúltima e deixou de ser a principal característica facilitadora da síncope. Durante esse período, o esquema rítmico do latim se modificou, baseando-se em troqueus bimoraicos, e a síncope ocorria como ferramenta para se adequar o esquema rítmico.

Dessa forma, é possível estabelecer uma cronologia relativa para o fenômeno em latim: 1) durante o LA e o LPC, a síncope estava relacionada ao acento tônico inicial; 2) durante o LC, a síncope estava relacionada ao esquema rítmico de troqueus bimoraicos. Além disso, em ambas as épocas, a presença de soantes (principalmente antes da vogal) também auxiliava a engatilhar o processo. 
No sabélico, a situação é diferente, a síncope acontece de maneira sistemática: é possível estabelecer regras para a ocorrência da síncope; os casos complicados se restringem à falta de conhecimento da língua ou à ausência de etimologia plausível.

Nas línguas sabélicas, pode-se falar em dois tipos de síncope, síncope em sílabas finais e síncope em sílabas mediais. A síncope do primeiro tipo ocorria em ambiente restritos, antes de um-s\# e no sufixo ii_m\#, e o encontro consonantal resultante dessa síncope poderia ser simplificado ou não. Já a síncope em sílabas mediais ocorria de modo mais amplo, quase toda vogal breve medial era sincopada. Pode-se identificar alguns contextos fonológicos semelhantes ao latim, como síncope no sufixo *-tero- e no sufixo diminutivo *-elo-, mas em outros casos os ambientes fonológicos são bem diferentes. Ou seja, pode-se delinear a seguinte cronologia relativa: 1) síncope em sílabas finais; 2) síncope em sílabas mediais. A cronologia relativa que se pode estabelecer para o sabélico é muito diferente da do latim, outras questões são colocadas em evidência. No latim, não há diferença cronológica entre a síncope em sílaba final e em sílaba medial, e parece não ter ocorrido mudança das regras de acentuação no sabélico.

O fato de que a síncope se comportar de modo muito distinto em latim e em sabélico impede que a conclusão de que a síncope seja um fenômeno de área. Mesmo entre o osco e o úmbrio se pode observar algumas diferenças do processo fonológico. Ainda que a resposta encontrada não seja a esperada, as dúvidas levantadas no começo da pesquisa ainda podem ser respondidas. Apesar de a síncope existir em diferentes línguas da Itália Antiga, pode-se ver que elas não funcionam do mesmo modo.

$\mathrm{O}$ aspecto linguístico que parece funcionar da mesma forma nessas línguas é o acento tônico inicial, pois tanto o sabélico, o LA e o etrusco apresentam esse acento. É mais provável que o acento tônico inicial seja um fenômeno de área e que a síncope vocálica seja uma consequência desse acento inicial. Esse tipo de acento é considerado uma inovação dentro do PIE, o que corrobora a hipótese de ser algo típico da península itálica. No entanto, mesmo em relação ao acento tônico inicial, é difícil determinar com certeza se é um fenômeno de área ou não, questão que não pode ser detalhadamente explorada nesta pesquisa. 


\section{BIBLIOGRAFIA}

ADIEGO LAJARA, Ignacio J. (1999). "Sobre la correptio iambica del drama latino arcaico”. In: MORENO, J. L . \& DÍAZ, P. R. D. (Ed.). Estudios de Métrica Latina Vol. I, p. 55-67.

(1990). "Der Archaismus des Südpikenischen”. In: Historische Sprachforschung 103, p. 69-80.

BAKKUM, Gabriel C. L. M. (2009A). The Latin Dialect of the Ager Faliscus. Amsterdã: University of Amsterdam.

(2009B). The Latin Dialect of the Ager Faliscus - Vol. II. Amsterdam:

University of Amsterdam.

BALDI, Philip (2002). The Foundations of Latin. Berlim: Mouton De Gruyter.

BEEKES, Robert S. P. (2003) The Origin of the Etruscans. Amsterdã: Koninklijke Nederlandse Akademie van Wetenschappen. (1995). Comparative Indo-European Linguistics: an introduction. Trad. UvA Vertalers/Paul Gabriner. Amsterdã \& Philadélfia: John Benjamins Publishing Company. BEELER, Madison S. (1952). "The Relation of Latin and Osco-Umbrian". In: Linguistic Society of America 28, 4, pp.435-443.

BENEDIKTSSON, Hreinn (1960). "The Vowel Syncope in Oscan-Umbrian”. In: Norsk Ttidsskrift for Sprogvidenskap 19, 157-297.

BUCK, Carl D. (1962). Comparative Grammar of Greek and Latin. Chicago: The University of Chicago Press (1904). A Grammar of Oscan and Umbrian. Boston: The Athenaeum Press. (1892). Der Vocalismus der Oskischen Sprache. Leipzig: K. F. Koehler's Antiquarium.

BYNON, Theodora. (1993). Historical Linguistics. Cambridge: Cambridge University Press.

CLACKSON, James (2015). "Subgrouping in the Sabellian Branch of Indo-European". In: Transactions of the Philological Society 113, p. 4-37.

CRAWFORD, M. H. et al. (Ed.) (2011). Imagines Italicae: a Corpus of Italic Inscriptions - Vol. I. London: Institute of Classical Studies, University of London. (2011). Imagines Italicae: a Corpus of Italic Inscriptions - Vol. II. London: Institute of Classical Studies, University of London. 
(2011). Imagines Italicae: a Corpus of Italic Inscriptions - Vol. III.

London: Institute of Classical Studies, University of London.

CROOSWHITE, Katherine M. (2001). Vowel Reduction in Optimality Theory. Nova York \& Londres: Routledge.

(2000). “The Analysis of Extreme Vowel Reduction”. In: ALBRIGHT,

A. \& CHO, T. (Ed.). UCLA Working Papers in Linguistics, 4 - Papers in Phonology 4.

DEVOTO, Iacobo (1937). Tabulae Iguvinae. Roma: Typis Publicae Officinae Polygraphicae.

ERNOUT, Alfred \& MEILLET, Antoine (1959). Dictionnaire Étymologique de la Langue Latine. Paris: Klincksieck.

EXON, Charles (1907). "Medial Vowel-Syncope in Latin”. In: Hermathena 14, pp.117143.

FLEMMING, Edward (2005). “A Phonetically-Based Model of Phonological Vowel

Reduction”. Disponível em: http://web.mit.edu/flemming/www/paper/vowelred.pdf. Último acesso: 27/02/2016.

FORTSON IV, Benjamin J. (2010). Indo-European Language and Culture: an Itroduction. Oxford \& Carton: Blackwell.

GARNIER, Romain (2012). “Allomorphisme et Lois de Limitation Rythmique en Latin”. In: Bulletin de la Société de Linquistique de Paris 107, fasc 1, p. 235-259.

GIACOMELLI, Gabriella (1963). La Lingua Falisca. Firenze: Leo S. Olschki Editore. GÖTZE, Albrecht (1923). "Relative Chronologie von Lauterscheinungen im Italischen". In: Indogermanische Forschungen 41, p. 78-149.

GOUSKOVA, Maria (2003). Deriving Economy: Syncope in Optimality Theory. Tese (Doutorado). University of Massachusetts Amherst.

HAWKINS, Peter (1995). Introducing Phonology. Londres \& Nova York: Routledge.

KÜMMEL, Martin J. (2012/2013). "Etymologie und Phonologie: Umbrisch amboltu". In: Die Sprache 50, 1-2, p. 1-13.

KÜMMEL, Martin J. \& TICHY, Eva. Grundzüge der historischen lateinischen

Sprachwissenschaft. Disponível em: http://www.indogermanistik.uni-

freiburg.de/seminar/pers/kuemmel/studierende/lehre/latsprawi.pdf. Último acesso: 27/02/0216.

JONES, D. M. (1950). "The Relation of Latin to Osco-Umbrian”. In: Transactions of the Philological Society 49, 1, pp.60-87. 
JOSEPH, Brian \& WALLACE, Rex (1991). “Is Faliscan a local Latin Patois?”. In: Diachronica 8,2, pp. 159-186.

(1989). "Further Thoughts”. In: Classical Philology, 84, 4, pp. 319-321.

(1987). "Latin Sum/Oscan Sum, Sim, esum". In: American Journal of Philology, 108, 4, pp. 675-693.

LEHMANN, Winfred. P. (1996). Theoretical bases of Indo-European Linguistics. Londres \& Nova York: Routledge. (1992). Historical Linguistics. Londres \& Nova York: Routledge.

LEUMANN, Manu (1933) Lateinische Laut- und Formenlehre 1933. Munique: Beck. MALLORY, James P. \& ADAMS, Douglas Q. (2008). The Oxford Introduction to Proto-Indo-European and the Proto-Indo-European World. Oxford: Oxford University Press.

MARINETTI, Anna (1985). Le Iscrizioni Sudpicene: I Testi. Firenze: Leo S. Olschki Editore.

MEIER-BRÜGER, Michael (2003). Indo-European Linguistics. Berlim \& Nova York: Walter de Gruyter.

MEISER, Gehard (2003). Veni Vidi Vici: Die Vorgeschichte des lateinischen Perfektsystem. Munique: Verlag C. H. Beck.

(1998). Historische Laut- und Formenlehre der lateinischen Sprache. Darmstadt: Wissenverbindet. (1987). "Pälignisch, Latein und Südpikenisch“. In: Glotta 65, p. 104-127. (1986). Lautgeschichte der umbrischen Sprache. Innsbruck: Institut für Sprachwissenschaft der Universität Innsbruck.

MESTER, Armin (1994). “The Quantitative Trochee in Latin”. In: Natural Language and Linguistic Theory 12, p. 1-61.

NISHIMURA, Kanehiro (2012). "Vowel Redution and Deletion in Sabellic". In: WHITEHEAD, B. et al. (Ed.) The Sound of Indo-European: Phonetics, Phonemics and Morphophonemics. Copenhagen: Museum Tusculanum Press, p.381-398. (2008). Vowel Reduction and Deletion in Italic: Efects of Stress. PhD Dissertation: UCLA.

NISHIMURA, Kanehiro (2011). "Syncope in Latin: a historical restatement of its conditions". In: International Journal of Diachronic Linguistics and Linguistic Reconstruction 8, pp. 1-41. 
(2009). "Vowel Reduction and Deletion in Sabellic: a synchronic and diachronic interface”. In: WHITEHEAD, B. et al. (2009) The Sound of Indo-European Phonetics, Phonemics, and Morphophonemics. Copenhague: Museum Tusculanum Press, pp. 381-396.

(2008). Vowel Reduction and Deletion in Italic: Effects of Stress. Tese (Doutorado). University of California. Los Angeles.

NUSSBAUM, Alan (1997). "The 'Saussure Efect' in Latin and Italic". In: LUBOTSKY, A. (Ed.) Sound Law and Analogy: papers in honor of Robert S. P. Beekes on the occasion of his $60^{\text {th }}$ birthday. Amsterdã \& Atlanta: Rodopi, p. 181-203. (1976). "Umbrian pisher". In: Glotta 54, p. 241-263.

PALlOTTINO, Massimo (1975). The Etruscans. Trad. J. Cremona. Londres: Penguin Books.

von PLANTA, Robert (1897). Grammatik der Oskisch-Umbrischen Dialekte - Zweiter Band. Strassburg: Karl J. Trübner. (1892). Grammatik der Oskisch-Umbrischen Dialekte - Ersten Band.

Strassburg: Karl J. Trübner.

POULTNEY, James W. (1959). The Bronze Tables of Iguvium. Baltimore: American Philological Association.

PROSDOCIMI, Aldo (1984). Le Tavole Iguvine. Firenze: Olschki. (Org.) (1978). Popoli e Civiltà dell' Italia Antica, Vol. 6. Biblioteca di Storia Patria.

RAMÓN, José L. G. (2011). "Initial Stress and Syncope as Implicators of Secondary yod and Palatalization: Sabellic and Thessalian”. In: Alessandria - Rivista di glottologia 5, pp. 115-135.

RIX, Helmut (2004A). "Etruscan”. In: WOODARD, R (Ed.) The Ancient Languages of the World. Cambridge: Cambridge University Press, pp.141-164.

(2004B). "I Nomi delle Figure dei Miti Greci nelle Lingue dell' Italia Arcaica The First Traces of Achilles and Hercules in Latin". In: PENNEY, J. H. (Ed.). IndoEuropean Perspectives: Studies in Honour of Anna Morpurgo Davies. Oxford: Oxford University Press, p. 436-446.

(2002). Sabellische Texte: die Texte des Oskischen, Umbrischen und Südpikenischen. Heidelberg: Universitätsverlad C. Winter.

(2001A). Lexicon der Indogermanischen Verben. Wiesbaden: Dr. Ludwig Reichert Verlag. 
(2001B). Kleine Schriften. Bremen: Hempen Verlag.

Vamos pensar direito “

(2000). "Tribú, stato, città e insediamento nelle lingue italiche". In: Archivio glottologico italiano 85, pp. 196-231.

(1998). Rätisch und Etruskisch. Innsbruck: Institut für Sprachwissenschaft der Universität Innsbruck.

(1966). "Die lateinische Synkope als historisches und philologisches Problem". In:

Kratylos 11, pp 156-165.

SALMONS, Joe (1992). Accentual Change and Language Contact. Stanford: Stanford University Press.

SANDFELD, K. (1968). Linguistique Balkanique: problèmes et résultats. Paris: Klincksieck.

SCHIRMER, Brigitte (1998). Studien zum Wortschatz der Iguvinischen Tafeln: die Verben des Betens und Sprechens. Frankfurt: Peter Lang.

SCHRIJVER, Peter (1991). The Reflexes of the Proto-Indo-European Laryngeals in Latin. Amsterdam \& Atlanta: Rodopi B.V.

SCHUMACHER, Stefan (2004). Die Rätischen Inschriften. Innsbruck: Institut für Sprachwissenschaft der Universität Innsbruck.

SEN, Ranjan (2012A). "Exon's Law and the Latin syncopes“. In: PROBERT, P. \& WILLI, A. (Eds.). Laws and Rules in Indo-European. Oxford: Oxford University Press, cap. 13.

(2012B). "Reconstructing Phonological Change: duration and syllable structure in Latin vowel reduction". In: Phonology 29, 3, p. 465-504.

SIHLER, Andrew L. (2008). New Comparative Grammar of Greek and Latin. Oxford: Oxford University Press.

STUART-SMITH, Jane (2004). Sound Change in Italic. Oxford: Oxford University Press.

SOLMSEN Felix (1894). Studien zur lateinischen Lautgeschichte. Estrasburgo: Karl Trübner.

SOMMER, Ferdinand (1914). Handbuch der lateinische Laut- und Formenlehre. Heidelberg: Universitatsbuchhandlung.

SZEMERÉNYI, Oswald J. L. (1999). Introduction to Indo-European Linguistics. Oxford: Oxford University Press. 
UNTERMANN, Jürgen (2000). Wörterbuch des Oskisch-Umbrischen. Heidelberg: Universitätsverlad C. Winter.

de VAAN, Michiel (2008). Etymological Dictionary of Latin and the other Italic Languages. Leiden \& Boston: Brill (2007). "The etimology of Latim adūlāre". In: GEORGE, C. et. al. (Eds.) Greek and Latin from an Indo-European Perspective. Cambridge: Philological society, pp. 140-144.

VETTER, E. (1953). Handbuch des italischen Dialekte. Heidelberg; Carl Winter. VINE, Brent (2012). "PIE mobile accent in Italic: Futher evidence". In: WHITEHEAD, B. et al. (Ed.) The Sound of Indo-European: Phonetics, Phonemics and Morphophonemics. Copenhagen: Museum Tusculanum Press, p. 545-575.

(2006). "On 'Thurneysen-Havet's Law in Latin and Italic". In: Historische Sprachforschung 119, p. 211-249.

(1993). Studies in Archaic Latin Inscriptions. Innsbruck: Innsbrücker Beiträge zur Sprachwissenschaft.

WALDE, Alois \& HOFFMAN, J. B. (1954). Lateinisches etymologisches Wörterbuch. Heidelberg: Winter.

WALLACE, Rex E. (2008A). Zikh Rasna: a manual of the Etruscan language and inscriptions. Nova York: Beech Stave Press.

(2008B). "Sabellian languages". In: WOODARD, R (Ed.) The Ancient Languages of the World. Cambridge: Cambridge University Press, pp. 96-123. (2007). The Sabellic Languages of Ancient Italy. Munique: Lincom. WEISS, Michael (2012). “Interesting $i$-Stems in Irish”. In: Multi Nominis Grammaticus: Studies in Classical and Indo-European linguistics in honor of Alan Nussbaum on the occasion of his $65^{\text {th }}$ birthday. Ann Arbor \& New York: Beech Stave Press. (2010). Language and Ritual in Sabellic Italy. Leiden \& Boston: Brill. (2009). Outline of the Historical and Comparative Grammar of Latin. New York \& Ann Arbor: Beech Stave Press. 


\section{APÊNDICE: SÍNCOPE EM ETRUSCO}

\section{Ramo Tirsênico}

De acordo com Rix (1998), o etrusco não era uma língua isolada como muitos estudiosos defendem, na verdade, é possível identificar mais duas línguas semelhantes: o rético e o lêmnio. O autor conferiu o nome de ramo Tirsênico para esse ramo linguístico.

\section{Rético e Lêmnio}

Porque há poucas inscrições réticas e o conhecimento sobre elas é muito limitado, não é possível verificar se de fato ocorria síncope nessa língua, como no etrusco, ou não. Apesar disso, é possível supor ao menos que não se tratava de um fenômeno comum, pois existem muitas palavras com sílabas de estrutura $\mathrm{CV}$, tais como kuninasi (Schumacher: SZ-9) tinesuna (Schumacher: VR-1), lavisielavisealu (Schumacher: VN-1), laseke (Schumacher: RN-1), estruturas que certamente seriam sincopadas em etrusco.

Por outro lado, há alguns encontros consonantais que podem ser resultados de desaparecimento vocálico, como xixku (Schumacher: NO-3) and ackver (Schumacher: ST-8). Ainda que não haja como resolver essa questão, há poucos exemplos de encontros consonantais incomuns e, por isso, é plausível supor que a síncope vocálica não era um fenômeno comum em rético, ao menos não tão comum como em etrusco.

Quanto ao lêmnio, não há evidências suficientes para se afirmar qualquer coisa sobre o acento tônico nem sobre síncope.

\section{Etrusco}

Segundo Wallace (2008A:37), a síncope em etrusco ocorre principalmente em palavras trissílabicas, mas também acontece em palavras com quatro sílabas ou mais. Como resultado do desaparecimento de vogais mediais, surgiram encontros consonantais que antes não existiam na língua. Além disso, o autor (2008A:38) aponta o curioso caso da síncope de vogais em -ie- > -i. À primeira vista, pode-se pensar que se trata de um ditongo e que o resultado da síncope deveria ser a eliminação dos dois elementos, contudo não é o que acontece. De modo que há duas possíveis explicações 
para o fato: 1) -ie- = ie, apenas o -e- desapareceu e mais tarde i se vocalizou em -i-; 2) trata-se de duas vogais em um hiato e o -e- foi assimilado pelo -i-.

Exemplos de síncope em etrusco (Wallace 2008A:37-39): avile > avle, aule

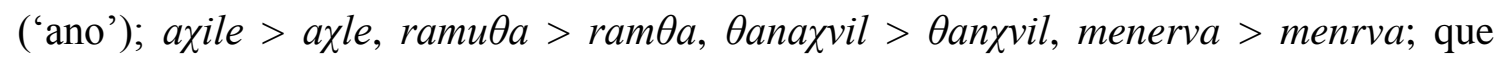
resultam em encontros consonantais incomuns: laricena > larcna, vestiricina > vestrcna, elacsantre > elcsntre; em sílabas -ie-: vipiienna > vipina, spuriena > spurina, aniena > anina; em final de sílaba: $\operatorname{aran} \theta>\operatorname{arn} \theta$; turans > turns; laruns > larns; selvansel > selvansl; ikan > ecn.

A questão do acento tônico em etrusco é delicada porque não se conhece totalmente a língua. Wallace (2008A: 39) comenta que possivelmente havia acento tônico em sílabas iniciais, enquanto Pallotino (1985: 213) afirma com mais segurança que havia acento tônico em sílabas iniciais e que a síncope de vogais átonas é uma consequência desse acento. 
ANEXOS

ANEXO I: CORPUS DE PALAVRAS LATINAS

- abdūcōo 'conduzir para longe’

Análise

*apo-doukō $>$ abdūcō

Leumann (1977: 96)

*apo-doukō > abdīcō

Ambiente Fonológico:

Consoantes adjacentes: p_d

Posição da síncope: Segunda Sílaba (SM)

Quantidade de Sílabas: 4

Sílaba Tônica: /a-/

- àcer 'afiado'

$\underline{\text { Análise }}$

PIt. *akris $>*$ akirs $>*$ akirs $>*$ akerr $>$ $\bar{a} c e r$

Não há síncope.

Nishimura (2008: 149, 151)

*akris $>$ *akrs > *akers > *akerr > $\bar{a} c e r$

*CrV->*C ${ }^{a} r V>* C \partial r^{V}>C e r$

Ambiente Fonológico:

Consoantes adjacentes: $r \_s \#$

Posição da síncope: Não há síncope $(\mathrm{N})$

Quantidade de Sílabas: 2

Sílaba Tônica: /a-/

- adūlor 'adular'

Análise

Incerto quanto à etimologia
Ernout \& Meillet (1959: 9-10)

Cognatos: scr. vālah, vārạ̣ 'pelo da cauda'

de Vaan (2007:25)

$\mathrm{O} / \bar{u} /$ longo de adūlāre não pode ser explicado por meio da raiz do PIE *uel, como afirmam Ernout \& Meillet e Walde \& Hoffmann. A melhor etimologia seria correlacionar adūlāre com auidus 'ávido': síncope *ad-auidos $>$ com síncope *ad-audos > adūdos > adūlos.

Ocorrências em Cássio Hemina, Lucrécio e Cícero.

Ambiente Fonológico:

Consoantes adjacentes: u﹎ d

Posição da síncope: Preposição +

Segunda Sílaba (SM / IN)

Quantidade de Sílabas: 3 + preposição

Sílaba Tônica: /a-/

- aetās 'idade'

Análise

*aeuitās $>$ aetās

Nishimura (2008: 119)

*aeuitās $>$ aetās

aeuiternus 'permanente' > com síncope aeternus 'eterno'

Data: Latim Clássico

de Vaan (2008:29) 
PIt. *aino- 'período', *aiuno-tāt 'idade'

Cognato itálico: osc. aítateís (gen., sg.)

'idade'

Duas etimologias possíveis: * ainotāt-s

$>$ *ainotas >com síncope aetās ou

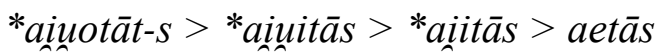

Ambiente Fonológico:

Consoantes adjacentes: $\underline{\sim}_{-} \mathrm{t}$

Posição da síncope: Segunda Sílaba

(SM)

Quantidade de Sílabas: 3

Sílaba Tônica: /ai-/

- agellus 'pequena porção de terra; campo'

Análise

*agr-elos $>$ *agrlos $>*$ agerlos $>$

agellus

Nishimura (2008: 147, 151)

*agre-lo- > *agrlo- > *agerlo- >

agellus

$* C r V->* C^{\partial} r V>* C \partial r^{V}>C e r$

Leumann (1977:97)

*agrelos $>$ *agrlos $>$ agellus

de Vaan (2008:29)

Etimologia de ager, -grī:

PIt. *agro- 'campo

Cognatos itálicos: umb. ager (nom., sg), agre (gen., sg), SP. akren 'pedaço de terra'

Weiss (2009: 123)

Ambiente de síncope $=$ vogais breves em sílabas abertas seguidas de $l, r$ ou $n$ : *agr-elos $>$ *agrlos $>*$ agerlos $>$

agellus

Ambiente Fonológico:

Consoantes adjacentes: $r \_1$

Posição da síncope: Segunda Sílaba

(SM)

Quantidade de Sílabas: 3

Sílaba Tônica: /a-/

- alacer 'ativo'

Análise

PIt. *alakris > *alakirs > *alakirs >

*alakerr > alacer

Não há síncope

Nishimura (2008: 149, 151)

*alacris > alacer

Ocorrência em Ênio.

Ambiente Fonológico:

Posição da síncope: Não há síncope $(\mathrm{N})$

Quantidade de Sílabas: 3

Sílaba Tônica: /a-/

- alter 'outro'

Análise

*ali-ter(os) > alter

Ernout \& Meillet (1959:22-23)

alter $=$ al- + sufixo de comparação $*_{-}$ tero-

É mais provável que alter tenha vindo de *al-tero-, e não de *ali-tero-, ou seja, não haveria síncope.

Leumann (1977:96)

*aliter(os) > aliter > alter

Cognato itálico: osc. alttram 
Weiss (2009: 285)

*ali-teros > alter

Ambiente Fonológico:

Consoantes adjacentes: $1 \_t$

Posição da síncope: Segunda Sílaba

(SM)

Quantidade de Sílabas: 4

Sílaba Tônica: /a-/

- ampulla 'garrafa'

Análise

Diminutivo

Nishimura (2008: 145)

*ampore-lā $>$ ampollā $>$ ampulla

Diminutivo de amphora 'ânfora'

Substantivo com o sufixo diminutivo $*_{-}$ le/o- próximo a soantes.

Data: Latim Pré-Clássico

Weiss (2009: 281, 481)

* amporela > com síncope ampulla (de amp(h)ora)

Cognato Itálico: SLo. ampuḍda

Ambiente Fonológico:

Consoantes adjacentes: r_l

Posição da síncope: Terceira Sílaba

(SM / SNPT)

Quantidade de Sílabas: 4

Sílaba Tônica: /am-/

- anceps 'que aponta para duas direções opostas'

Análise

ancipes > anceps

Leumann (1977: 96, 386)
PIt. *ambi-caputs >LA ancipes >

anceps

Ambiente Fonológico:

Consoantes adjacentes: $\mathrm{p} \_s$

Posição da síncope: Última Sílaba (SF)

Quantidade de Sílabas: 3

Sílaba Tônica: /an-/

- antae 'pilastras quadradas'

$\underline{\text { Análise }}$

*anatā- > antae

Leumann (1977: 97)

*anatā- > antae

de Vaan (2008: 44)

PIE $* h^{2} e n h_{x} t h^{2}-$ ou $* h^{2} n h_{x} t a h^{2}-$ (a primeira reconstrução parece mais plausível)

Weiss (1993:46)

*anatae > antae

PIE $* h^{2} e n h_{x} t a h^{2}-$ ou $* h^{2} n h_{x} t a h^{2}-$ (a segunda reconstrução parece mais plausível)

Ambiente Fonológico:

Consoantes adjacentes: $\mathrm{n} \_\mathrm{t}$

Posição da síncope: Segunda Sílaba (SM)

Quantidade de Sílabas: 3

Sílaba Tônica: /a-/

- aper 'javali'

Análise

*apro- > aper

Nishimura (2008: 150)

*apro- > aper 
Ambiente Fonológico:

Consoantes adjacentes: $\mathrm{r}_{-} \mathrm{C}$

Posição da síncope: Última Sílaba (SF)

Quantidade de Sílabas: 2

Sílaba Tônica: /a-/

- ārdus 'árido'

Análise

$\overline{a r i d u s}>\operatorname{ardus}$

Nishimura (2008: 199)

$\overline{a r i d u s}>\operatorname{ardus}$

Ocorrências em Plauto.

Data: Latim Clássico

de Vaan (2008:53)

PIt. * $\bar{a} s-\bar{e}-$ 'estar seco'

āridus x ardus (Ocorrência em Plauto)

Ambiente Fonológico:

Consoantes adjacentes: $r \_d$

Posição da síncope: Segunda Sílaba

(SM)

Quantidade de Sílabas: 3

Sílaba Tônica: /a-/

- ars 'habilidade'

$\underline{\text { Análise }}$

$*$ artis $>$ *arts $>$ ars

Leumann (1977: 96, 386)

$*$ artis $>*$ arts $>$ ars

Ambiente Fonológico:

Consoantes adjacentes: $t \_s$

Posição da síncope: Última Sílaba (SF)

Quantidade de Sílabas: 2

Sílaba Tônica: /ar-/
- asellus 'burro'

Análise

Diminutivo

Nishimura (2008: 145)

*asene-lo- > asellus

Diminutivo de asinus 'asno'

Substantivo com o sufixo diminutivo ${ }^{*}$ le/o- próximo a soantes.

Data: Latim Pré-Clássico

Ambiente Fonológico:

Consoantes adjacentes: $n \_1$

Posição da síncope: Terceira Sílaba

(SM / SNPT)

Quantidade de Sílabas: 4

Sílaba Tônica: /a-/

- auceps 'caçador de pássaros'

Análise

*aui-kap-s > auceps

Nishimura (2008: 19, 117)

*aui-cap-s > auceps

Weiss (2009: 261)

*aui-kap-s > auceps

Ambiente Fonológico:

Consoantes adjacentes: u c

Posição da síncope: Segunda Sílaba

(SM)

Quantidade de Sílabas: 3

Sílaba Tônica: /a-/

- audēre 'ousar'

Análise

*auid-ē- > audēre

Nishimura (2008:118) 
*auid-e-e (de auidus 'ganacioso') > audēre

Ambiente Fonológico:

Consoantes adjacentes: $u_{-} \mathrm{d}$

Posição da síncope: Segunda Sílaba (SM)

Quantidade de Sílabas: 4

Sílaba Tônica: /a-/

- auillus 'carneirinho'

Análise

Diminutivo

*ag ${ }^{u}$-nelo- > *ag ${ }^{u}$ nlo $>$ auillus

Ernout \& Meillet (1959:15)

Derivativos: agniculus, agnicellulus, agnicellus 'carnerinho'

de Vaan (2008:30)

PIE $* h_{2} e g^{u}$-no 'carneiro'

PIt. *ag ${ }^{u}$-no- 'carneiro'

$*^{*} g^{u}{ }^{u}$-nelo- $>*^{*} g^{u}{ }^{u}$ nlo $>$ auillus

Ambiente Fonológico:

Consoantes adjacentes: $\mathrm{n} \_1$

Posição da síncope: Terceira Sílaba

(SM / SNPT)

Quantidade de Sílabas: 3

Sílaba Tônica: /a-/

- balneum 'balneário'

Análise

balineum > balneum

Leumann (1977: 96)

balineum > balneum

Cognato: gr. $\beta \alpha \lambda \alpha v \varepsilon i ̃ o v ~ ' b a l n e a ́ r i o '$

Nishimura (2008:1, 118, 127, 134) *balaneom > balineum > balneum

Derivativo: balneātor 'trabalhador em casa de banho'

Cognato: gr. $\beta \alpha \lambda \alpha v \varepsilon i ̃ o v ~ ' b a l n e a ́ r i o '$

Data: Final do Latim Pré-Clássico

Ambiente Fonológico:

Consoantes adjacentes: $1 \_n$

Posição da síncope: Segunda Sílaba (SM)

Quantidade de Sílabas: 4

Sílaba Tônica: /ba-/

- bellus 'belo'

Análise

Analogia em diminutivo.

Nishimura (2008:146)

*duene-lo- > bellus

Diminutivo de *dueno > bonus 'bom'

Substantivo com o sufixo diminutivo $*_{-}$ le/o- próximo a soantes. Diminutivo trissilábico em analogia a diminutivos com sequência de sílabas breves.

Ambiente Fonológico:

Consoantes adjacentes: $\mathrm{n} \_1$

Posição da síncope: Segunda Sílaba

(SM / A)

Quantidade de Sílabas: 3

Sílaba Tônica: /due-/

- caldus 'quente'

Análise

calidus > caldus

Nishimura (2008:119)

calidus > caldus 
Síncope resulta em $-l d->-l l$ - como no caso de Lat. Pollūx

Ocorrência em Lucilío.

Ambiente Fonológico:

Consoantes adjacentes: 1_d

Posição da síncope: Segunda Sílaba (SM)

Quantidade de Sílabas: 3

Sílaba Tônica: /ka-/

- calficiō 'aquecer'

Análise

calē-faciō > com abreviamento jâmbico

calefaciō > calficiō

Leumann (1977: 97, 160)

calfacio, acs. calcem

Cognato: Gr. $\chi \alpha ́ \lambda \jmath \xi$ 'cal'

Nishimura (2008: 19, 119)

*kálēfakiō (ou *kalēfákiō) > cálefaciō

(ou calefáciō) > com síncope calficiō

Data: Latim Clássico

Weiss (2009: 124)

cale-faciō > com abreviamento jâmbico

calefaciō > calficiō

Ambiente Fonológico:

Consoantes adjacentes: $1 \_f$

Posição da síncope: Segunda Sílaba

(SM)

Quantidade de Sílabas: 4

Sílaba Tônica: /ka-/

- caper 'bode'

Análise

*kapros > caper
Nishimura (2008: 150)

*kapros > caper

Ocorrência em Catulo.

Ambiente Fonológico:

Consoantes adjacentes: r_s\#

Posição da síncope: Última Sílaba (SF)

Quantidade de Sílabas: 2

Sílaba Tônica: /ka-/

- catella 'corrente leve'

Análise

Diminutivo

Nishimura (2008: 145-146)

*katēne-lā- > catella

Diminutivo de catēna 'corrente'

Substantivo com o sufixo diminutivo $*_{-}$ le/o- próximo a soantes.

Data: Latim Pré-Clássico

Ambiente Fonológico:

Consoantes adjacentes: $n \_1$

Posição da síncope: Terceira Sílaba

(SM / SNPT)

Quantidade de Sílabas: 4

Sílaba Tônica: /ka-/

- catellus 'filhote de cachorro'

Análise

Diminutivo

Nishimura (2008: 145)

*katēle-lā- > catellus

Diminutivo de catulus 'jovem animal' Substantivo com o sufixo diminutivo ${ }^{*}$ le/o- próximo a soantes.

Data: Latim Pré-Clássico 
Ambiente Fonológico:

Consoantes adjacentes: 1_1

Posição da síncope: Terceira Sílaba

(SM / SNPT)

Quantidade de Sílabas: 4

Sílaba Tônica: /ka-/

- catīllus 'vasilha pequena'

Análise

Analogia em diminutivo.

Nishimura (2008: 146)

*katīne-lā- > catīllus

Diminutivo de catīnus 'vasilha grande'

Substantivo com o sufixo diminutivo *le/o- próximo a soantes. Analogia a diminutivos com sequência de sílabas breves.

Data: Latim Pré-Clássico

Ambiente Fonológico:

Consoantes adjacentes: $n \_1$

Posição da síncope: Terceira Sílaba

(SM / A)

Quantidade de Sílabas: 4

Sílaba Tônica: /ka-/

- cautum (sup. de caueō) 'tomar conta'

Análise

*caultum > cautum

Leumann (1977: 97)

*cauitum > cautum

Supino do verbo *koueō > caueō

Ambiente Fonológico:

Consoantes adjacentes: $\mathrm{u} \_\mathrm{t}$
Posição da síncope: Segunda Sílaba

(SM)

Quantidade de Sílabas: 3

Sílaba Tônica: /ka-/

- celeber 'ocupado'

$\underline{\text { Análise }}$

*kelebris > *kelebirs > *kelebers >

*keleberr > celeber

Não há síncope.

Leumann (1977: 98)

*celebris > *celebrs > *celebers >

*celeberr $>$ celeber

Ambiente Fonológico:

Posição da síncope: Não há síncope $(\mathrm{N})$

Quantidade de Sílabas: 3

Sílaba Tônica: /ce-/

- celer 'rápido'

Análise

*keleris > *keleirs > *kelers > *kelerr

$>$ celer

Não há síncope.

Ambiente Fonológico:

Posição da síncope: Não há síncope (N)

Quantidade de Sílabas: 2

Sílaba Tônica: /ce-/

- cernō 'peneirar; distinguir'

Análise

PIt. *krinō $>*$ kirno $>*$ kerno $>$ cernō

Não há síncope.

Nishimura (2008: 150)

*krinō > cernō 
$\mathrm{V}>0 / * C r V-$

Síncope na sílaba tônica.

Ambiente Fonológico:

Posição da síncope: Não há síncope (N)

Quantidade de Sílabas: 2

Sílaba Tônica: /kri-/

- certus 'certo'

Análise

PIt. *krito $>*$ kirto $>*$ kerto $>$ certus

Não há síncope.

Nishimura (2008: 150)

*krito- > certus

$\mathrm{V}>0 / * C r V$ -

Síncope na sílaba tônica.

Ambiente Fonológico:

Posição da síncope: Não há síncope (N)

Quantidade de Sílabas: 2

Sílaba Tônica: /kri-/

- cette (imp. de cēdō) 'retirar'

Análise

*kedate > cette

Mudança ocorrida na passagem do

Proto-Itálico > Latim Antigo

Nishimura (2008:118)

$\mathrm{PIE} * \hat{k} e-d h_{3}-t e$

PIt. *kedate

*kedate > com síncope cette

Ocorrências em Plínio e Ênio.

Data: Latim Pré- Clássico

Weiss (2009: 123)

*kedate > cette

Ambiente Fonológico:
Consoantes adjacentes: $d \_t$

Posição da síncope: Segunda Sílaba

(SM)

Quantidade de Sílabas: 3

Sílaba Tônica: /ke-/

- cistella 'caixinha'

$\underline{\text { Análise }}$

Diminutivo

Nishimura (2008: 145)

*kistele-lā- > cistella

Diminutivo de *kistelā- > cistula 'caixa'

Substantivo com o sufixo diminutivo *le/o- próximo a soantes.

Data: Latim Pré-Clássico

Ambiente Fonológico:

Consoantes adjacentes: 1_1

Posição da síncope: Terceira Sílaba

(SM / SNPT)

Quantidade de Sílabas: 4

Sílaba Tônica: /kis-/

- citrāa (adv./prep.) 'desse lado’

Adjetivos construídos com o sufixo

*-tero apresentam síncope vocálica.

Análise

citer- $>*$ citr- $>$ citrā

Leumann (1977: 97)

citer- $>*$ citr- > citrā

Cognato itálico: lat. citerior 'mais perto'

Ambiente Fonológico:

Consoantes adjacentes: $t \_r$ 
Posição da síncope: Segunda Sílaba (SM)

Quantidade de Sílabas: 3

Sílaba Tônica: /ki-/

- colmine 'pico'

Análise

Difícil de decidir se ocorreu síncope ou epêntese.

Nishimura (2008:129)

columine > colmine

Cognato: lat. columen 'pico'

Incerto

Ambiente Fonológico:

Consoantes adjacentes: $1 \_m$

Posição da síncope: Segunda Sílaba (SM / IN)

Quantidade de Sílabas: 4

Sílaba Tônica: /ko-/

- colurnus 'de avelã'

Análise

$*$ koselinos > *korelinos $>*$ korlinos $>$

*kolrinos $>$ *kolrunos $>$ colurnus

Não há síncope.

Nishimura (2008:143)

*koselinos > *korelinos > *korelnos >

*corulnus > colurnus

Cognato: lat. corilus 'aveleira'

Vogais não-acentuadas que não são imediatamente pós-tônicas também estão sujeitas a sofrer síncope, e a presença de aproximantes (ressonantes) parece auxiliar o processo.
Ambiente Fonológico:

Consoantes adjacentes: 1_n

Posição da síncope: Não há síncope (N)

Quantidade de Sílabas: 4

Sílaba Tônica: /ko-/

- concutiō 'agitar'

$\underline{\text { Análise }}$

*con-quatiō > com síncope concutiō

Leumann (1977: 97)

* con-quatiō > concutiō

Ambiente Fonológico:

Consoantes adjacentes: $\underline{u}_{-} \mathrm{t}$

Posição da síncope: Segunda Sílaba (SM)

Quantidade de Sílabas: 4

Sílaba Tônica: /kon-/

- contrā (adv./prep.) 'contra'

Análise

Adjetivos construídos com o sufixo *tero apresentam síncope vocálica.

conter- $>*$ contr- > contra $\bar{a}$

Leumann (1977: 97)

conter- $>*$ contr- > contra $\bar{a}$

Cognato itálico: osc. contrud 'contra'

Untermann (2000: 417)

Cognato itálico: osc. contrud (abl., sg., m./n.) $<* k o m$-tero-

Ambiente Fonológico:

Consoantes adjacentes: $t \_r$

Posição da síncope: Segunda Sílaba (SM)

Quantidade de Sílabas: 3 
Sílaba Tônica: /kon-/

- corōlla 'pequena coroa'

Análise

Analogia em diminutivo.

Nishimura (2008: 146)

*korōne-lā- > corōlla

Diminutivo de corōna 'coroa de flores ou de metais preciosos'

Substantivo com o sufixo diminutivo *le/o- próximo a soantes. Analogia a diminutivos com sequência de sílabas breves.

Data: Latim Pré-Clássico

Weiss (2009: 166)

*korōn-ela > corōlla (de corōna)

Exemplo de encontro consonantal no qual $*_{-} n l->-l l-$.

Ambiente Fonológico:

Consoantes adjacentes: $n \_1$

Posição da síncope: Terceira Sílaba

(SM / A)

Quantidade de Sílabas: 4

Sílaba Tônica: /ko-/

- culmus 'caule'

Análise

Incerto

Nussbaum (1997:196-197)

*kolamos > com síncope *kolmos > culmus

Obs: Talvez a laringal nunca tenha sido vocalizada, pois está entre soantes depois de um grau /o/. $\underline{\text { Schrijver (1991:327) }}$

É mais provável que a laringal nunca tenha sido vocalizada.

de Vaan (2008:150)

PIE *kolh ${ }_{2}-m o-$

PIt. *kol(a)mo-

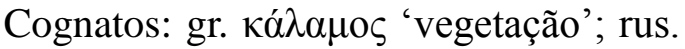

solóma 'caule'

Ambiente Fonológico:

Consoantes adjacentes: 1_m

Posição da síncope: Segunda Sílaba

(SM / IN)

Quantidade de Sílabas: 3

Sílaba Tônica: /ko-/

- cunctus 'todo; inteiro'

$\underline{\text { Análise }}$

con-citus (de con-cieo) $>$ cūnctī, cūnctārī

Talvez se trate de uma analogía.

Ernout \& Meillet (1959: 157)

Os latinos explicavam a etimologia de cunctī (pl. de cunctus) como proveniente de co-iunctī. Fonologicamente, essa etimologia não se sustenta. con-citos (de ciēo 'mover') parece mais coerente.

Data: Latim Antigo e Clássico

Leumann (1977: 217)

con-citus (de con-cieo) $>$ cūnctī, cūnctārī

Sihler (1995: 145)

Não possuía etimologia até a descoberta do Hit. pa-na-ku-uš 'todo, senado', de 
tema $\mathrm{r} / \mathrm{n}$; a partir dessa descoberta, reconstruiu-se a forma ${ }^{*} p o n k^{w} u$-. Nessa perspectiva, a palavra úmbria puntes pode ser reinterpretada como 'todos', em vez de 'grupos de cinco'.

de Vaan (2008:154)

PIE *ki-to- 'misturado'

PIt. *kom-kito- 'coletado

Obs: Como síncope não é comum em temas em -o-, parece ser uma analogia.

Ambiente Fonológico:

Consoantes adjacentes: $\mathrm{k} \_\mathrm{t}$

Posição da síncope: Segunda Sílaba (SM / IN)

Quantidade de Sílabas: 3

Sílaba Tônica: /kon-/

- dexter 'direita'

$\underline{\text { Análise }}$

Adjetivos construídos com o sufixo *tero apresentam síncope vocálica.

$*$ deksiteros $>*$ deksteros $>$ dexter

Duas síncopes, sendo que a primeira síncope deve ter sido a da segunda sílaba.

Nishimura (2008: 19, 116-117, 127, 134)

*déksiteros > dexter

Cognato: Gr. $\delta \varepsilon \xi ı \varepsilon \varepsilon \rho o ́ \varsigma$

Data: Latim Pré-Clássico

Sihler (1995: 68, 199, 239)

*deḱsiteros > dexter : A vogal sincopada se encontra na sílaba que deveria ter sido acentuada de acordo com o sistema histórico.

A síncope criou o encontro consonantal $-x t-$

de Vaan (2008: 168)

PIE *deḱs-tero-

PIt. *dekstero-; *dek(i)wo- 'direita; mão direita'

Cognatos Itálicos: Umb. destrame (acs., sg., f.), Umb. testru, testre, Osc. destrst (nom., sg. + íst), Umb. desua, dersua 'direita'

Cognatos: scr. dákșina- 'direita', gr.

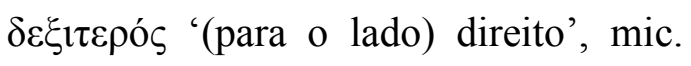
de-ki-si-wo /deksiwos/

Weiss (2009: 123)

*deksiteros $>$ dexter

Ambiente Fonológico:

Consoantes adjacentes: s_t, t_r

Posição da síncope: Segunda Sílaba

(SM), Terceira Sílaba (SM)

Quantidade de Sílabas: 4

Sílaba Tônica: /de-/

- disciplīna 'instrução'

Análise

discipulina $>$ disciplīna

Nishimura (2008: 119)

discipulīna $>$ disciplīna

Data: Latim Clássico

de Vaan (2008:172)

PIt. *kapelo- 'aquele que toma'

Derivativo: disciplinōsus 'bem treinado'

Ambiente Fonológico: 
Consoantes adjacentes: $\mathrm{p} \_1$

Posição da síncope: Terceira Sílaba

(SM / SNPT)

Quantidade de Sílabas: 5

Sílaba Tônica: /dis-/

- doctus (part. passado de docēo) 'informar'

Análise

$*$ dokitos $>$ doctus

Leumann (1977: 96)

$*$ dokitos $>$ doctus

Reconstrução baseada no paralelo com monitus (part. passado de moneō)

'aconselhar'

Ambiente Fonológico:

Consoantes adjacentes: $\mathrm{k} \_\mathrm{t}$

Posição da síncope: Segunda Sílaba (SM)

Quantidade de Sílabas: 3

Sílaba Tônica: /do-/

- expergīscor 'acordar'

Análise

*ex-pro-grīscor $>$ expergiscor

Leumann (1977: 97)

*ex-pro-grīscor > expergiscor

Cognato: av. fra-yrīsamnō 'desperto'

Ambiente Fonológico:

Consoantes adjacentes: $r \_g$

Posição da síncope: Segunda Sílaba (SM)

Quantidade de Sílabas: 4

Sílaba Tônica: /ex-/
- extrāa (adv./prep.) 'fora de’

Análise

Adjetivos construídos com o sufixo $*_{-}$ tero apresentam síncope vocálica.

extera $>$ extrā

Leumann (1977: 97)

extera $>$ extra $\bar{a}$

Ambiente Fonológico:

Consoantes adjacentes: $t \_r$

Posição da síncope: Segunda Sílaba

(SM)

Quantidade de Sílabas: 3

Sílaba Tônica: /ex-/

- faber 'artesão'

Análise

*fabros > faber

Nishimura (2008: 150)

*fabros > faber

Ambiente Fonológico:

Consoantes adjacentes: $\mathrm{r} \_\mathrm{s}$

Posição da síncope: Última Sílaba (SF)

Quantidade de Sílabas: 2

Sílaba Tônica: /fa-/

- facultās 'capacidade'

Análise

Leumann (1977: 97)

*facli-tās $>*$ faclotās $>$ facultās

Ambiente Fonológico:

Consoantes adjacentes: 1_t

Posição da síncope: Segunda Sílaba (SM) 
Quantidade de Sílabas: 3

Sílaba Tônica: /fa-/

- Falernus 'falêrnio'

Análise

Talvez não se trate de um caso de síncope em vogal não-imediatamente pós-tônica:

$*$ falisinos $>$ *falerinos $>>$ falrinos $>$ falirnos $>$ falernos $>$ Falernus

Nishimura (2008:143-144) *falisinos $>*$ falerinos $>$ Falernus

Cognato: lat. Faliscus 'um tipo de salsicha; de Falerii'

Vogais não-acentuadas que não são imediatamente pós-tônicas também estão sujeitas a sofrer síncope, e a presença de aproximantes (ressonantes) parece auxiliar o processo.

Ambiente Fonológico:

Posição da síncope: Não há síncope (N)

Quantidade de Sílabas: 4

Sílaba Tônica: /fa-/

- ferculus 'bandeja (para alimentos)'

Análise

*fericulus vs ferculum

Nishimura (2008:118-119)

praefericulus vs ferculum

Cognatos: gr. $\varphi \alpha \rho \varepsilon ́ \tau \rho \alpha$ 'aljava', scr.

bhari-/bhari- $\left(<* b^{h}\right.$ erH- $)$

Ambiente Fonológico:

Consoantes adjacentes: $\mathrm{r} \_\mathrm{k}$
Posição da síncope: Segunda Sílaba (SM)

Quantidade de Sílabas: 4

Sílaba Tônica: /fe-/

- ferre, ferrem, fert, fers do verbo ferō 'carregar'

Análise

*feres $>$ fers ( $2^{\mathrm{a}}$ sg., pres., ind.)

*feresi > ferre (inf.)

Possivelmente se trata de síncope regular do paradigma do verbo.

Meiser (1998: 224)

*ferete > ferte, *feresem > *fererem >

ferrem (subj., impf)

Cognato itálico: Sab. FERET

Sihler (1995: 68)

A síncope da sílaba final em *feres e *feret parece ser regular; e possivelmente é o único verbo da terceira conjugação cuja raiz termina em $-r$.

de Vaan (2008:213-4)

PIE $* b^{h}$ er-elo

PIt. *fere/o

Presente do Indicativo: *feres > fers, $*_{\text {feret }}>$ fert, *feretis > fertis

Infinitivo: *feresi > ferre

Ambiente Fonológico:

Consoantes adjacentes: $r \_s ; r \_t$

Posição da síncope: Segunda Sílaba

(SM), Última Sílaba (SF)

Quantidade de Sílabas: 2, 3

Sílaba Tônica: /fe-/ 
- fêstra- 'janela'

$\underline{\text { Análise }}$

fenestra $>$ fèstra-, fề(n)stra

Incerto

Meiser (2002: 66)

fenestram $>$ fēstram

Nishimura (2008: 137, 140)

fenestra $>$ fèstra-, fề(n)stra

Síncope em sílaba fechado com coda em /-s/. Silabificação -SC(R)-.

Ocorrência em Plauto.

Data: Latim Pré-Clássico

Oxford Dictionary (1968: 685)

festra (Ênio)

fenstra (Plauto)

Ambiente Fonológico:

Consoantes adjacentes: n_s

Posição da síncope: Segunda Sílaba

(SM / IN)

Quantidade de Sílabas: 3

Sílaba Tônica: /fe-/

- figlīna 'oficina de vasos de argila'

Análise

figulu- > figlina

Leumann (1977: 96)

figulus vs figlīna

Data: Latim Pré-Clássico

Oxford Dictionary (1968: 699)

figil- (Varrão)

figul- (Plínio)

Ambiente Fonológico:

Consoantes adjacentes: g_1
Posição da síncope: Segunda Sílaba

(SM)

Quantidade de Sílabas: 4

Sílaba Tônica: /fi-/

- fiscella 'cestinha'

$\underline{\text { Análise }}$

Diminutivo

Nishimura (2008: 145)

*fiscene-lā- > fiscella

Diminutivo de *fiscus > fiscina 'cesta'

(Ocorrência em Catão)

Substantivo com o sufixo diminutivo *le/o-próximo a soantes.

Data: Latim Pré-Clássico

Ambiente Fonológico:

Consoantes adjacentes: $n \_1$

Posição da síncope: Terceira Sílaba

(SM / SNPT)

Quantidade de Sílabas: 4

Sílaba Tônica: /fis-/

- flagellum 'chicote'

Análise

*flagrelo- > falgrlo- > flagellum

Nishimura (2008: 147)

*flagrelo- > flagellum

Diminutivo de flagrum 'chicote'

Ambiente Fonológico:

Consoantes adjacentes: $r \_1$

Posição da síncope: Segunda Sílaba (SM)

Quantidade de Sílabas: 3

Sílaba Tônica: /fla-/ 
- forceps 'pinça'

Análise

*formo-kap- > *formkap- > fórceps

Mudança ocorrida na passagem do

Proto-Itálico > Latim Antigo

Nishimura (2008:117)

*formo-kap- > *formkap- > forceps

Data: Latim Pré-Clássico

Ambiente Fonológico:

Consoantes adjacentes: $\mathrm{m} \_\mathrm{k}$

Posição da síncope: Segunda Sílaba (SM)

Quantidade de Sílabas: 3

Sílaba Tônica: /for-/

- frīgdārium 'despensa fria'

Análise

*frīgi- >com síncope frīgdārium

Nishimura (2008: 126)

*frīgi- >com síncope frīgdārium

Cognato: lat. frīgidārius

Data: Latim Literário

Ambiente Fonológico:

Consoantes adjacentes: g_d

Posição da síncope: Segunda Sílaba (SM)

Quantidade de Sílabas: 4

Sílaba Tônica: /fri-/

- gaudeō 'estar contente'

Análise

PIt. *gāuep-ē- > gaudeō

Leumann (1977: 97) gaudeō vs gāunisus

de Vaan (2008:255)

PIE *g'eh $h_{2} u-e d^{h}$ - 'regozijar'

PIt. *gāuipo- (adj.) ou *gāuep-e-e-(verbo)

Ambiente Fonológico:

Consoantes adjacentes: uي__p

Posição da síncope: Segunda Sílaba (SM)

Quantidade de Sílabas: 3

Sílaba Tônica: /ga-/

- hālō 'emitir fragrância'

$\underline{\text { Análise }}$

-Vnsl- > Vl: *an-an-slō 'eu estou

ofegante' > *an-enslō $>$ an(h)elō (de

(h) $\bar{a} l \bar{o})$

Mudança ocorrida na passagem do

Proto-Itálico > Latim Antigo

$\underline{\text { Schrijver (1991: 44) }}$

$* h_{2}$ enh $h_{1}-$ sl- $>*$ anaslā- > anslā

$* h_{2} n h_{1-s l-}>* n e \bar{s} l \bar{a}->$ aneslā (sob a influência de *anaslā-)

Dois desenvolvimentos diferentes a partir de uma mesma raiz, mas depois o segundo desenvolvimento é contaminado pelo primeiro. $\mathrm{O} h$ - parece ter sido inserido posteriormente, por pura caracterização ou por analogia a hiāre 'bocejar'.

de Vaan (2008:279)

PIE $* h_{2}$ enh $h_{1}$-slo- 'respiração'

PIt. *anaslo- 'respiração'

Weiss (2009: 177) 
-Vnsl- > Vl: *an-an-slō 'eu estou

ofegante' > *an-enslō $>$ an(h)elō (de

(h) $\bar{a} l \bar{o})$

Cognato: scr. ániti 'respirar'

Ambiente Fonológico:

Consoantes adjacentes: n_s

Posição da síncope: Segunda Sílaba (SM)

Quantidade de Sílabas: 3

Sílaba Tônica: /a-/

- Herclēs 'Hércules'

Análise

*Hēracles $>$ Herclēs

Leumann (1977: 96)

*Hēracles $>$ Herclēs

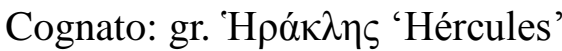

Oxford Dictionary (1968: 791)

hercle (ercle), hercule: interjeição em

forma de apelo a Hércules.

Herculēs (Plauto, Varrão, Cícero,

Catulo)

Ambiente Fonológico:

Consoantes adjacentes: $\mathbf{r} \_\mathrm{k}$

Posição da síncope: Segunda Sílaba (SM)

Quantidade de Sílabas: 3

Sílaba Tônica: /he-/

- hībernus 'relativo ao inverno'

Análise

$* \hat{g}^{h}$ eimr-ino- $>*$ *ībrinos $>*$ hìbirnos $>$ hībernus

Não há síncope.
Nishimura (2008: 147)

$* \hat{g}^{h}$ eimr-ino- $>$ *hībrinos $>$ com síncope hībernus

Ambiente Fonológico:

Consoantes adjacentes: $\mathrm{r} \_\mathrm{n}$

Posição da síncope: Não há síncope (N)

Quantidade de Sílabas: 3

Sílaba Tônica: /hī-/

- hortārī (part. passado de hortor) 'exortar'

Análise

horitā- > hortāri

Leumann (1977: 96)

horitātur, horitur vs hortārī

Ambiente Fonológico:

Consoantes adjacentes: $\mathrm{r} \_t$

Posição da síncope: Segunda Sílaba (SM)

Quantidade de Sílabas: 4

Sílaba Tônica: /ho-/

- hospes 'hóspede'

Análise

*hosti-pot-s > *hospus > hospes

Nishimura (2008:117)

*hosti-pot-s 'potencial

inimigo/hóspede' > *hospus > hospes

Data: Latim Pré-Clássico

Ambiente Fonológico:

Consoantes adjacentes: $t \_p$

Posição da síncope: Segunda Sílaba (SM)

Quantidade de Sílabas: 3 
Sílaba Tônica: /hos-/

- ïlignus 'feito de azinheira ou da sua madeira'

Análise

Talvez não se trate de um caso de síncope em vogal não-imediatamente pós-tônica:

*īlik-ino-s > *ïlkinos > *iliknos > ìlignus

de Vaan (2008:298)

Sem etimologia

*īlik-ino-s $>*$ illiknos $>$ ìlignus

Ambiente Fonológico:

Consoantes adjacentes: 1_k

Posição da síncope: Segunda Sílaba (SM)

Quantidade de Sílabas: 4

Sílaba Tônica: /̄̄/

- imber 'chuva

Análise

PIt. *mb $b^{h}$ ris > *embris > *embirs >

*embers $>$ *emberr $>$ imber

Não há síncope.

Nishimura (2008: 150)

$*_{m} b^{h}$ ris > *embris > imber

Cognato: véd. abhrá- 'tempo nublado'

Ambiente Fonológico:

Posição da síncope: Não há síncope (N)

Quantidade de Sílabas: 2

Sílaba Tônica: /em-/

- ìmus 'parte mais baixa'
Análise

inferus $>$ *inf-mo $>$ imus

Ernout \& Meillet (1959: 311)

Cognato itálico: osc. imad

Parece ter passado por um processo semelhante ao de summus (a partir de superus), imus teria vindo de inferus, ou seja: *inf-mo > imus. No entanto, o /i/ inicial não se explica na forma em osco, a menos que se entenda como um empréstimo do latim.

de Vaan (2008: 300)

WH e Meiser defendem que imms seria uma remodelagem de infimus em comparação a summus.

Untermann (2000: 341)

É discutível se a forma osca imad (abl. sg. f.) é cognata de ìmus, e se esses termos foram construídos do mesmo modo que summus (a partir de superus).

Ambiente Fonológico:

Consoantes adjacentes: f_m

Posição da síncope: Segunda Sílaba (SM)

Quantidade de Sílabas: 3

Sílaba Tônica: /in-/

- infrā (adv./prep.) 'abaixo'

Análise

infera $>$ infrā

Leumann (1977: 97)

infera $>$ infrā

Ambiente Fonológico:

Consoantes adjacentes: f_r 
Posição da síncope: Segunda Sílaba (SM)

Quantidade de Sílabas: 3

Sílaba Tônica: /in-/

- integer 'intocado'

Análise

*entagros > integer

Nishimura (2008: 150)

*entagros > integer

Ambiente Fonológico:

Consoantes adjacentes: $r \_s$

Posição da síncope: Última Sílaba (SF)

Quantidade de Sílabas: 3

Sílaba Tônica: /en-/

- ì̄grā (tipo de medida de terra, equivalente aproximadamente a dois terços de um acre)

Análise

inügera > iugrā

Leumann (1977: 97)

iūgera $>$ iugra

Ocorrência em Varrão

Ambiente Fonológico:

Consoantes adjacentes: g_r

Posição da síncope: Segunda Sílaba (SM)

Quantidade de Sílabas: 3

Sílaba Tônica: / $i \bar{u}-/$

- iuncus 'junco'

Análise

*ioiniko- > *ioinko- > *iūnko- > iuncus
Mudança ocorrida na passagem do Proto-Itálico > Latim Antigo

de Vaan (2008: 313)

PIt. *ioiniko-

Derivativo: iuniperus (estranhamente não apresenta síncope) 'junípero'

Walde \& Hoffmann (1954: 729-730)

*ioiniko- > *ioinko- > *iūnko- > iuncus

Ambiente Fonológico:

Consoantes adjacentes: $\mathrm{n} \_\mathrm{k}$

Posição da síncope: Terceira Sílaba (SM ( SNPT)

Quantidade de Sílabas: 4

Sílaba Tônica: /i-/

- iūs 'lei'

Análise

iouestod $>$ iūstus

Mudança ocorrida na passagem do Proto-Itálico > Latim Antigo

de Vaan (2008: 316- 317)

PIE $* h_{2} o i-u$

PIt. *iouos, * ioues 'juramento; lei', * iouesto- 'justo', * ioues-a-a-ie 'jurar', * iouesago- 'disputa', * ioue-dik- 'julgar'

*ieuos $>$ *iouos $>i \bar{u} s$

iouestod $>$ iūstus

Data: Latim Antigo

Ambiente Fonológico:

Consoantes adjacentes: u﹎s

Posição da síncope: Segunda Sílaba (SM)

Quantidade de Sílabas: 2

Sílaba Tônica: /i-/ 
- iuxtāa (adv./prep.) 'perto de'

Análise

*iūgVstād > iuxtā

Mudança ocorrida na passagem do

Proto-Itálico > Latim Antigo

de Vaan (2008: 318)

PIE *(H)ieug-s 'jungir'

PIt. *jougVsto-

A preservação do /-kst-/ aponta para síncope de *iūgVstād (abl., sg.)

Ambiente Fonológico:

Consoantes adjacentes: $g_{-} \mathrm{S}$

Posição da síncope: Segunda Sílaba (SM)

Quantidade de Sílabas: 4

Sílaba Tônica: /iu-/

- lārdī 'toucinho'

Análise

Possivelmente: $l \bar{a} r i d \bar{\imath}>l \bar{a} r d \bar{\imath}$

Nishimura (2008: 126)

lārid̄̄ $>$ lārdì

Oxford Dictionary (1968: 1003)

lāridum vs lārdum

Cognato: gr. $\lambda \alpha \rho i v o ́ \varsigma$ 'gordura'

de Vaan (2008:327-328)

Há várias etimologias sugeridas: 1)

laies-idos que resultaria normalmente em *laeridus (Meiser: 1998: 88); 2)

Empréstimo do grego $\lambda \bar{\alpha} \rho \bar{\imath} v o \varsigma$ 'gordura', o qual poderia ter sua origem em $\lambda \alpha \rho o ́ \varsigma$ ‘delicioso’.

Ambiente Fonológico:
Consoantes adjacentes: r_d

Posição da síncope: Segunda Sílaba (SM)

Quantidade de Sílabas: 3

Sílaba Tônica: /la-/

- lībella 'pequena moeda de prata'

$\underline{\text { Análise }}$

Diminutivo

Nishimura (2008: 147)

*lībrelā- > lībella

Diminutivo de lībra 'libra' (medida de peso)

Ambiente Fonológico:

Consoantes adjacentes: $r \_1$

Posição da síncope: Segunda Sílaba (SM)

Quantidade de Sílabas: 3

Sílaba Tônica: /lì-/

- libellus 'livreto'

Análise

Diminutivo

Nishimura (2008: 147)

*librelo- > libellus

Diminutivo de liber 'que tem o status de livre'

Ambiente Fonológico:

Consoantes adjacentes: r_l

Posição da síncope: Segunda Sílaba (SM)

Quantidade de Sílabas: 3

Sílaba Tônica: /li-/ 
- macellus 'chuva fina'

$\underline{\text { Análise }}$

Diminutivo

Nishimura (2008: 147)

*makrelo- > macellus

Diminutivo de macer 'magro'

Ambiente Fonológico:

Consoantes adjacentes: $\mathrm{r}_{-} 1$

Posição da síncope: Segunda Sílaba (SM)

Quantidade de Sílabas: 3

Sílaba Tônica: /ma-/

- malleus 'machado'

Análise

*molalo- > perda de arredondamento do

$*_{o}$ depois de $m$ - *malaleos- $>$ malleus

de Vaan (2008: 360)

PIE *molH-tlo- 'machado'

PIt. *molalo- 'machado'

*molalo- > *malaleos- > malleus

Ambiente Fonológico:

Consoantes adjacentes: 1_1

Posição da síncope: Segunda Sílaba (SM)

Quantidade de Sílabas: 4

Sílaba Tônica: /ma-/

- maxumus 'máximo'

Análise

*mag-ismmo- > *magisomo > maxumus

Bakkum (2009A: 102)
Cognato itálico: fal. maximo (MF89), maxom[o] (MF98) 'máximo' <

*magisomo

Nishimura (2008:117)

*mag-ismmo- > *magisomo > maxumus

Data: Latim Pré-Clássico

de Vaan (2008:73-74)

*magisomo > maxumus

Ambiente Fonológico:

Consoantes adjacentes: g_s

Posição da síncope: Segunda Sílaba (SM)

Quantidade de Sílabas: 4

Sílaba Tônica: /ma-/

- mēns 'mente'

$\underline{\text { Análise }}$

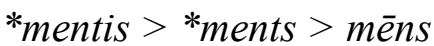

Leumann (1977: 98)

$\mathrm{PIE} *$ mntis $>*_{\text {mentis }}>*_{\text {ments }}>$ mēns

Ambiente Fonológico:

Consoantes adjacentes: $t \_s$

Posição da síncope: Última Sílaba (SF)

Quantidade de Sílabas: 2

Sílaba Tônica: /men-/

- mīscellus 'híbrido'

Análise

*minuscellus $>$ mīscellus

Nishimura (2008: 137, 139-140)

*minuscellus > mīscellus

Síncope em sílaba fechado com coda em /-s/. Silabificação -SC(R)- 
(*mi.nu.scel.lus). Data: Latim Pré-

Sílaba Tônica: /mi-/

Clássico

Ambiente Fonológico:

Consoantes adjacentes: $\mathrm{n} \_\mathrm{s}$

Posição da síncope: Segunda Sílaba (SM)

- misertus (part. passado de miseror) 'sentir compaixão'

Análise

miseritus > misertus

Quantidade de Sílabas: 4

Leumann (1977: 96)

Sílaba Tônica: /mi-/

miseritus vs misertus est

Ambiente Fonológico:

- misellus 'pobrezinho'

Consoantes adjacentes: t_s

Análise

Posição da síncope: Terceira Sílaba

Diminutivo

Nishimura (2008: 145)

*misere-lo/ā- > misellus

Diminutivo de miser 'pobre'

Substantivo com o sufixo diminutivo *le/o- próximo a soantes.

Data: Latim Pré-Clássico

Ambiente Fonológico:

Consoantes adjacentes: $r \_1$

Posição da síncope: Terceira Sílaba (SM ( SNPT)

Quantidade de Sílabas: 4

Sílaba Tônica: /mi-/

- miser 'pobre'

Análise

*miseros $>*$ misers $>$ miser

Leumann (1977: 98)

*míseros > miser

Ambiente Fonológico:

Consoantes adjacentes: $r \_s$

(SM / SNPT)

Quantidade de Sílabas: 4

Sílaba Tônica: /mi-/

- mōnstrum 'sinal sobrenatural'

Análise

Não há síncope

Nishimura (2008: 137, 140)

*monestrum > mōnstrum

Síncope em sílaba fechado com coda em /-s/. Silabificação -SC(R)-.

Data: Latim Pré-Clássico

Weiss (2010: 395n131)

lat. mōnstrum $<*$ mont-tlom,

raíz *mont- 'mostrar'

Cognato itálico: SP. múfqlúm

Não há síncope

Ambiente Fonológico:

Posição da síncope: Não há síncope (N)

Quantidade de Sílabas: 3

Sílaba Tônica: /mon-/

Posição da síncope: Última Sílaba (SF)

Quantidade de Sílabas: 3

- mors 'morte' 
Análise

$*_{\text {mortis }}>*_{\text {morts }}>$ mors

Leumann (1977: 98)

PIE *mrtis $>*^{*}$ mortis $>*_{\text {morts }}>$ mors

Ambiente Fonológico:

Consoantes adjacentes: $t \_s$

Posição da síncope: Última Sílaba (SF)

Quantidade de Sílabas: 2

Sílaba Tônica: /mor-/

- necdum 'ainda não'

Análise

neque-dum > necdum

Leumann (1977: 96)

neque-dum > necdum

Ambiente Fonológico:

Consoantes adjacentes: u_d

Posição da síncope: Segunda Sílaba

(SM)

Quantidade de Sílabas: 3

Sílaba Tônica: /ne-/

- niger 'preto'

Análise

*nigros > niger

Nishimura (2008: 150)

*nigros > niger

Ambiente Fonológico:

Consoantes adjacentes: $r \_s$

Posição da síncope: Última Sílaba (SF)

Quantidade de Sílabas: 2

Sílaba Tônica: /ni-/

- nōnus 'nono'
Análise

*nouenos $>$ nōnus

Leumann (1977: 97)

*nouenos $>$ nōnus

Ambiente Fonológico:

Consoantes adjacentes: $\underline{n}_{-} \mathrm{n}$

Posição da síncope: Segunda Sílaba (SM)

Quantidade de Sílabas: 3

Sílaba Tônica: /nō-/

- nostro- 'nosso'

Análise

Adjetivos construídos com o sufixo *tero apresentam síncope vocálica.

*nostero- > nostro-

Leumann (1977: 97)

nostro- vs gr. ๆ $\mu \varepsilon ́ \tau \varepsilon \rho o \varsigma$ 'nosso'

Ambiente Fonológico:

Consoantes adjacentes: $t \_r$

Posição da síncope: Segunda Sílaba (SM)

Quantidade de Sílabas: 3

Sílaba Tônica: /ne-/

- nouellus 'jovem'

Análise

Diminutivo

Nishimura (2008: 145)

*nouele-lo/ā- > nouellus

Diminutivo de nouns 'jovem'

Substantivo com o sufixo diminutivo $*_{-}$ le/o- próximo a soantes.

Data: Latim Pré-Clássico 
Ambiente Fonológico:

Consoantes adjacentes: 1_1

Posição da síncope: Segunda Sílaba (SM / SNPT)

Quantidade de Sílabas: 4

Sílaba Tônica: /no-/

- nuncupāre 'nomear'

Análise

*nōmicupāre > nuncupāre

Leumann (1977: 97)

*nōmicupāre > nuncupāre

Síncope nos moldes de agellus.

Ambiente Fonológico:

Consoantes adjacentes: $\mathrm{m} \_\mathrm{k}$

Posição da síncope: Segunda Sílaba (SM)

Quantidade de Sílabas: 5

Sílaba Tônica: /n̄̄-/

- nūper 'recentemente'

Análise

*nouo-paros > nüper

Mudança ocorrida na passagem do

Proto-Itálico > Latim Antigo

Nishimura (2008:116)

*nouno-paros > nüper

Data: Latim Pré-Clássico

Ambiente Fonológico:

Consoantes adjacentes: $\mathrm{u} \_\mathrm{p}$

Posição da síncope: Segunda Sílaba (SM)

Quantidade de Sílabas: 4

Sílaba Tônica: /no-/
- (ob)iūrgō 'censurar'

Análise

*ob-iūrigō > (ob)iūrgō

Nishimura $(2008: 119,124)$

*iouns-agōo $>*_{i \bar{u} r i g o \bar{o}}>i \bar{u} r g \bar{o}$

Data: Latim Clássico

Ambiente Fonológico:

Consoantes adjacentes: $r \_g$

Posição da síncope: Segunda Sílaba (SM)

Quantidade de Sílabas: 4

Sílaba Tônica: /iū-/

- occa 'rastelo'

Análise

$*_{o C V C a-}>*_{o k t a-}($ ou *otka- $)>$ occa

de Vaan (2008:423)

Duas possibilidades de desenvolvimento: 1) Hirt (1916:230):

*oketa (PIE) > *okita (Pré-Latim) >

*otika > com síncope *otka > occa; 2)

Empréstimo de algum dialeto itálico:

*oketa- > *okta- > occa

occāre 'quebrar no chão'

Ambiente Fonológico:

Consoantes adjacentes: $t \_k$ ou k_t

Posição da síncope: Segunda Sílaba (SM)

Quantidade de Sílabas: 3

Sílaba Tônica: /o-/

- ofella 'pedaço pequeno de carne'

$\underline{\text { Análise }}$ 
Diminutivo

Nishimura (2008: 145)

*offele-lā- > offellā- > ofella

Diminutivo de *offelā- > offula 'pedaço de carne'

Substantivo com o sufixo diminutivo $*_{-}$ le/o- próximo a soantes.

Data: Latim Pré-Clássico

Oxford Dictionary (1968: 1244):

offula vs offla (Ocorrência em Petrônio 56.8-56.9)

Ambiente Fonológico:

Consoantes adjacentes: 1_1

Posição da síncope: Terceira Sílaba (SM ( SNPT)

Quantidade de Sílabas: 4

Sílaba Tônica: /o-/

- officium 'trabalho'

Análise

*opi-fakiom > officium

Leumann (1977: 96)

*opificium > officium

opificina (Ocorrência em Plauto)

Nishimura (2008:116)

*ópi-fakiom > officium

Derivativos: opifex 'artesão', opificinna 'desempenho de trabalho construtivo', opificium (composição tardia)

Data: Latim Pré-Clássico

Ambiente Fonológico:

Consoantes adjacentes: $\mathrm{p} \_\mathrm{f}$

Posição da síncope: Segunda Sílaba (SM)
Quantidade de Sílabas: 5

Sílaba Tônica: /o-/

- ōpiliō 'pastor'

Análise

*aui-pol-ó- > *auii-pol-o- > *áu-pol-o-

$>\overline{o p i l i o ̄}$

Mudança ocorrida na passagem do

Proto-Itálico > Latim Antigo.

Nishimura $(2008: 1,19)$

*h $h_{2}$ oui-polh ${ }_{2}$-ó- $>$ *oui-pol-ó- 'condutor de ovelhas' > *aui-pol-ó- $>$ * áui-polo- > *áu-pol-o- > ōpiliō

Data: Latim Pré-Clássico

Ambiente Fonológico:

Consoantes adjacentes: $u \_p$

Posição da síncope: Segunda Sílaba (SM)

Quantidade de Sílabas: 4

Sílaba Tônica: / aú-/

- ornus 'cinzas'

Análise

*orinos > ornus

Leumann (1977: 96)

*ozinos $>$ *orinos $>$ ornus

$\underline{\text { Schrjiver (1991:327) }}$

*osenos $>$ *orinos $>$ ornus

Ambiente Fonológico:

Consoantes adjacentes: $\mathrm{r} \_n$

Posição da síncope: Segunda Sílaba (SM)

Quantidade de Sílabas: 3

Sílaba Tônica: /o-/ 
- palmus 'palma (da mão)'

$\underline{\text { Análise }}$

*palamos > palmus

*palamā > palma

Nishimura (2008: 118)

PIE *plíh $h_{2}-m e h_{2-}$

PIt. *palam $\bar{a}-$

Cognatos: Gr. $\pi \alpha \lambda \dot{\alpha} \mu \eta$, IrA. lām 'mão'

$\underline{\text { Schrjiver (1991:327) }}$

*palamos > palmus, *palamet- > palmes, ${ }^{*}$ palama $>$ palma

Ambiente Fonológico:

Consoantes adjacentes: $1 \_m$

Posição da síncope: Segunda Sílaba (SM)

Quantidade de Sílabas: 3

Sílaba Tônica: /pa-/

- pars 'parte'

Análise

*paratis $>$ *partis $>$ pars

Dupla síncope

Leumann (1977: 96)

*paratis, -im > pars, partim

Ambiente Fonológico:

Consoantes adjacentes: $r \_t, t \_s$

Posição da síncope: Segunda Sílaba

(SM), Última Sílaba (SF)

Quantidade de Sílabas: 3

Sílaba Tônica: /pa-/

- patella 'pratinho'

$\underline{\text { Análise }}$
Diminutivo

Nishimura (2008: 145)

*patane-lā- > patella

Diminutivo de patina 'prato; panela'

Cognato: gr. $\pi \alpha \tau \alpha ́ v \varepsilon$

Substantivo com o sufixo diminutivo *le/o-próximo a soantes.

Data: Latim Pré-Clássico

Ambiente Fonológico:

Consoantes adjacentes: $\mathrm{n} \_1$

Posição da síncope: Terceira Sílaba (SM / SNPT)

Quantidade de Sílabas: 4

Sílaba Tônica: /pa-/

- paullus 'pequeno'

$\underline{\text { Análise }}$

Analogia em diminutivo.

Nishimura (2008: 146)

*paure-lo- > paullus

Substantivo com o sufixo diminutivo *le/o- próximo a soantes. Diminutivo trissilábico em analogia a diminutivos com sequência de sílabas breves.

Ambiente Fonológico:

Consoantes adjacentes: $r \_1$

Posição da síncope: Segunda Sílaba (SM / A)

Quantidade de Sílabas: 3

Sílaba Tônica: /paú-/

- pergō 'continuar; avançar'

Análise

*perregō > pergō 
Nishimura (2008: 124)

* perregō $>$ pergō

Data: Latim Literário

Ambiente Fonológico:

Consoantes adjacentes: $r \_g$

Posição da síncope: Segunda Sílaba (SM)

Quantidade de Sílabas: 3

Sílaba Tônica: /per-/

- persōlla 'mascarazinha'

Análise

Analogia em diminutivo.

Nishimura (2008: 146)

*persōne-lā- > persōlla

Diminutivo de persōna 'máscara'

Substantivo com o sufixo diminutivo *le/o- próximo a soantes. Analogia a diminutivos com sequência de sílabas breves.

Ambiente Fonológico:

Consoantes adjacentes: $\mathrm{n} \_1$

Posição da síncope: Terceira Sílaba (SM / A)

Quantidade de Sílabas: 4

Sílaba Tônica: /per-/

- piger 'preguiçoso'

Análise

*pigros > piger

Nishimura (2008: 150)

*pigros > piger

Ambiente Fonológico:

Consoantes adjacentes: $r \_s$
Posição da síncope: Última Sílaba (SF)

Quantidade de Sílabas: 2

Sílaba Tônica: /pi-/

- pōcillum 'pequena taça'

Análise

Analogia em diminutivo

Leumann (1977: 97)

*pōcle-lom > pōcllom > pōcillum

Síncope nos moldes de agellus.

Nishimura (2008: 146)

*pōkle-lo- > com síncope pōcillum

Substantivo com o sufixo diminutivo $*_{-}$ le/o- próximo a soantes. Diminutivo trissilábico em analogia a diminutivos com sequência de sílabas breves.

Ambiente Fonológico:

Consoantes adjacentes: 1_1

Posição da síncope: Segunda Sílaba (SM / A)

Quantidade de Sílabas: 3

Sílaba Tônica: / $p \overline{o-/}$

- Pollūx 'Pólux'

Análise

Mudança ocorrida na passagem do Proto-Itálico > Latim Antigo.

Leumann (1964: 84)

POLOCES (talvez o /-ld-/ esteja mal representado)

Nishimura (2008: 118)

*polud- > com síncope *Pold >

PODLOVQVEI 
POLOCES (talvez o /-ld-/ esteja mal representado) $>$ Pollūx

Ambiente Fonológico:

Consoantes adjacentes: 1_d

Posição da síncope: Segunda Sílaba (SM)

Quantidade de Sílabas: 3

Sílaba Tônica: /po-/

- pōnō 'colocar'

Análise

*posinō > *posnō > pōnō

Nishimura (2008: 118, 127, 134)

*posinō > *posnō > pōnō

Ocorrências em Plauto e Catão.

de Vaan (2008:479)

PIE *tk-i-n-(e/o-) 'construir'; 'viver'

PIt. *po-sine/o-

*po-sinō > com síncope *po-snō > *poznō > ponō

Ambiente Fonológico:

Consoantes adjacentes: s_n

Posição da síncope: Segunda Sílaba (SM)

Quantidade de Sílabas: 3

Sílaba Tônica: /po-/

- pōpulneus/nus 'derivado de álamo'

$\underline{\text { Análise }}$

pōpuli- > pōpulneus/nus

Nishimura (2008: 143-144)

pōpuli- > populneus/nus

Cognato: lat. pōpulus 'árvore de álamo'
Vogais não-acentuadas que não são imediatamente pós-tônicas também estão sujeitas a sofrer síncope, e a presença de aproximantes (ressonantes) parece auxiliar o processo.

Ambiente Fonológico:

Consoantes adjacentes: $1 \_n$

Posição da síncope: Terceira Sílaba (SM / SNPT)

Quantidade de Sílabas: 3

Sílaba Tônica: /po-/

- porgō 'esticar-se'

$\underline{\text { Análise }}$

*porrigō $>$ porgō

Nishimura (2008: 124)

*porrigō $>$ porgō

Data: Latim Literário

Ambiente Fonológico:

Consoantes adjacentes: $r \_g$

Posição da síncope: Segunda Sílaba (SM)

Quantidade de Sílabas: 3

Sílaba Tônica: /por-/

- postrīdiē (adv.) 'dia seguinte’

Análise

Adjetivos construídos com o sufixo *tero apresentam síncope vocálica.

postero- > postrī-die

Leumann (1977: 96)

postero- > postrī-diē

Ambiente Fonológico:

Consoantes adjacentes: t_r 
Posição da síncope: Segunda Sílaba (SM)

Quantidade de Sílabas: 3

Sílaba Tônica: /pos-/

- postus (part., perf., passado de ponō)

'colocar'

$\underline{\text { Análise }}$

positus $>$ postus

Leumann (1977: 96)

positus > postus

Ocorrência em Lucrécio.

Outras formas: lat. repostus (Ocorrência em Virgílio)

Ambiente Fonológico:

Consoantes adjacentes: $\mathrm{s} \_\mathrm{t}$

Posição da síncope: Segunda Sílaba (SM)

Quantidade de Sílabas: 3

Sílaba Tônica: /po-/

- praecō 'anunciador'

Análise

*praidikō $>$ *praedkō $>$ praecō

de Vaan (2008:169)

*praidikō > com síncope *praedkō>

praecō

Ambiente Fonológico:

Consoantes adjacentes: d_k

Posição da síncope: Segunda Sílaba (SM)

Quantidade de Sílabas: 3

Sílaba Tônica: /prai-/
- prīnceps 'líder'

$\underline{\text { Análise }}$

*pri(s)mo-kap-s > prīnceps

Leumann (1977: 96)

*prí(s)mo-kap-s > princeps

Nishimura $(2008: 1,19,117)$

* prí(s)mo-kap-s > prīnceps

Data: Latim Antigo

Ambiente Fonológico:

Consoantes adjacentes: $\mathrm{m} \_\mathrm{k}$

Posição da síncope: Segunda Sílaba (SM)

Quantidade de Sílabas: 3

Sílaba Tônica: /pri(s)-/

- propter (adv./prep.) 'perto de'

$\underline{\text { Análise }}$

*prope-ter > propter

Leumann (1977: 96)

*prope-ter > propter

Outras formas: lat. prope

Ambiente Fonológico:

Consoantes adjacentes: $\mathrm{p} \_t$

Posição da síncope: Segunda Sílaba (SM)

Quantidade de Sílabas: 3

Sílaba Tônica: /pro-/

- puer 'menino'

Análise

*pueros > puer

Leumann (1977: 98)

*pueros > puer

Ambiente Fonológico: 
Consoantes adjacentes: $r \_s$

Posição da síncope: Última Sílaba (SF)

Quantidade de Sílabas: 2

Sílaba Tônica: /pue-/

- puertia 'infância'

$\underline{\text { Análise }}$

Incerto

Nishimura (2008:129)

pueritia > puertia

Incerto

Ambiente Fonológico:

Consoantes adjacentes: $r \_t$

Posição da síncope: Segunda Sílaba (SM / SNPT / IN)

Quantidade de Sílabas: 3

Sílaba Tônica: /pu-/

- pugillus 'aquilo que pode ser pego na mão'

Análise

Analogia em diminutivo.

Nishimura (2008: 146)

*pugne-lo- > pugillus

Diminutivo de pugnus 'punho'

Substantivo com o sufixo diminutivo ${ }^{*}$ le/o- próximo a soantes. Diminutivo trissilábico em analogia a diminutivos com sequência de sílabas breves.

Ambiente Fonológico:

Consoantes adjacentes: n_l

Posição da síncope: Segunda Sílaba (SM / A)

Quantidade de Sílabas: 3
Sílaba Tônica: /pug-/

- purgō 'desculpar-se; purificar'

Análise

*purrigō > purgō

Leumann (1977: 98)

Conjectura feita por Plauto (Aulularia,

v. 753) *pūrigāre > pūrgāre

Derivado de pūrus 'puro'

Nishimura (2008: 124)

*purrigō > purgō

Data: Latim Literário

Ambiente Fonológico:

Consoantes adjacentes: $r \_g$

Posição da síncope: Segunda Sílaba (SM)

Quantidade de Sílabas: 3

Sílaba Tônica: /pur-/

- quīndecim '15'

Análise

$* k^{u}$ ink ${ }^{u}$ e-dekem $>$ quindecim

Leumann (1977: 217)

*kuinkue-decem > quindecim

Nishimura (2008: 19)

*k ${ }^{u}$ ink ${ }^{u} e$-dekem $>$ quīndecim

Data: Latim Pré-Clássico

Weiss (2009: 123)

$\mathrm{O} / \bar{l} /$ longo aparece provavelmente em analogia a quīnque e quīntus

Ambiente Fonológico:

Consoantes adjacentes: $\mathrm{k}_{-}^{\mathrm{u}} \mathrm{d}$

Posição da síncope: Segunda Sílaba (SM) 
Quantidade de Sílabas: 4

Sílaba Tônica: / $k^{u}$ in-/

- rāllus 'simples; ralo'

Análise

Analogia em diminutivo.

Nishimura (2008: 146)

*rāre-lo- > rāllus

Diminutivo de rārus 'raro'

Substantivo com o sufixo diminutivo *le/o- próximo a soantes. Diminutivo trissilábico em analogia a diminutivos com sequência de sílabas breves.

Ambiente Fonológico:

Consoantes adjacentes: $r \_1$

Posição da síncope: Segunda Sílaba (SM / A)

Quantidade de Sílabas: 3

Sílaba Tônica: /rāa-/

- reccidī (pref. de recidō) 'cair para trás'

Análise

*rekekadī $>$ reccid $\bar{\imath}$

Nishimura (2008: 117)

*rékekadī > reccid $\bar{\imath}$

$\mathrm{PIE} * \hat{k} a d-$

Data: Latim Pré-Clássico

$\underline{\operatorname{Rix}(2001 \mathrm{~A}: 318)}$

$\mathrm{PIE}$ *-k̂d- 'cair'

Ambiente Fonológico:

Consoantes adjacentes: $\mathrm{k} \_\mathrm{k}$

Posição da síncope: Segunda Sílaba (SM)

Quantidade de Sílabas: 4
Sílaba Tônica: /re-/

- repperī (perf. de reperiō) 'descobrir'

Análise

*repepari > repper $\bar{\imath}$

Nishimura (2008: 117)

*répepari $>$ repperī

PIE ${ }^{*} p_{\circ} h_{3-}$

Data: Latim Pré-Clássico

Rix (2001A: 474)

PIE * perh $3^{-}$'fornecer'

Ambiente Fonológico:

Consoantes adjacentes: p_p

Posição da síncope: Segunda Sílaba (SM)

Quantidade de Sílabas: 4

Sílaba Tônica: /re-/

- reppulī (perf. de repellō) 'repelir'

Análise

*repepat̄̄ > reppulī

Nishimura (2008: 117)

*répepalī > reppulī

PIE *-plh $h_{2-}$

Data: Latim Pré-Clássico

Rix (2001A: 470)

PIE *-pelh $2^{-}$'aproximar-se'

Ambiente Fonológico:

Consoantes adjacentes: p_p

Posição da síncope: Segunda Sílaba (SM)

Quantidade de Sílabas: 4

Sílaba Tônica: /re-/ 
- retrō (adv./prep.) 'atrás’

$\underline{\text { Análise }}$

Adjetivos construídos com o sufixo *tero apresentam síncope vocálica.

*reter- > *retr- > retrō

Leumann (1977: 97)

*reter- $>$ *retr- > retrō

Ambiente Fonológico:

Consoantes adjacentes: t_r

Posição da síncope: Segunda Sílaba (SM)

Quantidade de Sílabas: 3

Sílaba Tônica: /re-/

- rettulī (supletivo perf. de referō) 'carregar de volta'

Análise

*retetalī $>$ rettulī

Nishimura (2008: 117)

*rétetalī > rettulī

$\mathrm{PIE} *-t l h_{2-}$

Derivativo: extetulisses 'colocaste os pés para fora' (Ocorrência em Ênio)

Data: Latim Pré-Clássico

Rix (2001A: 622)

PIE *-telh $2^{-}$'levantar'

Ambiente Fonológico:

Consoantes adjacentes: $\mathrm{t} \_\mathrm{t}$

Posição da síncope: Segunda Sílaba (SM)

Quantidade de Sílabas: 4

Sílaba Tônica: /re-/

- Sabellus 'sabélico'
Análise

Analogia em diminutivo.

Nishimura (2008: 146)

*sabne-lo- > Sabellus

Cognatos itálicos: osc. safinim, lat.

Samnium 'região de Sâmnia', lat.

Sabinus 'sabino'

Substantivo com o sufixo diminutivo ${ }^{*}$ le/o- próximo a soantes. Diminutivo trissilábico em analogia a diminutivos com sequência de sílabas breves.

Ambiente Fonológico:

Consoantes adjacentes: $n \_1$

Posição da síncope: Segunda Sílaba $(\mathrm{SM} / \mathrm{A})$

Quantidade de Sílabas: 3

Sílaba Tônica: /sab-/

- sacellus 'templo'

Análise

Diminutivo

Nishimura (2008: 147)

*sakrelo- > sacellus

Diminutivo de sacer 'sagrado'

Ambiente Fonológico:

Consoantes adjacentes: $r \_1$

Posição da síncope: Segunda Sílaba (SM)

Quantidade de Sílabas: 3

Sílaba Tônica: /sa-/

- sacer 'sagrado'

Análise

SAKROS $>*_{\text {sakrs }}>$ sacer 
Nishimura (2008: 147, 151)

SAKROS $>*_{\text {sakrs }}>$ sacer

$* C r V->* C^{\ominus} r V>* C a r^{V}>C e r$

de Vaan (2008: 532)

PIE *sh $h_{2} k$-ro- 'sagrado'

PIt. *sakro- 'sagrado'

Cognatos itálicos: fal. sacra (nom., sg., f.), umb. sacru (nom., sg., f.), osc. бакоро (nom., sg., f. ou nom., pl., n.), umb. sacr (nom., sg.), osc. sakarakleís (gen., sg.) 'santuário', osc. sakrim (acs., sg.).

Ambiente Fonológico:

Consoantes adjacentes: $\mathrm{r}_{-} \mathrm{s}$

Posição da síncope: Última Sílaba (SF)

Quantidade de Sílabas: 2

Sílaba Tônica: /sa-/

- sacerdōs 'sacerdote'

Análise

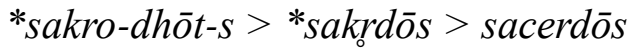

Leumann (1977: 97)

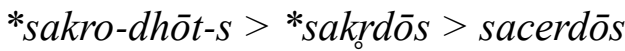

Formas mais antigas: sacrilegus

'sacrilégio', sacrificāre 'sacrificar'

Ambiente Fonológico:

Consoantes adjacentes: $\mathrm{r} \_\mathrm{d}$

Posição da síncope: Segunda Sílaba (SM)

Quantidade de Sílabas: 3

Sílaba Tônica: /sa-/

- salūber 'salubre'

$\underline{\text { Análise }}$ *salūbris > salūber

Nishimura (2008: 150)

$*_{\text {salūbris }>\text { salūber }}$

Ambiente Fonológico:

Consoantes adjacentes: $r \_s$

Posição da síncope: Última Sílaba (SF)

Quantidade de Sílabas: 3

Sílaba Tônica: /sa-/

- scabillum 'banquinho'

Análise

Analogia em diminutivo.

Nishimura (2008: 146)

*scabne-lo- > scabillum

Diminutivo de *scabno- > scamnum 'banco'

Substantivo com o sufixo diminutivo *le/o- próximo a soantes. Diminutivo trissilábico em analogia a diminutivos com sequência de sílabas breves.

Ambiente Fonológico:

Consoantes adjacentes: $\mathrm{n} \_1$

Posição da síncope: Segunda Sílaba (SM / A)

Quantidade de Sílabas: 3

Sílaba Tônica: /scab-/

- sēsqui- (adv./pref.) ' 1 e 1/2’

Análise

*sēmis-qui > sēsqui

Nishimura (2008: 137, 139-140)

*sēmis-qui > sēsqui-

Síncope em sílaba fechado com coda em /-s/. Silabificação $-S C(R)$-. 
Data: Latim Pré-Clássico

Ambiente Fonológico:

Consoantes adjacentes: m_s

Posição da síncope: Segunda Sílaba (SM)

Quantidade de Sílabas: 3

Sílaba Tônica: /sē-/

- sēstertius ' 2 e 1/2'

Análise

*sēmis-tertius > *sēstertius

Leumann (1977: 97)

*sēmis tertius 'a terceira metade' > sēstertius ' 2 e $1 / 2$ '

Nishimura (2008: 137, 140)

*sēmis-tertius $>$ sēstertius

Síncope em sílaba fechado com coda em /-s/. Silabificação $-s C(R)$-. Diferente de outros exemplos com essa sequência, o termo não apresenta uma sequência de vogais breves.

Ocorrências em Varrão e Cícero.

Ambiente Fonológico:

Consoantes adjacentes: m_s

Posição da síncope: Segunda Sílaba (SM)

Quantidade de Sílabas: 4

Sílaba Tônica: /sē-/

- sinciput 'meia-cabeça; bobo'

Análise

*sēmi-caput > sinciput

Leumann (1977: 97)

*suīno-caput $>$ *sēmi-caput > sinciput
Nishimura (2008: 116)

*sēmi-caput > sinciput

de Vaan (2008:91)

PIt. *kaput

*sēmi-caput > sinciput

Ambiente Fonológico:

Consoantes adjacentes: $\mathrm{m} \_\mathrm{k}$

Posição da síncope: Segunda Sílaba (SM)

Quantidade de Sílabas: 4

Sílaba Tônica: /sē-/

- socer 'sogro'

$\underline{\text { Análise }}$

*soceros $>*_{\text {socers }}>*_{\text {socerr }}>$ socer

Leumann (1977: 98)

*soceros > socer

Em Plauto, há tanto a forma socerus, quanto a forma socer.

Ambiente Fonológico:

Consoantes adjacentes: $r \_s$

Posição da síncope: Última Sílaba (SF)

Quantidade de Sílabas: 3

- subtrahō 'subtrair'

Análise

É difícil afirmar se a queda da vogal ocorreu antes ou depois da junção do prefixono verbo.

Nishimura (2008: 120)

*supo-trahō > subtrahō

Obs: A queda da vogal final da preposição parece ter ocorrido quando a preposição foi associada ao verbo trahō, 
ou seja, a queda ocorre praticamente em posição interna.

Ambiente Fonológico:

Consoantes adjacentes: $\mathrm{p} \_\mathrm{t}$

Posição da síncope: Segunda Sílaba (SM / IN)

Quantidade de Sílabas: 4 (com preposição)

Sílaba Tônica: /su-/

- suillus 'referente a porcos'

Análise

Analogia em diminutivo.

Nishimura (2008: 146)

*suīre-lā- > suillus

Substantivo com o sufixo diminutivo $*_{-}$ le/o- próximo a soantes. Analogia a diminutivos com sequência de sílabas breves.

Ambiente Fonológico:

Consoantes adjacentes: $\mathrm{p \_} t$

Posição da síncope: Terceira Sílaba (SM / SNPT / A)

Quantidade de Sílabas: 4

Sílaba Tônica: /su-/

- summus 'o mais alto'

Análise

Possivelmente: *supVmo- > com síncope *summo- > summus

de Vaan (2008: 600)

PIE $*\left(h_{2}\right)$ up $-m(H)_{o-}$

PIt. *sup (a)mo-
Duas possibilidades de desenvolvimentos:

1) *supamo- > com síncope *summo- > summus

2) *sup-mo- > *summo- > summus

Cognatos itálicos: umb. sume (loc., sg.), somo (abl., sg., m.)

Ambiente Fonológico:

Consoantes adjacentes: p_m

Posição da síncope: Segunda Sílaba (SM / IN)

Quantidade de Sílabas: 3

Sílaba Tônica: /su-/

- suprāa (adv./prep.) 'em cima de'

Análise

SUPERA > suprā

Meiser (1998: 7)

Data: Latim Antigo

Nishimura (2008: 118)

SUPERA > suprā

*supēremos > suprēmus 'supremo'

Derivativo: superus 'superior'

Data: Latim Pré-Clássico

Untermann (2000: 706-7)

*supero- (adj.) > suprā (abl., sg., f.)

Cognato itálico: umb. subra (prep./adv.)

Ambiente Fonológico:

Consoantes adjacentes: p_r

Posição da síncope: Segunda Sílaba (SM)

Quantidade de Sílabas: 3

Sílaba Tônica: /su-/ 
- surgō 'levantar'

Análise

*subregō > com síncope surgō

Nishimura (2008: 124)

*subregō > surgō

Data: Latim Literário

Ambiente Fonológico:

Consoantes adjacentes: $r \_g$

Posição da síncope: Segunda Sílaba (SM)

Quantidade de Sílabas: 3

Sílaba Tônica: /sub-/

- surpiō 'roubar'

Análise

*sub-rapiō > surpiō

Nishimura (2008: 135)

$*_{\text {sub-rapiō }>\text { surpiō }}$

Ambiente Fonológico:

Consoantes adjacentes: $r \_p$

Posição da síncope: Segunda Sílaba (SM)

Quantidade de Sílabas: 3

Sílaba Tônica: /sub-/

- tabella 'tablete'

Análise

Diminutivo

O desenvolvimento fonológico proposto por Nishimura é possível, mas incerto.

Nishimura (2008: 145)

*tablele-lā- > com dissimilação haplológica *tabelela > tabella

Diminutivo de tabula 'tábua'
Substantivo com o sufixo diminutivo ${ }_{-}$ le/o- próximo a soantes.

Data: Latim Pré-Clássico

Ambiente Fonológico:

Consoantes adjacentes: 1_1

Posição da síncope: Segunda Sílaba (SM / IN)

Quantidade de Sílabas: 4

Sílaba Tônica: /ta-/

- tegmine 'cobertura'

Análise

tegmine vs tegimine

Nishimura (2008:129)

tegimine > tegmine

Cognato: lat. tegimen

Ambiente Fonológico:

Consoantes adjacentes: g_m

Posição da síncope: Segunda Sílaba (SM)

Quantidade de Sílabas: 4

Sílaba Tônica: /te-/

- tenellus 'macio'

Análise

Diminutivo

Nishimura (2008: 145)

*tenere-lā- > tenellus

Diminutivo de tener 'delicado'

Substantivo com o sufixo diminutivo $*_{-}$ le/o- próximo a soantes.

Data: Latim Pré-Clássico

Ambiente Fonológico:

Consoantes adjacentes: $r \_1$ 
Posição da síncope: Terceira Sílaba (SM

/ SNPT)

Quantidade de Sílabas: 4

Sílaba Tônica: /te-/

- ter (adv.) 'três vezes'

Análise

PIt. *tris $>*$ tirs $>*$ ters $>*$ terr $>$ ter

Não há síncope.

Nishimura (2008: 150)

*tris > ter

$\mathrm{V}>0 / * C r V-$

Síncope na sílaba tônica.

Sihler (1995: 411)

$*$ tris $>$ ters $>$ terr $>$ ter

Cognato itálico: umb. tertim ' pela terceira vez'

de Vaan (2008: 628)

Cognatos itálicos: osc. trís (nom., pl., f.), umb. trif, tref (acs., pl., m.), terti, tertim (acs., sg., m/n.)

Ambiente Fonológico:

Posição da síncope: Não há síncope (N)

Quantidade de Sílabas: 1

Sílaba Tônica: /tris-/

- testis 'testemunha'

Análise

PIt. *triste- > *tirste- > *terste- > testis

Não há síncope.

Nishimura (2008: 150)

*triste- > *tersti- > testis

$\mathrm{V}>\mathrm{O} / * \mathrm{CrV}$ -

Síncope na sílaba tônica.
Sihler (1995: 411)

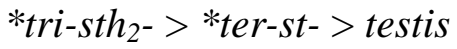

Untermann (2000: 749)

*tris-to 'terceiro' > *trsto > testis

'testemunha'

Cognato itálico: osc. trstus (nom., pl.)

'testemunhas'

de Vaan (2008: 618)

A pré-forma direta deve ter sido PIE *tri-sth ${ }_{2}-i$ - 'terceiro em espera', que depois passou ao sentido 'testemunha'. A forma ítalo-celta *tristo- pode ser resultado da perda haplológica da sílaba *-to-.

Ambiente Fonológico:

Posição da síncope: Não há síncope $(\mathrm{N})$

Quantidade de Sílabas: 2

Sílaba Tônica: /tris-/

- tigillum 'pequena viga (de madeira)'

Análise

Analogia em diminutivo.

Nishimura (2008: 146)

*tigne-lo- > tigillum

Diminutivo de tignum 'viga (de madeira)'

Substantivo com o sufixo diminutivo $*_{-}$ le/o- próximo a soantes. Diminutivo trissilábico em analogia a diminutivos com sequência de sílabas breves.

Ambiente Fonológico:

Consoantes adjacentes: $n \_1$

Posição da síncope: Segunda Sílaba $(\mathrm{SM} / \mathrm{A})$ 
Quantidade de Sílabas: 3

Sílaba Tônica: /ti-/

- uafer 'engenhoso'

$\underline{\text { Análise }}$

*uasro- ou *uap-ro-> uafer

Mudança ocorrida na passagem do

Proto-Itálico > Latim Antigo.

de Vaan (2008: 650)

PIt. *uasro- ou *uap-ro-> uafer

Cognato itálico: lat. uarius 'variado'

Ambiente Fonológico:

Consoantes adjacentes: $\mathrm{r}_{-} \mathrm{C}$

Posição da síncope: Última Sílaba (SF)

Quantidade de Sílabas: 2

Sílaba Tônica: /uas-/

- ualdē (adv.) 'muito'

$\underline{\text { Análise }}$

ualide $>$ ualdē

Leumann (1977: 97)

unalidēe (de ualidus) > unaldē

Nishimura (2008: 19)

ualide $>$ com síncope ualde vs com ênclise unalidus 'forte'

Ambiente Fonológico:

Consoantes adjacentes: 1_d

Posição da síncope: Segunda Sílaba (SM)

Quantidade de Sílabas: 3

Sílaba Tônica: /ua-/

- $\bar{u} d \overline{o s}$ 'molhado'

$\underline{\text { Análise }}$ $\bar{u} u i d \bar{o} s>\bar{u} d \bar{o} s$

Nishimura (2008: 12)

$\bar{u} u i d \bar{o} s>\bar{u} d \bar{o} s$

Data: Latim Literário

Ambiente Fonológico:

Consoantes adjacentes: $\mathrm{u}_{-} \mathrm{d}$

Posição da síncope: Segunda Sílaba (SM)

Quantidade de Sílabas: 3

Sílaba Tônica: / $\bar{u}$-/

- ueclus 'velho'

$\underline{\text { Análise }}$

*uetulus $>$ *uetlus $>$ ueclus

Leumann (1977: 97)

*uetulus $>$ *uetlus $>$ ueclus

Ambiente Fonológico:

Consoantes adjacentes: $t \_1$

Posição da síncope: Segunda Sílaba (SM)

Quantidade de Sílabas: 3

Sílaba Tônica: /une-/

- uernō (adv.) 'primavera'

Análise

*uērinōd > uernō

Nishimura (2008: 126)

*uērinōd > uernō

Data: Latim Literário

Ambiente Fonológico:

Consoantes adjacentes: $r \_n$

Posição da síncope: Segunda Sílaba (SM)

Quantidade de Sílabas: 3 
Sílaba Tônica: /ụe-/

- uestro- 'vosso'

Análise

Adjetivos construídos com o sufixo $*_{-}$ tero apresentam síncope vocálica.

*uestero- > uestro-

Leumann (1977: 97)

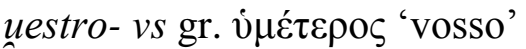

Ambiente Fonológico:

Consoantes adjacentes: $t \_r$

Posição da síncope: Segunda Sílaba

(SM)

Quantidade de Sílabas: 3

Sílaba Tônica: /ne-/

- ueternus 'estado mórbido de torpor'

Análise

Talvez não se trate de um caso de síncope em vogal não-imediatamente pós-tônica:

*uet-es-ino > *uet-er-ino > *uetrino > *uetirno > *ueterno- > ueternus

Nishimura (2008:143)

*uetusinos $>$ *ueterinos $>$ uneternus

Vogais não-acentuadas que não são imediatamente pós-tônicas também estão sujeitas a sofrer síncope, e a presença de aproximantes (ressonantes) parece auxiliar o processo.

Ambiente Fonológico:

Posição da síncope: Não há síncope (N)

Quantidade de Sílabas: 4

Sílaba Tônica: /ue-/
- uĩllum 'pequena porção de vinho'

Análise

Analogia em diminutivo.

Nishimura (2008: 146)

*uīnene-lo- > uīllum

Substantivo com o sufixo diminutivo ${ }^{*}$ le/o- próximo a soantes. Diminutivo trissilábico em analogia a diminutivos com sequência de sílabas breves.

Ambiente Fonológico:

Consoantes adjacentes: $\mathrm{n} \_1$

Posição da síncope: Segunda Sílaba (SM / A)

Quantidade de Sílabas: 3

Sílaba Tônica: / $/ \bar{\imath} \overline{-} /$

- uindēmia 'coleta de uvas para a produção de vinho'

Análise

*uini-dèmia > uindèmia

Leumann (1977: 97)

*uini-dèmia (de *uino-dēmos) > unindèmia

Ambiente Fonológico:

Consoantes adjacentes: $\mathrm{n} \_\mathrm{d}$

Posição da síncope: Segunda Sílaba (SM)

Quantidade de Sílabas: 4

Sílaba Tônica: /ui-/

- uirtūs 'qualidade viril'

Análise

*uiro-tūs $>$ uirtīs 
Leumann (1977: 96)

*uiro-tūs > uirtus

Palavra nos moldes de serui-tūs 'servitude'

Ambiente Fonológico:

Consoantes adjacentes: $r \_t$

Posição da síncope: Segunda Sílaba (SM)

Quantidade de Sílabas: 3

Sílaba Tônica: /uni-/

- uitellus 'vitelo'

Análise

Diminutivo

Nishimura (2008: 145)

*uitele-lo- > uitellus

Diminutivo de uitulus

Substantivo com o sufixo diminutivo $*_{-}$ le/o- próximo a soantes.

Data: Latim Pré-Clássico

Oxford Dictionary (1968: 2081)

uitulus 'filhote de animal'

Cognato Itálico: umb. uitlu (nom., sg.)

Ambiente Fonológico:

Consoantes adjacentes: $1 \_1$

Posição da síncope: Terceira Sílaba (SM / SNPT)

Quantidade de Sílabas: 4

Sílaba Tônica: /uni-/

- ūllus, nūllus 'qualquer um', 'nenhum’

Análise

Analogia em diminutivos.

Nishimura (2008: 146) *oine-lo- > üllus

*n(e)-oine-lo- > nüllus

Substantivo com o sufixo diminutivo $*_{-}$ le/o- próximo a soantes. Diminutivo trissilábico em analogia a diminutivos com sequência de sílabas breves.

Ambiente Fonológico:

Consoantes adjacentes: $\mathrm{n} \_1$

Posição da síncope: Segunda Sílaba (SM / A)

Quantidade de Sílabas: 3

Sílaba Tônica: /oi-/

- ulna 'antebraço'

$\underline{\text { Análise }}$

*olen $\bar{a}>*$ olna $\bar{a}>$ ulna

Leumann (1977: 96)

*olena $>$ *olna $>$ ulna

Cognato: gr. $\grave{\omega} \lambda \varepsilon^{\prime} v \eta$ 'antebraço'

Ambiente Fonológico:

Consoantes adjacentes: $1 \_n$

Posição da síncope: Segunda Sílaba (SM)

Quantidade de Sílabas: 3

Sílaba Tônica: /o-/

- ultrāa (adv./prep.) 'além’

Análise

*ulter- > *ultr- > ultrā

Leumann (1977: 97)

*ulter- > ultrā

Cognato: lat. ulterior 'mais distante'

Ambiente Fonológico:

Consoantes adjacentes: t_r 
Posição da síncope: Segunda Sílaba (SM)

Quantidade de Sílabas: 3

Sílaba Tônica: /ul-/

- undecim '11'

Análise

*oinoz-dekem > com síncope undecim

Leumann (1977: 107, 487)

*oinoz-decem > ǔndecim (*oinos >

$\bar{u} n u s+$ decem)

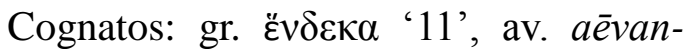
dasa- ' 11 '

Nishimura (2008: 19,116)

*óino-dekem > undecim

Data: Latim Pré-Clássico

Ambiente Fonológico:

Consoantes adjacentes: $\mathrm{n} \_\mathrm{z}$

Posição da síncope: Segunda Sílaba (SM)

Quantidade de Sílabas: 4

Sílaba Tônica: /oi-/

- īsurpāre 'usurpar'

Análise

*ūsu-rapos (de üsus e rapere) > com síncope $\overline{\text { surpare }}$

Leumann (1977: 97 )

*ūsu-rapos (de ūsus e rapere) > ūsurpare

Nishimura (2008: 19)

*oisu-rup-ā- > ūsurpāre

PIE *reup- > lat. rumpō 'romper'

$\bar{u} s \bar{u}$-capiō 'usucapião'
Ambiente Fonológico:

Consoantes adjacentes: $\mathrm{r} \_\mathrm{p}$

Posição da síncope: Terceira Sílaba (SM / SNPT)

Quantidade de Sílabas: 4

Sílaba Tônica: /-su-/

- uter 'mangueira de água'

$\underline{\text { Análise }}$

PIt. *udris > *udirs > *uders > *uderr $>$ uter

Não há síncope.

Meiser (1998: 123)

*udris > uter 'mangueira de água'

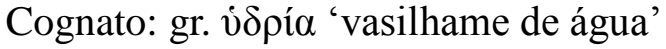

Untermann (2000: 785)

*udri > com síncope uter 'mangueira'

Ambiente Fonológico:

Consoantes adjacentes: $\mathrm{r}_{-} \mathrm{s}$

Posição da síncope: Não há síncope (N)

Quantidade de Sílabas: 2

Sílaba Tônica: /u-/

- uulnus 'ferida'

Análise

*uolenos $>$ *uolnos $>$ uulnus

Leumann (1977: 96)

*uolenos > uulnus

Ambiente Fonológico:

Consoantes adjacentes: 1_n

Posição da síncope: Segunda Sílaba (SM)

Quantidade de Sílabas: 3

Sílaba Tônica: /uno-/ 


\section{ANEXO II: CORPUS DE PALAVRAS SABÉLICAS}

- aadirans (Osco) 'Adiram' (gentílico) (nom., sg.)

Ocorrência

Po 3

Análise

$*_{\text {-anos }}>$ aadirans

Benediktsson (1960: 216)

*-anos > Aadirans

Antes de $-s$ final, toda vogal breve é sincopada $\left(-\breve{V}_{s} \#>-s \#\right)$.

Final secundário $-n s$ foi mantido em osco e também em úmbrio, enquanto o original $*-n s$ se tornou $-s s$.

Ambiente Fonológico:

Consoantes adjacentes: n_s\#

Posição da síncope: Última sílaba (SF)

Quantidade de Sílabas: 5

- aamanaffed (Osco) 'entregar' (3 $3^{\mathrm{a}}$ sg., perf.)

\section{Ocorrências}

aamanaffed: Po 4; Po 6; Po 7; Po 9; Po 14

amanafed: $\mathrm{Sa} 2$; $\mathrm{Sa} 9$

Análise

$*_{\text {-manufefed }}>*_{\text {-manfefed }}>*_{\text {-manffed }}$

$>$ com anaptixe *-manaffed

Benediktsson (1960: 237)

*-man-peped > aamanaffed ( $3^{\mathrm{a}} \mathrm{sg}$., perf.)
PIt. $* b(\mathrm{PIE} * d h)>f$ antecedeu a ocorrência da síncope.

Buck (1904:194)

*manfefom, *manfefed > aa-manaffed

Cognato itálico: lat. man-dō $(<\operatorname{mandhō})$

Untermann (2000: 449)

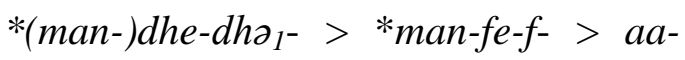
manaffed

Ambiente Fonológico:

Consoantes adjacentes: $\mathrm{f} \_\mathrm{f}$

Posição da síncope: Segunda sílaba + preposição (SM)

Quantidade de Sílabas: 4

- Abellā- (Osco) 'Abela' (uma cidade na região de Campanha)

Ocorrências

$\mathrm{Cm}$ 1B29; $\mathrm{Cm}$ 1A6; $\mathrm{Cm}$ 1A3; $\mathrm{Cm}$ 1B18; Cm 1B15; Cm 1B20

Análise

*ablonā-lā > abellā-

Buck (1904: 60, 96)

Provavelmente: *apro-lā- $>$ Abella(Abellanús)

Normalmente *pr permanece em osco, mas não neste exemplo.

Meiser (1986: 132)

*ablonā-lā > abellā-

$-C R V C->-C R C->-C e R C$

Ambiente Fonológico:

Consoantes adjacentes: 1_n 
Posição da síncope: Segunda sílaba (SM)

Quantidade de Sílabas: 4

- actud (Osco) 'fazer' (imp.)

Ocorrência

Lu 1, 15

Análise

*agetod $>$ actud

Meiser (1986: 130)

PIt. *agetod $>$ actud

Nishimura (2008:1)

Lat. agito x osc. actud (imp.)

Untermann (2000: 72)

Lat. agito $\mathrm{x}$ osc. actud

Ambiente Fonológico:

Consoantes adjacentes: $\mathrm{g} \_\mathrm{t}$

Posição da síncope: Segunda sílaba

(SM)

Quantidade de Sílabas: 3

- Aderl (Osco) 'Atela' (uma cidade osca na região da Campanha)

Ocorrência

$\mathrm{nCm} 2 \mathrm{a}$

Análise

É difícil estabelecer qual das suas soluções é a mais plausível, a de Benediktsson/Buck ou a de Meiser, pois fonologicamente ambas funcionam. De qualquer maneira, ambas apresentam uma vogal sincopada.

Benediktsson (1960: 198)

*ātrolā, $\bar{a}$ drolā $>$ Aderl
Síncope em formas tri- ou quadrissilábicas com uma vogal longa na terceira sílaba.

Cognato itálico: lat. Atella

Benediktsson (1960: 239, nota 84)

Segundo von Planta (I, 552), original $* t r>d r$ em Úmbrio e secundário *tr (produzido por síncope) > tr. Mas há mais contraexemplos do que exemplos pra corroborar essa teoria, como cringatro '?' (< PIE *-tro-)

Buck (1904: 60)

*ātro-lā > Aderl

Meiser (1986: 132)

*adrolā $>$ aderlā

$-C R V C->-C R C->-C e R C$

Ambiente Fonológico:

Consoantes adjacentes: $\mathbf{r} \_1$

Posição da síncope: Segunda sílaba (SM)

Quantidade de Sílabas: 3

- ager (Úmbrio) ‘campo’ (nom., sg.)

Ocorrência

ager: Um 10

Análise

*agros $>$ agrs $>$ agers $>$ ager

Benediktsson (1960: 216)

*agros > agrs > agers > ager (nom., sg.)

Antes de $-s$ final, toda vogal breve é sincopada $(-\breve{V} s \#>-s \#)$.

Nom. sg. de temas em $-O: *_{-}-o s>-s$.

Cognato itálico: lat. ager 


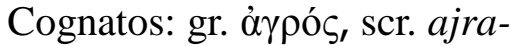

Meiser (1986: 59)

*agros > ager (nom., sg.)

$\mathrm{V}>0$ / i, u, , r, $1_{-} \mathrm{s} \#$

Untermann (2000: 60-61, 77)

Outras formas: umb. agre (gen., sg.)

Cognato itálico: PM akren

Ambiente Fonológico:

Consoantes adjacentes: $r \_s \#$

Posição da síncope: Última sílaba (SF)

Quantidade de Sílabas: 2

- ahtisper (Úmbrio) 'atos' (dat./abl., pl.

+ prep.per)

$\underline{\text { Ocorrências }}$

III 24; III 29

Análise

*aktifos > ahtis-per

Benediktsson (1960: 222)

*aktifos > ahtis-per (dat./abl., pl. + prep. per)

Dativo / ablativo plural de temas em $-i$, $-u,-e$ e em consoante: $*_{-} f o s>-f s>-s(s)$

Weiss (2010: 189)

*akti- > ahti-

Ambiente Fonológico:

Consoantes adjacentes: f_s\#

Posição da síncope: Última sílaba (SF)

Quantidade de Sílabas: 3

- akkatus (Osco) 'invocados' (nom., pl.)

Ocorrência

Cm 14
Análise

*aduokāto- > *adokāto- > akkatus

Benediktsson (1960: 189)

*aduokātōs > *adokātōs > akkatus (nom., pl.)

Síncope em formas tri- ou quadrissilábicas com uma vogal longa na terceira sílaba.

Buck (1904: 58)

*aduokāto- > *adokāto- > akkatus

Ambiente Fonológico:

Consoantes adjacentes: $\mathrm{d} \_\mathrm{k}$

Posição da síncope: Segunda sílaba (SM)

Quantidade de Sílabas: 4

- alttrú (Osco) 'outro'

Ocorrência

$\mathrm{nCm} 2 \mathrm{a}$

Análise

Cognato itálico: lat. alter

Duas síncopes: *ali-tero- > *altero- > alttrú

Geminação: -LT- > -LTT-

Benediktsson (1960: 213)

*ali-tero- > *altero- > alttrú

Síncope em formas tri- ou quadrissilábicas com uma vogal longa na terceira sílaba.

Ambiente Fonológico:

Consoantes adjacentes: 1_t, t_r

Posição da síncope: Segunda sílaba e terceira sílaba (SM)

Quantidade de Sílabas: 4 
- amboltu (Úmbrio) 'dar voltas ao redor de' (imp.)

Ocorrência

VIb 52

Análise

*ampeltōd > *am-beltōd > *am-boltu

Kümmel (2012/2013)

Prefixo $a m$ (e não $a m b$ )

*ampeltōd > *am-beltōd > *am-boltu

Cognato: lat. colere 'cultivar'; gr. $\pi \varepsilon ́ \lambda o \mu \alpha \imath$ 'movimentar-se ao redor'

Ambiente Fonológico:

Posição da síncope: Não há síncope (N)

Quantidade de Sílabas: 3

- amfiret (Osco) 'cercar' ( $3^{\mathrm{a}}$ pl., pres., ind.)

Ocorrência

Cm 1B19/20

Análise

*am(bi)-fer-ent > amfret

Benediktsson (1960: 189)

*amferent > amfret ( $3^{\mathrm{a}}$ pl., pres., ind.)

Síncope em formas tri- ou quadrissilábicas com uma vogal longa na terceira sílaba.

Ambiente Fonológico:

Consoantes adjacentes: f_r

Posição da síncope: Segunda sílaba (SM)

Quantidade de Sílabas: 3

- ampe(n)tu, apentu (Úmbrio)

'aproximar-se' (imp.)
Ocorrências

ampentu: IIa 20; III 23

ampetu: IIb 10; IIb 11

apentu: III 27

Análise

A etimologia apresentada por Benediktsson já não é mais aceita pela maioria dos estudiosos.

Benediktsson (1960: 175)

*-pendetōd > ampe(n)tu, apentu (imp.)

Síncope em formas tri- ou quadrissilábicas com uma vogal longa na terceira sílaba.

Cognato itálico: lat. pendō 'eu estou pendurado'

Meiser (1986: 162-165)

Tradicionalmente, relaciona-se o verbo ampentu a *(s)pend- 'puxar', como no latim pendo.

Weiss (2010: 164)

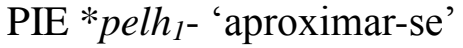

$*_{-}$peln(e)- > penn- (pres.)

$\mathrm{O} / \mathrm{h} / \mathrm{em}$ ampentu seria apenas um infixo nasal de presente.

Ambiente Fonológico:

Posição da síncope: Não há (N)

Quantidade de Sílabas: 3

- amprehtu, apretu (Úmbrio) 'levar (os animais) para uma volta' (imp.)

Ocorrências

amprehtu: Ib 21

apretu: Ib 20 
amprefru $\{\mathbf{u}\} \mathbf{s :}$ Ib 20

$\underline{\text { Análise }}$

*am-pre-ei-tōd > amprehtu

Não há síncope.

Benediktsson (1960: 189)

PIt. *amfereitōd > amprehtu, apretu (imp.)

Síncope em formas tri- ou quadrissilábicas com uma vogal longa na terceira sílaba.

Poultney (1959: 143)

*amber-ei-tod > amprehtu

Untermann (2000: )

*am-pre-ei-tōd > amprehtu

Vetter (1953: 183)

$* a(m b i)$-pre-etu $>$ apretu

amprehtu: com $h$ para ênfase

Ambiente Fonológico:

Posição da síncope: Não há (N)

Quantidade de Sílabas: 4

- a(n)tentu (Úmbrio) 'erguer até o topo' (imp.), ententu (Úmbrio) 'inserir' (imp.)

Ocorrências

andendu: VIIa 46

antentu: IIa 20; III 15; III 16; III 17; III 17; III 22; IV 21; IV 27

atentu: IIb 28

endendu: VIb 40; VIb 40; VIb 49

ententu: Ib 12; III 15

Análise

Ambas as etimologias, a que relaciona tentu ao lat. tendō e a que relaciona ao lat. tollō, apresentam uma vogal sincopada. Apesar de as duas funcionarem bem fonologicamente, a segunda etimologia parece ser uma solução semanticamente melhor e por isso a etimologia apresentada por Benediktsson já não é mais aceita pela maioria dos estudiosos.

Benediktsson (1960: 175-6)

PIt. *-tendetōd > a(n)tentu, andendu (imp.)

Síncope em formas tri- ou quadrissilábicas com uma vogal longa na terceira sílaba.

Cognato itálico: lat. tendō 'alongar'

Meiser (1986: 162-165)

Tradicionalmente, relaciona-se o verbo endendu a *tend- 'alongar', como no latim tendo. No entanto, semanticamente faz mais sentido:

*-telnatōd $>*$ en-tennatōd $>$ endendu

Cognato itálico: tollōo 'erguer'

Untermann (2000: 742)

$*^{*}$ telh $_{2^{-}}>$-tentu + an- = antentu, andendu ( $3^{\text {a }}$ sg., imp.) 'ficar no topo' (talvez)

$*^{*}$ elh $_{2^{-}}>$-tentu + en- $=$ententu, endendu ( $3^{\mathrm{a}} \mathrm{sg} .$, imp.) 'inserir' (talvez)

${ }^{*} t_{e} l h_{2^{-}}>-$tentu + per- $=$pertentu $\left(3^{\mathrm{a}}\right.$ sg., imp.) 'deitar-se estendido' (talvez) $* t e l 2_{2^{-}}>-t e n t u+s u(p)-=$ sutentu $\left(3^{\mathrm{a}}\right.$ sg., imp.) (significado desconhecido)

Cognato itálico: tollō 'erguer'

Weiss (2010: 119n71) 
antentu e ententu são compostos de $* / \mathrm{t} \varepsilon \mathrm{n}: \mathrm{V}-/<* t e \ln V-<\mathrm{PIE} * t^{-} l_{h} 2_{2^{-}}$ 'erguer'

Cognato itálico: lat. tollō 'erguer'

*an-telnetod > antentu

Ambiente Fonológico:

Consoantes adjacentes: $n \_t$

Posição da síncope: Segunda sílaba + preposição (SM)

Quantidade de Sílabas: 3

- ařkkani (Úmbrio) 'canto ritual' (acs., sg., n.)

Ocorrência

IV 28

Análise

*ad-kan-iiiom > ařkani

Cronologia relativa: *ados-kan-iiom > *ar̆-kan-iiiom > ařkani

Benediktsson (1960: 229)

*-kaniom > ařkani (nom./acs., sg., n.)

Em sílabas finais, qualquer vogal breve era sincopada depois de $-i$, mesmo antes de outras consoantes que não $-S$.

Nominativo / acusativo singular neutro e acusativo singular masculino de temas em -io: *iom > -im.

\section{Buck (1904: 83)}

A presença de $\check{\mathbf{r}}, r s$ antes e depois de consoantes indica que houve síncope de uma vogal ou uma mudança da posição intervocálica. É o caso do prefixo ař-, ars-.

Meiser (1986: 60) *ad-kaniom > ařkani (acs., sg.)

Untermann (2000: 50-51)

Possivelmente da raiz *kan (lat. canere 'cantar'; umb. kanetu 'tocar' um instrumento)

Weiss (2010: )

ado-kaniiom > ado-kanim > aro-kanim $>$ ařkanim > ařknim > por analogia ar̆kani

Ambiente Fonológico:

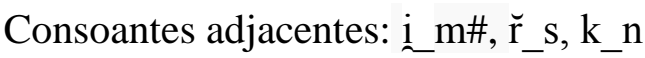
Posição da síncope: Última sílaba (SF), última sílaba (SF no prefixo), terceira sílaba (SM)

Quantidade de Sílabas: 4

- arsmor (Úmbrio) 'rito' (nom., pl.)

Ocorrências arsmo: VIa 30; VIa 32; VIa 39; VIa 42; VIa 52; VIb 13; VIb 32; VIb 34; VIIa 17; VIIa 30

arsmor: VIa 26; VIa 36; VIa 46; VIb 29 asmo: VIa 49

Análise

É difícil estabelecer qual vogal foi sincopada, mas parece claro que houve alguma: *adVma- $(* a d V s m a-)>$ arsmor Benediktsson (1960: 235)

*ademā > arsmor (nom., pl.),

Outras formas: a(r)smo (acs., pl.)

Cognatos: IrA. adem, aidme (gen, sg)

'ferramenta'

Ambiente Fonológico:

Consoantes adjacentes: $d \_m$ 
Posição da síncope: Segunda Sílaba (SM)

Quantidade de Sílabas: 3

- Atiersir (Úmbrio) 'Artirse' (gentílico ou nome de uma fraternidade) (dat., pl.)

Ocorrências

atiersir: $\mathrm{Vb} 8 ; \mathrm{Vb} 14$

Análise

Atiersir (dat., pl.)

Não há síncope.

Benediktsson (1960: 216, 268)

*atiiedios $>$ Atiersir (nom., sg.)

Antes de $-s$ final, toda vogal breve é sincopada (-V̌Vs\#> -s\#).

Ambiente Fonológico:

Posição da síncope: Não há síncope (N)

Quantidade de Sílabas: 4

- Aukíl (Osco) 'Aquil'(sobrenome)

(nom., sg.)

Ocorrência

Cm 10

Análise

*-ilos > Aukíl (nom., sg.)

Benediktsson (1960: 216)

*aukílos > Aukíl (nom., sg.)

Antes de $-s$ final, toda vogal breve é sincopada (-V̆ $s \#>-s \#)$.

Depois da síncope: -1s\# > -l\#

Buck (1904: 116)

*-ilos > Aukíl

Ambiente Fonológico:

Consoantes adjacentes: 1_s\#
Posição da síncope: Última Sílaba (SF)

Quantidade de Sílabas: 3

- avis, aves (Úmbrio) 'aves' (dat./abl., pl.)

Ocorrências

aves: Ia 1

avis: IIa 16

aиeis: VIa 1

Análise

*auifos > avis, aves, aueis

Benediktsson (1960: 222)

*auifos > avis, aves, aueis (dat./abl., pl.)

Dativo / ablativo plural de temas em $-i$, $-u,-e$ e em consoante: $*_{-f o s}>-f s>-s(s)$

Ambiente Fonológico:

Consoantes adjacentes: f_s\#

Posição da síncope: Última Sílaba (SF)

Quantidade de Sílabas: 3

- bantins (Osco) 'Bantino' (cidadão de Banto) (nom., sg.)

Ocorrência

Lu 1, 19

Análise

*bantīnos > bantins (nom., sg.)

*-ns por síncope > $-n s$; mas Benediktsson segue a lógica antiga de Buck (1904: 73) de que original $*_{-} n s$ se torna $-s s$ em úmbrio, na verdade $*_{-} n s>$ umb. $-f$.

$\underline{\text { Benediktsson (1960: 216) }}$

Antes de $-s$ final, toda vogal breve é sincopada $(-\breve{V} s \#>-s \#)$. 
Final secundário $-n s$ foi mantido em osco e também em úmbrio, enquanto o original $*_{-} n s$ se tornou $-s s$.

Meiser (1986: 59)

*bantīnos > bantins (nom., sg.)

Ambiente Fonológico:

Consoantes adjacentes: n_s\#

Posição da síncope: Última Sílaba (SF)

Quantidade de Sílabas: 3

- berus (Úmbrio) ‘estacas’ (abl., pl.)

Ocorrências

IIa 23; IIa 35

Análise

* guerufos $>$ berus

Benediktsson (1960: 222)

* $g^{u}$ erufos > berus (dat./abl., pl.)

Cognato itálico: lat. ueru 'estaca'

Dativo / ablativo plural de temas em $-i$,

$-u,-e$ e em consoante: ${ }^{*}-f o s>-f s>-s(s)$

Untermann (2000: 145)

berus (abl., pl.)

Outras formas: berva (acs., pl.)

Ambiente Fonológico:

Consoantes adjacentes: f_s\#

Posição da síncope: Última Sílaba (SF)

Quantidade de Sílabas: 3

- cebnust (Osco) (significado desconhecido) ( $3^{\mathrm{a}}$ sg., pres., ind.)

Ocorrência

Lu 1, 20

Análise

*ke-benust > cebnust
Benediktsson (1960: 187)

*ke-g $g^{u}$ enust > cebnust ( $3^{\mathrm{a}}$ sg., pres., ind.)

Síncope em formas tri- ou quadrissilábicas com uma vogal longa na terceira sílaba.

Ambiente Fonológico:

Consoantes adjacentes: b_n

Posição da síncope: Segunda Sílaba (SM)

Quantidade de Sílabas: 3

- censtur (Osco) 'censores' (nom., pl.)

Ocorrências

Lu 1, 18; Lu 1, 20; Lu 1, 27; Lu 1, 28;

Lu 129

Análise

*-tōres > censtur

Benediktsson (1960: 219)

*-tōres > censtur (nom., pl.)

Antes de $-s$ final, toda vogal breve é sincopada (- $\breve{V} s \#>-s \#)$.

Nominativo plural masculino $\mathrm{e}$ feminino de temas terminados em consoantes: $*_{-} e s>-s$.

Ambiente Fonológico:

Consoantes adjacentes: $r \_s \#$

Posição da síncope: Última Sílaba (SF)

Quantidade de Sílabas: 3

- ceus (Osco) ‘cidadão’ (nom., sg.)

Ocorrência

Lu 1, 19

Análise 
Empréstimo

Benediktsson (1960: 218)

*keiuis > ceus (nom., sg.)

Cognato itálico: lat. cìuis

Antes de $-s$ final, toda vogal breve é sincopada (-V̆ $s \#>-s \#)$.

Nominativo singular de temas em $-i$ : - $_{-}$ is $>$-s.

Ambiente Fonológico:

Posição da síncope: Não há síncope (N /

E)

Quantidade de Sílabas: 3

- contrud (Osco) 'contra'

Ocorrências

Lu 1,11; Lu 1, 17; Lu 1, 25; Lu 1, 33 frag.

Análise

Adjetivos construídos com o sufixo *_ tero apresentam síncope vocálica.

*kom-tero- > contrud

Untermann (2000: 417)

*kom-tero- > contrud (abl., sg., m./n.)

Cognato itálico: lat. contrā 'contra'

Ambiente Fonológico:

Consoantes adjacentes: $t \_r$

Posição da síncope: Segunda sílaba (SM)

Quantidade de Sílabas: 3

- dadid (Osco) 'dar' (3ª sg., subj., perf.)

Ocorrência

Cp 37,4

Análise *dād-dedēt $>$ dadid

Não é possível saber se a forma seria /dadid/ ou /daddid/, pois a inscrição na qual a forma aparece não explicita consoantes geminadas na escrita.

Benediktsson (1960: 189)

*dad-detêt > dadid ( $3^{\mathrm{a}}$ sg., subj., perf.)

Síncope em formas tri- ou quadrissilábicas com uma vogal longa na terceira sílaba.

Ambiente Fonológico:

Consoantes adjacentes: $\mathrm{d} \_\mathrm{t}$

Posição da síncope: Segunda Sílaba (SM)

Quantidade de Sílabas: 3

- destr- (Osco e Úmbrio) 'direita'

Ocorrências

umb. destruco: VIb 24; VIb 38

osc. destrst: $\mathrm{Cp} 8$

Análise

Adjetivos construídos com o sufixo *tero apresentam síncope vocálica.

Duas síncopes mediais: *deksi-tero- > *destero- > destro-

Benediktsson (1960: 213)

*deksi-tero- > *destero- > destro-

Síncope em formas tri- ou quadrissilábicas com uma vogal longa na terceira sílaba.

Untermann (2000: 170)

Cognato itálico: lat. dexter

Ambiente Fonológico:

Consoantes adjacentes: $s \_t, t \_r$ 
Posição da síncope: Segunda sílaba (SM) e terceira sílaba (SM)

Quantidade de Sílabas: 4

- dirstu, teřtu (Úmbrio) 'dar' (imp.)

$\underline{\text { Ocorrências }}$

dirstu: VIb 17; VIb 38; VIb 38; VIb 39;

VIIa 5

teřtu: IIa 40; IIa 40; IV 28

Análise

Tendo em mente que em úmbrio $* \mathrm{VdV}$ $>\mathrm{VrV}$, podemos traçar uma cronologia relativa: PIt. *didatōd > diratod > dirstu, teřtu. Isso significa que a mudança do /d/ intervocálico ocorreu antes da síncope em sílaba medial e que a síncope vocálica não pode ser considerada um fenômeno Proto-Itálico, uma vez que o /d/ intervocálico não se transforma em /r/ em osco.

Benediktsson (1960: 189)

*didatōd $>$ dirstu, teřtu

Síncope em formas tri- ou quadrissilábicas com uma vogal longa na terceira sílaba.

Ambiente Fonológico:

Consoantes adjacentes: d_t

Posição da síncope: Segunda Sílaba (SM)

Quantidade de Sílabas: 3

- duti (Úmbrio) 'segunda vez'(acs., sg., n.)

Ocorrência
VIb 63

Análise

*dutiiom > duti

Benediktsson (1960: 229)

*dutiom > duti (nom./acs., sg., n.)

Em sílabas finais, qualquer vogal breve era sincopada depois de $-i$, mesmo antes de outras consoantes que não $-s$.

Nominativo / acusativo singular neutro e acusativo singular masculino de temas em -io: *iom > -im.

Untermann (2000: 193-4)

*du-tio-m $>$ duti (acs., sg., n.)

Ambiente Fonológico:

Consoantes adjacentes: $\underset{\sim}{\mathrm{i}} \mathrm{m} \#$

Posição da síncope: Segunda Sílaba (SF)

Quantidade de Sílabas: 2

- efidans (Piceno Meridional) 'Efidano' (cognome ou epíteto) (nom., sg.)

Ocorrência

AP 5

$\underline{\text { Análise }}$

*-nos > efidans

$*_{-} n s$ \# original $>-f$, como em vitluf $<*_{-}$ ns (acs, sg, m) e umb. klavlaf $<*_{-} n s$ (acs, pl), enquanto ${ }^{*} n s$ por síncope $>$ $n s$.

Ambiente Fonológico:

Consoantes adjacentes: n_s\# Posição da síncope: Última Sílaba (SF)

Quantidade de Sílabas: 4 
- embratur (Pelígio) 'imperador' (nom., sg.)

Ocorrência

nPg 6a; nPg 6b

Análise

Empréstimo

Benediktsson (1960: 189)

*emparātōr > embratur (nom., sg.)

Síncope em formas tri- ou quadrissilábicas com uma vogal longa na terceira sílaba.

Ambiente Fonológico:

Consoantes adjacentes: $\mathbf{p} \_r$

Posição da síncope: Segunda Sílaba (SM / E)

Quantidade de Sílabas: 4

- emps (Úmbrio) 'comprado' (part. pass.)

Ocorrência

Um 10

Análise

Empréstimo

Benediktsson (1960: 216)

*emtos > emps (part. pass)

Antes de $-s$ final, toda vogal breve é sincopada (-V̌s\# > -s\#).

Nom. sg. de temas em $-O:{ }^{*}-o s>-s$.

Untermann (2000: 193-4)

Significado: 'pegar' $\rightarrow$ 'comprar' ou

'aceitar' $\rightarrow$ 'comprar'

Ambiente Fonológico:

Consoantes adjacentes: $t \_s \#$
Posição da síncope: Última Sílaba (SF /

E)

Quantidade de Sílabas: 2

- Entraí (Osco) 'Entre' (nome próprio ou epíteto) (dat., sg.)

Ocorrências

Sa 1A8; Sa B10

Análise

*enterāi > Entraí

Benediktsson (1960: 241)

*enteräi > Entraí (dat., sg.)

Cognato itálico: lat. interior 'interior'

Cognato: véd. ántara- 'interior'

Untermann (2000: 226)

*h $h_{1}$ en-tero-/ā $>$ entraí

Ambiente Fonológico:

Consoantes adjacentes: $t \_r$

Posição da síncope: Segunda Sílaba (SM)

Quantidade de Sílabas: 3

- esono-, esunu (Úmbrio) ‘divino' (acs., sg. / nom., pl.)

Ocorrência

esona: VIa 3; VIa 5

esone: $\mathrm{VIb} 11$

esoneir: VIa 18

esono: VIa 57; VIb 47

esonome: VIb 50 (frag.); VIb 52

esuna: Va 5

esunesku: Va 11

esune: Va 4; Va 6 
esunu: Ib 8; Ib 9; Ib 38; IIa 2; IIa 2 (frag.); IIa 20; IIa 21; IIa 42; III 1; III 14; IV 30

esunume: Ib 14

esunumen: III 20

Análise

*aizezōno- > aizzono- > esono-

Benediktsson (1960: 173)

*aizezōno- > aizzono- > esono-

Síncope em formas tri- ou quadrissilábicas com uma vogal longa na terceira sílaba.

Ambiente Fonológico:

Consoantes adjacentes: $z_{-}$z

Posição da síncope: Segunda Sílaba (SM)

Quantidade de Sílabas: 4

- etre (Úmbrio) ‘outro’ (acs., sg., f.)

Ocorrências

etrama: III 34

etre: IIb 2; IIb 3; IIb 3; IIb 4; IIb 4; IIb

5; IIb 5; IIb 6; IIb 6; IIb 14

etru: VIa 35; VIa 38; VIa 43

Análise

*eter- > etre

Benediktsson (1960: 241)

*eter- > etre (acs., sg., f.)

Outras formas: etre (dat., sg.), etru (ab.l, sg., n.)

Cognato itálico: lat. cèterī 'outro'

Ambiente Fonológico:

Consoantes adjacentes: $t \_r$
Posição da síncope: Segunda Sílaba (SM)

Quantidade de Sílabas: 3

- factud (Osco) 'fazer' (imp.)

Ocorrência

$\mathrm{Lu} 1,9$

Análise

*fakitōd > factud

Benediktisson (1960: 178)

*pakitōd > factud (imp.)

Síncope em formas tri- ou quadrissilábicas com uma vogal longa na terceira sílaba.

Cognato itálico: lat. faciō 'fazer'

Ambiente Fonológico:

Consoantes adjacentes: $\mathrm{k} \_\mathrm{t}$

Posição da síncope: Segunda Sílaba (SM)

Quantidade de Sílabas: 3

- famel (Pelígio) 'escravo'

Ocorrência

Pg 11

Análise

*famelos $>$ famels $>$ famel

Benediktsson (1960: 216)

*famelos > famels > famel (nom., sg.)

Cognato itálico: lat. famulus

Antes de $-s$ final, toda vogal breve é sincopada $(-\breve{V} s \#>-s \#)$.

Depois da síncope: $-l s \#>-l \#$

Ambiente Fonológico:

Consoantes adjacentes: 1_s\# 
Posição da síncope: Última Sílaba (SF)

Quantidade de Sílabas: 3

- felsva (Úmbrio) 'significado desconhecido'

Ocorrência

Va 11

$\underline{\text { Análise }}$

A etimologia mais plausível é a apresentada por Meiser, a que não apresenta empecilhos morfofonológicos e que funciona semanticamente. Nesse caso, não se pode falar de síncope, pois nessa solução não há vogal breve a ser sincopada

Benediktsson (1960: 260) \& Buck (1904: 94)

*xelesuā > felsva 'vegetal'

Cognato itálico: lat. holus

Meiser (1988: 169)

$*^{h} b^{h} e^{h}{ }^{h}$-os $>* f e l \chi-s-u \bar{a}>$ felsva 'festival'

Vetter (1953: 223-4)

Cognato itálico: lat. follis 'dinheiro'

Ambiente Fonológico:

Posição da síncope: Não há (N)

Quantidade de Sílabas: 3

- fertlid (Pelígio) 'fértil' (abl., sg.)

Ocorrência

$\operatorname{Pg} 9$

Análise

* fertVlìd $>$ fertlid

Benediktsson (1960: 259)

*fertelìd > fertlid (abl., sg.)
Cognato itálico: lat. fertilis

Ambiente Fonológico:

Consoantes adjacentes: t_l

Posição da síncope: Segunda Sílaba (SM)

Quantidade de Sílabas: 3

- fertu (Úmbrio) 'fazer' (imp.)

Ocorrências

VIb 50; VIb 50

Análise

É difícil estabelecer se houve síncope ou não, uma vez que não se sabe se o verbo era atemático ou não. Portanto, há duas possibilidades de reconstrução: 1) *feretōd > fertu; 2) *fertōd > fertu.

\section{Benediktsson (1960: 165)}

*feretōd > fertu (imp.)

Síncope em formas tri- ou quadrissilábicas com uma vogal longa na terceira sílaba.

Ambiente Fonológico:

Consoantes adjacentes: $r \_t$

Posição da síncope: Segunda Sílaba (SM / I)

Quantidade de Sílabas: 4

- filktu (Úmbrio) 'moldar' (imp.)

Ocorrência

Ia 28

Análise

$* d^{h}{ }^{i n g}{ }^{h}$ etō $d>*$ fingetō $d>\mathbf{f i}(\mathbf{n}) \mathbf{k t u}$

Benediktsson (1960: 182)

*pi-g ${ }^{u} e t \bar{o} d$ 'consertar' > fiktu (imp.) 
Síncope em formas tri- ou quadrissilábicas com uma vogal longa na terceira sílaba.

Untermann (2000: 284)

PIE * $d^{h} e i \hat{g}^{h}-$

Cognato itálico: lat. fingere

Ambiente Fonológico:

Consoantes adjacentes g_t

Posição da síncope: Segunda Sílaba (SM)

Quantidade de Sílabas: 3

- fons (Úmbrio) 'gracioso' (nom., sg.)

Ocorrências

fons: VIa 42; VIa 50; VIa 52; VIb 7;

VIb 11; VIb 13; VIb 26; VIb 32; VIb

34; VIIa 13; VIIa 17; VIIa 31; VIIa 49

fos: VIa 23; VIa 30; VIa 33; VIa 40

fon: VIb 26

Análise

*fauVno-> fo $(n) s$

Benediktsson (1960: 218)

* $x^{u}$ ouenis $>$ fo(n)s (nom., sg.)

Antes de $-s$ final, toda vogal breve é sincopada (- $\breve{V} s \#>-s \#)$.

Nominativo singular de temas em $-i: *_{-}$ is $>$-S.

De Vaan (2008: 207)

PIt. *fauVno- > fons

Cognato itálico: lat. faveō 'ser favorável a', lat. Faunus 'Fauno' (rei mítico); 'entidades do campo' (no plural)

Ambiente Fonológico:

Consoantes adjacentes n_s\#
Posição da síncope: Última Sílaba (SF)

Quantidade de Sílabas: 3

- fortis (Osco) 'mais forte' (nom./acs., sg.)

\section{Ocorrência}

Lu 1,12

Análise

Síncope final no sufixo de comparativo *fort-ios > com epêntese *fortiios > *fortiis > fortis (nom/acs, sg)

Benediktsson (1960: 217)

*forktios $>$ fortis (nom./acs., sg.)

Cognato itálico: lat. fortius

Antes de $-s$ final, toda vogal breve é sincopada $\left(-\breve{V}_{s} \#>-s \#\right)$.

Nominativo/Acusativo singular de neutros com temas em $-s: *_{-}-s>-s$.

Ambiente Fonológico:

Consoantes adjacentes: $\underset{\sim}{\mathrm{i}} \mathrm{s} \#$

Posição da síncope: Última Sílaba (SF)

Quantidade de Sílabas: 2

- frater (Úmbrio) 'irmãos' (nom., pl.)

Ocorrências

frater: $\mathrm{Vb} 11$

frater: II 5; Va 1; Va 14; Va 22

frateer: $\mathrm{Vb} 16$

Análise

*frāteres > frater, frat(e)er

Benediktsson (1960: 218)

*fräteres > frater, frat(e)er (nom., pl.)

Cognato: scr. bhrātara- 'irmão' 
Antes de $-s$ final, toda vogal breve é sincopada $(-V s \#>-s \#)$.

Nominativo plural masculino e feminino de temas terminados em consoantes: $*_{-}$es $>-s$.

Ambiente Fonológico:

Consoantes adjacentes: r_s\#

Posição da síncope: Última Sílaba (SF)

Quantidade de Sílabas: 3

- fratreks (Úmbrio) 'fraterno’ (nom., sg.)

Ocorrências

fratreks: $\mathrm{Va} 23 ; \mathrm{Vb} 1$

fratrex: VIIb 1

Análise

*frātrikos > fratreks

Benediktsson (1960: 215)

*frātrikos > fratreks, fratrex (nom., sg.)

Antes de $-s$ final, toda vogal breve é sincopada (-Vs\# > -s\#).

Nominativo singular de temas em $-O$ : $*_{-}$ $o s>-s$.

Meiser (1986: 59)

*frātrikos > fratreks (nom., sg.)

Ambiente Fonológico:

Consoantes adjacentes: k_s\#

Posição da síncope: Última Sílaba (SF)

Quantidade de Sílabas: 3

- fratrus (Úmbrio) 'irmãos’ (dat., pl.)

Ocorrências

Vb 8; Vb 13; VIIb 1

Análise *fratrufos $>$ fratrus

Benediktsson (1960: 222)

*fratrufos $>$ fratrus (dat./abl., pl.)

Dativo / ablativo plural de temas em $-i$, $-u,-e$ e em consoante: ${ }^{*}-f o s>-f s>-s(s)$

Ambiente Fonológico:

Consoantes adjacentes: f_s\#

Posição da síncope: Última Sílaba (SF)

Quantidade de Sílabas: 3

- fruktatiuf (Osco) 'uso' (nom., sg.)

Ocorrência

$\mathrm{Cm} 1 \mathrm{~A} 21$

Análise

*fruge-tātiōn-s $>$ fruktatiuf

Benediktsson (1960: 185)

*fru-g $g^{u}$ etation > fruktatiuf 'uso'

Síncope em formas tri- ou quadrissilábicas com uma vogal longa na terceira sílaba.

Buck (1904: 58)

*fru-g $g^{u}$ etation > fruktatiuf 'fruto'

Em latim, ter-se-ia * fruitātiō

Untermann (2000: 226)

$*$ frū g-i-ta-ōm > *frūktāom > fruktatiuf (nom., sg.)

Ambiente Fonológico:

Consoantes adjacentes: $\mathrm{g} \_\mathrm{t}$

Posição da síncope: Segunda sílaba (SM)

Quantidade de Sílabas: 4

- funtlere, fondlire (Úmbrio) 'Fontler' (nome de um local) (abl., pl.) 
Ocorrências

funtlere: $\mathrm{Ib} 24$

fondlire: VIIa 3

Análise

*fontelo- > funtlere, fondlir

Benediktsson (1960: 238)

*fontelois > funtlere, fondlir (abl., pl.)

Derivativo do lat. fōns

Untermann (2000: 301) \& Buck (1904:

*fontelo- > funtlere, fondlire 'em

Fontler' (local)

Cognato itálico: lat. fōns 'fonte'

Ambiente Fonológico:

Consoantes adjacentes: $\mathrm{t} \_$l

Posição da síncope: Segunda sílaba

(SM)

Quantidade de Sílabas: 3

- Fuvfdis (Osco) 'Fufido' (gentílico)

(nom., sg.)

Ocorrência

Cm 14, 4 f. C2

Análise

Há duas síncopes e de acordo com a cronologia relativa estabelecida por Benediktsson (1960: 258), pode-se afirmar: *foufediios > *foufedis > fuvfdis, ou seja, a síncope final ocorreu antes que a síncope medial.

Benediktsson (1960: 264)

*foufedios > foufedis > Fuvfdis (nom., sg.)

Cognato itálico: lat. Fufidius
Ambiente Fonológico:

Consoantes adjacentes: i $\underset{\sim}{\text { s }} \mathrm{B} \#, \mathrm{f}$ d

Posição da síncope: Última sílaba (SF) e segunda sílaba $(\mathrm{SM})$

Quantidade de Sílabas: 3

- ha(h)tu (Úmbrio) 'tomar' (imp.)

Ocorrências

hahtu: IIa 22

hatu: Ib 11

Análise

*habitod $>$ ha(h)tu

Benediktsson (1960: 187)

*xabitōd > ha(h)tu (imp.)

Síncope em formas tri- ou quadrissilábicas com uma vogal longa na terceira sílaba.

Meiser (1986: 126)

*habitōd > ha(h)tu (imp.)

Ambiente Fonológico:

Consoantes adjacentes: $\mathrm{b} \_t$

Posição da síncope: Segunda sílaba

(SM)

Quantidade de Sílabas: 3

- herekleís (Osco) 'Hércules’ (gen., sg.)

$\underline{\text { Ocorrências }}$

herekleís: $\mathrm{Cm}$ 1A11; $\mathrm{Cm}$ 1A24; $\mathrm{Cm}$

B4; Cm B6

hereklúí: Sa 1A13; Sa B16

herclei: Pg 6; Pg 7; Pg 56

herclit: $\mathrm{Pg} 41$

herclo: MV 5

Análise 
Muito provavelmente trata-se de um empréstimo, porém não se sabe se a palavra veio diretamente do grego ou por influência etrusca. Se for um empréstimo grego, então houve uma síncope: *herakleis > *herkleis > com anaptixe herekleís. No entanto, se for um empréstimo etrusco, é provável que a síncope tenha ocorrido já no etrusco: hercle > com anaptixe herekleís.

Benediktsson (1960: 270)

*herakleis > *herkleis > com anaptixe

Herekleís (gen., sg.)

Vest. herclo: empréstimo do gr.

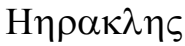

$\underline{\operatorname{Rix}(2004: 440-445)}$

A forma Herecles (a qual aparece em uma peça do séc. V a.C.), usualmente tida como etrusca, é na verdade latina.

Ambiente Fonológico:

Consoantes adjacentes: $\mathrm{r} \_\mathrm{k}$

Posição da síncope: Segunda sílaba (SM)

Quantidade de Sílabas: 3

- herte(r) (Úmbrio) 'ser necessário' (3 sg, pres. pass.)

Ocorrências

herte: Va 6; Va 8; Va 10

herter: IIa 40; III 1

pisher: VIb 41

Análise

$*$ heriter $>$ herte(r)

Benediktsson (1960: 237) *xeriter $>$ herte(r) ( $3^{\text {a }}$ sg, pres. pass.)

Nussbaum (1976: 252-3)

Pode-se relacionar a forma umb. pisher (*pis herit) à forma herter e ambas possuem sentido médio-passivo ('ser necessário'). Outras formas construídas com -io-, como umb. heris, heriest não podem ser relacionadas às duas primeiras e possuem o sentido 'querer'.

$\underline{\operatorname{Rix}(2001: 223)}$

Significado passivo

Ambiente Fonológico:

Consoantes adjacentes: $r \_t$

Posição da síncope: Segunda sílaba (SM)

Quantidade de Sílabas: 3

- homonus (Úmbrio) 'homens' (dat., pl.)

Ocorrências

Vb 10; Vb 15

Análise

*homonufos $>$ homonus

Benediktsson (1960: 222)

*homonufos > homonus (dat./abl., pl.)

Dativo / ablativo plural de temas em $-i$, $-u,-e$ e em consoante: $*_{-f o s}>*_{-} f s>-$ $s(s)$

Ambiente Fonológico:

Consoantes adjacentes: f_s\#

Posição da síncope: Última sílaba (SF)

Quantidade de Sílabas: 4 
- huntrus, hutra (Osco e Úmbrio) 'inferior'

Ocorrências

osc. huntrus: Cp 37, 11; Cp 37, 11 (frag.)

osc. húnttram: $\mathrm{PO} 1$

osc. hu[n]truis: p 37, 7

umb. hondra: VIa 15; VIIa 52

umb. hutra: Ib 42

Análise

Adjetivos construídos com o sufixo

*-tero apresentam síncope vocálica.

*hontero- > huntrus (nom./acs., pl.)

Cognato itálico: lat. humus 'terra'

Benediktsson (1960: 213)

*xontero- > hontro-

Cognato itálico: umb. hondomo- 'a parte mais inferior possível'

Ambiente Fonológico:

Consoantes adjacentes: $t \_r$

Posição da síncope: Segunda sílaba

Quantidade de Sílabas: 3

- humuns (Osco) 'homens' (nom., pl.)

Ocorrências

Cp 37, 9

Análise

*homones $>$ humuns

$\mathrm{Na}$ inscrição na qual se escontra esta forma não há letras modificadas, ou seja, não há distinção entre vogais longas e breves. O mais provável é que o /o/ medial seja uma vogal breve, assim como a forma dat/abl pl. homonus.

Benediktsson (1960: 219)

*humōnes > humuns (nom., pl.)

Cognato itálico: lat. hemōnem

Antes de $-s$ final, toda vogal breve é sincopada $\left(-\breve{V}_{S} \#>-s \#\right)$.

Nominativo plural masculino $\mathrm{e}$ feminino de temas terminados em consoantes: *-es $>-s$.

Weiss (2009: 205, 468)

*homones $>$ humuns

Cognato itálico: lat. homō 'homem'

Ambiente Fonológico:

Consoantes adjacentes: $n \_s \#$

Posição da síncope: Última sílaba (SF)

Quantidade de Sílabas: 3

- húrz (Osco) 'bosque' (nom., sg.)

Ocorrência

Sa 1B23

Análise

*xortos > húrz

Benediktsson (1960: 216)

*xortos > húrz

Antes de $-s$ final, toda vogal breve é sincopada $(-\breve{V} s \#>-s \#)$.

Meiser (1986: 59)

* yortos > húrz (nom., sg.)

Untermann (2000: (334-5)

Cognato itálico: lat. hortus 'jardim'

Ambiente Fonológico:

Consoantes adjacentes: t_s\#

Posição da síncope: Segunda sílaba (SF) 
Quantidade de Sílabas: 2

- iouies (Úmbrio) 'rapazes' (dat./abl., pl.)

Ocorrências

VIb 62; VIIa 13; VIIa 14; VIIa 28; VIIa 50; VM 4 (i]ouies)

Análise

*-êfos > iouies

Cognato itálico: lat. iuuenis 'jovens'

Benediktsson (1960: 222)

*-êfos > iouies (dat./abl., pl.)

Dativo / ablativo plural de temas em $-i$, $-u$, - $e$ e em consoante: ${ }_{-}-f o s>-f_{s}>-$ $s(s)$

Ambiente Fonológico:

o > 0 / f_s\#

Consoantes adjacentes: f_s\#

Posição da síncope: Última sílaba (SF)

Quantidade de Sílabas: 4

- kanetu (Úmbrio) 'cantar' (imp.)

Ocorrência

IV 29

Benediktsson (1960: 200)

*kanetōd > kanetu

Não há síncope nessa forma.

Possivelmente a forma provém de um verbo da segunda conjugação e o /e/ medial era longo.

$\underline{\text { Schirmer (1998) }}$

Verbo causativo, e verbos causativos normalmente fazem parte da $2^{\mathrm{a}}$ conjugação.
Ambiente Fonológico:

Posição da síncope: Não há síncope (N)

Quantidade de Sílabas: 3

- kartu (Úmbrio) 'distribuído'

Ocorrência

IIa 23

Análise

*karVto- > kartu ( $3^{\mathrm{a}} \mathrm{sg}$, impf.)

Benediktsson (1960: 164)

*karetōd, *karitōd > kartu $\left(3^{\mathrm{a}} \mathrm{sg}\right.$., impf.)

Síncope em formas tri- ou quadrissilábicas com uma vogal longa na terceira sílaba.

Ambiente Fonológico:

Consoantes adjacentes: $r \_t$

Posição da síncope: Segunda sílaba

(SM)

Quantidade de Sílabas: 3

- karnus (Úmbrio) 'partes' (dat./abl., pl.)

Ocorrência

IV 7

Análise

*karnufos > karnus

Benediktsson (1960: 222)

*karnufos > karnus (dat./abl., pl.)

Dativo / ablativo plural de temas em $-i$, $-u,-e$ e em consoante: $*_{-} f o s>-f s>-s(s)$

Ambiente Fonológico:

Consoantes adjacentes: f_s\# 
Posição da síncope: Última sílaba (SF)

Quantidade de Sílabas: 3

- katel (Úmbrio) 'filhote de cachorro' (nom., sg.)

Ocorrência

IIa 43

Análise

*katelos > katel Cognato itálico: lat. catulus

Benediktsson (1960: 216)

*katelos > katel (nom., sg.)

Antes de $-s$ final, toda vogal breve é sincopada (-V̆ $s \#>-s \#)$.

Nom. sg. de temas em $-o: *_{-}-o s>-s$.

Ambiente Fonológico:

Consoantes adjacentes: 1_s\#

Posição da síncope: Última sílaba (SF)

Quantidade de Sílabas: 3

- katlu (Úmbrio) 'filhote de cachorro' (acs., sg.)

Ocorrências

katlu: IIa 18; IIa 20; IIa 29

katle: IIa 15

katles: IIa 22; IIa 27

Análise

*katelo- > katlu

Cognato itálico: lat. catellus 'filhote'

Benediktsson (1960: 238)

*katelom > katlu (acs., sg.)

Outras formas: katle(s) (gen., sg.)

Ambiente Fonológico:
Consoantes adjacentes: t_1

Posição da síncope: Segunda sílaba (SM)

Quantidade de Sílabas: 3

- Kavkdis (Osco) 'Caucideu' (gentílico) (nom., sg.)

Ocorrência

Cm 14

Análise

Há duas síncopes, e de acordo com a cronologia relativa estabelecida por Benediktsson (1960: 258), pode-se afirmar: *kaukediios > *kaukedis > kavkdis, ou seja, a síncope final ocorreu antes que a síncope medial.

Benediktsson (1960: 264)

*kaukedios > Kaukdis (nom., sg.)

Cognatos itálicos: lat. Caucideius

Ambiente Fonológico:

Consoantes adjacentes: $\underset{\sim}{\mathrm{i}} \mathrm{s} \#, \mathrm{k}$ _d

Posição da síncope: Última sílaba (SF) e segunda sílaba $(\mathrm{SM})$

Quantidade de Sílabas: 4

- kazi (Úmbrio) ‘nó cego’ (acs., sg.)

Ocorrências

III 16; III 18

Análise

Duas síncopes, sendo que a cronologia relativa seria: *kates-iinom > *katesim > kazi.

Benediktsson (1960: 263) 
Etimologia incerta: *katesiom > Quantidade de Sílabas: 3

*katesim > kazi (acs., sg.)

Vetter (1953: 214) \& von Planta (1892:

$\underline{392)}$

Cognato itálico: lat. catīnus

Weiss (2012: 127)

*kates-iiom > *katesim > kazi 'nó cego"

Cognatos itálicos: lat. catēna (<

*katesna) 'corrente'

Ambiente Fonológico:

Consoantes adjacentes: $\underset{\sim}{\mathrm{i}} \mathrm{m} \#, \mathrm{t} \_\mathrm{s}$

Posição da síncope: Última sílaba (SF) e segunda sílaba $(\mathrm{SM})$

Quantidade de Sílabas: 4

- klavlaf (Úmbrio) 'estaca’ (acs., pl.)

Ocorrências

klavlaf: IIa 33

klavles: IIa 36; IV 11

Análise

*klāuelans > klavlaf

Benediktsson (1960: 172)

*klāuelans > klavlaf (acs., pl.)

Outras formas: klavles (abl., pl.)

Síncope em formas tri- ou quadrissilábicas com uma vogal longa na terceira sílaba.

Buck (1904: 331)

- Kerrí, Keri (Osco) ‘Ceres’ (dat., sg.)

Ocorrências

kerrí: Sa 1 A3; Sa 1 B7

keri: Cp 37 A1; Cp 37 A3; Cp 37 A12; Cp37 B

*klāuela- > klavlaf, klavles

Cognatos itálicos: lat. clāua, clāuola

Vetter (1953: 391)

Cognatos itálicos: lat. claunulas, clunes

Ambiente Fonológico:

kerí: tSa 27; tSa 30

Análise

*keresē > kerrí, keri

Benediktsson (1960: 166)

Consoantes adjacentes: $\underline{\sim}_{-} \_$

Posição da síncope: Segunda sílaba (SM)

Quantidade de Sílabas: 3

*keresē > kerrí, keri (dat., sg.)

Cognato itálico: lat. Ceres

Síncope em formas tri- ou quadrissilábicas com uma vogal longa na terceira sílaba.

Ambiente Fonológico:

Consoantes adjacentes: $\mathrm{r} \_s$

Posição da síncope: Segunda sílaba

- krapuvi (Úmbrio) 'Graboio (epíteto de Júpiter ou de Marte) (dat., sg.)

Ocorrências

krapuvi: Ia 3; Ia 11; Ia 21

graboue: VIa 24; VIa 25

grabouei: VIa 22; VIb 1

graboui: VIa 23

grabouie: VIa 25; VIa 26; VIa 27; VIa

28; VIa 29; VIa 29; VIa 31; VIa 32; VIa 
33; VIa 34; VIa 35; VIa 36; VIa 31; VIa

37; VIa 31; VIa 38; VIa 38; VIa 39; VIa

41; VIa 41; VIa 43; VIa 44; VIa 45; VIa

46; VIa 47; VIa 48; VIa 48; VIa 49; VIa

51; VIa 51; VIa 53; VIa 54; VIa 55; VIb

19

Análise

Não há síncope

*grabouiioi > krapuvi

Benediktsson (1960: 216, 268)

*grabōuiōi > krapuvi, Grabouie (dat., sg.)

Ambiente Fonológico:

Posição da síncope: Não há síncope (N)

Quantidade de Sílabas: 4

- ligis (Osco) ‘leis’ (dat./abl., pl.)

Ocorrência

Lu 1, 25

Análise

*legifos $>$ ligis

Talvez um empréstimo, mas não há como ter certeza.

Benediktsson (1960: 222)

*legifos > ligis (dat./abl., pl.)

Dativo / ablativo plural de temas em $-i$, $-u,-e$ e em consoante: $*_{-} f o s>*_{-}-f_{s}>-$ $s(s)$

Ambiente Fonológico:

Consoantes adjacentes: f_s\#

Posição da síncope: Última sílaba (SF)

Quantidade de Sílabas: 3
- Lúvkis (Osco / Pelígio) 'Lúcio’ (nom., sg.)

Ocorrências

lúvkis: Cp 36 7; Fr 6; nPg 7; Sa 24

I(úvkis): Cm 2; M 10; Po 39

Análise

*loukios > lúvkis

Meiser (1986: 60)

*loukios > lúvkis (nom., sg.)

$\mathrm{V}>0 / \mathrm{i}, \mathrm{u}, \mathrm{r}, 1_{-} \mathrm{s} \#$

Ambiente Fonológico:

Consoantes adjacentes: $\underset{\sim}{\mathrm{i}} \mathrm{s} \#$

Posição da síncope: Última sílaba (SF)

Quantidade de Sílabas: 2

- maimas (Osco) ‘máximo’ (gen., sg.,

f.)

Ocorrências

Lu 1, 3; Lu 1, 7

Análise

Superlativo com síncope em ambiente labial.

*maisVmo- > maimas

Benediktsson (1960: 258)

*maisemo- > maimas (gen., sg., f.)

Buck (1904: 76)

*maisemo- > *maizemo > *maizmo- > maimas

$\underline{\text { Weiss (em conersa privada) }}$

*maisVmo- > maimas

$V s V m>\bar{V} m$

Não há como ter certeza de qual é a qual é a vogal, mas a forma pré-samnita Fo $\lambda \alpha \imath \sigma v \mu \rho_{\varsigma}$ sugere $/ \mathrm{u} /$. 
Ambiente Fonológico:

Consoantes adjacentes: s_m

Posição da síncope: Segunda sílaba

Quantidade de Sílabas: 3

- ku-maltu (Úmbrio) ‘triturar’ (imp.)

Ocorrências

IIa 9/10; IIa 41; IV 28

Análise

*maletod $>$ ku-maltu

Cognato itálico: lat. molō 'moer'

Benediktsson (1960: 171)

*maletod > ku-maltu (imp.)

Síncope em formas tri- ou quadrissilábicas com uma vogal longa na terceira sílaba.

Ambiente Fonológico:

Consoantes adjacentes: $1 \_t$

Posição da síncope: Segunda sílaba (SM)

Quantidade de Sílabas: 3

- medicim (Osco) 'aquele que trabalha como medix', 'praetor' (nom./acs., sg., n.)

\section{Ocorrências}

Lu 1, 30; Lu 1, 31 frag.; Lu 1, 33

Análise

Há duas síncopes, e de acordo com a cronologia relativa estabelecida por Benediktsson (1960: 258), pode-se afirmar: *medodik-iiom > *medodikiim
> medicim, ou seja, a síncope final ocorreu antes que a síncope medial.

Benediktsson (1960: 229)

*med(o)dikiom > medicim (nom./acs., sg., n.)

Em sílabas finais, qualquer vogal breve era sincopada depois de $-\underset{i}{i}$, mesmo antes de outras consoantes que não $-s$.

Nominativo / acusativo singular neutro e acusativo singular masculino de temas em-io: *iom > -im.

Ambiente Fonológico:

Consoantes adjacentes: $\underset{\sim}{i} \mathrm{m \#}, \mathrm{d} \_\mathrm{d}$

Posição da síncope: Última sílaba (SF) e segunda sílaba $(\mathrm{SM})$

Quantidade de Sílabas: 4

- medíkeis (Osco) 'aquele que trabalha como medix', 'praetor'(gen., sg.)

Ocorrências

medíkeí: Cm 1A5

medíkeis: Po 1

medix: MV 3; Pg 1

meddís: $\mathrm{Cm} 7$; $\mathrm{Cp} \mathrm{31;} \mathrm{Sa} 5$

med(dís): Po 5; Po 6; Po7

m(eddís): $\mathrm{Cm}$ 4; $\mathrm{Cm}$ 5; $\mathrm{Cm}$ 9; $\mathrm{Sa}$ 9; $\mathrm{Sa}$

10; Sa 12; Sa 28

meddíss: $\mathrm{Cm}$ 6; $\mathrm{Cm}$ 10; $\mathrm{Sa} 25$ :

Análise

$*_{\text {medo-diks }>\text { medíkeis }}$

Benediktsson (1960: 215, 219)

*medo-diks > medíkeis (gen., sg.) 
Síncope em formas quadrissilábicas com uma sequência de duas vogais breves nas sílabas mediais.

Weiss (2009: 238)

*med- 'lei' e *dik- 'dizer' = meddíks

Ambiente Fonológico:

Consoantes adjacentes: d_d

Posição da síncope: Segunda sílaba

Quantidade de Sílabas: 4

- memnim (Osco) 'monumento'

(nom./acs., sg., n.)

Ocorrência

Cp 36

Análise

Há duas síncopes, e de acordo com a cronologia relativa estabelecida por

Benediktsson (1960: 258), pode-se afirmar: *memen-iiom > memenim > memnin, ou seja, a síncope final ocorreu antes que a síncope medial.

Benediktsson (1960: 229)

*memeniom > memnim (nom./acs., sg.,

n.)

Em sílabas finais, qualquer vogal breve era sincopada depois de $-i$, , mesmo antes de outras consoantes que não $-s$.

Nominativo / acusativo singular neutro e acusativo singular masculino de temas em-io: *iom > -im.

Buck (1904: 184)

*me-men-io- > memnim

Ambiente Fonológico:
Consoantes adjacentes: $\underset{\sim}{\mathrm{i}} \mathrm{m} \#, \mathrm{~m} \_\mathrm{n}$

Posição da síncope: Última sílaba (SF) e segunda sílaba (SM)

Quantidade de Sílabas: 3

- menzne (Úmbrio) 'mês' (abl., sg.)

Ocorrência

IIa 17

Análise

*mens-en- > menzne

Benediktsson (1960: 272)

*menseni > menzne (abl., sg.)

Cognatos itálicos: vest. mesene, lat. mensum (gen., pl.)

Weiss (2009: 314)

*mens-en- > menzne 'mês'

Ambiente Fonológico:

Consoantes adjacentes: s_n

Posição da síncope: Segunda sílaba (SM)

Quantidade de Sílabas: 3

- mers, meřs (Úmbrio) 'lei' (nom./acs., sg.)

Ocorrências

meřs: Ib 18; Ib 18

mers: VIb 31; VIb 55; VIb 55

Análise

*medos > mers, meřs

Benediktsson (1960: 217)

*medos > mers, meřs (nom./acs., sg.)

Antes de $-s$ final, toda vogal breve é sincopada $(-\breve{V} \#$ \# $>-s \#)$. 
Nominativo/Acusativo singular de neutros com temas em $-s$ : *-os $>-s$.

Weiss (2010: 419)

*medos > meřs, mers

Ambiente Fonológico:

Consoantes adjacentes: d_s\#

Posição da síncope: Última sílaba (SF)

Quantidade de Sílabas: 2

- mersus (Úmbrio) ‘justo’ (dat./abl., pl.)

Ocorrência

III 6

Análise

Há duas síncopes, e de acordo com a cronologia relativa estabelecida por Benediktsson (1960: 258), pode-se afirmar: *medesufos $>*$ medesus $>$ mersus seja, a síncope final ocorreu antes que a síncope medial.

Benediktsson (1960: 222)

*medesufos > mersus (dat./abl., pl.)

Dativo / ablativo plural de temas em $-i$, $-u$, $-e$ e em consoante: *-fos $>-f s>-s(s)$

Meiser (1986: 59, 175)

*medesuos $>$ mersus

$\mathrm{V}>0$ / i, u, , r, $1_{-} \mathrm{s} \#$

*mersuuo- 'customeiro'

Ambiente Fonológico:

Consoantes adjacentes: u﹎s\#

Posição da síncope: Última sílaba (SF)

Quantidade de Sílabas: 3

- merst- (Úmbrio) ‘justo’ (acs., sg., m.)

Ocorrências meersta: VIa 17

mersta: VIa 3; VI 3; VIa 4; VIa 4; VIa

16; VIa 18; VIa 18

merstaf: VIa 4

mersto: VIa 3; VIa 4; VIa 16; VIa 17

merstu: VIa 1

$\underline{\text { Análise }}$

*medes-to- > mersto-

Benediktsson (1960: 259)

*medestom > mersto (acs., sg., m.)

Weiss (2010: 68)

*medes-to- > mersto-

Ambiente Fonológico:

e $>0$ / d_s

Consoantes adjacentes: d_s

Posição da síncope: Segunda sílaba (SM)

Quantidade de Sílabas: 3

- mestru (Úmbrio) 'maior' (gen., sg., f.)

Ocorrências

Va 24; Va 27; Vb 4

Análise

*maisterā > mestru

Benediktsson (1960: 242)

*maisterā > mestru (gen., sg., f.)

Untermann (2000: 475)

mestru: comparativo

osc. maimas: superlativo

Ambiente Fonológico:

Consoantes adjacentes: $t \_r$

Posição da síncope: Segunda sílaba

(SM) 
Quantidade de Sílabas: 3

- mi(n)streis (Osco) 'menor' (gen., sg.)

Ocorrências

minstreis: Lu 1, 12; Lu 1, 27

mistreis: Lu 1, 18; Lu 1, 35

Análise

*minustereis $>*$ minstereis $>$ mi(n)streis

Benediktsson (1960: 215)

*minustereis $>*$ minstereis $>$ mi(n)streis (gen., sg.)

Síncope em formas quadrissilábicas com uma sequência de duas vogais breves nas sílabas mediais. As duas vogais podem sofrer síncope se forem abertas, no caso de ambas desaparecerem, é esperado que a vogal da segunda sílaba seja sincopada antes da vogal da terceira sílaba.

Buck (1904: 58, 135)

*min-is-tero- > minstereis

Cognato itálico: lat. minister

Ambiente Fonológico:

Consoantes adjacentes: $n \_s, t \_r$

Posição da síncope: Segunda sílaba

(SM) e terceira sílaba (SM)

Quantidade de Sílabas: 4

- Mitl (Osco) 'Mitil' (cognome) (nom., sg.)

Ocorrências

mit(e)l: Sa 32;

mitl: tSa 21

Análise
Há duas síncopes, e de acordo com a cronologia relativa estabelecida por Benediktsson (1960: 258), pode-se afirmar: *mitelos $>*$ mitels $>\operatorname{mit}(\mathbf{e}) \mathbf{l}$ seja, a síncope final ocorreu antes que a síncope medial.

Benediktsson (1960: 217)

*fimelos (ou *fémelos) > *mītelos > Mitl (nom., sg.)

Antes de $-s$ final, toda vogal breve é sincopada $(-\breve{V} s \#>-s \#)$.

Depois da síncope: $-l s \#>-l \#$

Buck (1904: 61)

*Mitel > Mitl

Cognato itálico: lat. Mitulus

Ambiente Fonológico:

Consoantes adjacentes: 1_s\#, t_1

Posição da síncope: Última sílaba (SF) e terceira sílaba (SM)

Quantidade de Sílabas: 3

- Mutíl (Pelígio) 'Mutil' (cognome) (nom., sg.)

Ocorrências

nPg 2; nPg 3; nPg 5; nPg 6a; nPg 6b

Análise

*-ilos > Mutil

Benediktsson (1960: 216)

*mutilos > Mutil (nom., sg.)

Antes de $-s$ final, toda vogal breve é sincopada (-V̌V s\# > -s\#).

Depois da síncope: $-l s \#>-l \#$

Buck (1904: 116)

*-ilos > Mutíl 
Ambiente Fonológico:

Consoantes adjacentes: 1_s\#

Posição da síncope: Última sílaba (SF)

Quantidade de Sílabas: 3

- nertru (Úmbrio), nertrak (Osco)

'esquerda' (abl., sg.)

Ocorrências

umb. nertru: VIb 25

umb. nertruco: VIb 37; VIb 39

umb. nertruku: Ia 32

osc. nertrak: Po 39; Po 39 (frag.)

Análise

Adjetivos construídos com o sufixo *tero apresentam síncope vocálica.

*nertero- > umb. nertru, osc. nertrak

Benediktsson (1960: 24, 244)

*nerterōd > umb. nertru (abl., sg.)

*nerterād > osc. nertrak (abl., sg.)

Cognatos: gr. ( $\varepsilon) v \varepsilon \rho \tau \varepsilon \rho \circ \varsigma$

Weiss (2010: 70n150)

nertrak: Exemplo de adição da partícula -k a uma forma nominal. A forma é somente atestada em uma inscrição quebrada, o que torna difícil entender a função de nertrak.

Untermann (2000: 492)

nertruco, nertruku: ablativo singular + preposição com

Ambiente Fonológico:

Consoantes adjacentes: t_r

Posição da síncope: Segunda sílaba (SM)

Quantidade de Sílabas: 3
- ninctu (Úmbrio) 'atacar' (imp.)

Ocorrências

VIb 60; VIIa 49

Análise

A melhor reconstrução, a que funciona

fonologicamente, sintaticamente $\mathrm{e}$ semanticamente, é a de Meiser: *ni-n-ke-tōd $>$ nénketōd $>$ ninctu.

Benediktsson (1960: 182)

*nin- $x^{u}$ etōd > ninctu (imp.)

Síncope em formas tri- ou quadrissilábicas com uma vogal longa na terceira sílaba.

Buck (1904: 76, 95)

Cognatos: ing. snow, lit. snëgas 'nevar'

*ning ${ }^{u}$ etōd, $\quad *_{n i n k}^{u}$ etōd $>$ ninctu 'nevado'

Meiser (1986: 85-87)

*ni-n-k-e-tōd > nénketōd > ninctu /nénktu/

Cognato: lit. su-ninkù 'atacar alguém',

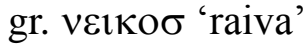

Poultney (1959: 278) \& Devoto (1937: $\underline{284)}$

ninctu 'que neve'

Cognato itálico: lat. ninguit 'neva'

Ambiente Fonológico:

Consoantes adjacentes: $\mathrm{k} \_\mathrm{t}$

Posição da síncope: Segunda sílaba

(SM)

Quantidade de Sílabas: 3 
- Niumsieís (Osco) 'Niumse' (nome próprio) (gen. Sg.)

Ocorrências

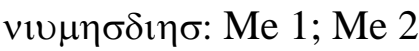

niumsieís: $\mathrm{Cm} \quad 6$; $\mathrm{Cm}$ 9frag.; $\mathrm{Cp}$

21 frag.; Si 11frag.; Si 12frag.

Análise

*numasedieis > *numsedieis >

$v i v \mu \eta \sigma \delta i \eta \sigma$

Benediktsson (1960: 215)

*numasedieis > *numsedieis >

$v i u \mu \eta \sigma \delta i \eta \sigma$

Síncope em formas tri- ou

quadrissilábicas com uma vogal longa

na terceira sílaba.

Cognato itálico: lat. Numerius

Ambiente Fonológico:

Consoantes adjacentes: $\mathrm{m} \_r$

Posição da síncope: Segunda sílaba

(SM)

Quantidade de Sílabas: 4

- numneís (Osco) ‘nome’ (gen., sg.)

Ocorrência

Sa 17

Análise

*nomeneis > numneís

Benediktsson (1960: 272)

*nomeneis > numneís (gen., sg.)

Cognato itálico: lat. nōminis

Ambiente Fonológico:

Consoantes adjacentes: $\mathrm{m} \_\mathrm{n}$

Posição da síncope: Segunda sílaba

(SM)
Quantidade de Sílabas: 3

- Núvlanam (Osco) 'nolano’ (habitante de Nola) (acs., sg., f.)

Ocorrências

núvlan-: Cm 1A25

núvlanam: Cm 1B29

núvlanúís: $\mathrm{Cm} 1 \mathrm{~A} 7$

núvlanúm: Cm 1B14

núvlanús: $\mathrm{Cm}$ 1A23; Cm B12; Cm B21

Análise

*nouelān- > nuvlan-

Benediktsson (1960: 173)

*nouelānoi > Nuvlanam (acs., sg., f.)

Síncope em formas tri- ou quadrissilábicas com uma vogal longa na terceira sílaba.

Ambiente Fonológico:

$\mathrm{e}>0 / \mathrm{u}_{-} 1$

Consoantes adjacentes: u_ 1

Posição da síncope: Segunda sílaba (SM)

Quantidade de Sílabas: 4

- ocar (Úmbrio) ‘cidade’ (nom., sg.)

Ocorrência

$\mathrm{VIb} 46$

Análise

A solução apresentada por Weiss e Benediktsson parece mais plausível que a reconstrução usual.

*okaris > ocar, ukar

$\underline{\text { Benediktsson (1960: 218) }}$ 
*okaris > ukar, ocar

Meiser (1986: 59)

*okris > ocar (nom., sg.)

de Vaan (2008: 424)

PIt. *okri > lat. ocris 'montanha'

Cognato itálico: umb. ukar, ocar

Weiss (2012: 337-8)

*okaris > ocar, ukar

Cognato: IrA. ochair 'fronteira'

ocar não é cognato da forma latina ocris 'montanha', na verdade, tratam-se de duas formas diferentes.

A hipótese *okris > *okrs > ocar não é possível porque $*_{r}$ não se tornaria $-a r$, mas sim -er. Prova disso, é o desenvolvimento *agros $>$ ager e *-tro $>$-ter.

Ambiente Fonológico:

Consoantes adjacentes: r_s\#

Posição da síncope: Última sílaba (SF)

Quantidade de Sílabas: 3

- oseto, osatu (Úmbrio) 'construir' (part. pass., nom., sg., f.)

Ocorrências

oseto: $\mathrm{Um} 7$

osatu: VIb 24; VIb 37

Análise

*opeseta $>$ *oseta $>$ umb. oseto

Possível cognato não-sincopado: PM opesauom

Benediktsson (1960: 215)

*opeseta > *oseta > umb. oseto (part. pass., nom., sg., f.)
Meiser (1986: 130)

Cognato Itálico: osc. *opesandam > úpsannam (Ve 11)

Weiss (2010: 326)

*opesatod > osatu (verbo): forma denominal de um tema em $-s$ *opos 'trabalho' (cognato do lat. opus).

Verbo atestado em osco, úmbrio $\mathrm{e}$ piceno meridional

osc. úpsannam (gerundivo)

Ambiente Fonológico:

Consoantes adjacentes: p_s

Posição da síncope: Segunda sílaba (SM)

Quantidade de Sílabas: 3

- Paakul (Osco) 'Paco' (nome próprio) (nom., sg.)

Ocorrência

$\mathrm{Cm} 7$

Análise

*-ulos > Paakuls > Paakul

Benediktsson (1960: 216)

*Paakulos > Paakuls > Paakul (nom., sg.)

Antes de $-s$ final, toda vogal breve é sincopada $(-\breve{V} s \#>-s \#)$.

Depois da síncope: -ls\# > -l\#

Buck (1904: 116)

*-ulos > Paakul

Ambiente Fonológico:

Consoantes adjacentes: 1_s\#

Posição da síncope: Última sílaba (SF)

Quantidade de Sílabas: 4 
- pacer (Úmbrio) ‘propício’ (nom., sg.)

\section{Ocorrências}

VIa 23; VIa 30; VIa 33; VIa 40; VIa 42;

VIa; VIa 50; VIa 52; VIb 7; VIb 11; VIb

13; VIb 26; VIb 32; VIb 34; VIIa 14;

VIIa 17; VIIa 31; VIIa 50

Análise

Metátese

Benediktsson (1960: 218)

*pakris > pacer (nom., sg.)

Antes de $-s$ final, toda vogal breve é sincopada (-V̌s\# >-s\#).

Nominativo singular de temas em $-i$ : *$\breve{\imath s}$ > $-s \#$

Weiss (2010: 281)

*pakri- > pacer

Cognato: gót. fagrs 'razoável'

Ambiente Fonológico:

Posição da síncope: Não há síncope (N)

Quantidade de Sílabas: 2

- ПакFๆı, pakkuiiis (Osco) 'Pacuio' (gentílico)

Ocorrências

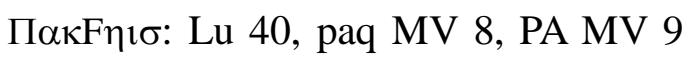
(GS)

pakkuiis: Si 19 (NSm)

Análise

Há duas síncopes e de acordo com a cronologia relativa estabelecida por Benediktsson (1960: 258), pode-se afirmar: *pākouiios > *pākouiiis >
Pacuies, ou seja, a síncope final ocorreu antes que a síncope medial.

Benediktsson (1960: 264)

*pākouniios > *pākouiis > Pacuies

Cognato itálico: lat. Pacuuius (< *pākouo-)

Ambiente Fonológico:

Consoantes adjacentes: i $\underset{\sim}{\sim} \mathrm{s} \#, \mathrm{k} \_\mathrm{u}$

Posição da síncope: Última sílaba (SF) e segunda sílaba (SM)

Quantidade de Sílabas: 4

- pakis, pakim (Osco) 'Paco' (acs., sg., m.)

Ocorrências

pakim: $\mathrm{Cp} 37,3 ; \mathrm{Cp} 37,10$

pakis: $\mathrm{Cm} \mathrm{14,} 5$ (frag.); Cp 37, 9; Fr 7;

Sa 36

pak(is): $\mathrm{Cp}$ 1; Sa 10; Sa 11 (frag.); Sa 12; tSa 38 (frag.)

p(a)k(is): $\mathrm{Cm}$ 48; Po 5; Sa 18; tSa 5

Análise

No caso da forma no nominativo singular, a síncope na sílaba final é esperada, pois a regra $*-V s \#>-s \#$ sempre se aplica: *pakiios > pakis.

Benediktsson (1960: 30)

*pakiom > pakim (acs., sg., m.)

Em sílabas finais, qualquer vogal breve era sincopada depois de $-i$, mesmo antes de outras consoantes que não $-s$.

Nominativo / acusativo singular neutro e acusativo singular masculino de temas em -io: *iom > -im. 
Meiser (1986: 59)

*pākiom > pakim

Ambiente Fonológico:

Consoantes adjacentes: $\underset{\sim}{\mathrm{i}} \mathrm{m} \#$

Posição da síncope: Última sílaba (SF)

Quantidade de Sílabas: 2

- $\pi \alpha k F \eta 1 \sigma$ (Osco) 'Paco' (nome

próprio) (gen., sg.)

Ocorrência

Lu 40

Análise

*pākoueis > $\pi \alpha \kappa F \eta ı$

Benediktsson (1960: 258)

*pākoueis > $\pi \alpha \kappa F \eta \imath$ (gen., sg.)

Cognato itálico: lat. Pacuuius

Ambiente Fonológico:

Consoantes adjacentes: $\mathrm{k} \_\mathrm{u} \#$

Posição da síncope: Segunda sílaba

(SM)

Quantidade de Sílabas: 3

- parfam, parfa (Úmbrio) 'parra' (tipo de pássaro) (acs., sg.)

Ocorrências

parfam: Ib 13

parfa: VIa 1; VIa 2; VIa 4; VIa 15; VIa

17; VIb 51

Análise

*parVsa- > parfa, parfam

Não há como ter certeza de qual é a vogal que foi sincopada.

Benediktsson (1960: 166)

*paresām > parfam, parfa (acs., sg.)
Síncope em formas tri- ou quadrissilábicas com uma vogal longa na terceira sílaba.

Cognato itálico: lat. parram

Stuart-Smith (2004:114)

*paresām > parfam

Secundário *-rs- > -rf-

Ambiente Fonológico:

Consoantes adjacentes: $r \_s$

Posição da síncope: Segunda sílaba (SM)

Quantidade de Sílabas: 3

- patensíns (Osco) 'abrir' (3 $3^{\mathrm{a}}$ pl., subj., impf.), Patanai (Osco) (significado desconhecido), Padellar (Úmbrio) 'Padela' (nome de uma deusa)

Ocorrências

osc. patensíns: Cm 1B24; Cm 1B25

osc. patanai: Sa 1A 14; Sa 1B17

umb. padellar: VIa 14

Análise

Não é possível ver síncope nas três formas, mas apenas em patensins.

Benediktsson (1960: 175, 208)

- Patanai: *patenāi > *patnai > Patanai (dat., sg.)

Síncope e anaptixe

Síncope em formas tri- ou quadrissilábicas com uma vogal longa na terceira sílaba.

- Padella: *patenolās > *patnola- > *padla- > osc. Padella- 
Síncope em formas quadrissilábicas com uma sequência de duas vogais breves nas sílabas mediais. As duas vogais podem sofrer síncope se forem abertas, no caso de ambas desaparecerem, é esperado que a vogal da segunda sílaba seja sincopada antes da vogal da terceira sílaba.

Cognato itálico: lat. Patella

- patensíns: *patenesē- > *patnesē- > *patnsē- > patensí-, patensíns ( $3^{\mathrm{a}} \mathrm{pl}$., subj., impf.)

\section{Meiser (1986: 133)}

*patanesēnt $>$ *patnsens > patensíns

Untermann (2000: 516-7)

*pat- > Patanai

*peth ${ }^{2}$ - > patensíns ( $3^{\mathrm{a}}$ pl., subj., impf.)

Ambiente Fonológico:

- patensíns

Consoantes adjacentes: $\mathrm{t} \_\mathrm{n}$

Posição da síncope: Segunda sílaba (SM)

Quantidade de Sílabas: 4

- pelmner (Úmbrio) ‘carne’ (gen., sg.)

Ocorrências

$\mathrm{Vb} 12 ; \mathrm{Vb} 17$

Análise

*pelpmen-eis > pelmner

Benediktsson (1960: 272)

*pelpmeneis > pelmner (gen., sg.)

Cognato itálico: lat. pulpa 'carne'

Untermann (2000: 528)

*pel-men- > pelmner
Cognato itálico: lat. pulmentum 'comida feita de carne'

Ambiente Fonológico:

Consoantes adjacentes: m_n

Posição da síncope: Segunda sílaba

(SM)

Quantidade de Sílabas: 3

- pelsans (Úmbrio) 'enterrar' (gerund., nom., sg.)

Ocorrência

IIa 43

Análise

*pelsandos $>$ pelsans

$*_{\text {-ns }}$ \# original $>-f$, como em vitluf $<*_{-}$ ns (acs, sg, m) e umb. klavlaf < *-ns (acs, pl), enquanto *ns por síncope > $n s$.

Benediktsson (1960: 216)

*pelsandos > pelsans (nom., sg.)

Antes de $-s$ final, toda vogal breve é sincopada $(-\breve{V} S \#>-s \#)$.

Nom. sg. de temas em $-O: *_{-} o s>-s$.

Weiss (2009: 443)

pelsans: gerundivo

Ambiente Fonológico:

Consoantes adjacentes: d_s\#

Posição da síncope: Última sílaba (SF)

Quantidade de Sílabas: 3

- ař-peltu (Úmbrio) 'aconselhar' (imp.)

$\underline{\text { Ocorrências }}$

IIa 32; IIb 19; IV 8

Análise 
*ados-pelletōd $>$ ař-pelletōd $>$ ař-peltu

$\underline{\text { Benediktsson (1960: 171) }}$

*pelletōd > ař-peltu (imp.)

Cognato itálico: lat. pellō 'bater'; 'impelir'

Síncope em formas tri- ou quadrissilábicas com uma vogal longa na terceira sílaba.

Buck (1904: 83)

A presença de $\breve{\mathbf{r}}, r s$ antes e depois de consoantes indica que houve síncope de uma vogal ou uma mudança da posição intervocálica. É o caso do prefixo ař-, ars-.

Ambiente Fonológico:

Consoantes adjacentes: d_s\#, 1_t

Posição da síncope: Última sílaba (SF no prefixo) e segunda sílaba (SM)

Quantidade de Sílabas: 3

- perca(m), perkaf (Úmbrio) 'haste' (acs., sg. - acs., pl.)

$\underline{\text { Ocorrências }}$

perca:VIa 19; VIb 49; VIb 50; VIb 51;

VIb 63; VIIa 46; VIIa 51

percam: VIb 53

perkaf: Ib 15

Análise

*pertikā- > perca $(m)$, perkaf

Benediktsson (1960: 175)

*pertikām > perca(m) (acs., sg.), perkaf (acs., pl.)
Síncope em formas tri- ou quadrissilábicas com uma vogal longa na terceira sílaba.

Ambiente Fonológico:

Consoantes adjacentes: $\mathrm{t} \_\mathrm{k}$

Posição da síncope: Segunda sílaba (SM)

Quantidade de Sílabas: 3

- Perkens (Osco) 'Perse' (nome próprio) (nom., sg.)

Ocorrência

Cm 6

Análise

*perkenos > Perkens

Benediktsson (1960: 216)

*perkenos > Perkens (nom., sg.)

Antes de $-s$ final, toda vogal breve é sincopada $(-V s \#>-s \#)$.

Final secundário $-n s$ foi mantido em osco e também em úmbrio, enquanto o original $*_{-} n s$ se tornou $-s s$.

Ambiente Fonológico:

Consoantes adjacentes: $\mathrm{n} \_$s\#

Posição da síncope: Última sílaba (SF)

Quantidade de Sílabas: 3

- pe(r)stu (Úmbrio) 'colocar' (imp.)

Ocorrências

perstu: IIa 32

pestu: IIb 19

Análise

*persketōd > pe(r)stu

$\underline{\text { Benediktsson (1960: 178) }}$ 
*persketōd > pe(r)stu (imp.)

Síncope em formas tri- ou quadrissilábicas com uma vogal longa na terceira sílaba.

Buck (1904: 91)

*persk(e)tōd > pe(r)stu

Weiss (2010: 362n10)

Significado pouco claro, por causa do contexto, pode-se assumir que se trata de um verbo transitivo e que provavelmente envolve movimento

Ambiente Fonológico:

$\mathrm{e}>0 / \mathrm{k} \_\mathrm{t}$

Consoantes adjacentes: $\mathrm{k} \_\mathrm{t}$

Posição da síncope: Segunda sílaba

(SM)

Quantidade de Sílabas: 3

- pertumum (Osco) 'significado

desconhecido'

Ocorrência

Lu 1, 7

Análise

Neste contexto, é difícil decidir se houve um enfraquecimento ou síncope seguida de anapitixe, pois há exemplo dos dois casos no mesmo ambiente fonológico. $\quad$ Pode-ser ver enfraquecimento no caso de pra-hubia (<*prae-habeo), no qual /a/ > /u/ antes de uma labial; pode-se ver síncope no caso de sumtu (<* supemetod) e no caso de maimas (<*maisemo-), no qual /e/ > 0 antes de uma labial.
Ainda que ambas as soluções sejam possíveis, parece mais plausível supor que se trata de uma síncope seguida de anaptixe. Isso porque o ambiente fonológico é perfeito para sincope em sílaba medial: sílaba breve imediatamente pós-tônica entre uma oclusiva e uma labial.

$\underline{\text { Benediktsson (1960: 175) }}$

*pertemom > *pertmom > pertumum

Síncope e anaptixe

Síncope em formas tri- ou quadrissilábicas com uma vogal longa na terceira sílaba.

Buck (1892: 71)

Exemplo de enfraquecimento do $/ e />$ lu/ em sílaba medial antes de uma consoante labial.

Ambiente Fonológico:

Consoantes adjacentes: $t \_m$

Posição da síncope: Segunda sílaba (SM ( IN)

Quantidade de Sílabas: 3

- persklum, persclo (Úmbrio) 'ritual' (acs., sg.)

Ocorrências

persclo: VIa 1

persklum: Ia 1

perscler: VIa 27; VIa 28; VIa 37; VIa 38

pescler: VIa 47; VIa 48; VIb 30; VIb 30

persklu: III 12 
persclu: VIb 36; VIIa 20; VIIa 34; VIIa

34

pesclu: VIb 15; VIIa 8

$\underline{\text { Análise }}$

*per(k)skelo- > perskl-, perscl-

Benediktsson (1960: 235)

*per $(k)$ skelom > persklum, persclo (acs., sg.)

Ambiente Fonológico:

Consoantes adjacentes: $\mathrm{k} \_1$

Posição da síncope: Segunda sílaba

(SM)

Quantidade de Sílabas: 3

- praicime (Pelígio) ‘reino’ (acs., sg.)

Ocorrência

$\operatorname{Pg} 9$

Análise

Há duas síncopes e de acordo com a cronologia relativa estabelecida por Benediktsson (1960: 258), pode-se afirmar: *praidik-iiom > praidikim > praicim, ou seja, a síncope final ocorreu antes que a síncope medial.

Benediktsson (1960: 263)

*praidikiom > praidikim > praicim (acs., sg.)

Untermann (2000: 569)

Praicime: praicim + preposição en

Ambiente Fonológico:

Consoantes adjacentes: $\underset{\sim}{i} \mathrm{~m} \#, \mathrm{~d} \_\mathrm{k}$

Posição da síncope: Última sílaba (SF) e segunda sílaba (SM)

Quantidade de Sílabas: 3
- pretra (Úmbrio) 'as primeiras' (acs., pl., f.)

Ocorrência

$\mathrm{Vb} 12$

Análise

Adjetivos construídos com o sufixo *tero apresentam síncope vocálica.

*praitero- > pretra

Benediktsson (1960: 241)

*praiterans > pretra (acs., pl., f.)

Buck (1904: 184)

*prai-tero- > pretra

Ambiente Fonológico:

Consoantes adjacentes: $\mathbf{t} \_r$

Posição da síncope: Segunda sílaba (SM)

Quantidade de Sílabas: 3

- pritrome (Pelígio) 'anterior'

Ocorrências

Pg 9

Análise

Adjetivos construídos com o sufixo *tero apresentam síncope vocálica.

*pritero- > pritrom

Benediktsson (1960: 241)

*priterom > pritrom

Em Pelígio, *tr > $k r$, como há a sequência $t r$ nesta forma, deve-se supor que havia uma vogal entre $t r$, que foi sincopada.

Ambiente Fonológico:

Consoantes adjacentes: t_r 
Posição da síncope: Segunda sílaba (SM)

Quantidade de Sílabas: 3

- prúffed (Osco) 'arrumar' (3 3 sg., perf.)

Ocorrências

Cm 10; Sa 25

Análise

*pro-fefed $>$ prúffed

Benediktsson (1960: 237)

*pro-peped > prúffed ( $3^{\mathrm{a}}$ sg., perf.)

PIt. $* p(\mathrm{PIE} * d h)>f$ antecedeu a ocorrência da síncope.

Ambiente Fonológico:

Consoantes adjacentes: $\mathrm{f} \_\mathrm{f}$

Posição da síncope: Segunda sílaba

(SM)

Quantidade de Sílabas: 3

- prúftú (Osco) 'estabelecer' (3 ${ }^{\mathrm{a}}$ pl., perf., pass.)

Ocorrência

Cm $1 \mathrm{~A} 16$

Análise

PIt. *propata > prúftú

Benediktsson (1960: 258)

*propata > prúftú (nom., pl., n.)

Cognato itálico: lat. umerus 'ombro'

Untermann (2000: 745)

prúftúset $\left(3^{\mathrm{a}} \quad\right.$ pl., $\quad$ perf., $\quad$ pass. $)$

'estabelecer'

Ambiente Fonológico:

Consoantes adjacentes: f_t
Posição da síncope: Segunda sílaba (SM)

Quantidade de Sílabas: 3

- Púmpaiians (Osco) 'Pompeiano' (nom., sg.)

$\underline{\text { Ocorrências }}$

Po 12frag.; Po 53frag.

Análise

*púmpaiianos > Púmpaiians

Benediktsson (1960: 216)

*púmpaiianos > Púmpaiians (nom., sg.)

Antes de $-s$ final, toda vogal breve é sincopada $(-\breve{V s} \#>-s \#)$.

Final secundário $-n s$ foi mantido em osco e também em úmbrio, enquanto o original $*_{-} n s$ se tornou $-s s$.

Ambiente Fonológico:

Consoantes adjacentes: n_s\#

Posição da síncope: Última sílaba (SF)

Quantidade de Sílabas: 4

- pupdiiis (Osco) 'Popido' (gentílico) (nom., sg.)

Ocorrências

popdis: $\mathrm{Pg} 1$

pupdiis: $\mathrm{Cm} 34$

Análise

Há duas síncopes, e de acordo com a cronologia relativa estabelecida por Benediktsson (1960: 258), pode-se afirmar: *poped(i)inos > *popediis > pupdiis, popdis, ou seja, a síncope final ocorreu antes que a síncope medial. 
Benediktsson (1960: 264)

*poped(i)ios > Pupdiis (nom., sg.)

Cognatos itálicos: pal. popdis (< *poped(i)ios); lat. Popidius

Ambiente Fonológico:

Consoantes adjacentes: i $\_$s\#, p_d

Posição da síncope: Última sílaba (SF) e segunda sílaba (SM)

Quantidade de Sílabas: 4

- pupřikes (Úmbrio) (epíteto) (gen., sg.)

Ocorrências

pupřçes: IV 26

pupřiçe: IV 24

pupřiçes: IV 4

pupřike: III 27; III 35; IV 10 (frag.); IV 12

pupřikes: IV 11; IV 13

Análise

Apesar das pequenas diferenças na escrita, pode-se constatar que todas essas formas por síncope: *popedik- > pupřk-, pupřç-. Além disso, na forma pupřçes pode-se ver duas síncopes em sílabas mediais: *popedik- > pupřiç- > pupřçes.

Benediktsson (1960: 211)

*popedikeis > Puprikes (gen., sg.)

Síncope em formas quadrissilábicas com uma sequência de duas vogais breves nas sílabas mediais.

Ambiente Fonológico:

Consoantes adjacentes: p_d
Posição da síncope: Segunda sílaba (SM)

Quantidade de Sílabas: 4

- pústiris (Osco) 'posterior' (nom./acs., sg.)

Ocorrência

$\mathrm{Sa} 4$

Análise

*postero- > pústiris

Benediktsson (1960: 217)

*posterios > pústiris (nom./acs., sg.)

Cognato itálico: lat. posterius 'posterior'

Antes de $-s$ final, toda vogal breve é sincopada $\left(-\breve{V}_{S} \#>-s \#\right)$.

Nominativo/Acusativo singular de neutros com temas em $-s: *_{-} o s>-s$.

Ambiente Fonológico:

Consoantes adjacentes: i s\#

Posição da síncope: Última sílaba (SF)

Quantidade de Sílabas: 3

- pústreí, pustrei (Osco) 'posterior' (loc., sg.)

Ocorrências

pustrei: $\mathrm{Cp} 9$

pústreí: Cp 33; Cp 34 (frag.)

Análise

Adjetivos construídos com o sufixo *tero apresentam síncope vocálica.

*posterei > pústreí, pustrei

Benediktsson (1960: 241)

*posterei > pústreí, pustrei (loc., sg.) 
Cognato itálico: umb. postra (acs., sg.,

f.), pustra, pustru, postro (acs., pl., n.);

lat. posterus 'posterior'

Cognatos: lit. pãstaras; let. pastars

Ambiente Fonológico:

Consoantes adjacentes: t_r

Posição da síncope: Segunda sílaba

Quantidade de Sílabas: 3

- putrespe (Úmbrio) ‘outro’ (gen., sg.)

Ocorrências

IV 14

Análise

Adjetivos construídos com o sufixo *tero apresentam síncope vocálica.

*potereis > putres-pe

Benediktsson (1960: 241-2)

$* k^{u}$ otereis > putres(-pe) (gen., sg.)

Outras formas: púterei(-pid) (loc., sg.), pútúrús(píd) (nom., pl.), pútúrú[m(-píd) (gen., pl.), pútúrú[ís(-píd)

Cognatos: lit. katròs; scr kataráh; gr. $\pi \mathrm{o} \varepsilon \rho \circ \varsigma^{\prime}$

Ambiente Fonológico:

Consoantes adjacentes: $t \_r$

Posição da síncope: Segunda sílaba

Quantidade de Sílabas: 3

- puz (Osco) ‘que', ‘como’ (conj.)

Ocorrências

Cm 1A 17; Po 39

Análise *pu- $t V s>\mathbf{p u z}$

Cognato itálico: lat. $u t$ 'que', 'como'

Ambiente Fonológico:

Consoantes adjacentes: t_s\#

Posição da síncope: Última sílaba (SF)

Quantidade de Sílabas: 2

- sacris (Úmbrio) 'vítimas sacrificiais' (dat./abl., pl.)

Ocorrências

VIb 52; VIb 56

$\underline{\text { Análise }}$

*sakrifos > sacris

Benediktsson (1960: 222)

*sakrifos > sacris (dat./abl., pl.)

Dativo / ablativo plural de temas em $-i$, $-u,-e$ e em consoante: $*_{-} f o s>-f s>-s(s)$

Ambiente Fonológico:

Consoantes adjacentes: f_s\#

Posição da síncope: Última sílaba (SF)

Quantidade de Sílabas: 3

- Safinim (Osco) 'Safino' (nom./acs., sg., n.)

\section{Ocorrências}

nPg 2; Sa 4

Análise

*safn-iiom > Safinim

Benediktsson (1960: 229)

*safniom > Safinim (nom./acs., sg., n.)

Cognato itálico: lat. Samnium

Em sílabas finais, qualquer vogal breve era sincopada depois de $-i$, mesmo antes de outras consoantes que não $-s$. 
Nominativo / acusativo singular neutro e acusativo singular masculino de temas em -io: *iom > -im.

Ambiente Fonológico:

Consoantes adjacentes: $\underset{\sim}{\mathrm{i}} \mathrm{m \#}$

Posição da síncope: Última sílaba (SF)

Quantidade de Sílabas: 2

- salaus (Osco) 'salvo' (nom., sg.)

$\underline{\text { Ocorrências }}$

MV 7; MV 8; MV 8frag.

Análise

*salauos > salaus, $\sigma \alpha \lambda \alpha F \sigma$

Benediktsson (1960: 216)

*salauos $>$ salaus, $\sigma \alpha \lambda \alpha F \sigma$ (nom., sg.)

Antes de $-s$ final, toda vogal breve é sincopada $(-\breve{V} S \#>-s \#)$.

Ambiente Fonológico:

Consoantes adjacentes: $u_{-}$s\#

Posição da síncope: Última sílaba (SF)

Quantidade de Sílabas: 3

- Serfer (Úmbrio) 'Ceres' (gen., sg.)

Ocorrências

s'erfe: VIIa 3

sérfer: VIb 57; VIb 58; VIIa 6; VIIa 9;

VIIa 10; VIIa 11; VIIa 13; VIIa 15; VIIa

18; VIIa 19; VIIa 20; VIIa 21; VIIa 22;

VIIa 24; VIIa 25; VIIa 27; VIIa 29; VIIa

29; VIIa 32; VIIa 33; VIIa 33; VIIa 34;

VIIa 35; VIIa 36; VIIa 41

Análise

*kereseis $>$ Serfer, Çerfer

Benediktsson (1960: 256) *kereseis > Serfer, Çerfer (gen., sg.)

Outras formas: *kerese > Serfe, Çerfe (dat., sg.)

Paradigmas nos quais ocorre síncope medial regularmente apenas nos casos oblíquos.

Cognato itálico: lat. Ceres

Ambiente Fonológico:

Consoantes adjacentes: $r \_s$

Posição da síncope: Segunda sílaba (SM)

Quantidade de Sílabas: 3

- seste, sestu (Úmbrio) 'derrubar' (3 ${ }^{\mathrm{a}}$ sg., pres. pass. - imp.)

Ocorrência

seste: IIb 22

sestu: IIb 22; IIb 24

$\underline{\text { Análise }}$

*sistat- > sestu, seste

Benediktsson (1960: 173,237)

PIE. * ${ }^{*} i$-sta-tōd $>$ PIt. *sistatod $>$ sestu (imp.)

Síncope em formas tri- ou quadrissilábicas com uma vogal longa na terceira sílaba.

* sistater $>$ seste ( $3^{\mathrm{a}} \mathrm{sg}$., pres. pass.)

Cognato itálico: lat. sistō 'ficar em pé'

Buck (1904: 345)

seste ( $2^{\mathrm{a}} \mathrm{sg}$., pres., ind.)

sestu (imp.)

Ambiente Fonológico:

Consoantes adjacentes: $t \_t$ 
Posição da síncope: Segunda sílaba (SM)

Quantidade de Sílabas: 3

- ander-sistu (Úmbrio) 'sentar entre' (imp.)

Ocorrências

VIa 6

Análise

*sizdVto- > ander-sistu

Benediktsson (1960: 174)

*sizdetōd > ander-sistu (imp.)

Síncope em formas tri- ou quadrissilábicas com uma vogal longa na terceira sílaba.

Cognato itálico: lat. sido (< PIE *sed-)

'sentar'

Buck (1904: 75)

*sizd(e)tōd > ander-sistu

Cognato itálico: lat. sidō

Ambiente Fonológico:

Consoantes adjacentes: $d \_t$

Posição da síncope: Segunda sílaba (SM)

Quantidade de Sílabas: 3

- scalse (Úmbrio) 'tipo de vasilhame usado em rituais' (abl., sg.)

Ocorrências

skalçeta: IV 15; IV 18; IV 20

scalseto: VIb 16

scalsie: VIb 5; VIIa 37

Análise

*skalik- > skalçe-ta
Benediktsson (1960: 272)

*skaliki > skalçe, scalse (abl., sg.)

Benediktsson (1960: 272)

*skalik- > skalçeta, scalseto, scalsie

Ambiente Fonológico:

Consoantes adjacentes: $1 \_k$

Posição da síncope: Segunda sílaba (SM)

Quantidade de Sílabas: 3

- $a(n)$-stintu (Úmbrio) 'instingar' (imp.)

$\underline{\text { Ocorrências }}$

anstintu: III 20

astintu: III 18; III 19

Análise

*stingeto- > a(n)-stintu

$\underline{\text { Benediktsson (1960: 178) }}$

*stingetōd > a(n)-stintu (imp.)

Síncope em formas tri- ou quadrissilábicas com uma vogal longa na terceira sílaba.

Meiser (1986: 82)

*steig- 'stick on'

Cognato itálico: lat. ìnstīgāre

Ambiente Fonológico:

Consoantes adjacentes: $\mathrm{g} \_\mathrm{t}$

Posição da síncope: Segunda sílaba (SM)

Quantidade de Sílabas: 3

- stru(h)çla (Úmbrio) 'massa assada'

Ocorrências

struçla: III 34

struhçla: IIa 18; IIa 28; IV 4 
struhçlas: IIa 41; IV 1

Análise

*struuekelā- > *strukelām > stru(h)çla, struçla

Benediktsson (1960: 211)

*struuekelā- > *strukelām > stru(h)çla, struçla (acs., sg.)

Síncope em formas quadrissilábicas com uma sequência de duas vogais breves nas sílabas mediais. As duas vogais podem sofrer síncope se forem abertas, no caso de ambas desaparecerem, é esperado que a vogal da segunda sílaba seja sincopada antes da vogal da terceira sílaba.

Essa palavra contém o sufixo de diminutivo PIt. *-kelo-/a-

Ambiente Fonológico:

Consoantes adjacentes: $u_{-} \ldots, k \_1$

Posição da síncope: Segunda sílaba (SM), terceira sílaba (SM)

Quantidade de Sílabas: 4

- sumtu (Úmbrio) 'apreender' (imp.)

Ocorrências

Ia 9 ; Ia 16

Análise

*supemetōd (ou *subemetōd) >

*submetōd $>$ *summetod $>$ sumtu

Benediktsson (1960: 212)

*supemetōd (ou *subemetōd) >

*submetōd > *summetod > sumtu (imp.)
Síncope em formas quadrissilábicas com uma sequência de duas vogais breves nas sílabas mediais. As duas vogais podem sofrer síncope se forem abertas, no caso de ambas desaparecerem, é esperado que a vogal da segunda sílaba seja sincopada antes da vogal da terceira sílaba.

Buck (1904: 76)

*sup(e)mō- > summō- > sumtu

Untermann (2000: 220)

sumtu 'apreender'

Ambiente Fonológico:

Consoantes adjacentes: $\mathrm{p} \_\mathrm{m}, \mathrm{m} \_\mathrm{t}$

Posição da síncope: Segunda sílaba (SM), terceira sílaba (SM)

Quantidade de Sílabas: 4

- supruis (Osco) 'superior' (dat./abl., pl.)

Ocorrência

Cp 37,7

$\underline{\text { Análise }}$

$*_{\text {s-uperois }}>$ supruis

Benediktsson (1960: 241)

$*_{\text {s-uperois }>\text { supruis (dat./abl., pl.) }}$

Cognato itálico: lat. superus 'superior'

Cognatos: véd. úpara-; gr. $\varepsilon \pi \varepsilon \rho o \varsigma$

Ambiente Fonológico:

Consoantes adjacentes: $\mathrm{p} \_r$

Posição da síncope: Segunda sílaba (SM)

Quantidade de Sílabas: 3 
- sverruneí (Osco) 'pensamento' (dat., sg.)

Ocorrência

CM 1A2

Análise

*sueresōnei > sverruneí

Benediktsson (1960: 166) \& Buck (1904: 63)

*sueresōnei > sverruneí (dat., sg.)

Síncope em formas tri- ou quadrissilábicas com uma vogal longa na terceira sílaba.

Ambiente Fonológico:

Consoantes adjacentes: $r_{-} s$

Posição da síncope: Segunda sílaba (SM)

Quantidade de Sílabas: 4

- taçez, tases (Úmbrio) 'tácito' (part. pass)

Ocorrências

taçez: Ia 26; Ib 26; Ib 30; Ib 32; Ib 44; IIa 7; IIa 39; IV 27

tases: VIa 55; VIa 59; VIb 2; VIb 4; VIb 20; VIb 44; VIb 46; VIIa 7; VIIa 42;

VIIa 54

$\underline{\text { Análise }}$

*taketos $>$ taçez, tases, tasis

Benediktsson (1960: 216)

*taketos > taçez, tases, tasis (part. pass)

Antes de $-s$ final, toda vogal breve é sincopada (-V̌Vs\# $>$-s\#).

Nom. sg. de temas em $-o: *_{-}-o s>-s$.

Ambiente Fonológico:
Consoantes adjacentes: t_s\#

Posição da síncope: Última sílaba (SF)

Quantidade de Sílabas: 3

- tehteřim (Úmbrio) ‘teto' (nom./acs., sg., n.)

Ocorrência

IV 20

Análise

*tektel-iiom > tehteřim

Benediktsson (1960: 229)

*tektediom > tehteřim (nom./acs., sg., n.)

Em sílabas finais, qualquer vogal breve era sincopada depois de $-i$, mesmo antes de outras consoantes que não $-s$.

Nominativo / acusativo singular neutro e acusativo singular masculino de temas em -io: *iom > -im.

Weiss (2010: 124)

*tekteliio- > tehteřim

Ambiente Fonológico:

Consoantes adjacentes: i $\mathrm{m} \#$

Posição da síncope: Última sílaba (SF)

Quantidade de Sílabas: 3

- teitu, deitu (Úmbrio) ‘dito’ (imp.)

Ocorrências

deitu: VIb 56; VIb 63; VIb 64; ; VIb 65;

VIIa 1; VIIa 20; VIIa 51

teitu: IIa 26; IIb 7; IIb 25; III 9; III 25

Análise

*deiketōd > teitu, deitu

Benediktsson (1960: 178) 
*deiketōd > teitu, deitu (imp.)

Síncope em formas tri- ou

quadrissilábicas com uma vogal longa na terceira sílaba.

Cognato itálico: lat. dicōo 'dizer'

Ambiente Fonológico:

Consoantes adjacentes: $\mathrm{k} \_\mathrm{t}$

Posição da síncope: Segunda sílaba (SM)

Quantidade de Sílabas: 3

- teremníss (Osco) 'limites terrioriais' (dat./abl., pl.)

Ocorrência

Cm 1A14

Análise

*termen-i-fos > *termen-i-fs >

*termníss > com anaptixe teremníss

Dupla síncope, sendo que a primeira a ocorrer foi necessariamente a síncope da sílaba final, seguida de anaptixe.

Benediktsson (1960: 223, 272)

*termenifos > teremníss (dat./abl., pl.)

Cognato itálico: lat. termen

Dativo / ablativo plural de temas em $-i$, $-u,-e$ e em consoante: ${ }^{*}-f o s>-f s>-s(s)$

Ambiente Fonológico:

Consoantes adjacentes: i m\#, m_n

Posição da síncope: Última sílaba (SF) e segunda sílaba (SM)

Quantidade de Sílabas: 4

- termnas (Úmbrio) 'delimitar' (part. pass., nom., sg., m.)
Ocorrência

Um 10

Análise

*termenā- > *termnā- > termnas

Benediktsson (1960: 173)

*termenā- > *termnā- > termnas (part.

pass., nom., sg., m.)

Síncope em formas tri- ou quadrissilábicas com uma vogal longa na terceira sílaba.

Untermann (2000: 747)

termnas 'delimitar'

Ambiente Fonológico:

Consoantes adjacentes: $\mathrm{m} \_n$

Posição da síncope: Segunda sílaba (SM)

Quantidade de Sílabas: 3

- termnome (Úmbrio) 'limites terrioriais' (dat./abl., pl.)

Ocorrências

VIb 57; VIb 63; VIb 64

Análise

*termenom > termnem

Benediktsson (1960: 256)

*termenom > termnem (dat./abl., pl.)

Paradigmas nos quais apenas ocorre síncope medial regularmente nos casos oblíquos.

Cognato itálico: lat. terminus 'marco (de um limite teritorial)'

Ambiente Fonológico:

Consoantes adjacentes: m_n 
Posição da síncope: Segunda sílaba (SM)

Quantidade de Sílabas: 3

- teřte (Úmbrio) 'dar' ( $3^{\mathrm{a}}$ sg., pres. pass.)

Ocorrências

IIa 40; IIa 40; IV 28 frag.

Análise

*didater $>$ teřte

Benediktsson (1960: 237)

$*$ didater $>$ teřte $\left(3^{\mathrm{a}}\right.$ sg., pres. pass.)

Ambiente Fonológico:

Consoantes adjacentes: $d \_t$

Posição da síncope: Segunda sílaba (SM)

Quantidade de Sílabas: 3

- terti (Úmbrio) 'terceiro’ (nom./acs., sg., n.)

Ocorrência

IIa 28

Análise

*trit-iiom $>$ terti

Benediktsson (1960: 229)

*tritiom > terti (nom./acs., sg., n.)

Em sílabas finais, qualquer vogal breve era sincopada depois de $-i$, mesmo antes de outras consoantes que não $-s$.

Nominativo / acusativo singular neutro e acusativo singular masculino de temas em -io: *iom > -im.

Ambiente Fonológico:

Consoantes adjacentes: $\underset{\sim}{\mathrm{i}} \mathrm{m} \#$
Posição da síncope: Última sílaba (SF)

Quantidade de Sílabas: 2

- tiçel (Úmbrio) 'oferenda' (nom., sg.)

Ocorrências

IIa 15

$\underline{\text { Análise }}$

$*$ dikelos $>$ tiçel

Benediktsson (1960: 216)

*dikelos > tiçel (nom., sg.)

Antes de $-S$ final, toda vogal breve é sincopada $(-\breve{V}$ \#\#>-s\#).

Nom. sg. de temas em $-o: *_{-o s}>-s$.

Ambiente Fonológico:

Consoantes adjacentes: 1_s\#

Posição da síncope: Última sílaba (SF)

Quantidade de Sílabas: 3

- tiçlu (Úmbrio) 'oferenda’ (acs./abl., sg.)

Ocorrências

IIb 22; III 25; III 27

Análise

*dikelom $>$ tiçlu

Benediktsson (1960: 238)

*dikelom > tiçlu (acs./abl., sg.)

Ambiente Fonológico:

Consoantes adjacentes: $\mathrm{k} \_1$

Posição da síncope: Segunda sílaba (SM)

Quantidade de Sílabas: 3

- tribřiçu, tribrisine (Úmbrio) 'três em número’ 
Ocorrências

tribřiçu: Va 9

tribrisine: VIa 54

Análise

A análise de Benediktsson parece mais sensata, a síncope ocorre na segunda sílaba, na sílaba imediatamente póstônica, conforme se espera em sabélico.

$\underline{\text { Benediktsson (1960: 213) }}$

*tri-pedikio > tribřiçu (nom., sg.)

Outras formas: tribrisine (abl., sg.)

Síncope em formas quadrissilábicas com uma sequência de duas vogais breves nas sílabas mediais. As duas vogais podem sofrer síncope se forem abertas, no caso de ambas desaparecerem, é esperado que a vogal da segunda sílaba seja sincopada antes da vogal da terceira sílaba.

Meiser (1986: 130)

*tri-plek-iīo $>*$ triplekiō $>$ tribřiçu

Untermann (2000: 764)

tribřiçu 'três em número'

Ambiente Fonológico:

Consoantes adjacentes:

Posição da síncope:

Quantidade de Sílabas: 4

- tris (Úmbrio) 'três' (dat./abl., pl.)

Ocorrências

III 18; III 18

Análise

*trifos $>$ tris

Benediktsson (1960: 222) *trifos $>$ tris (dat./abl., pl.)

Dativo / ablativo plural de temas em $-i$, $-u,-e$ e em consoante: *-fos $>-f s>-s(s)$

Ambiente Fonológico:

Consoantes adjacentes: f_s\#

Posição da síncope: Última sílaba (SF)

Quantidade de Sílabas: 2

- túvtílks (Osco) 'público’

Ocorrências

túvtíks: Cm 10; as 5 frag.

túv(tíks): Po 5; Po 6; Po 7

t(úvtíks): Sa 7; Sa 9; Sa 10, Sa 12; Sa

$21 ;$ Sa 28

Análise

*toutikos > túvtiks

Benediktsson (1960: 216)

*toutikos > túvtiks (nom., sg.)

Antes de $-s$ final, toda vogal breve é sincopada $(-\breve{V} s \#>-s \#)$.

Ambiente Fonológico:

Consoantes adjacentes: k_s\#

Posição da síncope: Última sílaba (SF)

Quantidade de Sílabas: 3

- uas (Úmbrio) ‘vício’ (nom./acs., sg.)

Ocorrências

VIa 28; VIa 38; VIa 48; VIb 30

Análise

*uakos > uas

Benediktsson (1960: 217)

*uakos > uas (nom./acs., sg.)

Antes de $-s$ final, toda vogal breve é sincopada $\left(-\breve{V}_{S} \#>-s \#\right)$. 
Nominativo/Acusativo singular de neutros com temas em $-s: *_{-o s}>-s$.

Ambiente Fonológico:

Consoantes adjacentes: k_s\#

Posição da síncope: Última sílaba (SF)

Quantidade de Sílabas: 2

- údiíns (Piceno Meridional)

(significado desconhecido)

Ocorrência

AP 1

$\underline{\text { Análise }}$

*-nos > údiíns

$*_{-} n s$ original $>-f$, enquanto $* n s$ por síncope >-ns (Buck 1904: 73).

Ambiente Fonológico:

Consoantes adjacentes: n_s\#

Posição da síncope: Última sílaba (SF)

Quantidade de Sílabas: 3

- ufestne (Úmbrio) 'vasos’ (dat./abl., pl.)

\section{Ocorrência}

IV 22

Análise

*op-fenstonois > ufestne

Benediktsson (1960: 256)

*op-fenstonois > ufestne (dat./abl., pl.)

Paradigmas nos quais apenas ocorre síncope medial regularmente nos casos oblíquos.

Cognato: scr. badhnāti, gót. bindan

Buck (1904: 86)

*bhendh-to- > *op-fest(i)no- > ufestne
Ambiente Fonológico:

Consoantes adjacentes:

Posição da síncope:

Quantidade de Sílabas: 4

- uincter (Osco) 'ser convencido' (3a sg., pres., pass.)

Ocorrência

Lu 1, 21

Análise

*uinketer > uincter

Benediktsson (1960: 237)

* uinketer > uincter ( $3^{\mathrm{a}} \mathrm{sg}$., pres., pass.)

Ambiente Fonológico:

Consoantes adjacentes: $\mathrm{k} \_\mathrm{t}$

Posição da síncope: Segunda sílaba (SM)

Quantidade de Sílabas: 3

- umne (Úmbrio) 'óleo para ungir' (abl., sg.)

Ocorrência

IIa 38

Análise

*ong ${ }^{u}$ eni > umne

Benediktsson (1960: 272)

*ong ${ }^{u}$ eni > umne (abl., sg.)

Ambiente Fonológico:

Consoantes adjacentes:

Posição da síncope: Segunda sílaba (SM)

Quantidade de Sílabas: 3

- umtu (Úmbrio) ‘ungir' (imp.) 
Ocorrências

IIa 38; IV 13

Análise

*on-g ${ }^{u} e t \bar{d} d>$ umtu

Benediktsson (1960: 185)

*on-g $g^{u}$ etōd > umtu (imp.)

Síncope em formas tri- ou

quadrissilábicas com uma vogal longa na terceira sílaba.

Cognato itálico: lat. unguō 'ungir'

Ambiente Fonológico:

Consoantes adjacentes:

Posição da síncope: Segunda sílaba (SM)

Quantidade de Sílabas: 3

- úpfals (Osco) 'Upífalo' (nome próprio) (nom., sg.)

Ocorrência

Cp 2

Análise

*upfalos > úpfals

Benediktsson (1960: 216)

*upfalos > Upfals (nom., sg.),

Upifalleis (gen., sg.)

Antes de $-s$ final, toda vogal breve é sincopada $\left(-\breve{V_{S}} \#>-s \#\right)$.

Depois da síncope: $-l s \#>-l \#$

Ambiente Fonológico:

Consoantes adjacentes: 1_s\#

Posição da síncope: Última sílaba (SF)

Quantidade de Sílabas: 3

- úpsed (Osco) 'fazer' (3ª sg., perf.)
Ocorrência

Sa 2

Análise

*opesed > upsed

Benediktsson (1960: 237)

*opesed $>$ upsed ( $3^{\mathrm{a}}$ sg., perf.)

Ambiente Fonológico:

Consoantes adjacentes: p_s

Posição da síncope: Segunda sílaba (SM)

Quantidade de Sílabas: 3

- urnasier, urnasiaru (Úmbrio) 'regular (?)' (gen., pl., f.)

Ocorrências

urnasiaru: III 3

urnasier: Va 2; Va 15

Análise

Etimologia Incerta

Benediktsson (1960: 175)

*ordenāsiais > urnasier, urnasiaru (gen., pl., f.)

Síncope em formas tri- ou quadrissilábicas com uma vogal longa na terceira sílaba.

Weiss (2010: 58-9)

Possivelmente o nome de um mês, embora seja difícil definir qual mês.

Ambiente Fonológico:

Consoantes adjacentes: d_n

Posição da síncope: Segunda sílaba (SM ( IN)

Quantidade de Sílabas: 4 
- uze, onse (Úmbrio) ‘ombro’ (loc., sg.)

$\underline{\text { Ocorrências }}$

onse: VIb 50

uze: Iib 27; Iib 28

Análise

*omese $i>$ uze, onze

Benediktsson (1960: 256)

*omesei > uze, onze (loc., sg.)

Paradigmas nos quais apenas ocorre síncope medial regularmente nos casos oblíquos.

Cognato itálico: lat. umerus 'ombro'

Weiss (2009: 140)

Cognato itálico: lat. umerus (<*omeso-) 'ombro'

Cognato: véd. ámsa- 'ombro'

Ambiente Fonológico:

Consoantes adjacentes: m_s

Posição da síncope: Segunda sílaba (SM)

Quantidade de Sílabas: 3

- veltu (Úmbrio) ‘desejar’ (imp.)

Ocorrência

IV 21

Análise

*ueletōd > veltu

Benediktsson (1960: 171)

*ueletōd > veltu (imp.)

Cognato itálico: umb. eh-veltu 'ordenar' (imp.)

Síncope em formas tri- ou quadrissilábicas com uma vogal longa na terceira sílaba.
Ambiente Fonológico:

Consoantes adjacentes: 1_t

Posição da síncope: Segunda sílaba (SM)

Quantidade de Sílabas: 3

- veskla (Úmbrio) 'vasilha' (acs., pl.)

Ocorrências

veskla: IIa 19

veskles: IIa 31; IIa 37; IIb 18; IV 9; IV

24

vesklu: Ib 29; Ib 37; IIa 34; IIb 19

$\underline{\text { Análise }}$

*ueskelo- > veskla

Benediktsson (1960: 235)

*ueskelā > veskla (acs., pl.)

Cognato itálico: volsc. uesclis

Buck (1904: 58)

*ues-kelo- > veskla

Ambiente Fonológico:

Consoantes adjacentes: $\mathrm{k} \_1$

Posição da síncope: Segunda sílaba (SM)

Quantidade de Sílabas: 3

- re-vestu (Úmbrio) 'verificar' (imp.)

Ocorrências

Va 7; Va 9

$\underline{\text { Análise }}$

PIt. *ueisseto- > re-vestu

Benediktsson (1960: 173)

*ueissetōd > re-vestu (imp.) 
Síncope em formas tri- ou quadrissilábicas com uma vogal longa na terceira sílaba.

Cognato itálico: lat. uisō 'olhar'

Buck (1904: 85)

Cognato itálico: lat. uīsō (<*ueid-sō)

'olhar'

Uma dental é assimilada se um $-s$ a seguir (Proto-Itálico).

Ambiente Fonológico:

Consoantes adjacentes: $\mathrm{s} \_\mathrm{t}$

Posição da síncope: Segunda sílaba (SM)

Quantidade de Sílabas: 3

- vetu (Úmbrio) ‘dividir’ (imp.)

Ocorrências

Ib 29; Ib 37

Análise

*ueifetōd > vetu

Benediktsson (1960: 176)

*ueipetōd > *ueifetōd > *ueiftōd >

*uęhtōd > vetu (imp.)

Síncope em formas tri- ou quadrissilábicas com uma vogal longa na terceira sílaba.

Cognato itálico: lat. dìuidō 'dividir

Cognato: scr. vidhyati 'dividir'

Ambiente Fonológico:

Consoantes adjacentes: $\mathrm{f} \_\mathrm{t}$

Posição da síncope: Segunda sílaba (SM)

Quantidade de Sílabas: 3
- vezkeí (Osco) 'Vezco’ (nome de um deus) (dat., sg.)

Ocorrências

Sa 1A2; Sa B3

Análise

*uetVskei > vezkeí

Benediktsson (1960: 272)

${ }^{*} u e t{ }^{\mathrm{e}}{ }_{0} s k e i>$ Vezkeí (dat., sg.)

A presença do -z- pressupõe que houve síncope.

Ambiente Fonológico:

Consoantes adjacentes: $t \_s$

Posição da síncope: Segunda sílaba (SM)

Quantidade de Sílabas: 3

- vitlu (Úmbrio) ‘vitelo’ (acs., sg.)

Ocorrências

vitlu: IIb 21; IIb 24

uitlu: VIb 43; VIb 45

vitluf: Ib 1 ; Ib 4

Análise

*uitelo- > vitlu

Benediktsson (1960: 238)

*uitelom > vitlu (acs., sg.)

Outras formas: vitluf, vitlup (acs., pl.)

Buck (1904: 58)

*uitelo- > vitlu

Cognato itálico: osc. Víteliú 'Itália'

Meiser (1986: 130)

*uitelo- > vitlu

Ambiente Fonológico:

Consoantes adjacentes: $t$ _1 
Posição da síncope: Segunda sílaba (SM)

Quantidade de Sílabas: 3

- vutu (Úmbrio) 'lavar' (imp.)

Ocorrência

IIa 39

Análise

*louVtōd > vutu

Benediktsson (1960: 172)

*louetōd > vutu (imp.)

Síncope em formas tri- ou quadrissilábicas com uma vogal longa na terceira sílaba.

Cognato itálico: lat. lauō 'lavar'

Ambiente Fonológico:

Consoantes adjacentes: $u_{-} t$

Posição da síncope: Segunda sílaba (SM)

Quantidade de Sílabas: 3

- zicolom (Osco) 'dia' (acs., sg. ou gen., pl.)

Ocorrências

zicolom: Lu 1, 14; Lu 1, 15 zico(lom);

Lu 1,17

ziculud: Lu 1, 16

Análise

Síncope seguida de anaptixe: *diiēekelo-

$>$ diēkelo- > dieklo- > com anaptixe zicolom

Sincope na terceira sílaba, no sufixo diminutivo $*$-kelo- .

Benediktsson (1960: 239) *diekelo- > *dieklom > zicolom (acs., sg.)

Outras formas: ziculud (abl., sg.), zicolom (gen., pl.)

Untermann (2000: 868)

O sufixo diminutivo ${ }^{*}$-kelo- pode ser entendido em comparação à forma latina dieccula 'dia mais curto'.

Weiss (2010: 48)

zicolom na Tabula Bantina 13-14 siginifica apenas 'dia', mas $\operatorname{sim}$ 'o último dia possível para o pagamento'; 'data limite do pagamento'. A palavra latina dies possui a mesma característica de mudança semântica em certos contextos.

Ambiente Fonológico:

Consoantes adjacentes: k_1

Posição da síncope: Segunda sílaba (SM)

Quantidade de Sílabas: 3 